\title{
Behavioural responses to
}

\section{photovoltaic systems in the}

\section{UK domestic sector}

\author{
James Keirstead \\ Keble College \\ Trinity Term 2006
}

Environmental Change Institute University of Oxford

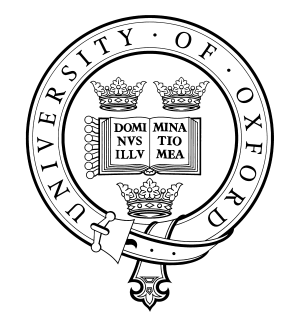





\title{
Behavioural responses to photovoltaic systems in the UK domestic sector
}

James Keirstead

Keble College

\author{
D.Phil. \\ Trinity Term 2006
}

\begin{abstract}
Microgeneration technologies, such as solar photovoltaics (PV), have recently been cited as a potential solution to energy policy challenges such as climate change and security of supply. International evidence suggests that the benefit of a PV installation will depend on both the amount of electricity generated and the technology's influence on energy consumption behaviour. This study seeks to quantify and explain this 'double-dividend' effect by examining photovoltaics in the UK domestic sector.

Questionnaire and interview data were collected from owner-occupier PV households, revealing that the installation of PV increased awareness of electricity generation and consumption in the home. Guided by monitoring devices, an overall electricity saving $(\approx 8 \%)$ and load-shifting behaviours were observed. Although the installation of PV followed a series of other energy-saving measures, respondents showed an ongoing commitment to environmentallyresponsible behaviour and further reduction of the carbon footprint of household energy consumption. PV household electricity data and interviews with industry and government found that electricity tariffs, metering and other institutional constraints were important determinants of a household's behavioural response. As these parts of the domestic PV system are largely still evolving, it is recommended that households and industry work together to develop systems that support sustainable electricity use, for both the early adopting households studied here and future adopters.
\end{abstract}





\section{PAPERS ARISING FROM THIS WORK}

Keirstead, J. (2005) 'Household behavioural responses to PV-system monitoring devices', in M. S. Imbabi and C. P. Mitchell, eds, World Renewable Energy Congress, pp. 458-463. Aberdeen: Elsevier.

Keirstead, J. (2005) 'Photovoltaics in the UK domestic sector: a doubledividend?', in F. Bartiaux and A. G. Selnæs, eds, ECEEE Summer Study, Vol. 3, pp. 1249-1258. Mandelieu, France: European Council for an Energy Efficiency Economy.

Keirstead, J. and Boardman, B. (2005) 'Response to Ofgem consultation document 123/05'. URL: http://www.ofgem.gov.uk/temp/ofgem/cache/ cmsattach/12425_12305_lcf.pdf.

Keirstead, J. (in press) 'Evaluating the applicability of integrated domestic energy consumption frameworks in the $\mathrm{UK}^{\prime}$, Energy Policy.

Keirstead, J. (accepted, pending corrections) 'The role of central government in the UK's emerging domestic photovoltaics industry', Energy Policy.

Keirstead, J. (in progress) 'Behavioural responses to photovoltaic systems in the UK domestic sector', Energy Policy or Area. 



\section{ACKNOWLEDGMENTS}

I would like to thank the following people for their help with this research: Malcolm MacLean, Malcolm Ball and Melanie Davis at Solar Century for their assistance with the mail questionnaires; Rachel Ellis at the Peabody Trust, Rebecca Gunning at NPower, Kirk Archibald at the Energy Saving Trust who helped the questionnaire design by providing data from internal surveys; John Parsons at Beama for visiting Oxford at the start of the project to discuss possible research ideas; Nicola Pearsall at the Northumbria Photovoltaics Application Centre for

providing the data for Chapter 5. Euan Dobbs of Blackwell's Book Shop kindly donated a $£ 20$ gift certificate for the mail questionnaires.

The contribution of the research participants (including the pilot studies) was of course invaluable and I'm grateful for the time and interest they invested in the project. The Lower Carbon Futures team also provided helpful input and advice, as well as timely distractions. Most of all, thanks to Brenda Boardman for her enthusiasm and incisive comments.

Last but not least, thanks to my family for all their support and encouragement. And Tanis, you were right — steter Tropfen höhlt den Stein. 



\section{CONTENTS}

1 Introduction 1

1.1 The challenges facing UK energy policy . . . . . . . . . . . 2

1.1.1 The Energy Review . . . . . . . . . . . . . . . . . 3

1.2 Microgeneration to the rescue? . . . . . . . . . . . 9

1.2.1 Promoting domestic microgeneration . . . . . . . . 10

1.2.2 Photovoltaics: power from the sun . . . . . . . . . . . 12

1.2.3 Metering and monitoring devices . . . . . . . . . . 16

1.2.4 Other developments in the policy environment . . . . . . 18

1.3 Microgeneration and consumer behaviour . . . . . . . . . . . . 20

1.3.1 Previous studies of PV and consumer behaviour . . . . . . 21

1.4 Aims and scope of the study . . . . . . . . . . . . . . . 25

1.4.1 Research boundaries . . . . . . . . . . . . . 25

1.4.2 Key terms and issues . . . . . . . . . . . . . 27

1.4.3 Aims of the study . . . . . . . . . . . . . . . 30

1.5 Methods and structure . . . . . . . . . . . . . . . . 32

1.5.1 Methodology ................. 32

1.5.2 Thesis structure . . . . . . . . . . . . . 36

$2 \quad$ PV and the sustainable consumer $\quad 37$

2.1 PV and domestic energy consumption . . . . . . . . . . . . . 39

2.1 .1 Disciplinary approaches to DEC . . . . . . . . . 39 
2.1.2 Integrated approaches to DEC . . . . . . . . . . . 42

2.1.3 An integrated approach to PV . . . . . . . . . . . . 47

$2.2 \mathrm{PV}$ as a socio-technical system . . . . . . . . . . . . . 51

2.2.1 From determinism to the actor-network . . . . . . . . 52

2.2.2 The diffusion of innovation . . . . . . . . . . 57

2.2.3 Nascent technologies and the role of users . . . . . . . . 61

2.3 Understanding sustainable consumer behaviour . . . . . . . . 65

2.3.1 PV: sustainable consumption or merely 'green'? . . . . . . 66

2.3.2 Changing energy use behaviour . . . . . . . . 70

2.3.3 Tacit knowledge and feedback . . . . . . . . . 75

3 The PV household questionnaires $\quad 83$

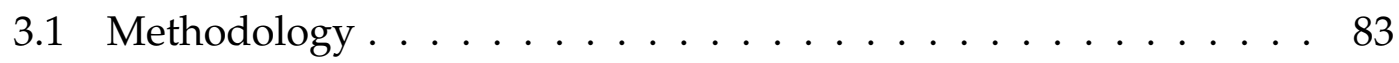

3.1 Questionnaire design ................ 84

3.1 .2 Implementation . . . . . . . . . . . . . 85

3.1 .3 Analysis ..................... 86

3.2 Characteristics of the survey respondents $\ldots \ldots$. . . . . . 87

3.2.1 Demographics and socio-economic status . . . . . . . 88

3.2.2 Psychological constructs . . . . . . . . . . . . . 95

3.3 Energy-saving actions . . . . . . . . . . . . . . 106

3.3.1 Before and after actions . . . . . . . . . . 106

3.3.2 Total savings . . . . . . . . . . . . . . . 110

3.3.3 Future actions . . . . . . . . . . . . . . . . 114

3.4 Monitors and meters . . . . . . . . . . . . . . . . . 121

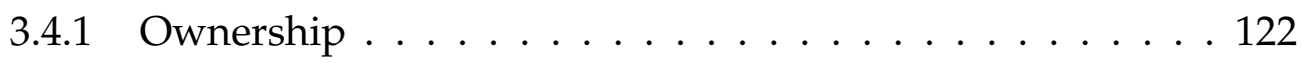

3.4.2 Patterns of use . . . . . . . . . . . . 126

3.4 .3 Impact on energy savings $\ldots \ldots \ldots 131$ 
4 Interviews with PV households $\quad 139$

4.1 Methodology . . . . . . . . . . . . . . . 139

4.1 .1 Interview themes . . . . . . . . . . . . . 140

4.2 Purchasing PV . . . . . . . . . . . . . . . . 141

4.2.1 Becoming aware of PV technology . . . . . . . . . . . 142

4.2.2 Possible purchase motivations . . . . . . . . . . 144

4.2.3 Catalysts for purchase . . . . . . . . . . . . . 147

4.2.4 Existing energy-saving measures . . . . . . . . . . . . . 149

4.3 Changes in energy consumption behaviour . . . . . . . . . . . 151

4.3.1 Overall savings . . . . . . . . . . . . . . . 151

4.3.2 Time-of-use changes . . . . . . . . . . . . 156

4.3 .3 Future energy savings . . . . . . . . . . . . . 159

4.4 The impact of monitoring devices . . . . . . . . . . . . . . . 162

4.4 .1 Acquiring the device . . . . . . . . . . . . 162

4.4.2 Observation patterns . . . . . . . . . . . . 164

4.4.3 Building energy awareness . . . . . . . . . . . 167

4.5 Social and industry connections . . . . . . . . . . . . . 171

4.5 .1 Peer reaction . . . . . . . . . . . . . . . . 172

4.5 .2 Community outreach . . . . . . . . . . . . . 174

4.5 .3 Installation issues . . . . . . . . . . . . 177

4.5.4 Metering and electricity supplier issues . . . . . . . . . 179

5 Electricity supply and demand in PV households 185

5.1 Methodology . . . . . . . . . . . . . . . 186

5.2 The UK solar resource and PV generation . . . . . . . . . . . 187

5.2.1 Solar resource patterns . . . . . . . . . . . . 188

5.2.2 PV generation patterns . . . . . . . . . . . . . . 194

5.3 Electricity demand in PV households . . . . . . . . . . . . . . . 197 
5.3.1 Electricity demand patterns . . . . . . . . . . . 198

5.3.2 Comparing electricity demand and PV generation . . . . . 202

5.4 Variations in generation and demand . . . . . . . . . . . . . . 209

5.4.1 Household variations . . . . . . . . . . . . . . 211

5.4 .2 Year-to-year variations . . . . . . . . . . . . . . . 214

5.5 Analysis of PV tariffs . . . . . . . . . . . . . . . . 216

5.5.1 Timing of PV incentives . . . . . . . . . . . . 218

5.5.2 Annual payments from different tariffs . . . . . . . 222

5.5 .3 The payback of PV . . . . . . . . . . . . . . 224

6 Interviews with PV industry representatives 233

6.1 Methodology . . . . . . . . . . . . . . . . 234

$6.2 \mathrm{PV}$ installation firms . . . . . . . . . . . . . . 234

6.2.1 The installation process and customer interaction $\ldots 236$

6.2.2 Monitors and meters . . . . . . . . . . . . . 238

6.2.3 Future policy and business issues . . . . . . . . . . . . 240

6.3 Monitoring and metering companies . . . . . . . . . . . . . 243

6.3.1 Monitoring: "a spin-off of other developments" . . . . . . 243

6.3.2 Metering: "a commodity item" . . . . . . . . . . . . . . . 248

6.4 Electricity suppliers . . . . . . . . . . . . . . . . . 253

6.4 .1 Offers for microgeneration . . . . . . . . . . . 254

6.4.2 Considerations affecting microgeneration tariffs . . . . . 255

6.4.3 Strategies for a growing market . . . . . . . . . . 258

6.4.4 Analysis of retail electricity prices . . . . . . . . . 260

6.5 Policy makers and lobbyists . . . . . . . . . . . . . . . . 264

6.5.1 Current policy issues and lessons learned . . . . . . . . 265

6.5.2 Lobbying and the consultation process . . . . . . . . . 267

6.5.3 Future prospects and challenges . . . . . . . . . . . 269 


\section{Discussion and conclusion}

7.1 Domestic photovoltaics: a double-dividend? . . . . . . . . . . 276

7.1 .1 Purchasing PV . . . . . . . . . . . . . 277

7.1 .2 Living with $\mathrm{PV} \ldots . . \ldots . . \ldots 279$

7.1.3 The future of PV in the UK . . . . . . . . . . 283

7.2 Contribution to theory . . . . . . . . . . . . 286

7.2.1 Mechanisms for encouraging a behavioural response . . . 287

7.2.2 Socio-technical constraints on PV behavioural responses . 290

7.2.3 PV and the conservation landscape . . . . . . . . . . . 296

7.3 Contribution to policy and industry . . . . . . . . . . 300

7.3.1 Defining a 'good' behavioural response to PV . . . . . . . . 301

7.3.2 Promoting the effective diffusion of PV . . . . . . . . 302

7.3.3 Encouraging appropriate behavioural responses to PV . . 306

7.3.4 Maintaining an energy-efficient lifestyle . . . . . . . . . . 308

7.4 Study limitations and opportunities for further research . . . . . . 314

$\begin{array}{ll}\text { Appendices } & 319\end{array}$

A The questionnaire . . . . . . . . . . . . . . . . . 319

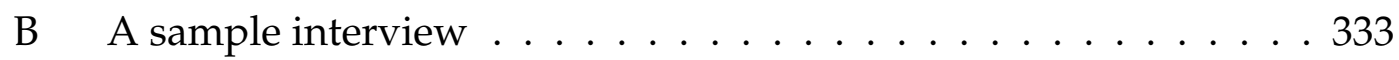

C Analysing the PV actor-network with Pajek . . . . . . . . . . . . 351

$\begin{array}{ll}\text { References } & 357\end{array}$ 



\section{LIST OF FIGURES}

1.1 UK greenhouse gas emissions: $1990-2012 \ldots \ldots$. . . . . . . . 5

1.2 UK gas supply: $1970-2004 \ldots \ldots$. . . . . . . . . . 6

1.3 UK energy prices: $1990-2005 \ldots \ldots$. . . . . . . . . 8

1.4 International installed PV capacity as of $2004 \ldots$. . . . . . . . 13

1.5 Installed PV capacity in the UK as of $2004 \ldots$. . . . . . . . . . 15

1.6 Examples of metering and monitoring devices . . . . . . . . 16

1.7 An explanation of microgeneration metering $\ldots . . . . . . . .17$

2.1 Citation history of integrated DEC frameworks . . . . . . . . . . 45

2.2 An integrated approach to domestic PV and consumer behaviour 50

2.3 The innovation diffusion process and adopter types . . . . . . 58

3.1 Location of PV households . . . . . . . . . . . . . . . . 93

3.2 Clustering of demographic data . . . . . . . . . . . . . 94

3.3 Summary of psychological constructs . . . . . . . . . . . 103

3.4 Clustering of value and belief data . . . . . . . . . . . . 104

3.5 Total electricity saving in PV households . . . . . . . . . . . . . . . 111

3.6 Future energy-saving actions . . . . . . . . . . . . . 115

3.7 Monitor model by age of system . . . . . . . . . . . . . . 124

5.1 Annual average sunshine hours in the UK . . . . . . . . . . . 190

5.2 Annual solar resource . . . . . . . . . . . . . . . . . . 191

5.3 Daily solar resource . . . . . . . . . . . . . . . . . . 191 
5.4 Daily temperatures at Totnes . . . . . . . . . . . . . 193

5.5 Annual PV generation . . . . . . . . . . . . . . . . 195

5.6 Daily PV generation . . . . . . . . . . . . . . . . 196

5.7 Electricity demand for England and Wales . . . . . . . . . . . 198

5.8 Annual electricity demand . . . . . . . . . . . . . . . . . . 199

5.9 Daily electricity demand . . . . . . . . . . . . . . . 200

5.10 Daily activities of PV households . . . . . . . . . . . . . . 201

5.11 Daily electricity activity at Nottingham . . . . . . . . . . 203

5.12 Annual PV fraction . . . . . . . . . . . . . . . . . 205

5.13 Daily PV fraction . . . . . . . . . . . . . . 206

5.14 Annual energy budgets . . . . . . . . . . . . . . . . 207

5.15 Daily energy budgets . . . . . . . . . . . . . . . 208

5.16 Demand and generation for one household in Totnes . . . . . . . 210

5.17 Annual PV generation and demand in Nottingham . . . . . . . 212

5.18 Daily PV generation and demand in Nottingham . . . . . . . . . 212

5.19 Demand and PV generation for two households in Nottingham . 213

5.20 Annual changes in demand and generation . . . . . . . . . . . 215

5.21 Annual payments for generation and demand . . . . . . . . . 219

5.22 Daily payments for generation . . . . . . . . . . . . . 220

5.23 Daily savings in electricity demand . . . . . . . . . . . . . . 221

5.24 Annual income from different payment types . . . . . . . . . 223

5.25 Payback periods for an average PV system . . . . . . . . . . 228

6.1 Sharp JH-G51X PV monitoring device . . . . . . . . . . . . . 247

7.1 The domestic PV actor-network . . . . . . . . . . . . . . . . 292

7.2 The role of technology within the PV actor-network . . . . . . . . 294

7.3 A monitor design for microgenerating households . . . . . . . . . 311 


\section{LIST OF TABLES}

1.1 UK microgeneration installations by technology . . . . . . . . . . 13

1.2 Existing research on PV and household behavioural responses . . 24

2.1 Domestic energy consumption as social action . . . . . . . . 71

2.2 Key determinants of DEC within a social cognitive framework . . 73

3.1 Gender of survey respondents . . . . . . . . . . . . . . . 88

3.2 Age of survey respondents . . . . . . . . . . . . . . . . 89

3.3 Education of survey respondents . . . . . . . . . . . . . 89

3.4 Income of survey respondents . . . . . . . . . . . . . . . 9 90

3.5 Household size of survey respondents . . . . . . . . . . . . . . 91

3.6 Residency of survey respondents . . . . . . . . . . . . . . . 91

3.7 Tenure of survey respondents . . . . . . . . . . . . . . . 92

3.8 Demographic groupings . . . . . . . . . . . . . . . 95

3.9 Knowledge question 1: climate change . . . . . . . . . . . 97

3.10 Knowledge question 2: fossil fuels . . . . . . . . . . . . . 97

3.11 Knowledge question 3: function of PV . . . . . . . . . . . . 97

3.12 Knowledge question $4: \mathrm{PV}$ in the UK . . . . . . . . . . . . . 98

3.13 Worldview question 1: the role of science . . . . . . . . . . 99

3.14 Worldview question 2: the severity of environmental threats . . . 99

3.15 Worldview question 3: personal responsibility . . . . . . . . . 99

3.16 Self-identity . . . . . . . . . . . . . . . . . 101 
3.17 Most important values of PV households . . . . . . . . . . . . 102

3.18 Demographic differences in psychological constructs . . . . . . 102

3.19 Opinion groupings . . . . . . . . . . . . . . . 105

3.20 Home energy-saving measures before and after PV . . . . . . . . 107

3.21 Rates of appliance ownership . . . . . . . . . . . . . . . 109

3.22 Barriers and incentives to installing additional microgeneration . 116

3.23 Barriers and incentives to installing more efficient lighting . . . . 117

3.24 Barriers and incentives to installing more efficient appliances . . . 118

3.25 Most popular PV monitoring devices . . . . . . . . . . . . . . 122

3.26 Features of the most popular PV monitors . . . . . . . . . . . . 123

3.27 Length of ownership of PV systems . . . . . . . . . . . . . . . . 124

3.28 Types of meters in PV households . . . . . . . . . . . . . . 125

3.29 Meter ownership by age of PV system . . . . . . . . . . . 126

3.30 Popular PV monitor locations . . . . . . . . . . . . . . 127

3.31 PV system age by location . . . . . . . . . . . . . . . 127

3.32 Frequency of PV monitor viewing . . . . . . . . . . . . . . . 128

3.33 Monitor location by viewing frequency . . . . . . . . . . . 128

3.34 PV system age by viewing frequency . . . . . . . . . . . . . . . . . 129

3.35 Monitor model by most popular metric . . . . . . . . . . . 129

3.36 Viewing frequency by most popular metric . . . . . . . . . . . 130

3.37 Desired metrics on an ideal PV display monitor . . . . . . . . . 131

3.38 Ownership of monitor by savings group . . . . . . . . . . . . 131

3.39 Investment in carbon abatement by monitor ownership . . . . . 132

3.40 Reasons for electricity savings by monitor ownership . . . . . . 132

3.41 Most popular metric by savings group . . . . . . . . . . . . . 134

3.42 Sources of information for determining PV payback . . . . . . . 134

3.43 Household estimates of PV payback periods . . . . . . . . . . 135 
4.1 Revised electricity saving groups . . . . . . . . . . . . 155

5.1 Summary of NPAC PV systems . . . . . . . . . . . . . . 187

5.2 Evaluating the folk model of PV system performance . . . . . . . 194

5.3 Total annual AC output for NPAC sites . . . . . . . . . . . . 195

5.4 Total annual electricity demand for NPAC sites . . . . . . . . . 199

5.5 Contribution of PV to annual electricity demand . . . . . . . . 205

5.6 Year-to-year changes in electrical performance . . . . . . . . . . . 214

5.7 Payment plans for PV microgeneration . . . . . . . . . . . . . 218

5.8 Annual payments for PV households in Nottingham . . . . . . . . 222

5.9 Parameters for payback scenarios . . . . . . . . . . . . 226

5.10 PV payback periods under different scenarios . . . . . . . . . . 227

6.1 Types of PV organizations interviewed . . . . . . . . . . . . 234

6.2 Interviewed PV installers . . . . . . . . . . . . . . . . . 235

6.3 Interviewed monitoring and metering companies . . . . . . . . 244

6.4 Payment plans for microgeneration . . . . . . . . . . . . . 254

6.5 A breakdown of UK electricity prices . . . . . . . . . . . . . 261

6.6 Description of the interviewed lobby groups and policy makers . 264

C.1 Description of PV actor-network nodes . . . . . . . . . . . . . 353

C.2 Description of connections within the PV actor-network . . . . . . 354 



\section{LIST OF ACRONYMS AND ABBREVIATIONS}

Acronyms and abbreviations follow the conventions of The Guardian Style Guide (Marsh and Marshall 2004). Pronounceable acronyms are in title case (e.g. Roc); abbreviations are in uppercase (e.g. DTI).

AC alternating current

Agnes agglomerative nesting cluster analysis

AMR automated meter reading

Ant actor-network theory

Beama British Electrotechnical and Allied Manufacturers' Association

Betta British Electricity Trading and Transmission Arrangements

CHP combined heat and power

CFL compact fluorescent light bulb

$\mathrm{CO}_{2} \quad$ carbon dioxide

DC direct current

DEC domestic energy consumption

Defra Department for Environment, Food and Rural Affairs

DIY do-it-yourself (home renovations)

DNO district network operator

DSM demand-side management

DTI Department of Trade and Industry

ECI Environmental Change Institute 
EEC Energy Efficiency Commitment

Esco energy service company

EST Energy Saving Trust

GHG greenhouse gases

GW gigawatt

kWh kilowatt hour $\left(\times 10^{3}\right.$ watt hours $)$

$\mathrm{kW}_{\mathrm{p}} \quad$ peak capacity in kilowatts

LCBP Low Carbon Buildings Programme

LTS large technical system

MDP Major Photovoltaics Demonstration Programme

MWh megawatt hour $\left(\times 10^{6}\right.$ watt hours $)$

$\mathrm{MW}_{\mathrm{p}} \quad$ peak capacity in megawatts

NEP New Ecological Paradigm

NPAC Northumbria Photovoltaics Application Centre

ODPM Office of the Deputy Prime Minister

Ofgem Office of Gas and Electricity Markets

Pam partitioning around medoids cluster analysis

PIU Performance and Innovation Unit

PTEM physical-technical-economic model

PV photovoltaics

PV-UK British Photovoltaic Association

REA Renewable Energy Association (formerly Renewable Power Association)

RO Renewables Obligation

Roc Renewables Obligation Certificate

Scot social construction of technological systems

TWh terawatt hour $\left(\times 10^{12}\right.$ watt hours $)$

UK United Kingdom 


\section{Chapter 1}

\section{INTRODUCTION}
“... as he walks down the hallway he taps the electricity meter and sees it shows that the family is in credit: his own windmill generator and solar panels are putting more energy into the grid than the household is using, adding to the family income."

'Life in 2020', Brown (2003)

For most UK households, generating electricity in the home would have been unthinkable until recently as the grid electricity system has provided this vital service for nearly one hundred years. Even innovations such as renewable energy technologies are still primarily seen in a 'centralised' context, for example, with wind turbines installed as part of large rural windfarms rather than individual household systems. Today however there are more than 80,000 smallscale heat and electricity generators installed in homes and buildings across the UK (EST 2005b).

If the provision of grid electricity in Western society was first perceived as something new and exciting (Nye 1990), then there is certainly reason to believe that the introduction of decentralised 'microgeneration' technology will be every bit as revolutionary. Instead of simply receiving electricity mysteriously through a cable in the wall, households can now be brought face-to-face with the way in which their demand for energy services is met. Coupled with 
technologies that promote interaction with microgeneration, such as the meter in the quote above, households may begin to think more carefully about the costs of supplying electricity, both in financial and environmental terms. Some authors have hypothesised that this may in turn lead to changes in consumer behaviour, resulting in the more efficient use of energy resources (i.e. heat and electricity) (e.g Haas et al. 1999, Dobbyn and Thomas 2005).

Microgeneration has recently been the focus of both UK central and local government interest, driven largely by policy concerns such as climate change and security of supply. This potentially radical change in the delivery of domestic energy therefore raises important and timely questions about how households conceptualize and manage their energy consumption and how, in turn, the introduction of microgeneration technologies might alter this demand. This thesis investigates one such technology, solar photovoltaics, and its influence on household energy consumption behaviour.

\subsection{The challenges facing UK energy policy}

The questions about household behaviour and microgeneration are set against the larger backdrop of UK energy policy. Historically the main goal of these policies was to support growth in the UK economy, addressing the concerns of trade and industry by providing a secure and affordable energy supply and managing the associated infrastructure (Helm 2002b). However the liberalization of energy markets (most notably via the Electricity Act 1989), increased awareness of fuel poverty (Boardman 1991), and the rise of environmentalism (RCEP 2000) have added new dimensions to energy policy. The importance of these issues was confirmed in 2002, when the Prime Minister's Performance and Innovation Unit (PIU) published a review of the UK's energy situation. The review noted that although the recent context had been relatively "benign", 
significant challenges lay ahead (PIU 2002: 5). Their recommendations were adopted by the government's 2003 energy white paper, enshrining four primary goals for UK energy policy (DTI 2003: 11):

- "to put ourselves on a path to cut the UK's carbon dioxide emissions ... by some $60 \%$ by about 2050 ... with real progress by 2020 ;

- "to maintain the reliability of energy supplies;

- "to promote competitive markets in the UK and beyond, helping to raise the rate of sustainable economic growth and to improve our productivity; and

- "to ensure that every home is adequately and affordably heated."

Shifting to a sustainable energy policy naturally takes time but it has been argued that, in the case of renewable energy for example, the necessary longterm planning has been hampered by an over-reliance on open markets (Meyer 2003) and the way in which industry is 'locked-in' to historic infrastructures and institutions (Fuchs and Arentsen 2002, Elliott 1994). The Climate Change Levy (Varma 2003, Richardson and Chanwai 2003), the Renewables Obligation (Fouquet 1998) and the Sustainable Energy Policy Network (DTI 2006e) are examples of efforts to resolve these tensions, but the government could do more to " 'learn' from its past results, mistakes and difficulties" (Mitchell and Connor 2004: 1935) and improve the coordination between these policies (Helm 2002a).

\subsubsection{The Energy Review: increasing pressure on energy policy}

Since the publication of the energy white paper, many of the issues flagged by the PIU's report have come to fruition; domestic gas prices, for example, have risen on average 3\% per year in real terms since 2000 (DTI 2006c). Consequently the government launched a review of its energy policy to ensure that 
the four goals of the 2003 white paper can be met in the medium to long term (DTI 2006b). The major trends affecting each of these goals is presented below, covering material published before April 2006.

\section{Climate change}

The UK currently accounts for approximately $4.3 \%$ of Annex I greenhouse gas (GHG) emissions (3\% of global emissions, UNFCCC 2006) and has committed itself under the Kyoto protocol to a $12.5 \%$ reduction in GHG emissions from its 1990 baseline level. Initially great progress toward this target was made, largely thanks to the 'dash for gas', when the low cost of gas, advances in turbine design and market liberalization led to coal-fired electricity generation being replaced with combined cycle gas turbines (Spooner 1995, Winskel 2002, Watson 2004b). Emissions were also reduced through better management of methane emissions, more nuclear power, changes in land use, and efficiency improvements in industrial processes (Eichhammer et al. 2001, Jardine et al. 2004).

However, in recent years greenhouse gas emissions have begun to rise, particularly carbon dioxide $\left(\mathrm{CO}_{2}\right)$ which accounts for about $88 \%$ of total UK GHG emissions (Figure 1.1). This growth comes primarily from transport, where there has been increased demand for aviation from the rise of low-cost fares ${ }^{1}$ and growth in road freight (National Statistics 2004a). Demand in the residential sector has also risen, due to growth in the number of households and increased electricity use in lights and appliances (Shorrock and Utley 2003, Boardman et al. 2005).

\footnotetext{
${ }^{1}$ International aviation emissions however do not count towards the UK's Kyoto commitments.
} 


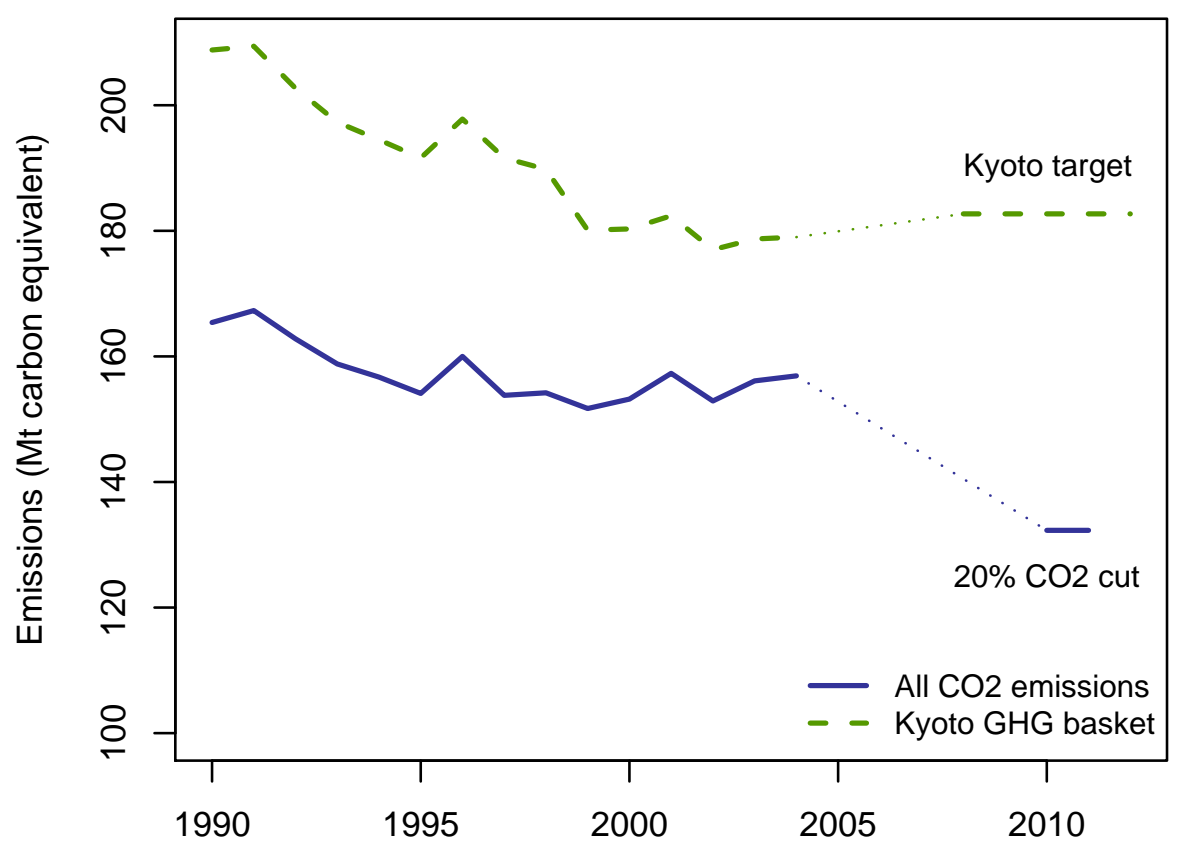

FIGURE 1.1: UK greenhouse gas emissions: 1990 - 2012 (Defra 2006a)

While the Kyoto target remains achievable, the more ambitious goal of a $20 \%$ reduction in $\mathrm{CO}_{2}$ by 2010 is likely to be missed (Defra 2006b). With new scientific evidence continuing to reinforce the severity of the situation (e.g. Siegenthaler et al. 2005, Osborn and Briffa 2006), concern about climate change is likely to encourage ongoing investment in low-carbon energy infrastructure.

\section{Reliability of energy supplies}

The thesis is primarily concerned with electricity, which in the UK is generated mainly from coal (37\%), gas (34\%) and nuclear (21\%) (DTI 2005a). The UK has significant coal reserves, but cost constraints mean that nearly $60 \%$ of coal demand is imported from cheaper international sources. However, while future coal supplies are likely to be secure and affordable (Mott MacDonald 2004), coal emits approximately twice as much $\mathrm{CO}_{2}$ per generated $\mathrm{MWh}$ as gas and it is therefore less desirable for electricity production from a climate change per- 
spective. ${ }^{2}$ Ten to fifteen gigawatts (GW) of coal plant are also likely to close by 2015 due to being at the end of its working life or the restrictions of the EU Large Combustion Plants Directive on sulphur dioxide emissions (CoalPro 2005). ${ }^{3}$

Until recently, gas has been the preferred fossil fuel for electricity generation offering cost and climate change advantages. Since the early 1990s, most of the UK's demand has been met indigenously but, as Figure 1.2 shows, production is in decline and imports are rising (the UK has been a net importer of gas since 2004). Future sources of gas include Russia, Africa, the Middle East, and Norway and there are concerns about the long-term reliability of these supplies (IEA 2005). The rising cost of gas means that coal may regain a cost advantage for electricity generation unless carbon emissions are appropriately priced (Mott MacDonald 2004).

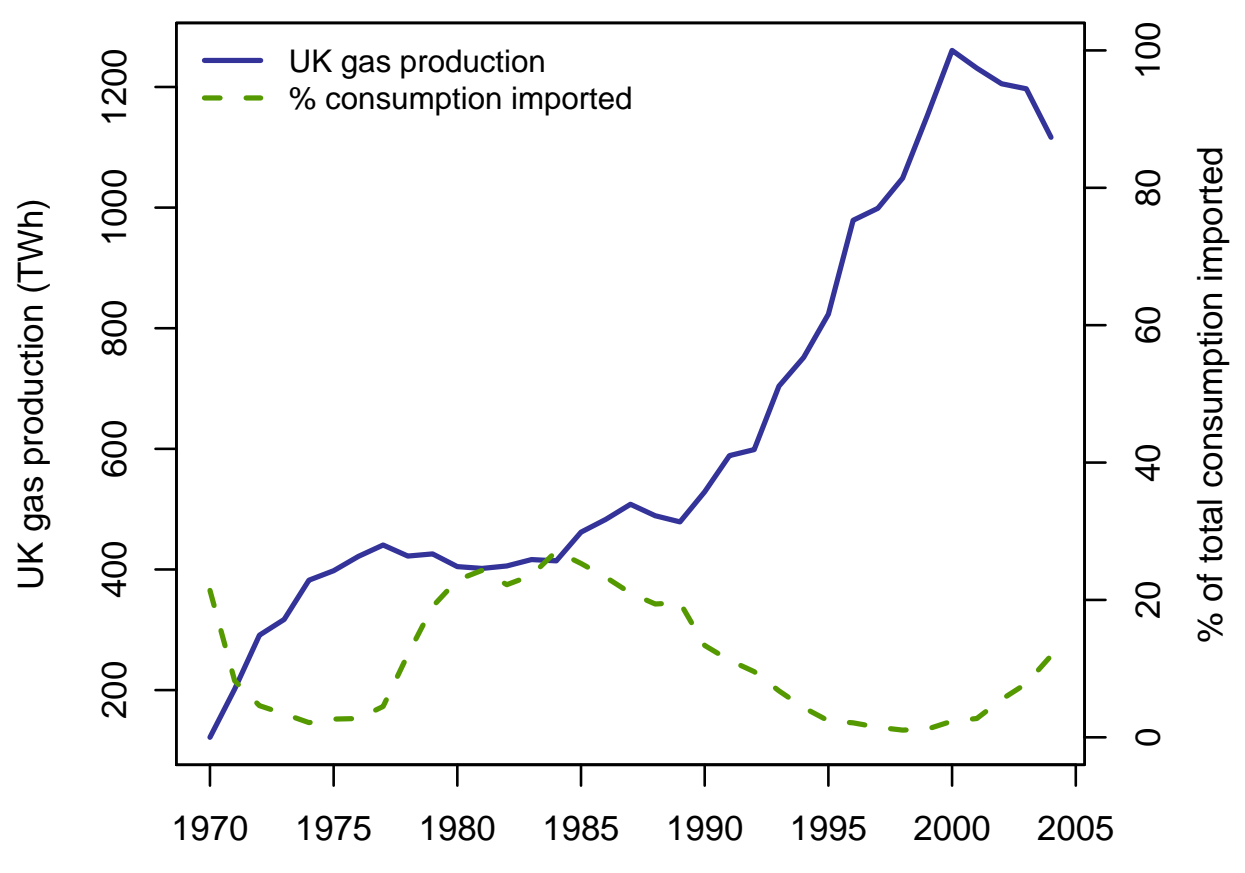

FIGURE 1.2: UK gas supply: 1970 - 2004 (DTI 2005a)

\footnotetext{
${ }^{2}$ Assuming that carbon capture and storage technology is not used.

${ }^{3}$ Some coal plants could continue to operate under the directive by installing flue gas desulphurisation.
} 
Nuclear power faces challenges as well with 8.2 GW of capacity due to go offline by 2020 (70\% of present nuclear capacity, nuclear accounting for $15 \%$ of total electrical generation capacity) (DTI 2005a, 2006b). The energy review indicates that the government will "re-examine" the arguments for new-build nuclear but public opinion remains mixed. Recent research showed that $77 \%$ of respondents would prefer investment in renewables over nuclear if the costs were the same; $49 \%$ indicated that existing nuclear plants should be shut-down, now or at the end of their lifecycle, and not be replaced (Poortinga et al. 2005).

Finally, transmission and distribution networks will require significant capital investment in the near future $-£ 1.9$ billion for the transmission system (2000-7) and $£ 5.7$ billion for the distribution system (2005-10) (DTI 2006b). This has encouraged interest in distributed networks as an alternative model for the electricity system (Ofgem 2002b, Supergen 2005).

\section{Competitive markets}

The UK electricity market was liberalized in 1998 and the resulting competition initially resulted in lower prices. However Figure 1.3 shows that the liberalised structure provides customers with little protection from increases in global wholesale fuel prices. Recent investigations have also found that gas prices have been inflated due to the uncompetitive practices of EU energy suppliers (Ofgem 2006c, EC 2006). Nonetheless competitive markets are viewed in the UK as the preferred mechanism for delivering many energy policy goals: as the energy review summarizes, "competition where it is desirable and regulation when it is necessary" (DTI 2006b: 17). However questions have been raised about whether or not the current market structure has encouraged sufficient investment in renewable electricity, energy efficiency and metering innovation (Eyre 1998, Thomas 2004, Ofgem 2006b). 


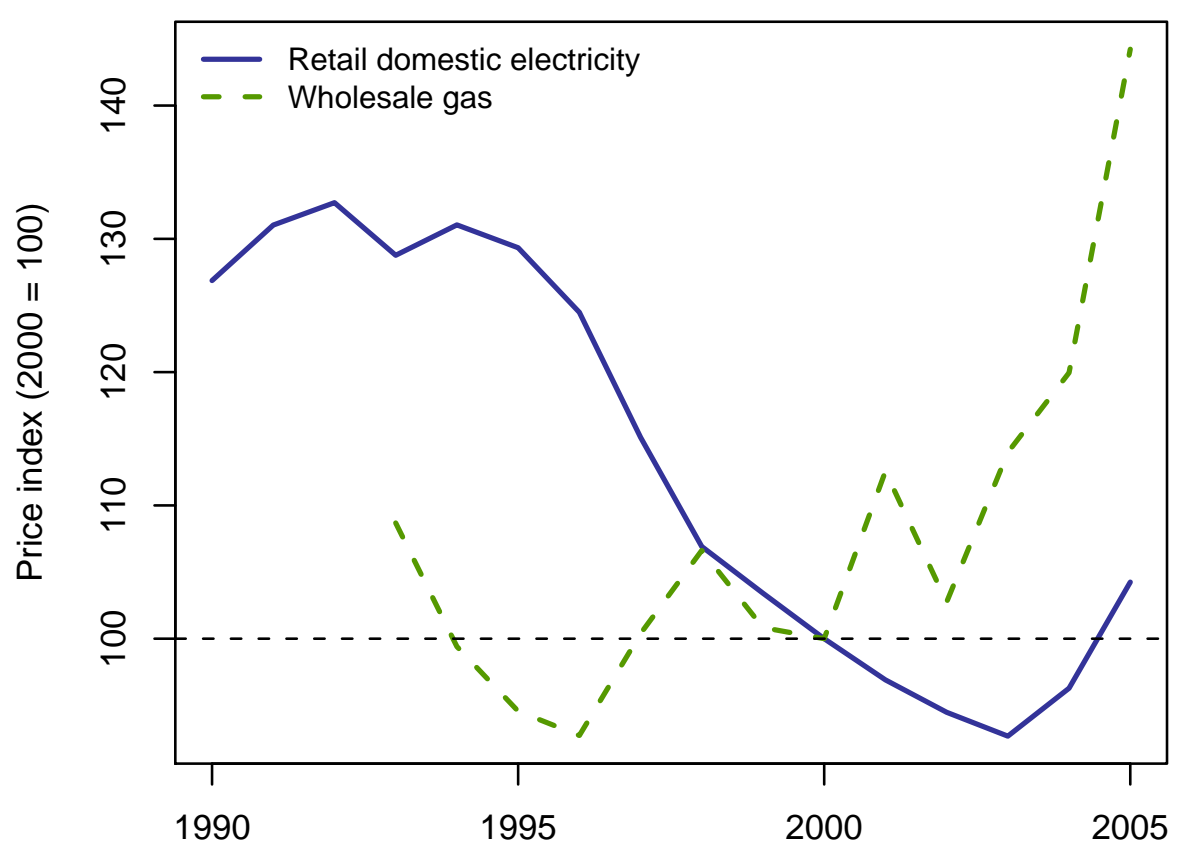

FIGURE 1.3: UK energy prices: 1990 - 2005 (GDP-deflated) (DTI 2006c)

One major benefit of the UK electricity market is that customers are free to choose a range of electricity tariffs and suppliers. For example, the EU internal electricity market directive 2003/54/EC requires electricity suppliers to provide consumers with information on how their electricity is generated including its climate change and nuclear waste impacts (DTI 2005b). This information empower consumers and may be an important driver for renewable energy demand and subsequent investment (Eikeland 1998, Boardman and Palmer 2003).

\section{Fuel poverty}

A household is said to be fuel poor if $10 \%$ or more of its income is spent on fuel costs (Boardman 1991). The government is committed to eliminating this "new social evil" from the UK by 2018 but it will have to address a number of causes (Asher 2005, Warm Homes and Energy Conservation Act 2000). There are three main mechanisms for reducing fuel poverty: increasing household incomes, 
decreasing energy prices, and making homes more efficient so that less fuel is required for the same (or higher) level of comfort. With the introduction of the UK Fuel Poverty Strategy in 2001 and low fuel prices, the number of fuel poor households in the UK fell from 6.5 million in 1996 to around 2 million in 2003 (DTI 2005e). Unfortunately $60 \%$ of this reduction came from increased incomes, via the Winter Fuel Payments and other credit schemes for vulnerable households (DTI 2006b). ${ }^{4}$ Therefore rising fuel prices since $2003^{5}$ pose a major threat to the government's strategy (Waddams Price 2005) and the number of vulnerable households in fuel poverty is expected to double to two million by 2006 . Although there is also a range of fuel poverty efficiency programmes, such as England's Warm Front Scheme, these may need to be redesigned for maximum benefit especially to the most vulnerable fuel poor (Milne and Boardman 2000, Oreszczyn et al. 2006, Sefton 2004, Wright 2004).

The energy review is a timely examination of the challenges facing UK energy policy and decision makers must choose how best to deliver progress on all four policy goals against these larger trends. There is a wide range of policy and technology options that might be pursued, such as personal carbon allowances, better building regulations, or investment in nuclear power. However one technology has a unique ability to deliver on all energy policy goals: microgeneration.

\subsection{Microgeneration to the rescue?}

Microgeneration is defined by the Energy Act (2004) as the generation of heat and/or electricity from renewable (or combined heat and power) technologies with a electrical capacity of less than $50 \mathrm{~kW}_{\mathrm{p}}$. These technologies are

\footnotetext{
${ }^{4}$ Vulnerable households are those with children, elderly, sick or disabled occupants.

${ }^{5}$ Several major suppliers (British Gas, Scottish Power, and PowerGen) have recently increased their tariffs by 8 to $18 \%$ on electricity and 15 to $24 \%$ on gas (BBC News $2006 a, c, d$ ).
} 
also known as 'embedded' or 'distributed' generation because they are located within the distribution network rather than the higher voltage transmission networks to which large central generators are connected. While distributed generation is often used in industrial settings (OECD/IEA 2002), microgeneration is attracting interest in other sectors as well, for example, to supply the $34 \%$ of UK electricity used in homes (DTI 2005a).

\subsubsection{Promoting domestic microgeneration}

Domestic microgeneration could be defined as electrical generation of less than $10 \mathrm{~kW}_{\mathrm{p}}$ (Electricity (Microgeneration) Bill 2005) and there are currently more than 80,000 microgeneration installation in the UK (EST 2005b). However legislation, such as the Management of Energy in Buildings Bill (2006), Climate Change and Sustainable Energy Act (2006), Sustainable and Secure Buildings Act (2004), aims to increase the uptake of microgeneration by setting targets, requiring annual Parliamentary reports on progress, and encouraging adoption through the building regulations. More directly, the government recently published its microgeneration strategy which was a requirement under $\$ 82$ of the Energy Act (2004). The strategy establishes a grant programme for microgeneration technologies, identifies areas for regulatory and planning improvements, and highlights the importance of coordinating policy with other key ministries such as Defra, the Office of the Deputy Prime Minister (ODPM), and the Treasury (DTI 2006a). However this strategy has been criticised by industry for lacking in specificity and ambition (Green Alliance 2006, BBC News 2006b). Instead, local government initiatives are being seen as increasingly important with over 75 councils planning to adopt the so-called 'Merton rule', which requires new developments to provide a portion of the building's energy needs on-site (e.g. $10 \%$ to $30 \%$; not all of these policies apply to residential buildings) (LBM 2006, Solar 
Century 2005b).

Environmental groups have been quick to highlight the benefits of microgeneration, indicating that it can deliver energy policy goals much more effectively than a similar investment in nuclear power (Greenpeace 2005, Collins 2004, Willis 2005). As recognized in a recent speech by the energy minister (Wicks 2005), microgeneration can potentially contribute to the four goals of energy policy:

Climate change As microgeneration is produced from renewable or co-generation sources, it provides low or zero carbon electricity. Research has shown that these technologies could play a central role in delivering a $60 \%$ reduction in the carbon dioxide emissions of the domestic sector by 2050 (Boardman et al. 2005).

Security of supply The 'fuel' for renewable microgenerating technologies, such as small-scale hydro, wind, and solar, is available indigenously. For fossilfuel microgeneration (e.g. CHP), the co-generation of heat and electricity reduces primary fuel demand. Generating electricity in the home also avoids the losses that occur during the transmission of centrally-generated electricity.

Fuel poverty By producing energy within the home, particularly from renewable sources, fuel-poor households can significantly reduce the amount of fuel that must be purchased from a supplier.

Competitive markets Excess electricity produced by these technologies can be sold by households to the grid, raising extra income and providing suppliers with another way of meeting their renewables obligation. Microgeneration also creates a new market for suppliers who wish to offer tariffs or services that incorporate the sale and operation of microgenerating equipment (e.g. energy service companies or 'Escos'). 
Despite these advantages, there are obstacles to the growth of microgeneration including cost, lack of consumer understanding, regulatory and legislative hurdles (EST 2005b). Some of these technologies (e.g. micro-hydro, micro-wind and Stirling engine $\mathrm{CHP}$ ) may overcome these barriers in the near future but cost concerns in particular are affecting investment decisions now. For example, the Office of the Deputy Prime Minister recently concluded that microgeneration technologies were not yet affordable enough to include as part of the building regulations (ODPM 2005). ${ }^{6}$

\subsubsection{Photovoltaics: power from the sun}

Although the EST report (2005b) found solar photovoltaics (PV) to be very expensive, it is currently the second most popular microgenerating technology in the UK (Table 1.1). There are a number of different photovoltaic chemistries but the most common cells are silicon-based. When the semiconducting material of the cells is exposed to light, a direct electrical current is produced; single cells are typically wired into larger arrays, boosting the power (i.e. current or voltage depending on set-up) and feeding it into an inverter. This device then converts direct current to alternating current, thus allowing the energy to be used in the home or exported to the grid. The term PV can therefore refer to both the photovoltaic panels themselves and the associated electricity production system at large.

The photovoltaic effect was first discovered by French scientist Edmond Becquerel in 1839 and in 1954, the first modern cell was created at Bell Labs in the United States (DoE 2005). PV has since been used for a number of different applications but its high cost initially led to specialization in remote power

\footnotetext{
${ }^{6}$ The report states that the calculations used to make this decision should not be contestable in subsequent consultations - even though it simplistically assumes constant electricity prices over 25 years with no sensitivity analysis. Since this research began, for example, prices have risen from approximately $7 \mathrm{p}$ to $10 \mathrm{p}$ per $\mathrm{kWh}$.
} 


\begin{tabular}{lr}
\hline Technology & Number of installations ${ }^{\dagger}$ \\
\hline Solar hot water & 78470 \\
Photovoltaics & 1301 \\
Micro CHP & 990 \\
Micro wind & 650 \\
Ground source heat pump & 546 \\
Biomass boilers & 150 \\
Micro hydro & 90 \\
Fuel cells & 5 \\
\hline Total & 82202 \\
\hline
\end{tabular}

TABLE 1.1: UK microgeneration installations by technology (EST 2005b)

applications, such as satellites. Modern high-efficiency mono-crystalline cells convert approximately $15 \%$ of the incoming solar energy into electrical energy; cheaper cell technologies have efficiencies in the range of 5 to $10 \%$ (Jardine and Lane 2003). Figure 1.4 shows the global installed PV capacity for selected countries as of 2004; the UK is ranked $14^{\text {th }}$ in this league table.

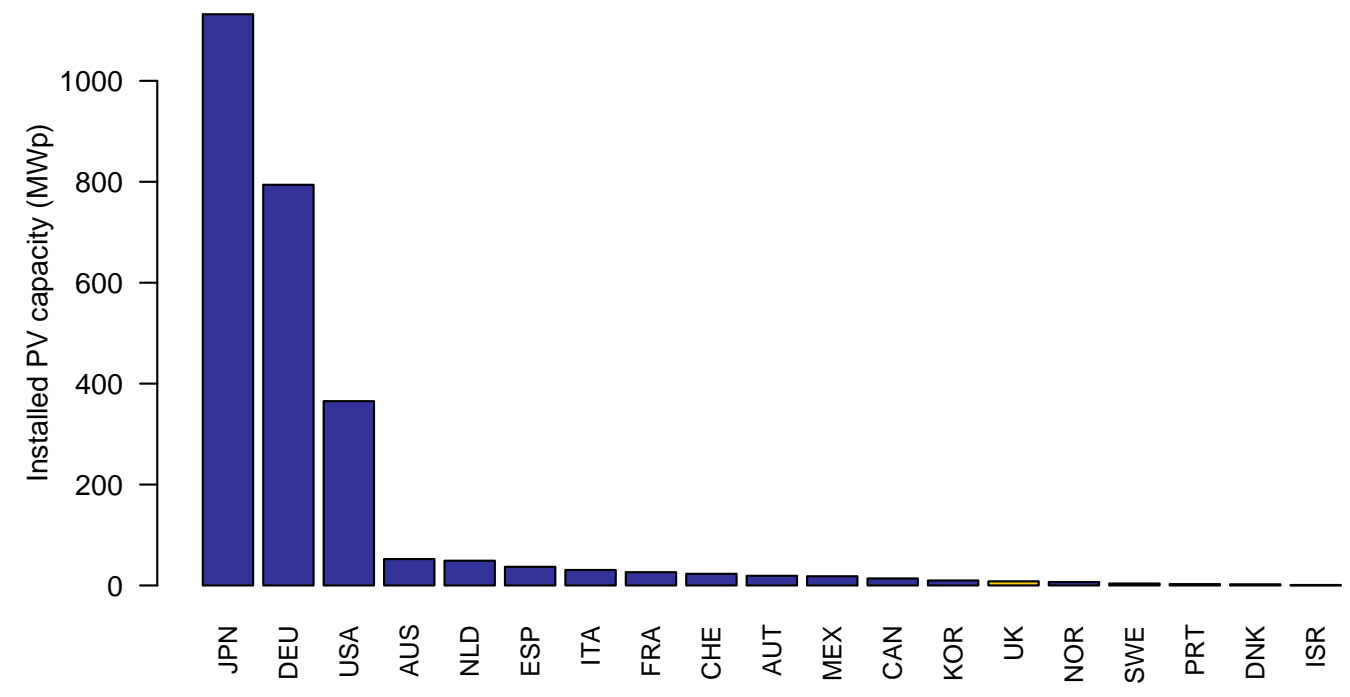

FIGURE 1.4: International installed PV capacity as of 2004 (IEA-PVPS 2005) 
While the UK may not be the most obvious location for solar energy, it does have a good solar resource ranging from 900 to $1300 \mathrm{kWh} / \mathrm{m}^{2}$ per year (Jardine and Lane 2003). The government has expressed an interest in PV technology, and noting the success of other countries, a joint government-industry PV group report in 2001 recommended a $£ 150$ million 10-year programme to install PV on 70,000 roofs and 1400 larger non-domestic buildings (Shanahan 2003). This plan has not yet come to fruition, but the Department of Trade and Industry (DTI) has supported three other notable policies:

PV Field Trials This programme began in 2000 and consisted of both domestic and large-scale projects (total budget of $£ 9.4$ million, total installed capacity of about $1.5 \mathrm{MW}_{\mathrm{p}}$ ). The grants were intended to provide opportunities to monitor system performance, build industry experience and refine installation and design practices (BRE 2002, Davies and Munzinger 2003).

Major Photovoltaics Demonstration Programme (MDP) The field trials demonstrated that PV installations were viable in the UK and established the technical knowledge necessary for a wider expansion of PV. Therefore in March 2002, the DTI launched the MDP to generate awareness and "make considerable headway in preparing a secure platform for long-term and sustained growth in the UK PV market" (EST 2003b: 3). There were small $\left(0.5-5 \mathrm{~kW}_{\mathrm{p}}\right)$ and large $\left(5-100 \mathrm{~kW}_{\mathrm{p}}\right)$ streams and the programme's total budget was about $£ 32$ million, having been extended several times by government. Approximately 1300 domestic and 160 large-scale projects were completed for a total installed capacity of nearly 8 MW $_{\mathrm{p}}$ (EST 2005c).

Low Carbon Buildings Programme (LCBP) The MDP finished in March 2006 and the successor Low Carbon Buildings Programme was announced by the DTI with a total budget of $£ 80$ million over 3 years (DTI 2006a). However, unlike the PV-specific MDP, the programme covers a range of mi- 
crogeneration and energy-efficiency technologies. This 'technology-blind' approach may be particularly challenging for photovoltaics (Solar Century 2005a) and the level of funding has been criticized as insufficient to meet household demand for microgeneration in general (Berry 2006). The small-scale stream of the programme will continue support for private households initially but this funding will be phased out in favour of largescale housing developments. As of April 2006, it had not been confirmed how $£ 50$ million of the funding would be allocated.

These programmes have been successful, increasing the UK's installed PV capacity to approximately 8.2 $\mathrm{MW}_{\mathrm{p}}$ (Figure 1.5). Installed costs have also fallen from approximately $£ 9000$ per $\mathrm{kW}_{\mathrm{p}}$ in 2001 to about $£ 6000$ per $\mathrm{kW}_{\mathrm{p}}$ in 2005 (Archibald 2005 pers. comm.).

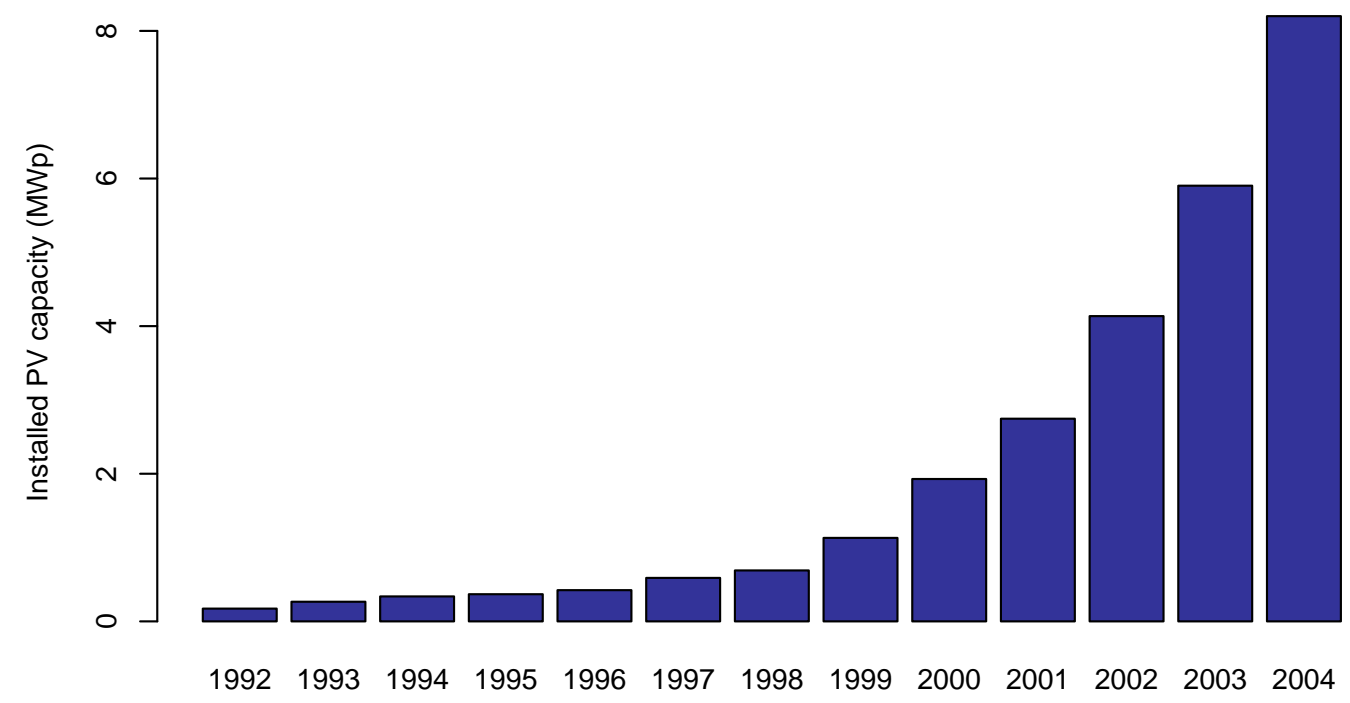

FIGURE 1.5: Installed PV capacity in the UK as of 2004 (IEA-PVPS 2005, DTI 2005a) 


\subsubsection{Metering and monitoring devices}

Microgeneration installations are comprised of more than just the generation technology and a typical system will also include metering and monitoring devices. The primary distinction is that meters form the basis of payments for electricity, thereby linking the household to the wider electricity system (for example, by facilitating payment for microgeneration electricity). Monitoring devices cannot be used for 'fiscal' purposes and instead provide valuable feedback on generation and consumption performance, potentially encouraging changes in energy consumption (e.g Darby 2000). Recent innovations have blurred this distinction (i.e. there are devices which may serve both roles) but the functional difference remains: meters are regulated registers of electricity flow, while monitors are consumer-focused information displays (Figure 1.6).

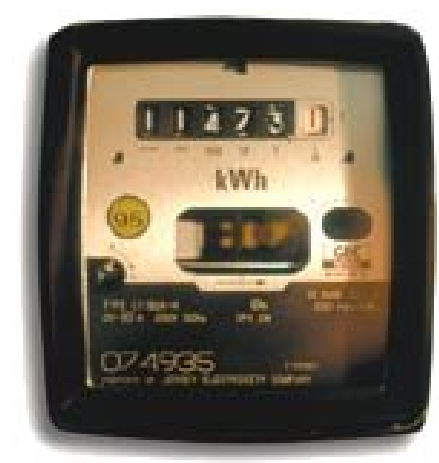

(a) An electricity meter

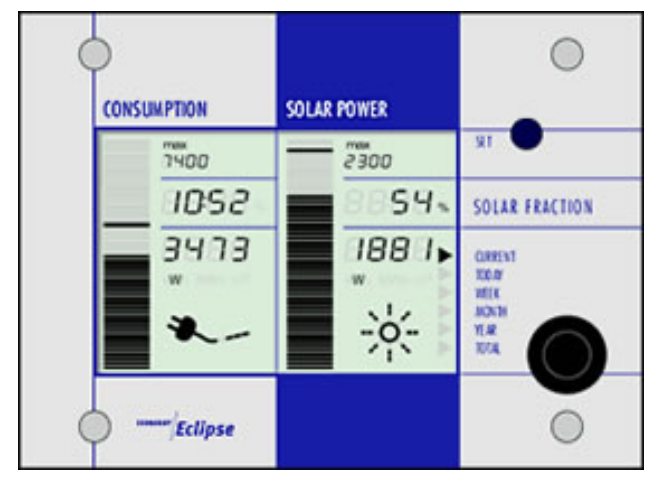

(b) A monitoring device

FIGURE 1.6: Examples of metering and monitoring devices 
Further clarification should also be provided regarding meters, as there are three types relevant to microgeneration (illustrated in Figure 1.7):

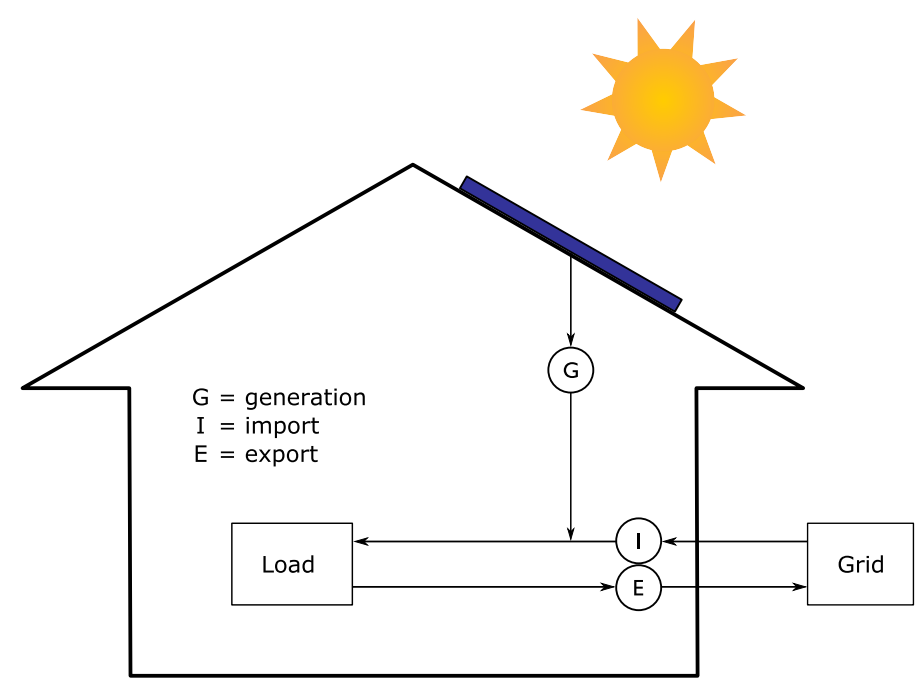

FIGURE 1.7: An explanation of microgeneration metering

Import meters measure the kilowatt-hours of electricity purchased from the national grid and are required in every UK household by law. The devices must meet the 'appropriate' meter standard set out in Schedule 7 of the Electricity Act (1989). In a home without microgeneration, this meter measures total electricity demand.

Generation meters measure the kilowatt-hours of electricity generated by a microgeneration system. They were a requirement of the MDP PV grant programme and must also meet the Schedule 7 'appropriate' standard in order for a microgeneration installation to claim renewable obligation certificates (via 'sale and buy-back' agreements, §1.2.4).

Export meters measure the kilowatt-hours of electricity returned to the grid. Therefore in a microgeneration household, the export meter registers the difference between the electricity supplied by the grid and microgeneration equipment and the household's total electricity demand. These meters are not required as part of a microgeneration installation. 
While these flows of electricity can be measured using simple meter designs, new 'smart' metering technologies may offer additional benefits to households and utilities such as more accurate billing, easier data collection, and even 5 to $10 \%$ reductions in domestic energy consumption through improved consumer awareness (SMWG 2001). A comprehensive review of metering innovation is currently being undertaken "to unlock the potential of smarter metering for domestic customers" (Ofgem 2006b: i) including microgenerators.

\subsubsection{Other developments in the policy environment}

PV policy has largely focused on the diffusion of the technology but the success of PV (and microgeneration technology more generally) depends not just on getting the equipment into homes, but also ensuring that the necessary infrastructure and institutions are in place to support its use once installed. The following are some of the policy issues which affect domestic photovoltaics in the UK, for example, by determining the nature of microgeneration tariffs.

Renewables Obligation (RO) Electricity suppliers in the UK are obliged by law to provide a certain percentage of their electricity from renewable sources (5.5\% in 2005/6). Each megawatt-hour of renewable electricity is awarded a Renewables Obligation Certificate (Roc), which can then be traded with suppliers who have not met their obligation requirements. Domestic microgeneration installations face numerous difficulties with this system primarily arising from the small size of the installations (perhaps only 1 Roc per year). Currently, 'sale and buy-back' agreements allow electricity suppliers to claim these $\operatorname{Rocs}^{7}$ but the administrative cost may outweight the benefit of approximately $£ 40$ per Roc. To resolve these

\footnotetext{
${ }^{7}$ Since microgenerated electricity used on-site does not count as 'supply' under current legislation, households must therefore 'sell' their microgenerated electricity to their supplier and buy it back. The electricity does not actually pass through the grid but a generation meter keeps track of these flows for accounting purposes (Ofgem 2005).
} 
issues, a consultation was held in 2005 and the final decision notably supported the creation of Roc amalgamation agents to simplify this process (DTI 2006d).

Balancing and settlement arrangements The UK wholesale electricity market is governed by the Balancing and Settlement Code. Under these rules, electricity suppliers must purchase supply to match their customer's demand in a half-hourly market. Since domestic customers do not have halfhourly meters, representative profiles are accepted as a proxy for anticipated customer demand. However, microgeneration might disrupt this balance due to the household's reduced requirement for grid-supplied electricity and ability to export. In 2002, the regulator allowed the use of modified electricity profiles to account for the contribution of microgeneration (Ofgem 2002a) and at current low volumes of microgeneration, this may be a better option for electricity suppliers than the use of export meters (DTI 2005c). Research is currently underway at the British Electrotechnical and Allied Manufacturers' Association (Beama) to develop improved profiles for a range of microgeneration technologies.

There have been public consultations on nearly all of these issues in recent months. However there are questions about whether the role of households is being appropriately considered: in other words, are households being viewed as fellow energy 'citizens' by other stakeholders within these debates (DevineWright and Devine-Wright 2005)? This is an important question because the final arrangement of meters, tariffs and other elements of the microgeneration system may influence household behaviour for years to come. 


\section{Summary}

This study is closely linked with contemporary debates on energy policy. Concerns over how to meet government targets on climate change, fuel poverty, and security of supply within a competitive market framework have led to the consideration of many policy options including microgeneration. As one of the main microgeneration technologies, photovoltaics provide an excellent opportunity to study how government policy and industry are shaping the growth and use of these new technologies. Furthermore the uncertainty of the long-term investment climate for renewables and microgeneration (Foxon et al. 2005), on-going regulatory debates and the increased role of local councils suggest that microgeneration will continue to feature on the policy agenda for some time.

\subsection{Microgeneration and consumer behaviour}

The policy context for the study places an emphasis on the diffusion of microgeneration technology, describing the regulatory frameworks and drivers for further adoption. However, if microgeneration does become widely adopted, there are questions about its impact on households and their energy consumption. For example, research has found that the energy consumption associated with domestic appliances (e.g. washing machines, freezers, power showers) can be changed by the form of these devices and the practices associated with them (Southerton et al. 2003). Photovoltaics also represent a kind of household appliance but, as a generating technology, one might expect that it will have a more disruptive effect on consumer behaviour. Therefore, while the diffusion of microgeneration technology is an important consideration, the research is primarily concerned with the effect of photovoltaics on domestic energy con- 
sumption behaviour. In other words, does PV create a 'double-dividend', encouraging households to use energy more efficiently as well as providing low carbon electricity?

\subsubsection{Previous studies of PV and consumer behaviour}

It could be argued that existing literature on photovoltaics has given insufficient weight to the role of the user. Setting aside the scientific work of developing new PV technologies (e.g. Kirov et al. 2004, Carey et al. 2004), there is a large body of research that examines the effectiveness of PV diffusion policies and business models (e.g. Midttun and Koefoed 2003, Payne et al. 2001, Duke et al. 2005). However these studies often miss opportunities to examine consumer behaviour. For example, Kurokawa and Ikki (2001) summarized the Japanese PV experience from a policy and technical perspective and although monitoring equipment was installed in 85 PV households, recording 10 system performance parameters, total household electricity demand was not measured. Similarly, Thomsen et al. (2005: 111) surveyed 12 low-energy solar houses around the world and concluded that discrepancies between the estimated energy savings and the higher levels of actual consumption were effectively the fault of the occupants, suggesting there was a "need to explain the building's behaviour thoroughly to its users" (emphasis added). Although this conclusion may be simplistic, the study's description of how consumer behaviour influences energy consumption (e.g. by controlling the indoor climate) does demonstrate that technical assessments alone cannot predict the energy consumption of a PV household.

The social and behavioural issues of photovoltaics and microgeneration are becoming more important. For example, some research programmes have incorporated basic social and consumer considerations into technical assessments 
(e.g. microgeneration in urban regeneration projects, NEF 2006, Resurgence 2006). The most interesting studies though, and those that are most relevant to this thesis, comment on whether or not photovoltaics have changed the energy consumption behaviour of PV households. These studies directly or indirectly develop a hypothesis that further energy conservation might occur by owning a microgeneration technology, further energy conservation will occur. In off-grid applications, for example, there is consistent evidence that households with photovoltaics take care to adapt their consumption to the production of their PV systems (Schweizer-Reis et al. 2000); this has even been seen in situations where communities share the generation of a PV system (Jenny et al. in press). In the UK however, most PV systems are grid-connected and so managing microgenerated electricity is arguably less important, as grid back-up is readily available.

There have been studies of consumer responses to PV in grid-connected situations throughout Europe but the results are mixed. Erge et al. (2001) found that there was no difference in the electricity consumption of households with or without PV. Anecdotal evidence presented in another study suggested that increased awareness of the cost of electricity led to other energy-saving measures being taken in the home (EC 1997). The most notable study however is a socio-economic evaluation of PV in Austria which suggested that PV may be "the last part in a chain of energy conservation investments" (Haas et al. 1999: 189). The study also indicated that households consuming more than approximately $3500 \mathrm{kWh}$ per year prior to the installation of PV were found to have reduced their consumption in the following year and households below $3500 \mathrm{kWh}$ per year increased their demand. Further investigation revealed that the data behind this conclusion were based on self-estimates and with no consideration of other changes within the home, e.g. building an extension, fuel switching, fewer occupants and so on (Haas et al. 1997, Haas 2005 pers. 
comm.). Therefore it is hard to draw firm conclusions about the overall effect of grid-connected PV on household electricity consumption.

These studies were published prior to this research beginning in 2003. Since that time, other researchers have also been attracted by the questions surrounding consumer behaviour and microgeneration. For example, the author's website has received emails from seven masters and doctoral students in the UK and Australia, asking for further details on the project. A web search also reveals that at least two other institutions in the UK (Southampton University and the Science and Technology Policy Research Unit, University of Sussex) are currently involved with microgeneration research with a social element (e.g. the role of consumers within microgeneration systems, Watson 2004a). One of the most valuable contributions comes from Dobbyn and Thomas (2005), who examined the use of various microgeneration technologies in the UK and its effect on the attitudes and behaviours of 29 households. While actual levels of energy consumption were not measured, the research did find compelling evidence that microgeneration "provides a tangible hook to engage householders emotionally with the issues of energy use" (p. 7). Furthermore the research examined different types of microgeneration households and found that 'passive' households (i.e. those that did not actually decide to purchase PV) exhibited the greatest change in attitudes and behaviour especially when properly introduced to the technology. A summary of these major studies is presented in Table 1.2.

These studies suggest that consumer behavioural responses to PV could be as diverse as changing the time of day at which appliances are used, purchasing more efficient appliances, conserving electricity by turning off lights or reducing the use of standby functions on consumer electronics. Each of these behaviours will have different motivations and carbon-saving potentials and therefore a study is needed to provide detail on the nature and motivations of 


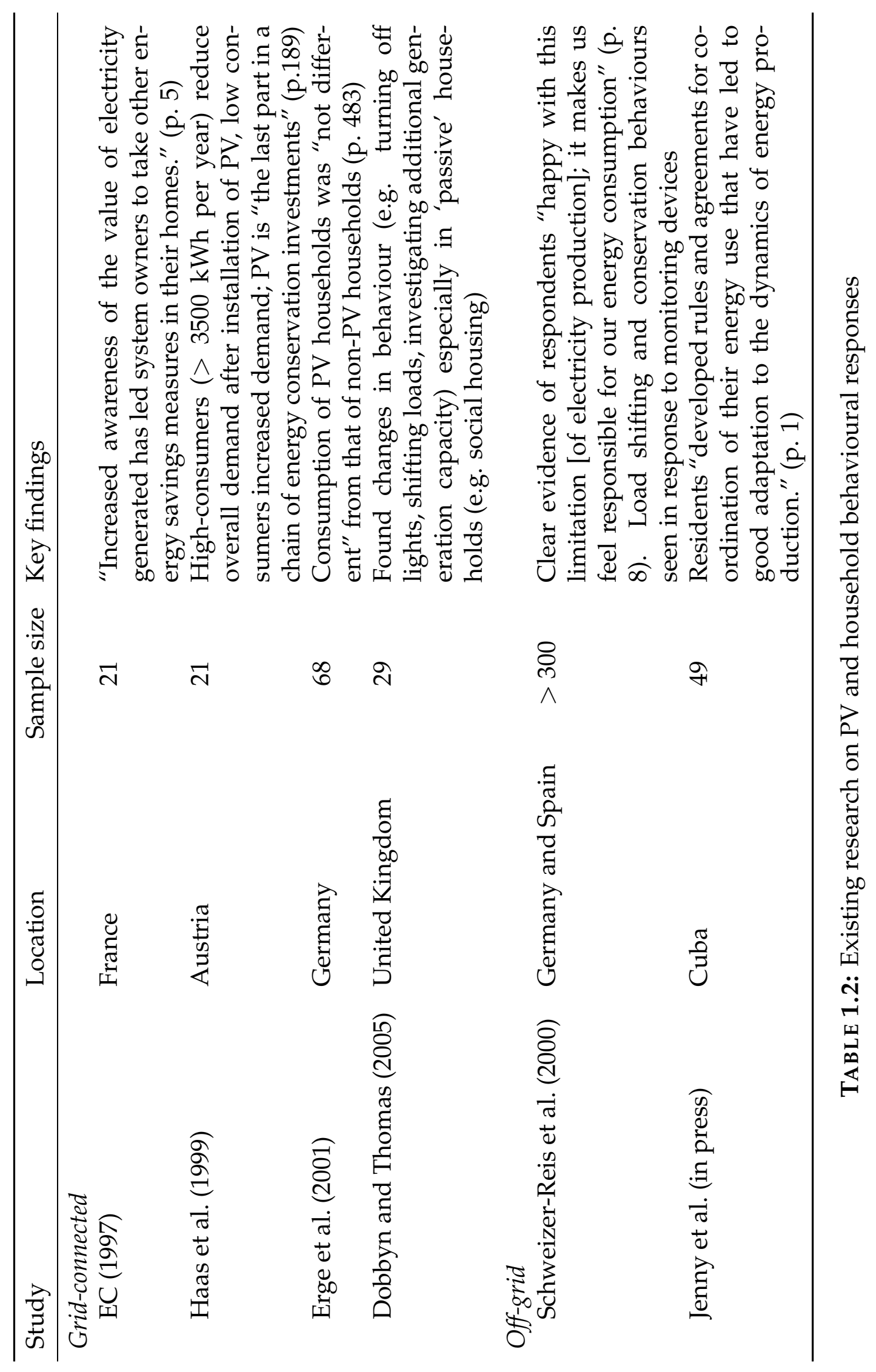


such changes. Recalling that microgeneration is part of on-going debates, it is critically important that these behaviours are described as soon as possible so that opportunities can be identified for the creation of a microgeneration system that meets the needs of users, producers, and policy makers and maximizes the potential of the 'double-dividend'.

\subsection{Aims and scope of the study}

A wide range of issues touch upon this study, from the dynamics of large sociotechnical systems and the diffusion of innovation to consumer behaviour and psychology. As a result, there is a risk that an investigation of the behaviour of photovoltaic households could lead in many different directions and fail to answer the core areas of inquiry. To resolve these issues, Robson (2002) advises researchers to define the boundaries of the study at the outset and set clear research questions.

\subsubsection{Research boundaries}

The thesis is an investigation of domestic energy consumption behaviour in response to the installation of solar PV technology. Consumer behaviour is therefore at the centre of the research, examining how photovoltaics affect the energy consumption behaviour at the household level; however broader issues, such as the diffusion of PV technology, are considered to the extent that they may also affect consumer behaviour.

While it is difficult to give an exhaustive list of what the study is, it is perhaps easier to define what the study is not. First the preceding research covered a range of microgeneration technologies, countries and applications (e.g. onand off-grid). Since microgeneration technologies are at varying stages of development and they deliver electricity and heat in different patterns (i.e. the 
timing and quantity of delivered energy will depend on the technology and the available resource or location), this study will focus on photovoltaics in the UK alone. Furthermore only grid-connected applications will be considered. This is partly because the existing research on off-grid systems appears to be reaching a consensus that a limited electricity supply forces users to adapt their consumption. These studies were also often set in developing countries where the installation of photovoltaics was the respondents' first exposure to electricity. In the UK, most PV installations are grid-connected and so the potential national benefit of a 'double-dividend' is greater in these mainstream applications.

PV can be installed in a variety of on-grid applications, including commercial and various domestic situations. Commercial PV installations are not of interest here and have been investigated elsewhere (Jardine 2004). The domestic side is not homogeneous though and Dobbyn and Thomas (2005), for example, investigated both 'active' (owner-occupiers who chose to install PV themselves) and 'passive' households (e.g. social housing where the landlord installs PV). This research will focus on the active owner-occupiers for two reasons. First, the literature suggests that monitoring devices and hence information feedback play an important role in shaping household behaviour (Darby 2000); these devices are typically not installed in social housing applications because of cost constraints or the technical difficulty of wiring all the flats in a larger building to reflect some share of the communal generation. Focusing on owner-occupiers also provides methodological benefits, as these households can be contacted through installers and having committed to purchasing PV, they may also be keen to participate in the research and share their experiences. This enthusiasm also means that these households may be more likely to be aware of their energy consumption including any history of energy-saving actions. Unfortunately since the research began, the government has begun to place more em- 
phasis on large developments, where the households are more likely to be of the 'passive' subset, thereby affecting the relevance of these findings to current policy.

\subsubsection{Key terms and issues}

Since the study cuts across several different fields of study, it is important to clarify some key concepts and terms that will be used throughout the thesis. These topics are considered in greater detail in Chapter 2 but introduced here in order to frame the research questions.

Domestic energy consumption (DEC) The thesis is concerned with the energy consumption behaviour of households within the home. For the purpose of national and international assessments (e.g. IEA 1997), this means the energy used for activities such as lighting, space heating, water heating, appliance use (consumer electronics, white goods and so on) and cooking. Associated areas of energy consumption, e.g. transport between home and work, is not considered. In the UK, DEC accounted for $28 \%$ of final energy consumption in 2004 (DTI 2005a).

A distinction needs to be made between energy and electricity. Electricity accounts for approximately $20 \%$ of domestic delivered energy (mainly lights and appliances), with the rest primarily gas for space and water heating (Shorrock and Utley 2003). Since photovoltaics generate electricity, the behavioural responses considered in this thesis are largely concerned with electricity use; i.e. are there changes in the use or ownership of lights and appliances? However respondents may be motivated by their greater awareness to change other aspects of their energy use (e.g. installing better insulation) and so these factors are also considered. 
Behavioural response There are several taxonomies of energy consumption behaviour and hence potential definitions of a behavioural response. For example, van Raaij and Verhallen (1983b) divide household energy consumption into purchase, use, and maintenance behaviours; Kasulis et al. (1981) describes similar purchase, conserve, and schedule behavioural responses to information feedback. Gardner and Stern (1996) offer two types of behaviours relating to household energy conservation: efficiency (e.g. one-time improvements to the energy consumption equipment) and curtailment (e.g. repetitive measures designed to reduce consumption). Finally, Jenny et al. (in press) observed that Cuban communities managed the output of their off-grid PV systems by either specifying times for, or prohibiting, the use of high-consuming appliances. Shifting the times of consumption has also been seen in the use of solar hot water systems (Klein 1983). These elements can be combined so that a behavioural response to PV might be defined to encompass both the purchase of more efficient appliances, insulation, lighting and so on and change patterns of use (including both an absolute reduction in demand or a change to the time of use).

Abrahamse et al. (2005) identified three criteria for evaluating the effectiveness of intervention strategies which can be adopted for use in this study. The most basic factors are effectiveness and attribution: in other words, what is the extent of the observed behavioural response and to what stimuli can the change be attributed? This also includes an assessment of how the underlying motivations of an observed behaviour have changed. The final element is permanence, which considers whether or not the behavioural response is likely to continue in the future. These criteria can therefore be used to assess the success of behavioural responses to PV. 
Behavioural motivation Behavioural responses to photovoltaics could be said to be influenced by two factors: the psyche of the individual and the social context in which s/he acts. The internal psychological aspects of consumer behaviour might be referred to as behavioural motivations. For example, the 'conservation chain' hypothesis of Haas et al. (1999) implies that the commitment of households towards low energy consumption may be important. Similarly de Young (1996), Leonard-Barton (1981b) and Seligman et al. (1979) found that the 'intrinsic satisfaction' of doing something to take responsibility for one's environmental impact can be a powerful incentive for long-lasting behavioural change. Symbolism may also be important and there is evidence to suggest that the installation of solar panels may project a 'green' image to one's neighbours, encouraging behaviours which are compatible with this vision (Leonard-Barton 1981a). A full review of these motivational factors is presented in Chapter 2.

Behavioural context Whereas the motivations of consumption behaviour are arguably of greater interest to academic debates, the context of these behavioural changes is particularly relevant to policy makers. Both industry and government can influence how households might respond to their microgeneration, for example, by determining how excess electricity is sold back to the grid. The relationships between customers and these stakeholders may also be important; for example, the extent to which installers provide adopting households with information about the operation of a new PV system and its associated equipment. A number of contextual factors may be relevant and the research is therefore framed by diffusion of innovation (i.e. the purchase of PV) and socio-technical systems literatures. 
The thesis examines the assumption that domestic energy consumption behaviour may be changed by the installation of a microgeneration technology. Both the internal motivations and external context are likely to shape these behavioural responses; these factors should therefore be considered not as separate elements, but as related pieces of the puzzle.

\subsubsection{Aims of the study}

Before outlining the individual research questions, the overall purpose of the thesis must be clear; that is, does the study intend to explore the topic, describe it in detail, or explain a particular phenomenon (Robson 2002). Since the literature surrounding behavioural responses to $\mathrm{PV}$ and microgeneration is quite new, this research can make the greatest contribution by exploring the issue, trying to assess the extent to which the hypothesized responses to microgeneration technology actually occur and suggest possible explanations. Therefore, the aim of the thesis is to investigate whether the purchase and installation of solar photovoltaics has led to changes in the energy consumption behaviour of the adopting households.

This general goal must then be subdivided into individual research questions that are clear, specific, answerable, interconnected, and relevant (Punch 2005). The policy review has demonstrated that microgeneration and consumer behaviour issues are very timely and the scope of the study, with its focus on domestic energy consumption and its motivations, ensures that the questions have a specific goal. In conjunction with the methodological considerations presented in §1.5.1, the following research questions were developed to cover the scope of the inquiry in a clear and interconnected manner.

1. Does the installation of a PV system change household energy consumption and if so, in what way? This addresses the descriptive element of the research, 
trying to catalogue the types of changes that occur within these microgenerating households. These responses may include changes in overall domestic energy consumption, new equipment purchases, new patterns of use, and any interactions with associated equipment (e.g. monitoring devices).

2. What are the mechanisms that shape these behavioural responses to PV? In other words, if a change is seen, how and why did it happen? If there is no change, were there barriers to action? An important sub-element of this question is assessing the claim of Haas et al. (1999) that PV is part of a chain of energy conservation or efficiency investments; in other words, understanding how the purchase context may affect subsequent behavioural motivations. The role of monitoring and metering devices is also important as they may facilitate specific responses. Findings from this question will form the primary contribution of the thesis to the literature.

3. How might policy makers and industry stakeholders encourage household behavioural responses to $P V$ that increase the energy policy benefits of this and other microgenerating technologies? This question addresses behavioural context issues so that even if a 'double-dividend' from PV is not found at present, decision makers might provide supportive policies and technologies to ensure that these benefits are not restricted in future (e.g. better tariffs for microgeneration). Issues include identifying desirable behavioural responses to PV and examining the trends shaping investment decisions in industry and government: for example, how might the diffusion of PV to a more diverse profile of UK households (e.g. via the LCBP) affect the wider applicability of the observed behavioural responses? These findings will contribute to discussions about market transformation and energy policy. 
Together, these three research questions will describe the extent to which PV encourages a behavioural response in households while exploring the internal motivations and socio-technical considerations that shape the potential benefits of this phenomenon.

\subsection{Methods and structure}

Developing the methodology was one of the biggest challenges of this study as it had to balance the availability of data and resources with theoretical design concerns. An overview of these issues is presented here while the specifics of questionnaire design, data collection and analysis are left for the appropriate data chapters. As the thesis combines a number of different approaches to the topic, a chapter outline provides the reader with a synopsis of how these elements work together.

\subsubsection{Methodology}

Installing photovoltaics in a household and monitoring the resultant change in behaviour is similar to previous studies of energy efficiency and conservation interventions. The recent review by Abrahamse et al. (2005) provides a critique of the methodologies of these studies and the identified issues could be divided into two categories: design and interpretation. Many of the studies reviewed were experimental in nature (i.e. introducing a change to the domestic energy consumption environment and observing the result) and poor experimental design was a common criticism. For example, the use of small sample sizes or the conflagration of multiple interventions often made it difficult to track the influence of a specific change. Regarding interpretation, it is noted that while the studies often discussed changes in behaviour in great detail, insufficient consideration was given to the actual changes in energy use 
(i.e. the implications of these behavioural responses) and any changes to the underlying determinants of behaviour. A lack of long-term data collection and the self-selection of participants were also flagged as barriers to applying the results of these interventions to wider populations and time scales. The review concluded that the design of a methodology for assessing interventions into household energy consumption behaviour needs to be aware of how design issues will affect the wider applicability of the findings and to describe not only the behaviours themselves but also their implications and motivations. These considerations therefore suggest that the thesis should take an integrated approach, using techniques from multiple disciplines where necessary to describe the context and motivations of domestic energy consumption behaviour fully. Integrated approaches have also been called for in recent recent theoretical and methodological literature (Goldblatt et al. 2005).

Sociology is one example of a discipline that can contribute to the methodology of this thesis. For example, Blumer's symbolic interactionism (1969) notes that non-habitual behaviour stems from how people interpret social situations and this has traditionally led to a two-stage research methodology (Fontana 2004). First a flexible exploration phase allows the researcher to collect information from a variety of sources before using a more detailed and analytic inspection process to refine initial perceptions. Similarly actor-network theory literature discusses the importance of following a story wherever it may lead as both technical and social actors may have equal importance in answering the question at hand (e.g. Callon 1986b, Latour 1987). Ideally the methodology might therefore proceed as follows. The exploration phase would combine household social surveying with the recording of detailed electrical demand data. Data would be collected from the years before and after the installation of PV in order to control for seasonal effects and to monitor any changes in the determinants of behaviour. Relationships between actual demand and behavioural 
changes could then be hypothesized before the inspection phase used detailed interviews or computer modelling to confirm and develop a more thorough understanding of the effects.

This approach, based on matching large quantities of electricity consumption data with detailed social surveys of the same households, was investigated at the start of the research but many problems were encountered. For example, when the research began, a joint industry-government project was intending to record detailed consumption in nearly $100 \mathrm{PV}$ households. The project coordinator was approached about the possibility of implementing a parallel social survey but the reluctance of other project partners meant that this was not possible. Other organizations were approached (including a social housing trust, electricity suppliers, and the grant administrator) and while these groups did provide useful advice, it was not possible to coordinate high-quality data collection with social surveying. Recording the data independently was also investigated but found to be too expensive and time-consuming. It was therefore decided that social surveying and interviewing would be the main techniques.

The next challenge was to gain access to PV households. When the research began in 2003, there were approximately 500 PV households in the UK and so random sample techniques, such as street interviewing, mass mailings, or cold calls, were inappropriate. However since most PV households acquired their system through the MDP grant programme, it was hoped that the grant manager (the Energy Saving Trust (EST)) might be willing to distribute an invitation to participate in the research. Data protection concerns ultimately ruled out this option, but the EST and the other potential partners mentioned above did provide the results of internal research which was useful in developing questionnaire ideas. Fortunately one of the UK's leading domestic PV installers, Solar Century, has a long-standing relationship with the Environmental Change Institute and after discussing the research proposal, they agreed to send a ques- 
tionnaire to 118 domestic PV customers on the author's behalf. Households were then free to respond to the mailing and participate in the research as they wished (more details on this process are available in Chapters 3 and 4). The household surveying was complemented by telephone interviews with industry and government representatives which were much easier to arrange. Highquality generation and consumption data were eventually acquired from the DTI Field Trials programme, managed by the Northumbria Photovoltaics Application Centre at the University of Newcastle.

It should be noted that the methodology chosen here is not without precedent and other PV and behaviour studies have similarly relied upon interviews and questionnaires (e.g. Dobbyn and Thomas 2005, Haas et al. 1999, Jenny et al. in press). This research however improves upon these designs by incorporating a larger sample size (91 respondents out of 118 approached, versus 20 to 50 respondents) and by collecting a wider range of data (e.g. household surveying, industry interviews and quantitative data). Furthermore while this methodology does not address all of the issues raised above by Abrahamse et al. (2005), it does seek to include the determinants of behaviour (e.g. PV as part of a chain of conservation actions), to estimate actual energy use, and to explore the wider context for any observed behaviours (e.g. the government and industry interviews). A remaining criticism, noted by both Abrahamse et al. (2005) and Rohracher (2003), is that intervention studies often end up with a self-selecting group of respondents, who are not representative of the wider public and are vulnerable to social desirability bias in their responses. To an extent, this cannot be avoided: the nature of the research is that it explores a small subset of early adopters who by definition are unlikely to be representative of the general population (Rogers 2003). Being aware of this potential source of error is important when determining the wider applicability of the results. 


\subsubsection{Thesis structure}

The thesis is presented as follows. Chapter $\mathbf{2}$ is a literature review, examining some of the theoretical concepts needed to understand how consumers might respond to the introduction of a new technology. Socio-technical systems and diffusion of innovation literatures are reviewed as well as key elements from sociological and psychological perspectives on energy consumption behaviour.

The methodology outlined broad exploration and inspection phases. For example, Chapter 3 presents the results of a mail questionnaire sent to $118 \mathrm{PV}$ households, identifying some behavioural responses and possible motivations for these changes. The inspection phase follows in Chapter 4, where interviews were held with the same respondents to examine the issues raised by the questionnaire in greater detail. Chapter 5 inspects two years of quantitative data from a different set of PV households to understand the nature of supply and demand within PV households and specifically consider how different microgeneration tariffs might influence consumer behaviour. The final data chapter, Chapter 6, investigates the wider context for microgeneration and household energy consumption behaviour through interviews with industry and government stakeholders.

Chapter 7 concludes by drawing together the key results from the data chapters. The findings are then discussed to give the implications of the research for both the literature and policy, thus addressing the original research questions. 


\title{
Chapter 2
}

\section{PV AND THE SUSTAINABLE CONSUMER}

\begin{abstract}
"If we stopped to think why our artefacts - our saucepans, our cars, our refrigerators, our bridges - work or take the form that they do, we would never get around to boiling the water to make coffee each morning. The conduct of daily life surely demands a tactical lack of curiosity! But that lack of curiosity carries costs and overhead expenses as well as benefits. Our artefacts might have been different. They might have worked better. They might not have failed. They might have been more user - or environmentally — friendly."
\end{abstract}

Bijker and Law (1992: 2)

Solving the UK's domestic energy policy challenges will require a two-pronged approach, first reducing demand and then providing sustainable supplies (Boardman et al. 2005). Photovoltaics clearly address the second concern, generating indigenous and renewable electricity, but the potential of PV to reduce demand remains uncertain $(\$ 1.3 .1)$. If the thesis does discover a reduction in total energy consumption following the installation of $\mathrm{PV}$, the epigraph suggests that this change might be explained by consumers questioning their present domestic energy consumption practices. The installation of decentralised generation may also lead households to ask questions about how traditional modes of electricity provision came to be and their subsequent effect on the form and use of energy-consuming technologies. In other words, domestic energy technologies are imbued with values and history; the hope is that, by disrupting the estab- 
lished domestic energy consumption environment, PV will make these hidden meanings visible once again.

Similarly, a PV installation is not simply a fixed artefact but a product of negotiations between designers, policy makers, electricity suppliers, consumers and other stakeholders; it too "might have been different". In addition to questioning the nature of existing technologies and their associated systems, the novelty of PV may give households an opportunity to become involved in emerging debates about the meaning and use of PV before they become wellestablished. For example, if early adopters encounter difficulties in trying to sell their generated electricity back to the grid, they may be able to communicate these experiences back to suppliers, hopefully creating a more user-friendly environment for future adopters. The experience of these early adopters and their interactions with other stakeholders are therefore likely to determine the ability of PV to alter energy consumption, both now and in future.

These questions seek to understand the potential of PV to encourage 'sustainable' consumer behaviour and three bodies of literature are explored to address these issues. First, photovoltaics are presented in light of domestic energy consumption literature to determine how PV might conceptually fit within the home of an adopter. Secondly since photovoltaics are a relatively new technology in the domestic sector, literature on the diffusion of innovation and socio-technical systems is reviewed to understand how the technology might develop in association with early adopters. Finally, literature on sustainable consumer behaviour, including domestic energy consumption interventions, suggests some potential causes of behavioural responses to PV. 


\subsection{PV and domestic energy consumption}

The domestic energy environment is primarily a consumption environment, dominated by demand for services such as lighting, space heating, water heating, or appliance use. If supply is considered at all by the consumer, it is likely to be restricted to the cost of fuels, such as electricity or gas. However by introducing a generation technology such as photovoltaics, this passive state may be disrupted, prompting a change in behaviour. Estimating the impact of this intervention will depend on how domestic energy consumption (DEC) is conceptualized; e.g. if DEC is viewed as a question of rational economics, this might lead to different conclusions than if a psychological approach was used. This section therefore reviews some common theories of DEC and discusses how photovoltaics might be conceptualized.

\subsubsection{Disciplinary approaches to DEC}

Domestic energy consumption is frequently studied using the tools, techniques, and theories of a single discipline such as engineering, economics, psychology or sociology. Each speciality addresses the question of domestic energy consumption differently. For example, engineering studies explore the technologies of the domestic sector and determine consumption using physical laws such as heat transfer. This approach can been seen in demand from heating (Shorrock and Dunster 1997), lighting (Stokes et al. 2004) and appliances (Hart and de Dear 2004). At the national scale, the effect of policy instruments can be readily assessed using these technical models (Shorrock and Dunster 1997, Boardman et al. 2005) but identifying the subtleties of individual decisionmaking is more difficult. Consequently human behaviour is often estimated from proxy records or statistical techniques (e.g. Capasso et al. 1994, Lampadi- 
tou and Leach 2005, Michalik et al. 1997). An example of this limitation comes from a study of home heating in Ireland that was unable to determine whether improved insulation would result in less fuel consumption or a higher standard of living (i.e. maintaining or increasing the pre-insulation temperature, Clinch et al. (2001); although Milne and Boardman (2000) did quantify some of these differences). Technical models of energy consumption may therefore be acceptable for aggregate analyses, but at smaller scales, "the individual consumer and ... the random components of demand become very important" (Stokes et al. 2002: 4).

The economic approach combines strong numerical analysis with elements of human behaviour. The classical model assumes rational behaviour, with households adjusting energy consumption to maximize their utility within income constraints (e.g Johnson 1971, Baker 1991, Ironmonger et al. 1995). Noting that households frequently fail to obey the assumptions of rational behaviour, variations on this model have been used in a range of domestic energy consumption situations (both modelled and evidence-based) including time-of-use pricing (Baladi et al. 1998, Filippini 1995), demand for lighting or appliances (Hausman 1979, Kooreman 1996, Fernandez 2001), and energy-efficiency investments (Brechling and Smith 1992, Thompson 2002). Even with these adjustments, some would argue that it is still "business as usual" for many economists (Darroch and Jardine 1998: 498) and more serious critiques have been given insufficient attention. These include concerns, for example, that neo-classical economics neglects the complexity of behaviours for different occupants within a single household (Wheelock and Oughton 1994, Kooreman and Wunderink 1997), it cannot adequately account for the non-market determinants of behaviours (e.g. social determinants of demand, Cogoy 1995), that 'rational' decisions depend greatly on how choices are framed (Tversky and Kahneman 1986), and that natural and financial capital are not necessarily substitutable (i.e. affecting 
cost-benefit analyses, Neumayer 1999). The underlying theme is that domestic energy consumption in practice does not conform to assumptions of rational behaviour (Deaton and Muellbauer 1980, Hinchliffe 1995, Simpson 2000).

Together these approaches constitute the physical-technical-economic model (PTEM) of domestic energy consumption, which has enjoyed a significant influence in the creation of energy policy (Lutzenhiser 1993). ${ }^{1}$ However it has long been argued that social scientists can make an important contribution to the understanding of DEC (Schnaiberg 1975, Winnett and Ester 1983), specifically to address the PTEM's "serious blind spots in the area of human behaviour" (Stern 1992: 1224). To this end, psychology has contributed by exploring the internal motivations for energy consumption behaviour such as the role of attitudes (Brent Ritchie et al. 1981), values (Poortinga et al. 2004) and knowledge (Socolow 1978). These constructs have been combined into models of behaviour and decision-making, such as the Theory of Planned Behaviour (Ajzen 1991), and support has been found for their use in DEC applications (Banks 1999, Stutzman and Green 1982). However these attitude-behaviour theories have not given sufficient consideration to the social and cultural contexts of energy use behaviour (Stern et al. 1995, Strang 1997).

While early attempts to study energy and society lacked a proper theoretical framework (Rosa and Machlis 1983), sociological studies have since demonstrated the importance of social context in understanding domestic energy consumption (Rosa et al. 1988). These contributions have ranged from including basic socio-economic data in technical studies (e.g. Cramer 1985) or examining the social equity impacts of conservation measures (e.g. Held 1983) to more thorough sociological analyses, for example, of energy use and housework (Cowen 1983), the evolution of domestic appliances (Hardyment 1988),

\footnotetext{
${ }^{1}$ Hammond (2004) believes that the disciplines within the PTEM are not evenly split and that economics have taken precedence over the engineering or technical approaches.
} 
and changing perceptions of comfort and cleanliness (Shove 2003a,b). Concepts such as lifestyle analysis (Wolvén 1991), the cultural inertia of technological systems (Lutzenhiser and Hackett 1993, Jensen 2005), and 'obligatory' or minimal culturally-accepted levels of consumption (Hackett and Lutzenhiser 1991, Wilhite and Lutzenhiser 1999) have provided means of evaluating the impact of social factors on energy use. However since these concepts are communicated primarily in qualitative terms, often in reference to specific households, they may have less influence with policy makers than the PTEM until quantitative sector-wide translations are made.

\subsubsection{Integrated approaches to DEC}

Disciplinary approaches have made valuable contributions to the study of domestic energy consumption but their specialization can pose difficulties for more complex research problems. In this study, for example, understanding household behaviour in response to PV could be viewed as a psychological issue by identifying the internal motivations of consumer behaviour and how these factors change after the adoption of PV. However as a new technology, the diffusion of PV and its use by consumers must also consider technical (e.g. grid-connection), economic (e.g. payback and tariffs for generated electricity) and social issues (e.g. response of neighbours and other peer groups). Fortunately there is increased interest in integrated approaches to energy issues which offer an attractive complement to disciplinary perspectives.

The limitations to disciplinary conceptualizations of DEC were first recognized over twenty years ago when early energy conservation studies discovered that the anticipated energy savings of intervention programmes were not occurring, due to a poor understanding of the interactions between technology, policy, and the consumer. The overall conclusion - that DEC "can no longer be 
viewed as a purely technical or economic problem but as a people problem as well" (Yates and Aronson 1983: 435) - remains true today. Thus there is a need for an integrated approach that can apply specialist expertise while recognizing the issue's larger context; it has been proposed that an integrated framework of domestic energy consumption might therefore be defined as:

"A conceptualization of domestic energy consumption that acknowledges the expertise of disciplinary approaches but seeks to situate this knowledge within the broader context of energy consumption including social and behavioural factors."

- Keirstead (in pressa: 3)

Six integrated frameworks of domestic energy consumption were identified as notable examples of the field after a review of domestic energy consumption studies found that theoretical conceptualizations of DEC were largely disciplinary. $^{2}$ Furthermore, the approach of these integrated studies stood out as an improvement upon the contributions of hybrid disciplines (i.e. partially integrated, such as economic psychology). The integrated studies include:

- the behavioural model (van Raaij and Verhallen 1983a)

- the political economy model (Dholakia et al. 1983)

- the cultural model (Lutzenhiser 1992)

- the systems approach (Hitchcock 1993)

- the global consumption model (Wilk 2002)

- the 'four-dimensional' approach (Parker et al. 2003)

While these articles will not be discussed in detail, three observations can be made. First, each paper cites the limitations of disciplinary approaches as

\footnotetext{
${ }^{2}$ The following discussion is paraphrased from Keirstead (in pressa).
} 
a justification for an integrated framework. In the case of van Raaij and Verhallen (1983a), this inspiration came from the observed failure of households to be more energy-conscious and they noted six barriers covering a range of technical, economic, and social factors. Secondly the variety of models proposed is impressive, providing a unique opportunity to understand, for example, how marketing experts such as Dholakia et al. view DEC compared to an engineer like Hitchcock. However these different concepts of integration also indicate that no single integrated model has emerged as the accepted form, suggesting that there has been insufficient debate about the merits of various proposed models and what form a unified integrated framework might take. Indeed, rather than these papers being cited as a single body of literature, they are typically cited in isolation and applied within the context of one or two disciplines (e.g. Greening 2004, Wood and Newborough 2003). Furthermore, the final observation is that the six integrated frameworks have largely failed to refer to one another (with the notable exception of Hitchcock who refers to all of the integrated models that precede his study). For example, Lutzenhiser's 1992 study laments that little effort has been spent bringing together social and technical models of domestic energy consumption and yet van Raaij and Verhallen's notable contribution (1983a) was not reviewed. ${ }^{3}$ Figure 2.1 demonstrates the influence of these papers over the past 25 years and using a time-weighted average of the number of citations, the most influential papers are Lutzenhiser (1992) and van Raaij and Verhallen (1983a).

\footnotetext{
${ }^{3}$ This may be an artefact of Lutzenhiser's representative sample methodology, compounded by differences in search technology and limited journal access at the time of his research.
} 


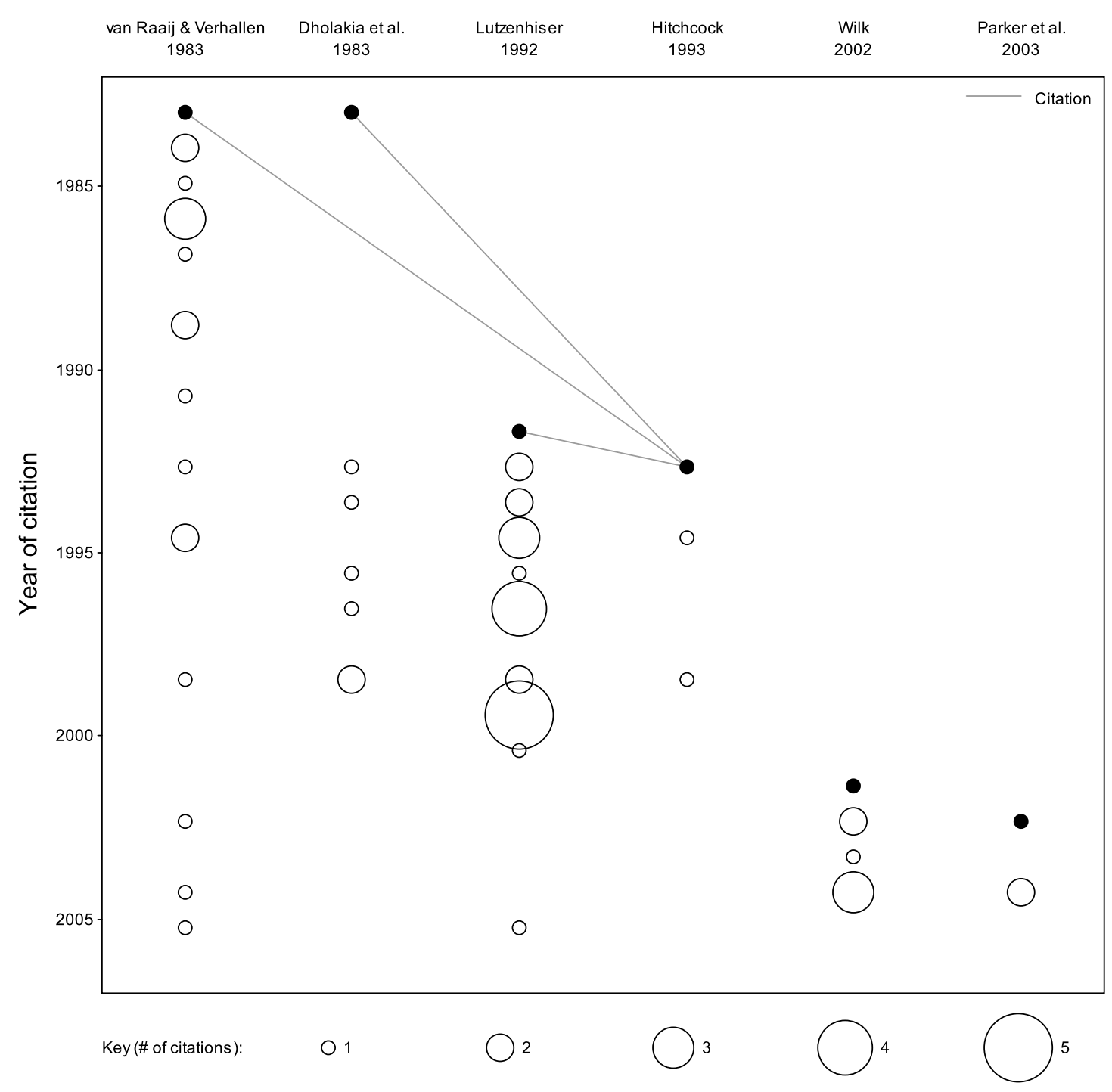

FIGURE 2.1: Citation history of integrated DEC frameworks (ISI 2006, Scopus 2006)

Understanding how different disciplines might cooperate within energy research is an on-going interest of academics and policy makers (Hammond 2004, UKERC 2006). However without a unifying framework, the diversity of integrated models may make it difficult for practitioners to see the issues from compatible perspectives. For example, Lutzenhiser's model might be used to describe how consumer behaviour is affected by the cultural significance of PV, but how does this theoretical insight relate to the policy focus of Parker et al.'s four-dimensional analysis? To resolve this tension, Keirstead (in pressa) pro- 
posed that the theories might be compared across three axes of differentiation:

Application DEC frameworks can lend themselves toward theoretical (i.e. stimulating debate) or practical (i.e. guiding policy) applications. The application attribute therefore determines how easily audiences might understand and use research findings, as suggested by policy makers favouring the practical PTEM. Integrated frameworks should ideally address both theory and practice but the studies reviewed often lean towards one extreme or the other. As an example, Hitchcock's systems approach focuses on practice by providing recommendations for the translation of social behaviours into a technical consumption model.

Form The form of an integrated framework may vary between structure and process extremes. A structure framework attempts to provide a template within which the work of others can be placed and therefore focuses mainly on the arrangement of individual DEC determinants (e.g. van Raaij and Verhallen 1983a). In contrast, a process framework concentrates primarily on the linking mechanisms that bind the entire DEC process. This is the case with the 'multigenic' theory which "could justify connecting energy consumption behaviour to gender relations within the family, community governance institutions, health and nutrition, or proper development regulations" (Wilk 2002: 12). A successful integrated framework should balance structure and process, accounting for all elements of the DEC system but also providing an explanation for how they work together.

Scale The scale of a DEC theory can be generally classified as broad or narrow. Disciplinary models have a narrow scale, investigating one part of DEC in great detail. Ideally integrated frameworks should be flexible enough to take in the big picture (e.g. van Raaij and Verhallen 1983a) while also offering insights into specific elements of the system (e.g. Hitchcock 1993). 
Some authors have noted that, even once the importance of human behaviour and social interactions are recognized, it can be difficult for these aspects to be incorporated into research, industry and policy making structures (Stern 1993, Lutzenhiser 1994, Lutzenhiser and Shove 1999). Therefore the goal of these three dimensions is to balance the needs of different stakeholders, as demonstrated by Parker et al. (2003) who use four similar "dimensions of integration" to bring together local and global actors conceptually. Integrated frameworks of domestic energy consumption should therefore strive to be comprehensive and flexible, facilitating description and management of the complexity of DEC. While these frameworks are still evolving, they do represent a notable improvement upon disciplinary approaches to DEC and hence offer a promising means of analysing photovoltaics and consumer behaviour.

\subsubsection{An integrated approach to PV}

Without an accepted standard integrated framework, a bespoke solution must be developed to interpret behavioural responses to PV. The main purpose of this framework is to provide an overall perspective to the relationship between PV and domestic energy consumption, rather than prescribing specific steps that should be taken during the research. This broad aspiration extends from the principles discussed above: that maintaining a balance across the application, form, and scale dimensions requires an integrated framework to be comprehensive and flexible. Keirstead (in press $a$ ) has suggested that an agent-based approach may facilitate this goal by allowing the complexity of DEC to be condensed into tangible actors that are expanded and explored in detail when necessary.

A comprehensive framework of domestic energy consumption might begin by listing all of the agents or stakeholders that influence household behaviour. 
This could include the household itself, electricity suppliers, regulators, appliance manufacturers, social pressure groups (e.g. neighbours), household appliances, and in the case of this research, the PV system, the installers, monitor manufacturers, grant providers and administrators. Determining how these agents relate to one another is complicated as the arrangements are likely to vary according to the specific research question at hand; accordingly two important stages have been identified for this thesis. First the adoption of PV must be considered, as the household's perceptions of PV technology, their motivations for purchase, and the installation process are likely to influence the subsequent use of the system. The actual post-PV consumption of energy can then be examined. The role of PV in domestic energy consumption might therefore be initially written as $P V \rightarrow$ Household $\rightarrow D E C$, although it will be shown that these relationships are not as linear as this schematic suggests.

Flexibility is important when trying to understand these processes in detail. The purchase of $\mathrm{PV}$, for example, requires adapting to different scales by considering the internal motivations of PV purchase alongside the larger context of this decision (e.g. cost of PV, the grant programme, climate change debates in the media). Flexibility may also mean employing different disciplines where appropriate. Consider the purchase of hybrid electric vehicles which, like PV, are an expensive but visible environmental technology. Recent research suggests that the adoption of hybrids cannot be answered from only one perspective and assessing whether these purchases are economically-rational, for example, is the "wrong question. A more basic question to ask is 'Do people who are buying hybrid cars really care about saving money?'" (Berman 2005). Indeed consumers have been found to be willing to sacrifice cost, performance and other tangible benefits in favour of more nebulous advantages such as taking responsibility for one's consumption or the symbolic social value of these vehicles (Heffner et al. 2005, Miller 2006). Here then, practical economic consid- 
erations (i.e. can the car be afforded?) need to be integrated with the insights of psychology or sociology.

Once PV is in the home, disciplinary flexibility again allows the household agent to be examined from different perspectives, which is particularly useful as the motivations of purchase are not necessarily the same as those which influence subsequent use behaviour. Continuing with the hybrid car example, social symbolism may have played a large role in the purchase of these vehicles but personal psychological factors may become more important during use. For example, one driver on a popular online discussion forum noted that his hybrid vehicle "has done the impossible, in completely changing my habits". Now instead of minimizing drive times (i.e. speeding), he has tried to maximize fuel efficiency: "I wanted to see just how high [the mileage] will go. I was hooked." (HybridCars.com 2005). ${ }^{4}$ Similarly, research on the owners of Apple iPod mp3 players found that, following the often socially-inspired purchase of an iPod, users developed a more personal focus and through their choice of music, became aware of a new ability to control everyday experiences like commuting to work (Bull 2005). Importantly both examples demonstrate the need for comprehensiveness in an integrated framework since these subsequent use behaviours cannot be viewed as activities taken solely at the discretion of the individual. The fact that these behaviours are clearly linked with the routines of daily life (e.g. driving cars or commuting to work) underlines the importance of recognizing the wider social context in which individuals act.

The relationship of photovoltaics within the domestic energy consumption environment is therefore likely to be multi-faceted and situation-specific. The integrated approach to photovoltaics and consumer behaviour outlined here uses the concept of agents to define loosely the stakeholders and key situations

\footnotetext{
${ }^{4}$ Most hybrid vehicles feature information displays which monitor fuel consumption performance.
} 
in which they interact (namely, a socio-technical investigation of the adoption PV technology and a detailed exploration of the behavioural motivations and subsequent energy use of the households). This approach emphasises the importance of a comprehensive and flexible approach, involving a multitude of agents whose relationships can be viewed through a combination of disciplinary 'lenses' (Figure 2.2). However it is important to note there are links between the two phases, for example, because purchase decisions are likely to be made in anticipation of use and use behaviours will be framed by the technologies that have been purchased.

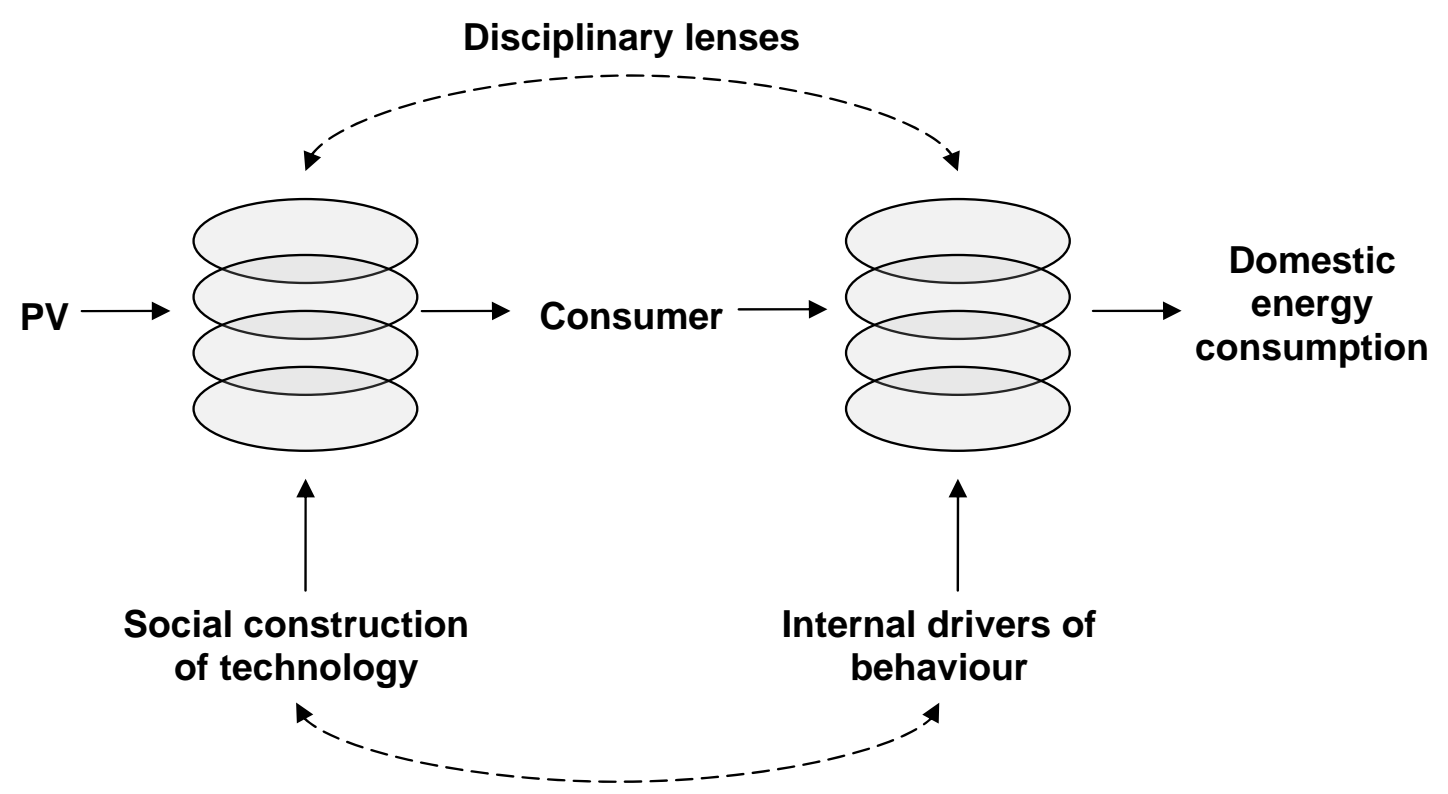

Other agents

(e.g. electricity suppliers, PV installers, neighbours, technologies, etc.)

FIGURE 2.2: An integrated approach to domestic PV and consumer behaviour

\section{Summary}

Explaining the effect of photovoltaics on household DEC behaviour is not a simple question, answerable using the theories of only one discipline. This is in part because unlike other technologies in the home, PV generates electricity 
and does not simply consume it, creating a potentially wide range of behavioural responses (e.g. some broadly economic, some broadly psychological). Fortunately the emergent literature on integrated frameworks of domestic energy consumption suggests that a comprehensive and flexible structure may be able to accommodate this complexity. The integrated approach outlined here uses the concept of agents to identify the stakeholders that impact DEC and examine their behaviour during two specific phases, the adoption of PV and the household's subsequent energy consumption. Although these stages are undoubtedly related, they will first be considered independently. To begin, a socio-technical examination of photovoltaic technology considers how PV might impact, and be impacted, by adopting households. Potential motivations for post-PV domestic energy consumption behaviour are then explored.

\subsection{PV as a socio-technical system}

It has been suggested by PV advocates that solving global climate and energy problems will require nothing less than a "solar revolution" (Leggett 2001, Berman and O'Connor 1997). Although a complete change to the way in which electricity is generated and delivered is likely to be even more complex than swapping centralised generation technologies as in the 'dash for gas', history shows that such shifts are not without precedent. Over the past one hundred years, for example, the provision of grid-supplied electricity in the UK has evolved from London (c. 1913), when there were forty-nine different types of supply system and seventy different tariffs, to the state distribution boards and their liberalization in the 1990s. Amidst all this change, perhaps the one constant was that the supply of electricity was more than just an assembly of generation and transmission technologies: the social dimension, especially politics, played an important role in guiding these systems (Hughes 1983, Thomas 
2004). This suggests that a solar revolution will therefore only succeed if technological and social factors align, for example, during the diffusion and user-led innovation processes that define the early stages of technological development.

\subsubsection{From determinism to the actor-network}

Several theories have been proposed to understand the relationship between society and technology. Initially technological determinism was the most common view, best summarized by the slogan from Chicago's 1933 World Expo: "Science finds, industry applies and man conforms" (Smits 2002: 863). In other words, the creation of and response to new technologies was perceived as a linear process. This view is codified by the central tenets of technological determinism: that the development of technology proceeds independently from social interaction and that technological advancements determine social change (Kline 2001). Some believed that viewing technology as "unambiguous and distinct from society" provided methodological advantages by allowing its influence on human behaviour to be easily measured (Bernard and Pelto 1987: 360). Others however interpreted technological determinism in a more negative light, suggesting that it might explain why mankind often feels alienated or overwhelmed by technology (Taviss 1970).

Although the complete separation of society and technology was eventually recognized as an oversimplification (hence the revised 'soft determinism', e.g. Harvard University Program on Technology and Society 1972), technological determinism remains popular particularly among policy makers (Shove 1998). However the difficultly posed by this "pervasive, yet controversial" theory (Kline 2001: 15495) is that it "suggests that all interventions are futile" and thus society is powerless to influence the development of its technologies (Bijker 1997: 281). In response, neo-Luddite writing has shifted to almost a 
cultural determinism perspective, stressing that a "life-enhancing" worldview should determine which technologies are developed (e.g. no nuclear technologies, no television or computer technologies) (Glendinning 2003: 605). A more moderate interpretation of this debate is that social scientists have simply spent too much time and effort examining the impact of technology on society and should also consider how society shapes technology (MacKenzie and Wajcman 1999).

In his critique of determinism, Misa (1988) argued that historians who take a macro view of technological systems often see a deterministic element in their findings. Ironically it was a historian, whose micro-level examination of electricity systems at the turn of the $20^{\text {th }}$ century, began to undermine the deterministic view. Hughes (1983) showed how 'system builders', such as Thomas Edison, were able to develop not only the technology but also a supporting system of institutions which necessitated the use of the innovation. This systems approach was very influential, ${ }^{5}$ highlighting that successful technologies are the result of people and devices working together. However it created a divide between the system and the environment (i.e. things external to the system but influencing it) and, as this split has an influence on the subsequent analysis, trying to locate the boundary between system and environment can be problematic (Joerges 1988).

Pinch and Bijker (1984) outlined a theory based on the premise that science and technology are socially constructed, drawing from studies on the sociology of scientific knowledge (e.g. Latour 1983). Although the social construction of technology approach (Scot) gives the social aspects of technical systems priority (Bijker et al. 1989), it is not a deterministic theory and there are strong interactions between these two dimensions. For example, in his study of light

\footnotetext{
${ }^{5}$ Examples of this approach, including the development of railways, telephone networks and other large technical systems, can be seen in Mayntz and Hughes (1988).
} 
bulbs, Bijker (1997) found that the final design of the high-intensity daylight fluorescent lamp was the result of iterative debates between bulb designers, electricity suppliers and other stakeholders. Similarly the social and cultural contexts of American and Danish life (e.g. individualism versus collectivism) had a major impact on how electricity systems of these nations were perceived and designed (Nye 1990). From a policy perspective though, the biggest advantage of rejecting the determinist view and exploring socio-technical networks is that it creates the possibility that policy makers and citizens might work with, not against, technology (Schot 1992).

Scot has been very successful and its analytical concepts (e.g. relevant social groups, interpretative flexibility, closure, stabilization, technological frames) have provided valuable tools to help understand how different stakeholders interpret and respond to technologies (Bijker et al. 1989, Bijker 2001). However some feel that the theory has focused too much on how individuals construct technology and ignored the structural considerations which influence the interactions of these actors and their different technological perceptions (Klein and Kleinman 2002). Furthermore by simply describing how each relevant social group conceptualizes the technology without examining the power of each actor to assert their view of a technology, Scot has a "lack of and, indeed, apparent disdain for anything resembling on evaluative stance of any particular moral or political principles that might help people judge the possibilities that technologies present." (Winner 1993: 371). These critiques, and a growing desire for Scot to make a practical contribution, led the original proponents of the theory to recommend that the approach combine "empirical work with theoretical reflection to strengthen the links between academic STS [science-technologysociety] studies and politically relevant action" (Bijker 1997: 289-90).

Actor-network theory (Ant) is also concerned with the political elements of socio-technical systems. Although the name of this approach may have been 
misinterpreted by some ${ }^{6}$ it has developed alongside Scot as a popular approach to the sociology of technical systems. Ant's most radical step was to abolish the divide between social and technical factors, arguing that methodologically both should be treated equally (Law 1989, Murdoch 1997). This can seem odd to the reader at times — for example, Callon's (1986b: 7) discussion about whether scallops will 'accept' an artificial anchorage - and indeed there have been critics who say this radical symmetry is excessive, even nihilistic (Collins and Yearley 1992, McLean and Hassard 2004). In practice though, allowing both humans and non-humans (e.g. objects, technology, nature, money) to be 'actors' is a powerful analytic tool and Ant has correspondingly found appeal in studies as diverse as the adoption of mobile telephony (McBride 2003), the use of GIS for conservation (Martin 2000) and the emergence of low energy housing in the UK (Lovell 2005).

Arguably one of the reasons for the success of Ant is that it offers a rich vocabulary for understanding how networks of actors form, how they expand and collapse, and how actors (both human and non-human) interpret and translate technical systems. Drawing on the methodological principles of agnosticism (that no actor is privileged in the analysis), generalized symmetry (using the same terminology to explain conflicting views) and free association (removing all distinctions between the technical and social) (Callon 1986b), Ant enables researchers to describe socio-technical systems using the language of translation. This is "the process of negotiation, representation and displacement which establish relations between actors, entities and places" (Murdoch 1998: 362) and it represents an improvement on Scot by allowing the politics and power elements of networks to be actively discussed. Specifically, the four stages of translation explain how actors exert their influence to forge networks and en-

\footnotetext{
${ }^{6}$ In response to critics, Latour (1999: 15) famously said "there are four things that do not work with actor-network theory; the word actor, the word network, the word theory and the hyphen! Four nails in the coffin."
} 
list others to their point of view (Callon 1986b, Latour 1987). Using the case of photovoltaics to demonstrate, electricity suppliers might offer an initial payment to PV households to ensure that they are part of the new microgeneration actor-network (problematisation) but design these tariffs so that the role of microgenerators is one that fits the suppliers' view of the market (interessement). Pilot households might then accept these tariffs (enrolment), suggesting that these payment structures represent an accepted negotiation between future PV households and the plans of the supplier (mobilisation). Ultimately this process of translation can lead to punctualisation, whereby actors have a shared interpretation of a particular network thus allowing it to be simplified until future controversies might re-open this 'black-box' (Callon 1986a, 1991).

Together Scot and Ant are part of a "broad church" known as the social shaping of technology (Williams and Edge 1996: 866). The theories share many constructs and beliefs such as a methodological emphasis on description (Law 1997, Latour 1991, Bruun and Hukkinen 2003); however Ant's concept of translation allows the formation of networks to be discussed in detail, including some consideration of the power relations between actors. This is important for the study of new technologies like photovoltaics, as the introduction of PV is likely to face significant challenges when negotiating with the entrenched centralised electricity structure. Although "ANT is an open building site, not a finished and closed construction." (Callon (2001: 65), citing Law and Hassard (1999)), it can be concluded for this thesis that the sociology of technical systems approach offers more valuable insights into domestic PV technology than a deterministic view. Specifically these theories can be applied to two important questions: how do actor-networks influence the diffusion of new innovations like PV and what is the the role of early users within these networks? Addressing these issues will clarify the socio-technical nature of photovoltaics and the context in which behavioural changes may occur. 


\subsubsection{The diffusion of innovation}

Electricity supply is best described as a large technical system (LTS) since it is "spatially extended and functionally integrated" and has "contributed to a significant change in lifestyle" (Mayntz and Hughes 1988: 5). Under this definition, a district heating system might also be considered as an LTS (Joerges 1988) and by extension, the current growth in microgeneration (including PV) might be optimistically interpreted as the development of a new LTS. Although the success of this alternative will be ultimately judged over the long-term, there are immediate questions about how PV technology is disseminated and the roles of both households and industry in this process.

Traditionally the spread of technology has been understood through Rogers' (2003) seminal work Diffusion of Innovations. ${ }^{7}$ This theory is iconically represented by an S-curve of the stages of technology adoption (Figure 2.3) and one of its greatest contributions has been to describe the different groups of consumers along this curve. An adoption decision is generally based on a user's perceptions of the characteristics of the innovation (e.g. Corrocher 2003) and Rogers lists five such features, almost all of which seem to be against adoption in the case of PV. That is, compared to existing grid electricity supply, PV has a small relative advantage, it has poor compatibility, it is more complex, and its current low-level of market penetration means that potential adopters are often unable to trial or observe the technology before purchasing.

Since these attributes appear to be so unfavourable, why have any households adopted PV to date? According to Rogers's definition, households that are currently adopting PV might be classed as either innovators or early adopters (his first and second adopter categories respectively). These groups are characterized by high levels of knowledge (i.e. they are able to understand and use

\footnotetext{
${ }^{7}$ First edition, 1962.
} 


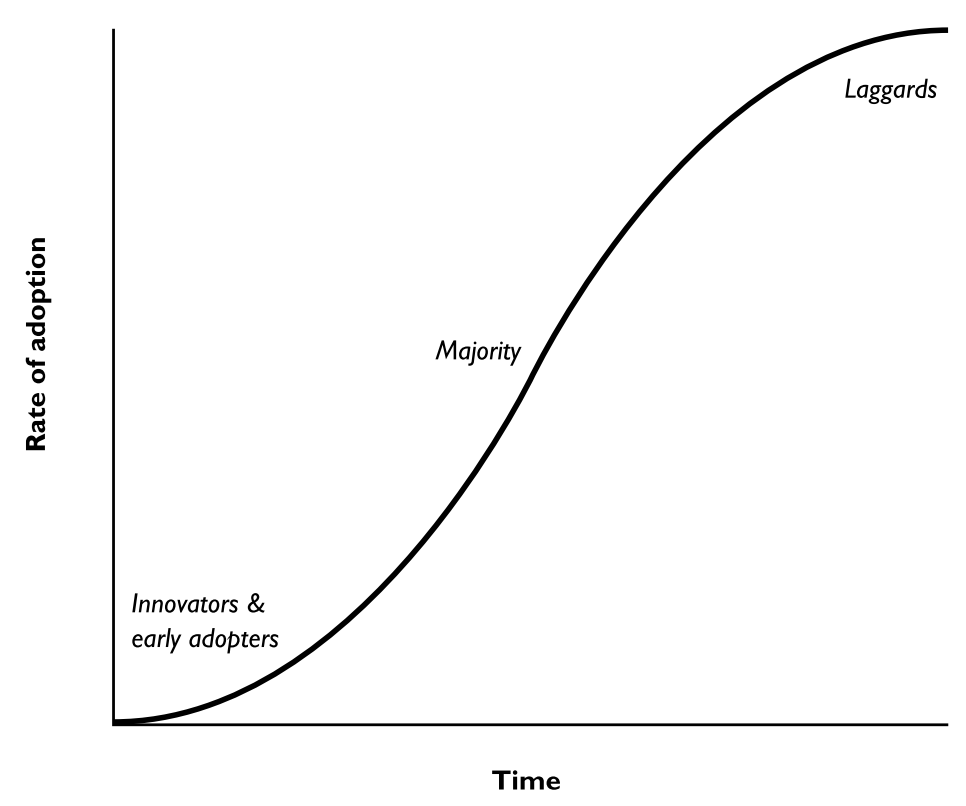

FIGURE 2.3: The innovation diffusion process and adopter types (Rogers 2003) complex new technology) and a desire to experiment with new technologies (including the ability to afford the potential costs of an unsuccessful adoption). The primary distinction between the two groups is that innovators are more independent of public opinion and hence more likely to take adoption 'risks'; that is, early adopters may be unwilling to try new technologies as failures could damage their reputation among their peers as 'experts' and opinion leaders. For example, in studies of energy conservation measures, including solar hot water, researchers found that the earliest adopters were more willing to take a chance with the new technology (Labay and Kinnear 1981, Darley 1977/78, Darley and Beniger 1981). The social role of early adopters (i.e. telling others about the technology) is particularly important for the diffusion of an innovation to the majority; therefore a basic task for this research is to identify whether the surveyed households represent innovators or early adopters and hence how PV technology (and any associated patterns of energy consumption) might be further diffused through social networks.

Diffusion of innovation theory has been extremely successful for explaining 
not just individual adoption decisions (e.g. internet banking (Hamilton et al. 2000), innovative forms of geography teaching (Solem 2001)) but also organizational technology diffusion. Although adoption criteria are slightly different in the corporate sphere (e.g. decision-making often adheres more closely to economic rationality, Utterback 1994, Gopalakrishnan et al. 2003, Verhoef and Nijkamp 2003), the underlying importance of the perceptions of a technology remains. For example, a case study on photovoltaics in the US found that utility managers failed to adopt PV for their firms because it was radically different from the existing, centralised method of electricity generation (Kaplan 1999). However organizations should not be too quick to reject 'disruptive' technologies, even if their customers say they are uninterested, because it may harm competitiveness in the long-term (Bower and Christensen 1995). This suggests that organizations should engage with new technologies, especially those which might represent the transition to a new LTS. However this can be a difficult process; research shows that incumbent organizations often try to adopt elements of the new LTS but the "revitilisation" may ultimately fail to comprehend the deeper significance of the innovation (Gökalp 1992: 60).

The popularity of diffusion of innovation theory in corporate and policy making spheres may be because it seems to imply that technology will spread solely on its own merits; that like technological determinism, the benefits of a technology will be realised following a linear process of technological development and dissemination. ${ }^{8}$ However this is an over-simplification:

"Researchers and policy makers... find themselves trying to close the gap between current practice and recognised technical potential. The ensuing process of technology transfer is often seen as a process of overcoming 'non technical barriers' which inhibit the realization of proven technical potential. This familiar approach depends upon a strong conceptual distinction between the social, on the one hand,

\footnotetext{
${ }^{8}$ Rogers briefly introduces the concept of equilibrium to describe the interactions between society and technology but overall, the technology is assumed to be a fixed entity.
} 
and the technical, on the other. But does it make sense to talk of technical potential in the abstract? Do people really have technologies 'transferred' upon them?"

The concept of 'barriers' to diffusion can be a valuable one (Weber 1997) but more importantly, this quote suggests that neither users nor producers have complete control over the form and diffusion of an innovation. Bijker (1992: 97) notes that "even in the diffusion stage, the process of invention continues" and therefore the diffusion of PV becomes a question of the interactions between consumers (i.e. households) and producers (i.e. installers, grant providers and so on).

The actor-network perspective sheds some light on this co-evolution process. For example, Murdoch (1998) discusses 'spaces of negotiation', i.e. the way in which the meanings and uses of new technologies are negotiated, rather than being 'prescribed' as in the case of established technologies. As a new technology, the role of PV will be defined in negotiation with stakeholders from the existing electricity LTS and proponents of the microgeneration alternative. Although this process need not be adversarial, Murdoch suggests that these spaces of negotiation can benefit from 'protection' so that a new LTS can develop sufficiently before becoming a full participant in an incumbent market. This can be achieved through strategic niche management, "a policy-oriented approach that aims to support programme and pilot project managers in coordinating the different driving forces of innovation" (Weber 2003: 160). These niches are essentially learning spaces where users and developers can collaborate and further improve their innovations, be it open-source software (von Hippel 2001), online national communities (Boczkowski 1999), or more relevantly, solar hot water heaters (Ornetzeder 2001) and green electricity tariffs (Wüstenhagen et al. 2003). 
Therefore while the classical diffusion of innovation literature may explain some of the drivers for individual adoption decisions, its focus on the perceptions of a technology fails to account for the ways in which technologies coevolve with users. Indeed Boczkowski (2004: 255) notes that the social shaping of technology and diffusion processes should be seen as "two sides of the same innovation coin". The thesis therefore needs to examine the roles of producers and consumers in the diffusion of PV. Specifically it must investigate whether PV occupies a space of negotiation, perhaps located in protected niches, and how stakeholders are trying to enroll others to their viewpoint, perhaps by 'inscribing' their beliefs into tangible and durable artefacts (e.g. meter designs or tariff arrangements). Ultimately the success of PV will depend not on the strategies of one group, but on the interaction of different groups (Rip 1995). However the thesis has a focus on PV household behaviour and therefore the household's specific role within these shaping and diffusion processes is now considered.

\subsubsection{Nascent technologies and the role of users}

When a new technology is introduced, a number of different roles for early users are presented. Traditionally risk assessment has been one of the most significant, with technology assessment literature stressing that early consultation with potential users is an excellent way to "give society time to reflect upon [the potential adverse impacts of technology] and take appropriate measures" (Schot 1992: 36). Consulting with users could change technology in other ways as well. For example, Herstatt and von Hippel (1992) recommend consulting with 'lead users', i.e. privileged individuals who have an excellent understanding of a technology, to inform the development process perhaps by suggesting useful new features. Furthermore, the use diffusion model of Shih and 
Venkatesh (2004) highlights how early users can make manufacturers aware of different uses for a new technology which may have been initially overlooked. In other words, the role of users in shaping a new technology is not simply limited to assessing the potential risk of a technology but must also view adopters “as producers or planners" (Ornetzeder and Rohracher 2006: 149).

While the participation of users in the development of new technologies clearly has benefits for producers, these consultation processes are also important for consumers. For example, if PV households are not consulted regarding the design and operation of related metering equipment, they could find themselves locked into modes of payment that are unacceptable. Similarly, the intended benefits of a technology for consumers may not be fully realised if users and producers fail to understand each other. This effect has been identified with green housing where user behaviour did not meet the expectations of designers thus undermining the technical potential of the buildings (Chappells and Shove 2005, Rohracher and Ornetzeder 2002). In the case of CD-interactive technology as well, these mishaps often arose because, compared to the single role envisioned by producers, users can have multiple and different interpretations of new technologies (Silverstone and Haddon 1996). Therefore coordinating the goals of users and producers is increasingly important in the design of innovations (Smits 2002). To explore user-producer relations, some researchers have found that social construction of technology or actor-network approaches can be valuable, especially in the case of sustainable technologies that may represent a major departure from existing technology (Rohracher 2001). Weber (2003), for example, suggests that 'shared visions' can help bring together actors when trying to manage innovation niches. However, the concept of visions is essentially another description of the basic processes that form and operate an actor-network, i.e. 'translation'. This process is best understood by examining the influence of users on a specific part of a technology's development. Many 
writers have taken a retrospective focus, centered on the maturation of technologies. However at the 'closure' of technical debates (Bijker and Law 1992) or during the 'stabilisation' of actor-networks (e.g. McBride 2003), the controversies that illustrate the interactions between stakeholders and technologies have already been settled. In the case of PV, it must first be asked whether the 'black-box' of PV has been sealed. If the meaning of PV is still being formed, then it will be important to examine the ability of different groups to shape this emergent network (e.g. Amsterdamska 1990). Parallel arguments about agency versus structure (e.g. Pickering 1993, Klein and Kleinman 2002, Mutch 2002) reinforce that the study of actor-networks, especially during their creation, must include the power relations which govern their creation and operation.

Given Ant's symmetry principles, control of an actor-network does not have to be exerted by human actors. For example, in his study of the development of an aircraft engine, Law (1992b: 440) concludes that the predictability of 'technical control" is more important than social control, even if the two are "joined together in an indissoluble discursive embrace" (e.g. standards and specifications demonstrate technical control and yet are an artefact of human activities, Joerges 1988). For PV, this suggests that, even if households are unlikely to be able to negotiate with major electricity suppliers on an equal social footing, an emergent PV network is likely to remain flexible until a durable technology is introduced to solidify the relationship, e.g. a particular kind of meter or billing arrangement that would be extremely difficult to change once implemented.

Another challenge of the actor-network approach is knowing where to draw the boundaries of the analysis, as it could potentially incorporate more and more stakeholders. Law (1989) suggests that a network might be delimited by the extent to which an actor's influence can be individually felt; others have similarly suggested that it may be useful to follow one particular stakeholder throughout the process of network formation (e.g. the innovator, Callon 1989). 
An alternative simplification strategy is to "stop the process [of building the actor-network] and ascertain, at least tentatively, what is affecting what" (Klein and Kleinman 2002: 35). However given the interest of this thesis in household behaviour, the analysis of the PV actor-network should perhaps be focused on the 'consumption junction', which "after all, is the interface where technological diffusion occurs, and it is also the place where technologies begin to organize social structures", i.e. begin to influence behaviour (Cowan 1989: 263). These concepts therefore offer a framework whereby the role of households within the PV actor-network can be examined, both the way in which consumers appropriate the use and meaning of technologies (Mackay and Gillespie 1992) and whether these early adopters have a broader role as 'heterogeneous engineers' (Law 1989), enrolling human and non-human elements into a stable socio-technical network. Although Latour (1987) argues that no single group has the 'correct' view of an actor-network, a user-focused analysis could also help to identify interventions which could guide this network towards the desired goal of sustainable domestic energy consumption.

\section{Summary}

Technology can no longer be viewed as simply objects, processes, and knowledge but instead as a socio-technical system, incorporating people and the ways in which they interpret and use technology (Kline 2003). Accordingly household behavioural responses to PV will not be determined solely as a reaction to the inherent characteristics of PV, but in negotiation with the technology, its producers and other intermediaries (both human and non-human). Therefore the diffusion of PV technology must be considered as a process that occurs in parallel with innovation, offering opportunities for the experiences of early adopters to be incorporated. Specifically then, the thesis needs to consider 
whether strategic niches for the development of PV exist and assess the ability (and desire) of early adopting households to guide these protected spaces towards sustainable post-PV energy consumption behaviour. In other words, has the PV actor-network already stabilised or are users and producers still working towards a mutual understanding of the technology and its potential?

It was suggested that the 'consumption junction' is an ideal location from which to explore the PV actor-network. However a focus on the household means that further information is needed about how these users interpret their place within the actor-network, the technologies around them, and the roles of other stakeholders. Therefore recalling the integrated approach to domestic energy consumption, the disciplinary expertise of psychologists and sociologists is now sought to identify some of the potential mechanisms which may influence consumer behaviour and the formation and operation of domestic PV actor-networks.

\subsection{Understanding sustainable consumer behaviour}

A model for the behaviour of consumers within a socio-technical system must explain how the internal goals and concerns of individuals shape their responses to the artefacts around them. In other words, if a behavioural response to PV is observed, it would be useful to identify whether this change is simply a new pattern of behaviour facilitated by the presence of PV or whether there has been a more fundamental shift in the underlying drivers of behaviour. This section will consider these questions by reviewing PV as an example of 'green' consumption, before examining a more detailed model of consumer behaviour. 


\subsubsection{PV: sustainable consumption or merely 'green'?}

Sustainable consumption can be defined as patterns of consumption which meet basic needs and improve quality of life while minimizing environmental impacts and protecting the requirements of future generations (UNEP 1995). The concept can apply to many different categories of consumption (e.g. energy, water, transport, waste management) and in recent years, questions have been raised about distinguishing sustainable consumption from simply 'green' alternatives (i.e. lower resource intensity than existing options, Alfredsson 2003). This debate might also be framed in terms of the difference between the decision to adopt PV and subsequent energy saving behaviour. That is, if PV is simply purchased and used within unchanged patterns of domestic energy consumption, this arguably represents a form of 'green' consumption rather than a more profound shift towards sustainable consumption patterns.

If the goal is sustainable consumption, it would be good to first understand the causes of unsustainable consumption. Shove and Warde (2002) (cited in Shove et al. 2005) have suggested several explanations for rising consumption patterns, drawing from the literature on the sociology of consumption. They suggest that escalating demand for goods and services can be explained, in part, by:

- social comparison; i.e. lower classes imitating the consumption patterns of the rich, who in turn consume to distinguish themselves from the imitators (Veblen 1899). Recent evidence however suggests that against rising levels of wealth throughout Western society, this conspicuous consumption is increasingly difficult and so to set themselves apart, the wealthy may seek alternative strategies such as conspicuous non-consumption or becoming early adopters of new technology (Economist 2005); 
- the creation of self-identity; i.e. choosing goods and services to establish and project one's identity. This motivation is particularly important as the rapid changes of modern life continuously challenge an individual's 'ontological security' and sense of self (Giddens 1991);

- the search for novelty; motivated by fashion, a reaction to mass culture, or simply the enjoyment of a new experience, the "desire for the new" is an important driver of modern consumption (Campbell 1994: 48). An example of this can be seen in the rising energy consumption of consumer electronics (Boardman et al. 2005);

- matching; McCracken (2001) demonstrates the importance of consuming compatible groups of objects with the story of Diderot, who acquires a new dressing gown and contemplates updating more and more of his belongings until his entire study is renovated to match. Diderot effects can be powerful motivations for radical changes in consumption patterns but they can also constrain consumers within existing modes of consumption.

These factors indicate that consumption should be viewed as a social action, reflecting how consumers position themselves within expected cultural roles. In this light, the actual objects that are purchased and used become symbolic of these social meanings (Miller 1991). Hence purchasing PV might be interpreted as a symbolic reflection of a household's concern for environmental issues; certainly the visibility of PV panels on a household's roof makes it a more likely candidate for this role than energy-efficient appliances or other inconspicuous conservation measures (Banks 1998, Jensen 2005). Yet households may not be fully aware of the meanings embedded in an artefact (the "humility of objects" (Miller 1997: 315)) and therefore PV may subtly encourage households to investigate more sustainable day-to-day energy use and future purchases (e.g. efficient lights and appliances), perhaps through matching effects. The symbol- 
ism of PV may also change over time, as has been seen with perceptions of the automobile (Sachs 1983).

Studies of sustainable consumption practices suggest that green households exhibit specific socio-economic and value patterns. For example, Gilg et al. (2005) surveyed 1600 households in Devon and found that those most committed to sustainable consumption (e.g. buying local or organic food, reducing energy and water use) were older, wealthier, better educated, owned their own homes and lived in smaller households (i.e. number of occupants). These circumstantial factors are coupled with 'green' values as well; a survey of potential purchasers of green electricity found that environmental concern, left-leaning political views and altruism were important (Rowlands et al. 2003). However these socio-demographic and attitudinal traits should not be considered as a laundry list of isolated variables but as part of a coherent lifestyle (i.e. wealthy, well-educated, Labour voting households will not necessarily be sustainable consumers). A more important influence on adoption and use behaviours can be the household's view of their domestic environment: for example, the Amish who resist the introduction of telephones as a threat to face-to-face communication, something which is extremely important within their broader lifestyle and beliefs (Strathern 1994). As Hirsch (1994: 222) notes: “What is resisted, then, is not the technology per se but a particular appropriation of it which transgresses the long-term moral environment of the household". This suggests that the socio-demographic attributes identified above reflect a particular domestic 'moral economy' (Silverstone et al. 1994), rather than vice versa. Therefore sustainable use behaviours may follow the installation of PV if the technology fits within an existing ecologically-oriented moral economy; otherwise the meaning of PV may be appropriated by the households as a smaller 'green' addition to an otherwise unsustainable lifestyle. This is an important question for the household questionnaires and interviews. 
If a household wishes to be sustainable, it must be able to choose sustainable options or live in a sustainable manner within the context of broader society. For example, consumers can be 'locked-in' to undesirable modes of consumption by technology, economy, and culture (Ekins 2004, Chappells and Shove 2005, Michaelis 2003). This balance between consumer responsibility and wider societal change is an issue that public policy has struggled with. While there is at least some recognition that consumers cannot always act unilaterally and need a supportive society-wide consumption environment (e.g. personal carbon allowances, Hillman and Fawcett 2004), the provision of green options (and better information about these options) seems to be the preferred solution of many (Bishop and Watson 2005, NCC 2005a,b). Again however, "consumer and provider perceptions of what constitutes 'sustainable' consumption are highly interpretative, context-dependent and open to negotiation over time" and it is the "utilities, intermediaries and infrastructures together with the conventions and routines of daily practices [that] configure the options available to individuals" (Chappells et al. 2004: 144). In the case of PV, for example, Watson et al. (2005) have identified at least three deployment models for microgeneration technologies (e.g. plug-and-play, community microgrids, company control), each of which is likely to have a different impact on consumers, the electricity grid and how consumption is determined by both.

The conclusion must then be that sustainable consumption is not simply a matter of consumers choosing 'green' options. Indeed the "limited autonomy of the consumer" (Southerton et al. 2004: 32) suggests that, although households may choose to adopt PV fairly independently, their subsequent use of the technology may be constrained by factors beyond their immediate control (i.e. their role within the wider electricity system). Therefore whether or not photovoltaics can encourage consumers to step beyond green consumption towards something truly sustainable remains to be seen. 


\subsubsection{Changing energy use behaviour}

The sociology of consumption can help to explain the consumption of many goods but unfortunately "the everyday services provided through energy, water, transport or waste networks cannot be analysed in the same terms as those items purchased over a shop counter" (Chappells et al. 2004: 144). This is in part because domestic energy consumption is determined by the use of services; energy is not explicitly purchased for its own sake (van Raaij and Verhallen 1983b). This gap between behaviour and actual energy consumption is further demonstrated by household ignorance of the energy consumption environment, e.g. the variable efficiency of appliances (Boardman 2004), the consumption caused by standby functions (Vowles et al. 2001) or understanding of how equipment works (Kempton 1987). Accordingly, demand for energy might be interpreted as the result of patterned social practices (e.g. showering, cooking) (Shove 2003a, Shove et al. 2005) and the efficiency of capital equipment. Table 2.1 demonstrates how DEC might be variously interpreted as a social action, often without requiring a conscious consideration of energy consumption.

Following the oil crises of the 1970s, researchers became increasingly interested in energy use within the domestic sector. In an attempt to understand how rising demand might be controlled, numerous studies were conducted to assess the effectiveness of interventions into the domestic energy environment (e.g. changing energy prices, providing consumption feedback and so on). This research area has continued to the present day and analysing the large resulting body of research requires a coherent framework. For example, the reviews conducted by Abrahamse et al. (2005) and Dwyer et al. (1993) divide this literature into antecedent and consequent interventions (after Geller et al. 1990). These categories are effective when assessing interventions by themselves, but the literature has also shown that energy demand is determined by values, at- 


\begin{tabular}{|c|c|c|}
\hline $\begin{array}{l}\text { Type of social } \\
\text { action }\end{array}$ & Explanation & DEC example \\
\hline $\begin{array}{l}\text { Instrumentally } \\
\text { rational }\end{array}$ & $\begin{array}{l}\text { "determined by expectations as to the } \\
\text { behaviour of objects in the environment } \\
\text { and of other human beings... these ex- } \\
\text { pectations are used... for the attain- } \\
\text { ment of the actor's own rationally pur- } \\
\text { sued and calculated end" }\end{array}$ & $\begin{array}{l}\text { Turning off the } \\
\text { lights to save } \\
\text { money }\end{array}$ \\
\hline Value rational & $\begin{array}{l}\text { "determined by a conscious belief in } \\
\text { the value for its own sake of some } \\
\ldots \text { forms of behaviour, independently } \\
\text { of its prospects of success" }\end{array}$ & $\begin{array}{l}\text { Turning off the } \\
\text { lights to reduce } \\
\mathrm{CO}_{2} \text { emissions }\end{array}$ \\
\hline Affectual & $\begin{array}{l}\text { "determined by the actor's specific af- } \\
\text { fects and feeling states" }\end{array}$ & $\begin{array}{l}\text { Petulant teenager } \\
\text { turning off the } \\
\text { lights to sulk in the } \\
\text { dark }\end{array}$ \\
\hline Traditional & "determined by ingrained habituation" & $\begin{array}{l}\text { Turning off the } \\
\text { lights when leaving } \\
\text { the house }\end{array}$ \\
\hline
\end{tabular}

TABLE 2.1: Domestic energy consumption as social action with hypothetical examples (Weber et al. 1968: 24)

titudes, lifestyle, and other factors. Therefore an extra dimension is needed to incorporate fully the social and psychological influences on behaviour.

Bandura (1986) has outlined a theory of social cognition and learning that can accommodate these factors, indicating that in addition to antecedent and consequent determinants, behaviour is mediated by cognitive control; i.e. "people are not simply reactors to external influences. They select, organize, and transform the stimuli that impinge upon them" (Bandura 1977: vii). Therefore regardless of how specific interventions might be categorized (e.g. feedback could come in both antecedent and consequent forms, Darby 2000), the internal determinants of consumer behaviour are arguably the most important (Bandura 1997). The DEC literature provides insight into these psychological and situational constraints on energy consumption behaviour (Table 2.2). 


\begin{tabular}{|c|c|c|}
\hline Mechanism & Example studies & Summary finding \\
\hline \multicolumn{3}{|c|}{ Antecedent determinants } \\
\hline $\begin{array}{l}\text { Commitment } \\
\text { to save }\end{array}$ & $\begin{array}{l}\text { Heberlein and Warriner } \\
\text { (1983), Katzev and Johnson } \\
\text { (1983), Gregory and Di Leo } \\
\text { (2003), Vringer et al. (in } \\
\text { press) }\end{array}$ & $\begin{array}{l}\text { Consumers respond to lower- } \\
\text { level incentives (or none at } \\
\text { all) if committed (esp. pub- } \\
\text { licly) to a savings goal, evi- } \\
\text { dence of long-term benefits }\end{array}$ \\
\hline Information & $\begin{array}{l}\text { e.g. Winnett et al. (1982- } \\
\text { 1983), Luyben (1982), Hen- } \\
\text { ryson et al. (2000), Mc- } \\
\text { Makin et al. (2002) }\end{array}$ & $\begin{array}{l}\text { General information provides } \\
\text { some change in attitudes, but } \\
\text { no clear reduction in en- } \\
\text { ergy use; tailored information } \\
\text { campaigns may be more effec- } \\
\text { tive. }\end{array}$ \\
\hline $\begin{array}{l}\text { Lifestyle and } \\
\text { habit }\end{array}$ & $\begin{array}{l}\text { Leonard-Barton (1981b), } \\
\text { Dillman (1983), Monnier } \\
\text { (1983), Wolvén (1991), } \\
\text { Hackett and Lutzenhiser } \\
\text { (1991), Lutzenhiser and } \\
\text { Hackett (1993), Wilhite } \\
\text { and Lutzenhiser (1999), } \\
\text { Maiteny (2002), Gregory } \\
\text { and Di Leo (2003) }\end{array}$ & $\begin{array}{l}\text { A valuable method to under- } \\
\text { stand the biographies of dif- } \\
\text { ferent groups and the context } \\
\text { for their behaviours, e.g. cul- } \\
\text { turally obliged minimum lev- } \\
\text { els of consumption. }\end{array}$ \\
\hline Perception & $\begin{array}{l}\text { Baird and Brier (1981), } \\
\text { Kempton and Montgomery } \\
\text { (1982), Kempton (1987), } \\
\text { Palutikof et al. (2004) }\end{array}$ & $\begin{array}{l}\text { Perceptions of the energy use } \\
\text { requirements of appliances, } \\
\text { the operation of technical sys- } \\
\text { tems (e.g. heating) or the } \\
\text { weather can impact behav- } \\
\text { iour. }\end{array}$ \\
\hline $\begin{array}{l}\text { Socio- } \\
\text { demographics }\end{array}$ & $\begin{array}{l}\text { e.g. Rowlands et al. (2003), } \\
\text { Gilg et al. (2005) }\end{array}$ & $\begin{array}{l}\text { Like lifestyle, an important } \\
\text { factor in determining con- } \\
\text { sumption; e.g. conservers } \\
\text { are often wealthier and bet- } \\
\text { ter educated, low income } \\
\text { households may not be able } \\
\text { to afford certain conservation } \\
\text { measures. }\end{array}$ \\
\hline
\end{tabular}




\begin{tabular}{|c|c|c|}
\hline Mechanism & Example studies & Summary finding \\
\hline \multicolumn{3}{|c|}{ Consequent determinants } \\
\hline Feedback & e.g. Darby (2000), see $\S 2.3 .3$ & $\begin{array}{l}\text { Savings of } 10 \% \text { possible, de- } \\
\text { pending on form of feedback }\end{array}$ \\
\hline $\begin{array}{l}\text { Price } \\
\text { response }\end{array}$ & $\begin{array}{l}\text { Stern et al. (1988), Baladi } \\
\text { et al. (1998), Kasulis et al. } \\
(1981)\end{array}$ & $\begin{array}{l}\text { For example, time-of-use } \\
\text { pricing encouraging load- } \\
\text { switching; primarily short- } \\
\text { term benefit }\end{array}$ \\
\hline $\begin{array}{l}\text { Intrinsic } \\
\text { satisfaction }\end{array}$ & $\begin{array}{l}\text { de Young (1996), Seligman } \\
\text { et al. (1979), Menges (2003) }\end{array}$ & $\begin{array}{l}\text { Conservers often need no ex- } \\
\text { plicit reward and enjoy trying } \\
\text { to save for its own sake. }\end{array}$ \\
\hline \multicolumn{3}{|c|}{ Cognitive control } \\
\hline \multirow[t]{2}{*}{$\begin{array}{l}\text { Personal } \\
\text { responsibility }\end{array}$} & \multirow[t]{2}{*}{$\begin{array}{l}\text { Kaiser and Shimoda (1999), } \\
\text { Moisander (2004) }\end{array}$} & $\begin{array}{l}\text { Moral responsibility (e.g. } \\
\text { guilt) can encourage }\end{array}$ \\
\hline & & $\begin{array}{l}\text { ecologically-friendly be- } \\
\text { haviour }\end{array}$ \\
\hline Self- - & $\begin{array}{l}\text { Hinchliffe (1996), Bandura } \\
\text { (1997), Norgaard (2003) }\end{array}$ & $\begin{array}{l}\text { Belief that you can act and } \\
\text { make a difference encourages } \\
\text { conservation action, but easy } \\
\text { to blame government for in- } \\
\text { action and avoid personal ac- } \\
\text { tion }\end{array}$ \\
\hline Self-identity & $\begin{array}{l}\text { Painter et al. (1983), } \\
\text { Banks (1998), Clancy } \\
\text { and O'Loughlin (2002) }\end{array}$ & $\begin{array}{l}\text { Energy savers tend to be inde- } \\
\text { pendent, thrifty and env. con- } \\
\text { cerned; poor evidence of a } \\
\text { generalised conservative ethic }\end{array}$ \\
\hline $\begin{array}{l}\text { Values and } \\
\text { attitudes }\end{array}$ & $\begin{array}{l}\text { Seligman et al. (1979), } \\
\text { Brent Ritchie et al. (1981), } \\
\text { Verhallen and van Raaij } \\
\text { (1981), van Raaij and Ver- } \\
\text { hallen (1983b), Kaiser et al. } \\
\text { (1999), Schultz and Zelezny } \\
\text { (1999), Poortinga et al. } \\
\text { (2004) }\end{array}$ & $\begin{array}{l}\text { Attitude and values impor- } \\
\text { tant, but env. concern does } \\
\text { not equate with action; spe- } \\
\text { cific attitudes are better pre- } \\
\text { dictors of action than general } \\
\text { attitudes }\end{array}$ \\
\hline
\end{tabular}

TABLE 2.2: Key determinants of domestic energy consumption within a social cognitive framework 
To assess the effectiveness of these interventions, de Young (1993) proposed a five-dimensional evaluation. Interventions can be judged on their reliability (can the intervention deliver guaranteed behavioural changes?), the speed of change (how quickly does behaviour change in response to the intervention?), particularism (can the technique be applied in the same way in all circumstances or does it need to be tailored for each instance?), generality (does the intervention lead to changes in untargeted but related behaviours?) and durability (can the behavioural change be maintained without repeated intervention?). The authors argued that if sustainability is the goal, a wide range of behaviours must be addressed over a long period of time and therefore generality and durability are the most important criteria. These are also relevant characteristics for PV as the more general the behavioural response to the system, the greater the potential for further energy saving measures (e.g. changing patterns of use, installing new equipment, and absolute conservation, as well as possible knock-on effects on transport, water use or other issues).

In order for these changes to be durable, intrinsic behavioural controls will be important as short-term extrinsic rewards typically only have an influence for the duration of the intervention (Seligman et al. 1979, Dwyer et al. 1993). Commitment to energy conservation is one of the most promising intervention techniques (de Young 1993), perhaps because it forms an important link between identity (or more broadly, internal psychology) and behaviour (Clancy and $\mathrm{O}^{\prime}$ Loughlin 2002). A sense of commitment helps to build resilience, allowing individuals to persevere in sub-optimal institutional arrangements: "the establishment of self-monitoring reinforcement systems is essential if induced behavioural changes are to generalize and endure, particularly where social environments provide either weak support for new modes of behaviour or conflicting patterns of reinforcement" (Bandura 1969: 624). However it has been noted that this internal commitment can be extremely difficult to establish if 
consumers feel that the negative impacts of energy consumption are too remote or someone else's problem, creating a sense of "hopelessness" (Hinchliffe 1996: 62), threatening their sense of security and self-identity (Norgaard 2003) and leading to a preference for short-term personal goals over long-term societal goals (Vringer et al. in press). In other words, a commitment to energy conservation reflects a household's sense of self-efficacy, i.e. their belief that they can act and make a difference. Therefore, although the purchase of PV appears to represent a major commitment (at least financially), the thesis needs to identify whether it will also encourage self-efficacy and the intrinsic motivations necessary for continued energy saving. One promising technique is the use of feedback, facilitated in the case of PV by monitoring devices.

\subsubsection{Tacit knowledge and feedback}

Feedback has been identified as a potentially valuable method for changing energy consumption behaviour by helping consumers to become aware of their energy consumption (Darby 2000). Changing behaviour by providing 'knowl-

edge of performance' (Ammons 1956) is not restricted only to energy behaviour and forms a central part of social learning theory as well. Specifically feedback builds self-efficacy, enabling individuals to compare their performance with previous expectations or the performance of similar social groups (Bandura 1997). Feedback can also be used in association with rewards (e.g. microgeneration tariffs) to persuade consumers to change their behaviour "in the case of activities that are personally inconvenient or uninteresting but important to the general welfare" (Bandura 1977: 114). Importantly then, feedback can build confidence in consumers that their actions have a real impact, a prerequisite for a satisfying conservation lifestyle: 
"A high sense of personal efficacy in a responsive environment that rewards valued accomplishments fosters aspirations, productive engagement in activities, and a sense of fulfillment [sic]."

- Bandura (1997: 20)

Feedback also enables individuals to correct any discrepancies between the anticipated and actual results of their behaviour, for example, through cognitive dissonance (where a mismatch between attitudes and behaviour can stimulate a change in either, Festinger 1957, Seligman and Darley 1977). In the domestic energy context, this has typically focused on the provision of information on consumption, either directly in home, indirectly through billing, or 'inadvertently' through household or social change (Darby 2000). While Darby's review suggests that savings in the order of $10 \%$ may be achieved, there can be a great deal of variability in the magnitude and durability of this change accordingly to the circumstances in which the feedback is provided. For example, the response to a similar feedback incentive from one study to the next can be quite different: Sexton et al. (1987) found that the use of direct feedback coupled with time-of-use pricing schemes led to consumers using more electricity during off-peak times with little change during on-peak periods, resulting in an overall increase in consumption; Stern et al. (1988) however suggested that on-peak consumption falls with no increase in off-peak and Kasulis et al. (1981) found some load-switching but no change in overall demand. More consistent findings from this literature conclude that feedback is most effective when combined with other mechanisms, such as positive environmental attitudes (Brandon and Lewis 1999) or goal setting and comparison with others (Siero et al. 1996, van Houwelingen and van Raaij 1989).

Effective feedback must be immediate, clear, and specific (Darby 2000) and certainly a household is more likely to benefit from feedback if the information is presented in a usable format: as has been noted, it would be extremely 
difficult to plan grocery budgets if these purchases were "billed via a monthly statement like 'US\$527 for 2362 food units in April' " (Kempton and Layne 1994: 857). However even well-designed feedback may be ineffective. Recent research has found that, although comparing consumption with others should be effective, many UK households have no interest in this information (Roberts et al. 2004). Therefore feedback is best understood alongside the provision of information, existing levels of energy awareness and other factors that shape the perceived ability and motivation of households to change their energy consumption behaviour. In other words, self-efficacy is closely related to a household's energy-related 'know-how' or tacit knowledge:

"The concept of tacit knowledge explains how it is that we possess the awareness and skills that enable us to select the information we want from all that is available, to carry out actions and to evaluate facts and theories... A householder will not attempt to find out how s/he can improve energy efficiency at home, or conserve energy, without a combination of the explicit knowledge that more affordable and/or less polluting energy services are possible and the tacit knowledge of how to make the necessary changes."

- Darby (in press: 3)

In the same way that combinations of information can lead to greater improvements in energy efficiency than a single measure (Henryson et al. 2000), tacit knowledge explains how specific feedback, general information, and previous actions together build the self-efficacy of consumers. This combined perspective has support from adult learning literature as well, which notes that adults learn from a variety of sources, including planned learning activities and spontaneous opportunities (Merriam and Caffarella 1991). Tacit knowledge has direct relevance to the study of PV, specifically the 'conservation chain' proposed by Haas et al. (1999) (§1.3.1). It would allow this series of investment decisions to be interpreted in a broader sense, incorporating dimensions other than just action. In other words, households without a full complement of 
double-glazed windows may still decide to adopt PV if they have tacit knowledge in another form, such as technical knowledge of PV systems. As for future energy consumption behaviours, an important question for the thesis is whether or not the accumulated tacit knowledge of PV households (and by extension, their self-efficacy) has brought them past the point of 'critical capability' at which learning becomes self-sustaining, enabling new information to be acquired and used as necessary (Darby 2003).

The monitoring devices designed for use with PV systems are a promising source of feedback for PV households, though critically these monitors typically provide information on electricity generation and not consumption. This design feature indicates that these devices cannot be considered separately from the socio-technical systems of which they are part. The research therefore needs to be aware of these interactions when considering the role of feedback, tacit knowledge and self-efficacy on consumer energy consumption behaviour.

\section{Summary}

Photovoltaic technology provides the potential for a more sustainable form of consumption, allowing consumers to engage with how their energy demands are met. However PV could simply be a 'green' improvement to an existing lifestyle, rather than leading a more comprehensive shift to sustainable energy consumption. Literature on interventions to change DEC behaviour suggests that individuals use 'cognitive control' to manipulate the context and anticipated consequences of their behaviour. For example, an individual's belief that they can act and make a difference (self-efficacy) and their energy 'know-how' (tacit knowledge) enables them to select information and choose an appropriate course of action. Feedback is one way to develop these important psychological factors but it should be seen as only one component of tacit knowledge; in other 
words, general knowledge levels and previous experience also shape the ability of households to switch to sustainable modes of energy consumption. The research must therefore assess whether there is any evidence of a PV-induced change in cognitive control (i.e. through improvements in tacit knowledge and self-efficacy) which might encourage general and durable shifts in energy consumption.

\section{Conclusion}

This review began by highlighting three areas of interest: the conceptualization of PV within domestic energy consumption generally, the socio-technical characteristics of PV and its diffusion, and the mechanisms which might drive the behavioural responses of consumers. Interestingly the answer to all three issues was quite similar, demonstrating that the basic research question in fact deals with very complex issues. For example, it was first shown that the potential of PV to stimulate a change in energy consumption behaviour cannot be fully appreciated using the perspectives of only one discipline and therefore an integrated approach was proposed. This has implications for how the diffusion of PV is understood and instead of a deterministic view, the technology and its users were presented as part of socio-technical system. It was then shown that the tacit knowledge and self-efficacy of consumers act as cognitive control, selecting information and mediating their behaviour within the system. Therefore this review indicates that the behavioural responses to PV will be shaped not by households alone, but by the interactions of different stakeholders and their interpretation of the socio-technical system.

Several hypotheses and areas of inquiry have been raised. First, PV technology was presented as an actor-network and therefore its ability to change the energy consumption behaviour of adopting households will be dependent 
on the way in which network members collectively define PV. For example, if $\mathrm{PV}$ is perceived as part of the existing electricity system, the appropriate electricity tariffs and metering equipment may not be in place to inform consumer behaviour and thus PV may simply 'green' existing modes of consumption. To achieve a more significant change in behaviour, it was suggested that users and producers will need to work together, developing 'shared visions' of PV and its role relative to the existing electricity system. Therefore the thesis needs to consider the following:

- Has the socio-technical meaning of PV already been fixed? That is, do all stakeholders share the same interpretation of the technological system (i.e. has it been 'black-boxed'?) or is there still potential to align the network with the goals of sustainable energy consumption?

- If the nature of the PV system is still being debated, what is the ability of households to influence this debate?

- Is there any evidence of strategic niches (Rohracher 2003), where users (e.g. households) and producers (e.g. electricity suppliers, regulators, etc.) can develop 'shared visions' of PV technology?

As a large socio-technical system, electricity provision is difficult to 'black box' completely (Joerges 1988: 25). This suggests that the introduction of PV and microgeneration may reopen previously settled debates about how electricity is provided and used. Specifically the hope is that PV will stimulate a new understanding of energy issues among households by building their tacit knowledge (e.g. through new experiences, feedback from monitors and other sources of information). In turn, this could provide households with the confidence to change their energy consumption (self-efficacy) and engage with the PV socio-technical system. If PV is to create these conditions for general 
and durable sustainable energy consumption practices, the following questions need to be addressed:

- Are the surveyed household 'innovators' or 'early adopters'? In other words, how do the respondents see themselves within the PV actor-network? What implication does this have for the spread of PV and any associated behavioural responses?

- Is there any evidence of PV or its associated equipment (e.g. monitors) developing or enhancing energy-related tacit knowledge and, by extension, a commitment to sustainable energy use behaviour? For example, how effective is feedback on generation with regard to developing consumptionrelated tacit knowledge?

- Have these changes in tacit knowledge also enhanced the self-efficacy of consumers, perhaps pushing them past the point of 'critical capability' (Darby 2003)? That is, have PV households acquired the ability and interest to use new sources of information and progress towards sustainable domestic energy consumption?

As the chapter's opening quote suggests, the form of PV technology is not absolute and each potential outcome may have a different influence on energy consumption behaviour. Therefore, if at least in part "you are what you purchase" (Ritzer et al. 2001: 413), the thesis must unravel what PV means in the context of domestic energy consumption. Specifically the challenge is to identify the characteristics of existing PV households, describing their role within the PV actor-network, their interpretation of this socio-technical system and its subsequent effect on their energy consumption behaviour. In the data chapters which follow, these issues will be explored by moving from the household (Chapters 3 and 4), to the nature of PV generation and electricity consumption 
(Chapter 5), to the role of industry and government (Chapter 6). The discussion begins by introducing the PV households and their energy consumption behaviour. 


\section{Chapter 3}

\section{THE PV HOUSEHOLD QUESTIONNAIRES}

Previous literature on photovoltaics and household behaviour has suggested that PV may induce changes in domestic energy consumption (e.g. Haas et al. 1999). However even studies with a primary focus on household behaviour (e.g. Dobbyn and Thomas 2005) have failed to describe these changes in detail, by providing evidence on the magnitude or causes of this behavioural response. To address this gap, the thesis used a combination of mail questionnaires sent to UK PV households and follow-up interviews. The questionnaire is presented first and it had two primary goals: to describe energy consumption behaviour before and after the installation of PV and to identify the factors which may influence this consumption (specifically demographics, attitudinal and value characteristics, and the role of monitoring equipment).

\subsection{Methodology}

Measuring changes in energy consumption would ideally be achieved by detailed monitoring of households before and after the installation of PV (§1.5.1). By studying single households, this approach would help control for factors that might be lost in an analysis of aggregate data sets (e.g. socio-economics, psychological constructs, equipment ownership). The questionnaire was also 
designed with a focus on the specific circumstances of respondent households.

\subsubsection{Questionnaire design}

Mail questionnaires allow households to be surveyed with relative ease but they are limited in the amount and type of information that can be collected. For example, a behavioural response to PV may include new equipment purchases, changes in the overall amount of energy used or changes to the time at which energy is used. However use behaviours can be very open-ended (e.g. turning down the thermostat, switching off lights, boiling a minimum amount of water in the kettle) and designing a survey instrument to encompass this diversity is difficult. In contrast, purchase behaviours - specifically, assessing the changes in energy equipment within the home - are much easier to measure in a closedformat questionnaire. The questionnaire therefore had three aims which were suitable for the technique.

- Identify the demographic and psychological profile of the respondent household (questions 1 - 18)

- Highlight the major features of domestic energy consumption before and after the purchase of PV (questions $19-41$ ). This included a survey of the energy-saving measures installed within the home (e.g. insulation, draught-proofing), the efficiency of major appliances, lighting, and anticipated future energy-saving actions. The main focus was on electricity use and provision was made for an overall assessment, allowing respondents to indicate their total electricity savings regardless of how it was achieved. Due to the self-reporting of these results, respondents were also asked to indicate the certainty of their self-assessment and to describe any other relevant changes to their domestic energy consumption environment (e.g. building an extension, family members leaving home). 
- Describe the ownership and use of monitoring devices (questions $42-52$ ).

A final section asked for further comments and solicited participation in the follow-up interviews (questions 53 -56). A copy of the questionnaire can be found in Appendix A and details on question selection are provided in the relevant sections of this chapter.

\subsubsection{Implementation}

The small number of UK PV households at the time of the questionnaire (approximately 500) posed three problems for the research. First it meant that the questionnaire could not be tested using a sample of the target group; the expert input of nine Environmental Change Institute colleagues was used instead. This pilot primarily lead to the questionnaire being shortened and the final version took approximately 15 to 20 minutes to complete.

Secondly the small population of PV households meant that techniques such as phone book or street sampling were not appropriate. A list of households therefore had to be obtained from a central source of PV information, such as the PV grant provider or an installation firm. Fortunately one of the UK's largest domestic installers, Solar Century, was willing to assist the research and, although the survey represents the customers of only one installation firm, the sample included approximately $20 \%$ of the UK's PV domestic installations at the time of the research. The questionnaire was distributed in November 2004, accompanied by a letter from Solar Century explaining the purpose of the research and encouraging household participation. The "head of the household" was asked to complete the survey.

Finally a poor response rate from a small population would have been very damaging to the research. Therefore, in addition to Solar Century's letter of support, responses were encouraged through the inclusion of a self-addressed 
stamped return envelope and the offer of a draw prize (a £20 gift certificate, kindly donated by Blackwell's Book Shop). In all, 118 questionnaires were mailed out and 91 responses were received. This excellent response rate can be attributed not only to the incentives mentioned here but also to the enthusiasm of the PV households themselves.

\subsubsection{Analysis}

After receiving the completed questionnaires, the data were prepared and coded for analysis, for example, by determining common themes in open-ended questions. R statistical software (R Development Core Team 2005) was employed for the analyses and a $5 \%$ level of significance was used for all tests.

The analysis used three primary techniques. First, descriptive statistics (e.g. frequency tables) were used to explore the data and assess the possibilities for further analysis. Tests of significant difference were then used to identify notable results. These methods included chi-square $\left(\chi^{2}\right)$ tests for expected values (e.g. when comparing the demographic characteristics of respondents to national samples) and Kruskal-Wallis or Wilcoxon tests (e.g. when comparing the responses of two groups on a Likert ${ }^{1}$ scale). Correlation tests were also used where appropriate. Each test is reported by giving the test statistics (e.g. $\chi^{2}$ ), probability $(p)$ and the degrees of freedom $(d f)$ where appropriate. It should also be noted that the data were first checked for normality using the ShapiroWilk test; however in a majority of cases, the data were not normally distributed and hence non-parametric statistics were used throughout.

The third major technique was the use of clusters. Clustering algorithms allow data to be grouped for easier comparison, for example, by combining age, income, and education data into distinct socio-economic brackets. These techniques are discussed further in the text but the main clusters included:

\footnotetext{
${ }^{1}$ i.e. a 5 or 7 point scale ranging from 'strong disagree' to 'strongly agree'
} 
- a demographic grouping, summarizing the socio-economic status of respondents;

- an opinion grouping, outlining the mindset of respondents;

- a savings grouping, sorting respondents into those who reported a decrease in overall energy consumption or and those with no change or an increase.

The following results give an initial picture of PV households in the UK, describing who they are and some characteristics of their energy consumption. To complete the picture, the notable findings of this questionnaire were given further consideration in the follow-up interviews.

\subsection{Characteristics of the survey respondents}

Energy consumption is greatly influenced by personal factors such as demographics, attitudes and beliefs. For example a study of 120 households in Bath, England found that income, age, household size, and environmental attitudes had a significant influence on household energy consumption and responses to feedback initiatives (Brandon and Lewis 1999). Attitudinal factors, such as environmental concern and altruism, have also been shown to identify those most likely to purchase green electricity (Rowlands et al. 2003). Understanding the household responses to PV should therefore consider the influence of demographic and belief factors.

The survey began exploring these issues by gathering a range of standard demographic data on gender, age, income, education, and household size. Occupancy and tenure information was also gathered as it was hypothesized that the investment in PV would be more likely among those who own their own homes. Attitudinal factors included environmental knowledge, worldview, 
self-identity and values as potential influences on domestic energy consumption. For both demographic and attitudinal questions, cluster analyses were performed in order to group respondents into manageable sets for later tests.

\subsubsection{Demographics and socio-economic status}

A household's socio-economic situation affects domestic energy consumption, for example, by limiting the types of appliances that are affordable, the times of day when the house is occupied and the desired level of energy services (e.g. heating and lighting). These characteristics of the sample are most useful when compared with reference datasets; e.g. using national data ${ }^{2}$ to determine whether PV is diffusing across a variety of demographic groups or a narrow subsection. Comparisons were also made with data from previous UK research on PV households (EST 2004) to determine if the sample was representative of UK PV households at large.

The gender of respondents is shown in Table 3.1. A significant difference from national statistics can be seen and one respondent noted that the wording of the questionnaire instructions, which asked for the head of the household to complete the survey, may have biased the results. However by grouping the respondents using all of the demographic information discussed here, the importance of gender decreases and the impact of such a bias is minimized. No equivalent PV dataset was available for comparison.

\begin{tabular}{lrrr}
\hline Gender & Count & Percent & National Percent \\
\hline Female & 24 & 26.4 & 51.2 \\
Male & 67 & 73.6 & 48.8 \\
\hline Total & 91 & 100 & 100 \\
\hline & & $\chi^{2}=22.4, d f=1, p \ll 0.001$
\end{tabular}

TABLE 3.1: Gender of survey respondents

\footnotetext{
${ }^{2}$ All national reference data sets are from National Statistics (2004b) unless otherwise stated.
} 
The survey indicated that PV households do not represent an even mix of ages, instead favouring older age brackets (Table 3.2). This significant difference from the national statistics may be explained by characteristics associated with older age such as higher income and owning one's own home. Although there was also a significant difference when comparing to the EST PV households, the tendency toward older ages is similar.

\begin{tabular}{lrrrrr}
\hline & \multicolumn{2}{c}{ Survey } & \multicolumn{2}{c}{ EST PV } & National \\
Respondent age & Count & Percent & Count & Percent & Percent \\
\hline $18-30$ & 0 & 0 & 2 & 1.1 & 20.5 \\
$31-44$ & 7 & 7.7 & 40 & 21.3 & 28.1 \\
$45-64$ & 48 & 52.8 & 101 & 53.4 & 30.9 \\
Over 65 & 36 & 39.6 & 45 & 24.0 & 20.5 \\
\hline Total & 91 & 100 & 188 & 100 & 100 \\
\hline \multicolumn{5}{c}{ Survey vs. National: $\chi^{2}=62.4, d f=3, p \ll 0.001$} \\
& Survey vs. EST PV: $\chi^{2}=12.9, d f=3, p=0.0050$
\end{tabular}

TABLE 3.2: Age of survey respondents

Diffusion of innovation theory suggests that the respondents might be "innovators" of PV technology and if so, they are likely to be well-educated (Rogers 2003). Table 3.3 confirms this, revealing that the majority of respondents had degree-level qualifications. This is significantly better-educated than the general population but no equivalent PV dataset was available for comparison.

\begin{tabular}{lrrr}
\hline Highest education level & Count & Percent & National Percent \\
\hline GCSE & 8 & 8.8 & 26.4 \\
A level & 7 & 7.7 & 28.8 \\
Degree & 70 & 76.9 & 29.6 \\
No qualification & 6 & 6.6 & 15.2 \\
\hline Total & 91 & 100 & 100 \\
\hline & & $\chi^{2}=269, d f=3, p \ll 0.001$
\end{tabular}

TABLE 3.3: Education of survey respondents 
PV systems are very expensive and therefore one would expect PV households to have higher incomes than the general public. Table 3.4 confirms this hypothesis; nearly $40 \%$ of respondents made more than $£ 50,000$ per year and a significant difference was found when this sample was compared with the general population. However with an average PV system costing nearly $£ 7,500$ (with a grant), a quarter of the respondents still paid more than a third of a year's entire salary to acquire PV. No significant difference was found when comparing to the EST's PV data set.

\begin{tabular}{lrrrrr}
\hline $\begin{array}{l}\text { Annual household } \\
\text { income }(\mathcal{E})\end{array}$ & \multicolumn{2}{c}{ Survey } & \multicolumn{2}{c}{ EST PV } & National \\
Count & Percent & Count & Percent & Percent \\
\hline Less than 14999 & 10 & 11.0 & 9 & 6.2 & 37.6 \\
15000-24999 & 14 & 15.4 & 26 & 18.1 & 21.3 \\
$25000-34999$ & 12 & 13.3 & 23 & 16.0 & 16.0 \\
$35000-49999$ & 19 & 20.9 & 35 & 24.3 & 11.8 \\
50000-100000 & 27 & 29.7 & 40 & 27.8 & 6.7 \\
More than 100000 & 9 & 9.9 & 11 & 7.6 & 6.7 \\
\hline Total & 91 & 100 & 144 & 100 & 100 \\
\hline & Survey vs. National: $\chi^{2}=99.1, d f=5, p \ll 0.001$ \\
& Survey vs. EST PV: $\chi^{2}=2.76, d f=5, p=0.737$
\end{tabular}

TABLE 3.4: Income of survey respondents

The number of individuals in a household has an impact on energy demand, with larger households making more efficient use of energy on a per capita basis; however the trend in the UK has been towards smaller household sizes (ONS 2004). Compared with these national data, Table 3.5 shows that PV household sizes were significantly larger than the national average as there are proportionally more one-person households in the general population. No significant difference was found in comparison with EST's PV data set. 


\begin{tabular}{lrrrrr}
\hline & \multicolumn{2}{c}{ Survey } & \multicolumn{2}{c}{ EST PV } & National \\
Household size & Count & Percent & Count & Percent & Percent \\
\hline 1 & 15 & 16.5 & 31 & 17.8 & 30.8 \\
2 & 42 & 46.2 & 85 & 48.9 & 34.8 \\
3 & 12 & 13.2 & 19 & 10.9 & 15.8 \\
4 & 15 & 16.5 & 28 & 16.1 & 12.8 \\
5 & 4 & 4.4 & 5 & 2.9 & 3.8 \\
6 & 3 & 3.3 & 6 & 3.4 & 1.8 \\
\hline Total & 91 & 100 & 174 & 100 & 100 \\
\hline \multicolumn{5}{c}{ Survey vs. National: $\chi^{2}=11.9, d f=5, p=0.0360$} \\
& Survey vs. EST PV: $\chi^{2}=0.832, d f=5, p=0.975$
\end{tabular}

TABLE 3.5: Household size of survey respondents

Having shown that the respondents were older than the national average, it is not surprising that PV households had been resident in their homes for a significantly longer time than the general population (Table 3.6). However there was no significant correlation between the length of residency and the length of PV ownership (Spearman's $\rho=0.00975, S=124000, p=0.927$ ), suggesting that households were as likely to add PV to a new home as they were to add it to a long-term residence. No equivalent PV data set was available for comparison.

\begin{tabular}{lrrr}
\hline Length of residency & Count & Percent & National Percent \\
\hline Less than 2 years & 7 & 7.7 & 16.5 \\
2-5 years & 10 & 11.0 & 19.5 \\
5-10 years & 17 & 18.7 & 17.0 \\
10-20 years & 29 & 31.9 & 22.0 \\
More than 20 years & 28 & 30.8 & 25.0 \\
\hline Total & 91 & 100.0 & 100.0 \\
\hline & & $\chi^{2}=13.0, d f=4, p=0.011$
\end{tabular}

TABLE 3.6: Residency of survey respondents

This survey covered PV households who were individual customers of Solar Century; i.e. they purchased the PV system themselves and were not part of a 
larger PV housing project. This therefore suggests that the respondents were able to do as they pleased with their roofs and so it is not surprising that Table 3.7 indicates that most respondents were owner-occupiers. This is significantly different from the general population but a comparison data set for UK PV households in general was not available.

\begin{tabular}{|c|c|c|c|}
\hline & Count & Percent & National Percent \\
\hline Own & 71 & 78.0 & 71.0 \\
\hline Mortgage & 17 & 18.7 & \\
\hline Other & 2 & 2.2 & 29.0 \\
\hline Rent & 1 & 1.1 & \\
\hline Total & 91 & 100.0 & 100.0 \\
\hline
\end{tabular}

TABLE 3.7: Tenure of survey respondents

Finally the district and area segments of the PV household postcodes (e.g. OX1) were mapped as shown in Figure 3.1. Respondents were scattered across Great Britain with pockets of PV in both urban (Manchester and Greater London) and rural areas (Devon, Northamptonshire, Buckinghamshire). One might expect more PV households in the southern regions of the country due to the greater solar resource and higher incomes and indeed the respondents were unevenly distributed across the administrative regions $\left(\chi^{2}=56.9, d f=11, p \ll\right.$ 0.001). A significant difference was also seen between the questionnaire sample and the EST's allocation of PV grants (EST 2005a), indicating a southern bias to the questionnaire sample $\left(\chi^{2}=46.6, d f=11, p \ll 0.001\right)$. This may be due to Solar Century's London location, though they do advertise themselves as a national installer. 


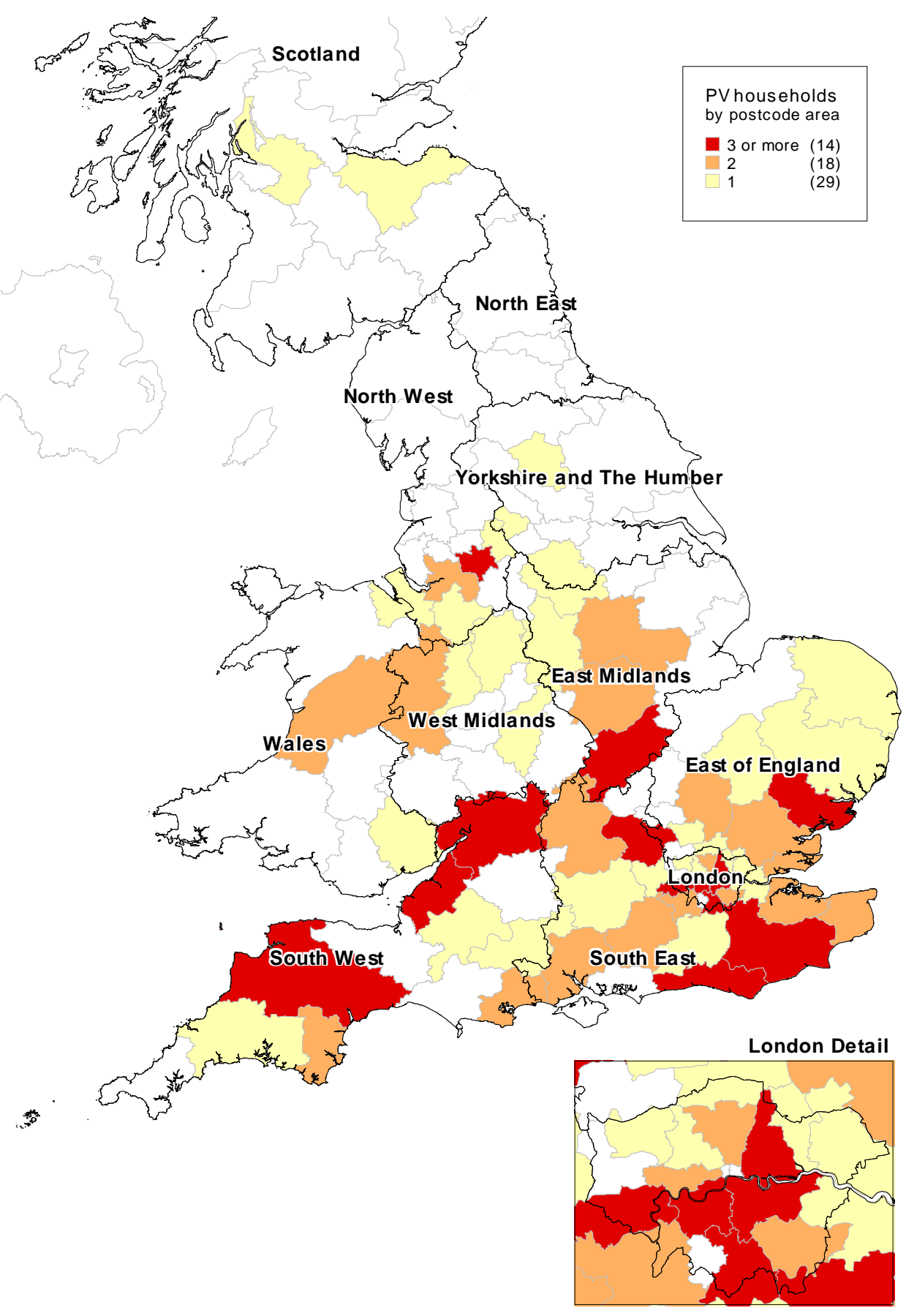

FIGURE 3.1: Location of PV households 


\section{Demographic clustering}

Clustering is a useful technique when trying to analyse a series of related measures, for example, to see if there are significant differences in behaviour according to socio-economic circumstance. However calculating these differences individually — by age, gender, income, education and so on — is time-consuming and can lead to data overload (i.e. too many significant differences to be able to see what is really important). The clustering technique makes such analyses more manageable and it has been used previously when studying patterns of energy behaviour (e.g. van Raaij and Verhallen 1983b, Banks 1998).

The analysis began with a hierarchical clustering routine that successively merges similar records into groups (agglomerative nesting or Agnes). The purpose of the analysis was to identify the number of clusters that might exist within the data set. Using gender, age, income, education, residency, tenancy, and household size data, two clear groups were seen (Figure 3.2).

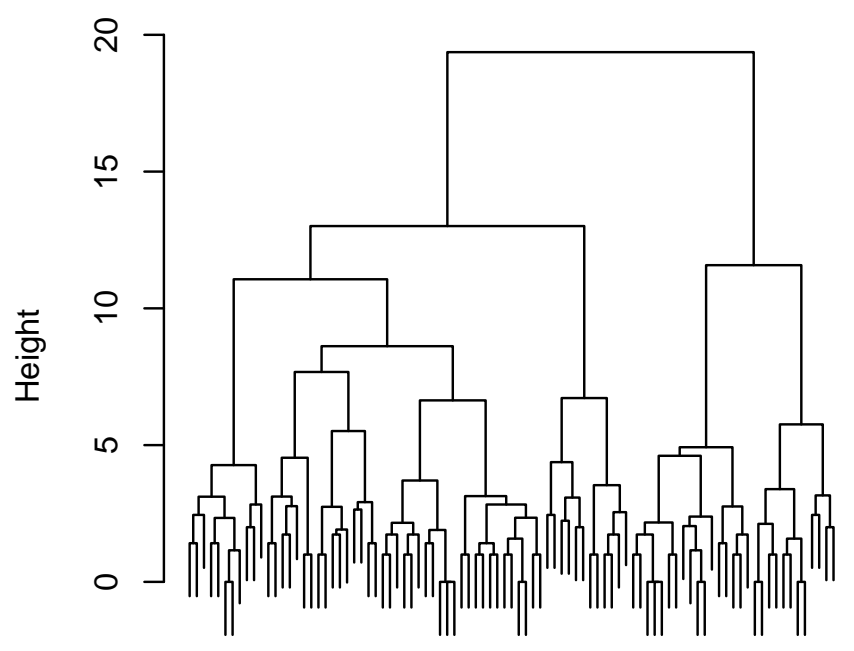

Demographic characteristics of respondents Agglomerative Coefficient $=0.94$

FIGURE 3.2: Clustering of demographic data 
Partition clustering (partitioning around medoids or Pam) was then used to identify the characteristics of the two groups. For easy identification, the clusters have been named Families and Retirees according to their attributes (Table 3.8). Due to the nature of the algorithms, individual respondents may fall within different clusters under the Agnes and Pam routines. In other words, the results of the Pam analysis cannot be applied to label the branches of the Agnes dendrogram.

\begin{tabular}{lcc}
\hline Attribute* & 'Families' & 'Retirees' \\
\hline Gender & Male & Male \\
Age & $45-64$ & Over 65 \\
Education & Degree & Degree \\
Annual income $(£)$ & $50000-100000$ & $35000-49999$ \\
Household size & 3 & 2 \\
Residency & $10-20$ years & More than 20 years \\
Tenancy & Own & Own \\
$n$ & 50 & 41 \\
\hline
\end{tabular}

*These are the characteristics of the medoid respondent and not an average of all respondents in the group.

TABLE 3.8: Demographic groupings

\subsubsection{Psychological constructs}

The behaviour of PV households may also be affected by psychological attributes. Behavioural research, specifically regarding energy and environmental behaviours (e.g. Banks 1998, Stutzman and Green 1982), has identified four important constructs: knowledge, worldview, self-identity, and values. Each factor can be measured using an established methodology, though the methods were adapted to suit the needs of this questionnaire. Since specific behaviours were not assessed in this survey, more precise psychological questionnaires (e.g. Ajzen 1991) were not appropriate. Where possible, questions were taken from existing national surveys to facilitate comparisons with the general 
public and a clustering analysis was again performed to summarize the results.

\section{Knowledge}

Diffusion of innovation theory suggests that if the surveyed households are innovators of PV technology, they will need "the ability to understand and apply complex technical knowledge" (Rogers 2003: 282). Therefore the first construct was knowledge, specifically knowledge of climate change and energy issues. Using the British Social Attitudes $18^{\text {th }}$ survey report on environmental values (Park et al. 2001), two general climate change and energy questions were selected (i.e. climate change is not caused by a hole in the atmosphere, but by the burning of fossil fuels). Drawing upon recent research at West Oxfordshire District Council (ECI 2004), two questions about photovoltaics were also included (i.e. that PV generates electricity, not hot water, and works well in the UK).

The respondents generally answered the questions correctly, revealing significantly higher levels of awareness on climate change and energy issues than the general public (Tables 3.9 and 3.10). Slightly higher levels of knowledge were also seen for the PV questions (Tables 3.11 and 3.12). ${ }^{3}$ This may be because the West Oxfordshire data encompasses the occupants of two buildings: one with PV and one without. While the data from the non-PV building was used here as a proxy of national understanding about PV, these individuals may still have had some awareness of PV.

\footnotetext{
${ }^{3}$ Some of the questionnaire scales were condensed to facilitate comparison to the reference data sets.
} 


\begin{tabular}{lrrrr}
\hline & \multicolumn{2}{c}{ Survey } & \multicolumn{2}{c}{ National } \\
& Count & Percent & Count & Percent \\
\hline Definitely true & 15 & 16.9 & 291 & 30.2 \\
Probably true & 16 & 18.0 & 407 & 42.3 \\
Can't choose & 6 & 6.7 & 58 & 6.0 \\
Probably not true & 14 & 15.7 & 76 & 7.9 \\
Definitely not true & 38 & 42.7 & 130 & 13.5 \\
\hline Total & 89 & 100 & 962 & 100 \\
\hline & & $\chi^{2}=66.3, d f=4, p \ll 0.001$
\end{tabular}

TABLE 3.9: Climate change is caused by a hole in the Earth's atmosphere.

\begin{tabular}{lrrrr}
\hline & \multicolumn{2}{c}{ Survey } & \multicolumn{2}{c}{ National } \\
& Count & Percent & Count & Percent \\
\hline Definitely true & 80 & 88.9 & 338 & 35.0 \\
Probably true & 6 & 6.7 & 445 & 46.0 \\
Can't choose & 3 & 3.3 & 62 & 6.4 \\
Probably not true & 1 & 1.1 & 99 & 10.2 \\
Definitely not true & 0 & 0 & 23 & 2.4 \\
\hline Total & 90 & 100 & 967 & 100 \\
\hline & & $\chi^{2}=101.1, d f=4, p \ll 0.001$
\end{tabular}

TABLE 3.10: Every time we use coal, oil or gas, we contribute to climate change.

\begin{tabular}{lrrrr}
\hline & \multicolumn{2}{c}{ Survey } & \multicolumn{2}{c}{ National } \\
& Count & Percent & Count & Percent \\
\hline Generate electricity & 85 & 93.41 & 26 & 83.4 \\
Heat water & 5 & 5.49 & 1 & 3.2 \\
Don't know & 1 & 1.10 & 4 & 12.9 \\
\hline Total & 91 & 100 & 31 & 100 \\
\hline & & $\chi^{2}=8.33, d f=2, p=0.0155$
\end{tabular}

TABLE 3.11: Solar photovoltaics use the energy of the sun to... 


\begin{tabular}{lrrrr}
\hline & \multicolumn{2}{c}{ Survey } & \multicolumn{2}{c}{ National } \\
& Count & Percent & Count & Percent \\
\hline Disagree & 86 & 95.6 & 27 & 87.1 \\
Neutral & 2 & 2.2 & 3 & 9.7 \\
Agree & 2 & 2.2 & 1 & 3.2 \\
\hline Total & 90 & 100 & 31 & 100 \\
\hline & & \multicolumn{2}{c}{$\chi^{2}=3.37, d f=2, p=0.185$}
\end{tabular}

TABLE 3.12: Solar photovoltaics don't work in the UK because it's not sunny enough.

\section{Worldview}

Environmental behaviour is partly determined by 'worldview', i.e. perceptions of the world and one's role within it. To explore this theme, three items from the New Ecological Paradigm (NEP) metric were selected (Dunlap et al. 2000). The original NEP scale has 15 items but to keep the survey to a reasonable length, a reduced set of questions was used. The selected items emphasized motivations relevant to $\mathrm{PV}$, such as the urgency of the climate change problem, the ability of technology to solve environmental problems, and the need for personal responsibility.

The three chosen items were also used on the British Social Attitudes survey (Park et al. 2001) and therefore comparisons could be made with the general population. These tests showed significant differences on all aspects of the NEP scale indicating that PV households have a significantly more proenvironmental worldview than the general population (Tables 3.13, 3.14 and 3.15). In particular the belief that environmental threats are an urgent matter, which cannot be resolved by technology alone, suggests a degree of personal responsibility for one's energy behaviour, a theme also noted by Kaiser and Shimoda (1999). 


\begin{tabular}{lrrrr}
\hline & \multicolumn{2}{c}{ Survey } & \multicolumn{2}{c}{ National } \\
& Count & Percent & Count & Percent \\
\hline Strongly disagree & 62 & 68.1 & 80 & 8.6 \\
Disagree & 6 & 6.6 & 361 & 38.9 \\
Neutral & 9 & 9.9 & 274 & 29.5 \\
Agree & 10 & 11.0 & 188 & 20.3 \\
Strongly agree & 4 & 4.4 & 25 & 2.7 \\
\hline Total & 91 & 100 & 928 & 100 \\
\hline & & $\chi^{2}=250.7, d f=4, p \ll 0.001$
\end{tabular}

TABLE 3.13: Modern science will solve our environmental problems with little change to our way of life.

\begin{tabular}{lrrrr}
\hline & \multicolumn{2}{c}{ Survey } & \multicolumn{2}{c}{ National } \\
& Count & Percent & Count & Percent \\
\hline Strongly disagree & 66 & 73.3 & 101 & 11.0 \\
Disagree & 8 & 8.9 & 342 & 37.3 \\
Neutral & 4 & 4.4 & 243 & 26.5 \\
Agree & 6 & 6.7 & 202 & 22.0 \\
Strongly agree & 6 & 6.7 & 29 & 3.2 \\
\hline Total & 90 & 100.0 & 917 & 100.0 \\
\hline & & $\chi^{2}=239.5, d f=4, p \ll 0.001$
\end{tabular}

TABLE 3.14: Many of the claims about environmental threats are exaggerated.

\begin{tabular}{lrrrr}
\hline & \multicolumn{2}{c}{ Survey } & \multicolumn{2}{c}{ National } \\
& Count & Percent & Count & Percent \\
\hline Strongly disagree & 3 & 3.3 & 15 & 1.6 \\
Disagree & 6 & 6.7 & 189 & 20.3 \\
Neutral & 3 & 3.3 & 310 & 33.4 \\
Agree & 37 & 41.1 & 374 & 40.3 \\
Strongly agree & 41 & 45.6 & 41 & 4.4 \\
\hline Total & 90 & 100.0 & 929 & 100.0 \\
\hline & & $\chi^{2}=206.1, d f=4, p \ll 0.001$
\end{tabular}

TABLE 3.15: I do what is right for the environment, even when it costs more money or takes more time. 


\section{Self-identity}

Banks (1999) confirmed the importance of self-identity in determining energy consumption behaviour, particularly repeat behaviours, and so self-identity was also included in this questionnaire. Using Callero's methodology (1992), respondents were asked to indicate their perceptions of a "home energy-saver" as well as their agreement with this target identity. Two items were selected as potential home energy-saver traits also seen in Darby (in press): an interest in household energy bills (to touch on energy awareness issues) and enjoyment of do-it-yourself (DIY) home renovations (potentially reflecting a commitment to make energy-saving changes). No national data sets were available for comparison but the data indicated two possible ideal identities for an energy-saver: an 'active' energy saver (strongly interested in electricity bills and DIY, 30\% of respondents) and a 'passive' energy saver (strongly interested in electricity bills but neutral interest in DIY, 70\% of respondents).

Each respondent's self-identity was then compared with their perceived 'ideal' energy-saver and a score calculated to reflect the agreement between the two. A significant difference was found between those reporting the 'active' and 'passive' ideals on all aspects of the target identity, although the difference was most pronounced with respect to DIY (Table 3.16). Therefore while all respondents generally see themselves as home-energy savers (i.e. agreement scores above 0.5 ), there is a subset who strongly agree with an 'active' form of energy-saving. This suggests that for this third of the respondents, improved energy information (via billing or monitoring) might lead to changes around the home (since DIY is enjoyable). The other two-thirds may still respond to energy information but might require assistance to make larger improvements in the home (e.g. measures beyond changing light bulbs). 


\begin{tabular}{lrrr}
\hline Respondent's identity* & \multicolumn{2}{c}{$\begin{array}{c}\text { Perceived identity } \\
\text { 'Active' }\end{array}$} & $\begin{array}{r}\text { Result of Kruskal-Wallis } \\
\text { 'Passive' }\end{array}$ \\
\hline Interest in energy bills? & 1.37 & 2.14 & $\chi^{2}=5.61, d f=1, p=0.0179$ \\
Enjoy DIY? & 1.93 & 3.75 & $\chi^{2}=22.8, d f=1, p \ll 0.001$ \\
Agreement score & 0.865 & 0.666 & $\chi^{2}=14.4, d f=1, p=0.00015$ \\
$n$ & 27 & 63 & \\
\hline
\end{tabular}

* The data in the table reflects the mean response measured on a seven-point Likert scale; i.e. 1 = pay attention to energy bills or enjoy DIY, $4=$ neutral. The agreement score is 1 for full agreement with the target identity, 0 for no agreement.

† An 'active' energy-saver pays attention to energy bills and enjoys DIY; a 'passive' energysaver pays attention to energy bills but has a neutral interest in DIY.

TABLE 3.16: Self-identity

\section{Values}

Values are a significant determinant of attitudes and behaviour, essentially providing the foundation upon which other psychological constructs are built. Rokeach (1973) outlined the traditional methodology for measuring values but his scale, which requires the respondent to sort two lists of 18 items each, was impractical for this survey. Some have used reduced lists of Rokeach values but in a recent study of values and energy consumption, Banks (1999) found five core groups of values relevant to energy issues. Mixing Banks' findings with Rokeach's method, respondents were asked to rank groups of values. These results were therefore an approximation and not a complete assessment of PV household values. Table 3.17 shows the values which respondents indicated were the most important to them and interestingly there was a strong emphasis on communal values such as equality and environmentalism, whereas more individualistic values such as social recognition or an exciting life were given less importance. 


\begin{tabular}{lrr}
\hline Value & Count & Percent \\
\hline Equality & 31 & 39.7 \\
Environment & 18 & 23.1 \\
Exciting life & 9 & 11.5 \\
Tradition & 9 & 11.5 \\
Social recognition & 3 & 3.8 \\
Selected more than one 'most important' value & 8 & 10.3 \\
\hline Total & 78 & 100.0 \\
\hline
\end{tabular}

TABLE 3.17: Most important values of PV households

Finally, an index was created to summarize the constructs discussed here. While each index was calculated slightly differently, all were designed so that a score of 1 would reflect the most environmentally-favourable response and a score of 0 would be the least favourable. Indices representing knowledge, worldview, self-identity, along with the most important values, are plotted in Figure 3.3, confirming that PV households have strong environmental values and beliefs. Tests were then performed to see if there were any variations in these psychological constructs by demographic grouping. Significant differences were found for both worldview and self-identity (Table 3.18); in both of these cases, the family groups had higher (i.e. pro-environmental) scores.

\begin{tabular}{lrrr}
\hline & \multicolumn{2}{c}{$\begin{array}{c}\text { Demographic group } \\
\text { Index score* }\end{array}$} & $\begin{array}{r}\text { Result of Kruskal-Wallis } \\
\text { difference test }\end{array}$ \\
\hline Knowledge & 0.856 & 0.869 & $\chi^{2}=0.209, d f=1, p=0.648$ \\
Worldview & 0.801 & 0.743 & $\chi^{2}=4.24, d f=1, p=0.0394$ \\
Self-identity & 0.769 & 0.655 & $\chi^{2}=5.43, d f=1, p=0.0199$ \\
Most important value & Equality & Equality & $\chi^{2}=4.63, d f=5, p=0.463$ \\
$n$ & 50 & 41 & \\
\hline
\end{tabular}

${ }^{*}$ The data in the table reflects the mean response; 1 is most environmentally-friendly, 0 is least.

TABLE 3.18: Demographic differences in psychological constructs 

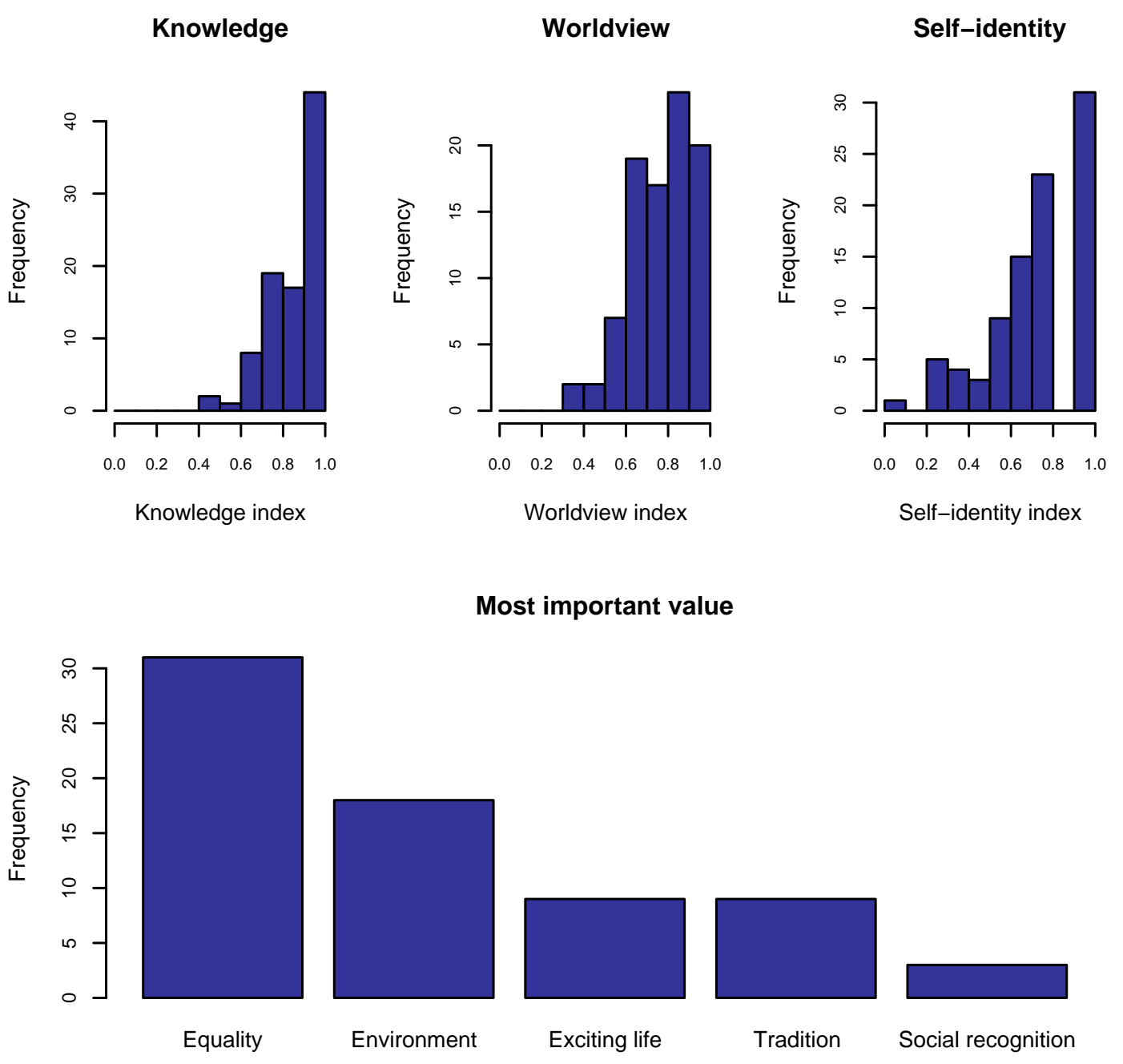

FIGURE 3.3: Summary of psychological constructs (A score of 1 is the most environmentally-favourable)

\section{Opinion clustering}

The scores for the four constructs - knowledge, worldview, self-identity, and values - were then used to cluster the responses, as was done with the demographic data. After first removing any incomplete data, an agglomerative clustering routine (Agnes) was applied and two significant groups were seen (Figure 3.4). 


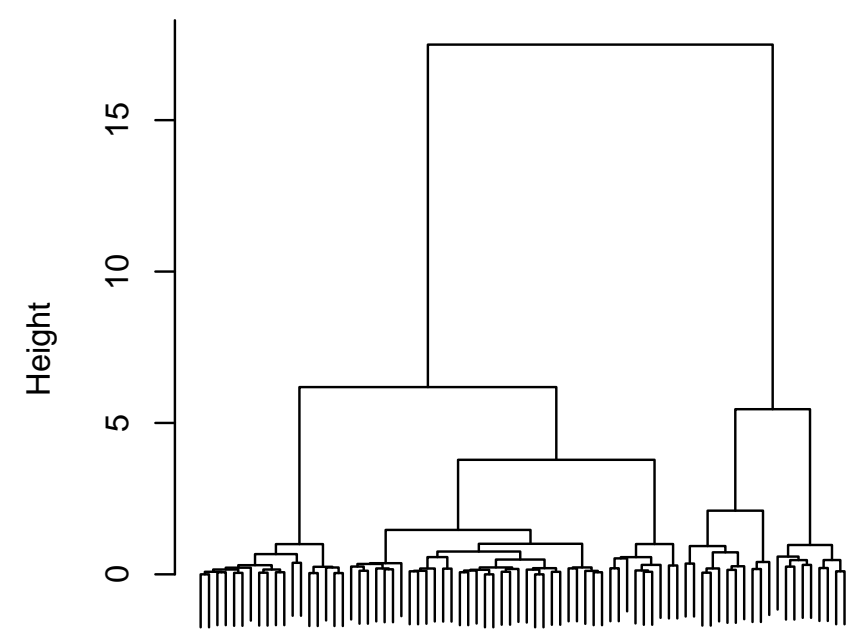

Attitudinal characteristics of respondents

Agglomerative Coefficient $=0.99$

FIGURE 3.4: Clustering of value and belief data

A Pam clustering analysis was then performed to provide details on the two groups. The self-identity of each group was the same but there are differences in values and knowledge levels (Table 3.19). The 'informed' green group therefore represents those with high knowledge levels and altruistic values. In contrast, the 'conservative' green group placed a greater emphasis on traditional values and had a more pro-NEP worldview, suggesting that taking responsibility for their actions may be important.

These opinion groupings will be used throughout the remaining analysis. For example, no significant difference in opinion was found by demographic group $\left(\chi^{2}=1.06, d f=1, p=0.303\right)$. This suggests that socio-economic factors alone cannot predict overall environmental beliefs and therefore both demographic and opinion groupings should be considered when trying to understand the motivations of behaviour. 


\begin{tabular}{lcc}
\hline Attribute* $^{*}$ & Informed green & Conservative green \\
\hline Knowledge & 0.917 & 0.750 \\
Worldview & 0.722 & 0.833 \\
Self-identity & 0.708 & 0.708 \\
Most important values & Equality, Environment & Tradition, Social recognition \\
$n$ & 58 & 20 \\
\hline
\end{tabular}

*These data are the index values of the medoid respondent and not an average of all respondents in the group.

TABLE 3.19: Opinion groupings

\section{Summary}

The surveyed PV households were not typical of UK households in general. Their demographic characteristics revealed high levels of education, income, home ownership and a bias toward middle-aged and older individuals. However the questionnaire sample was consistent with the larger population of UK PV households using the measures of age, income, and household size (although there was a regional bias to the sample arising perhaps from Solar Century's location in the south). Similarly compared with the general population, the respondents were better informed on energy and climate issues and showed a strong pro-environmental worldview. Value patterns also suggested that these individuals may feel a responsibility to do their bit for the environment.

These characteristics indicate that, according to diffusion of innovation literature, the respondents may represent typical technology 'innovators' (Rogers 2003). This classification will need to be confirmed in the follow-up interviews and it is also important to note that the respondents were not homogeneous. The demographic and opinion clusters calculated here encapsulate these differences and facilitate consideration of this diversity throughout the remaining analysis. 


\subsection{Energy-saving actions}

The main goal of the questionnaire was to determine whether owning PV had led to further energy savings in these households. As discussed above, it was not feasible to install monitoring equipment and actually measure energy consumption. Instead the questionnaire asked respondents to select from a list the energy-saving measures they had taken before and after the installation of PV, allowing the 'conservation chain' of Haas et al. (1999) to be verified. Although some changes may influence energy use in general (e.g. increased insulation reduces heating demand which might be powered by gas), most of the items referred to electricity demand (e.g. lights and appliances) since PV is an electrical generation technology. A self-assessment of total electricity savings since PV was also solicited to incorporate behavioural changes that might not have been covered explicitly by the survey. Finally, respondents were asked to indicate the energy-saving steps that might be taken next as well as the advantages and disadvantages of these possible changes. These motivational details provide insight into how PV households think about improving the energy efficiency of their home (i.e. their energy-related self-efficacy).

\subsubsection{Before and after actions}

Although closed-format questionnaires allow large numbers of questions to be answered quickly, the design must use a fixed set of items. This section therefore examines features of energy consumption which might have changed since the ownership of PV and could be easily measured, such as the installation of home energy-saving measures, changes in appliance ownership and lighting. 


\section{Home energy-saving improvements}

The first question was whether PV households had already made a number of energy improvements to their home before purchasing PV. Respondents were presented with a list of measures and indicated whether they owned them before and after PV. Table 3.20 shows the items used on the questionnaire and indicates the pre- and post-PV levels of ownership. There are three notable findings. First a significant change is only detected for the number of respondents on a green electricity tariff; this increase is likely because Solar Century recommended that new customers switch to a green electricity tariff in order to qualify for the benefits of selling their generated electricity. Secondly, a third of respondents owned solar hot water heaters before purchasing PV, which is surprisingly high. It may be that experience with solar hot water provided confidence in solar technologies generally, leading to the decision to purchase PV.

\begin{tabular}{lrrr}
\hline Measure & $\begin{array}{r}\text { Pre-PV } \\
\text { ownership (\%) }\end{array}$ & $\begin{array}{r}\text { Post-PV } \\
\text { ownership (\%) }\end{array}$ & $\begin{array}{r}\text { Results of } \\
\text { Binomial Test }\end{array}$ \\
\hline Loft insulation & 97.8 & 97.8 & $p=0.978$ \\
Floor insulation & 23.1 & 28.6 & $p=0.214$ \\
Wall insulation & 42.9 & 48.4 & $p=0.292$ \\
Pipe insulation & 76.9 & 78.0 & $p=0.901$ \\
Hot-water tank insulation & 90.1 & 91.2 & $p=0.861$ \\
Double-glazing & 83.5 & 87.9 & $p=0.322$ \\
Efficient boiler & 54.9 & 63.7 & $p=0.114$ \\
Solar hot water & 33.0 & 39.6 & $p=0.182$ \\
Draught-proofing & 69.2 & 70.3 & $p=0.910$ \\
Recycling & 87.9 & 92.3 & $p=0.259$ \\
Water-saving measures & 24.2 & 30.8 & $p=0.143$ \\
Public transport & 63.7 & 64.8 & $p=0.913$ \\
Green electricity tariff & 50.5 & 75.8 & $p \ll 0.001$ \\
Invested in carbon abatement & 13.2 & 14.3 & $p=0.756$ \\
\hline
\end{tabular}

TABLE 3.20: Ownership of home energy-saving measures before and after PV installation, $n=91$ 
Finally, national comparisons were possible on a number of metrics using the English House Condition Survey (ODPM 2001). Exact binomial tests reveal that PV households are significantly more likely to own loft (national ownership level $=87.7 \%, p=0.00115$ ) and cavity wall insulation (national ownership level $=25.4 \%, p \ll 0.001$ ) than the general population; however no significant difference was found for the ownership of double-glazing (national ownership level $=82.6 \%, p=0.214$ ). This provides further evidence of a conservation chain, although the survey could not reveal whether these measures had been taken by the present owners or if they were part of the building when the home was first purchased. The long residency times shown in Table 3.6 suggest however that these measures were likely taken by the current occupants.

The results were then analysed to determine whether particular demographic or opinion groupings were more likely to make these improvements. No significant differences were found in the ownership of these measures with one exception, regarding the installation of an efficient boiler. In this case, 'conservative green' households were significantly more likely than 'informed green' households to own such a boiler ( $57 \%$ ownership in 'informed' households versus $90 \%$ in 'conservative' households, $\chi^{2}=5.81, d f=1, p=0.0159$ ). There is no apparent explanation for this finding.

\section{Lights and appliances}

Lights and appliances account for $23 \%$ of delivered UK domestic energy consumption, with the balance used primarily for space and water heating (Boardman et al. 2005). While heating services can be provided by electricity, the questionnaire found that only $5.6 \%$ of respondents used only electricity for space and water heating; gas accounted for $80 \%$ of space heating and $62 \%$ of water heating (with an additional 26\% from solar hot water systems). Therefore electricity demand in these households is primarily due to lights and appliances. 
Respondents were asked to indicate the efficiency of six common household appliances before and after the installation of PV. Table 3.21 indicates that about $25 \%$ of appliances were A-rated after the installation of PV but there were no significant changes in any of the appliances since PV was installed. These findings were not surprising since most of these PV systems had been purchased in the two years preceding the survey. This does not allow much time for appliances to be replaced, given lifespans in the range of 10 to 20 years. Furthermore, if the appliances are approximately ten years old, A-rated options may not have been available at the time of purchase. For example, there were no Arated fridge-freezers available in Great Britain in 1996 (Boardman et al. 1997).

\begin{tabular}{lrrrrr}
\hline Appliance & $\begin{array}{r}\text { A-rated } \\
\text { pre-PV } \\
(\%)\end{array}$ & $\begin{array}{r}\text { A-rated } \\
\text { post-PV } \\
(\%)^{*}\end{array}$ & $\begin{array}{r}\text { Total sample } \\
\text { ownership } \\
(\%)\end{array}$ & $\begin{array}{r}\text { National } \\
\text { ownership } \\
(\%)\end{array}$ & $\begin{array}{r}\text { Binomial } \\
\text { test } \\
\text { results }\end{array}$ \\
\hline Fridge-freezer & 23.1 & 28.6 & 73.6 & 60 & $p=0.00741$ \\
Fridge & 19.8 & 22.0 & 61.5 & 43 & $p<0.001$ \\
Freezer & 17.6 & 24.2 & 40.4 & 21 & $p \ll 0.001$ \\
Dishwasher & 24.2 & 28.6 & 45.9 & 22 & $p \ll 0.001$ \\
Washing machine & 31.9 & 37.4 & 97.8 & 77 & $p \ll 0.001$ \\
Tumble dryer & 7.7 & 9.9 & 37.4 & 35 & $p=0.661$ \\
\hline
\end{tabular}

${ }^{*}$ No significant differences were found between the pre and post-PV levels of A-rated appliance ownership.

TABLE 3.21: Rates of appliance ownership, $n=91$

In comparison with national ownership rates (Boardman et al. 2005), these respondents were significantly more likely to own all major appliances with the exception of tumble-dryers. It seems likely that the higher levels of household income might explain these levels of appliance ownership, while environmental concern might limit the ownership of tumble dryers. No significant differences were found for the ownership of appliances by demographic or opinion grouping. 
Turning to lighting, compact-fluorescent lights (CFLs) represented on average $49 \%$ of the respondents' household lighting points before the installation of PV. This is much higher than the estimated 2004 national average of $6.4 \%$ (MTP 2005) (Wilcoxon rank test $V=4041, p \ll 0.001$ ). After the purchase of $\mathrm{PV}$, ownership of CFLs rose to $58 \%$ of lighting points, a significant increase (Wilcoxon $V=3378, p=0.0485)$. There were no significant differences in CFL ownership between the different demographic and opinion groupings.

\subsubsection{Total savings}

These assessments of energy-using equipment provide some indication of electricity consumption within a PV household. However since many factors that could influence this consumption were not explicitly covered by the survey, respondents were asked to consider whether their overall electricity consumption (i.e. the total demand, regardless of whether it was provided by PV or the grid) had changed since the installation of PV. This self-assessment is not perfect but it does provide a reference point, raising issues which can be explored further in the follow-up interviews (Chapter 4).

The mean overall change in total household electricity consumption was $-8.4 \%$, which is significantly different from zero (Figure 3.5; Wilcox $V=117, p \ll$ 0.001). Comparing by demographic and opinion grouping, no significant differences were found. This is slightly surprising but it may be that, owing to the conservation chain, the possible energy-saving changes which remain for PV households were inconvenient, expensive or impossible to take in the shortterm. Notes provided on the questionnaires suggest that the increases in consumption were due to changes in the household (e.g. an extension being built or more occupants). 


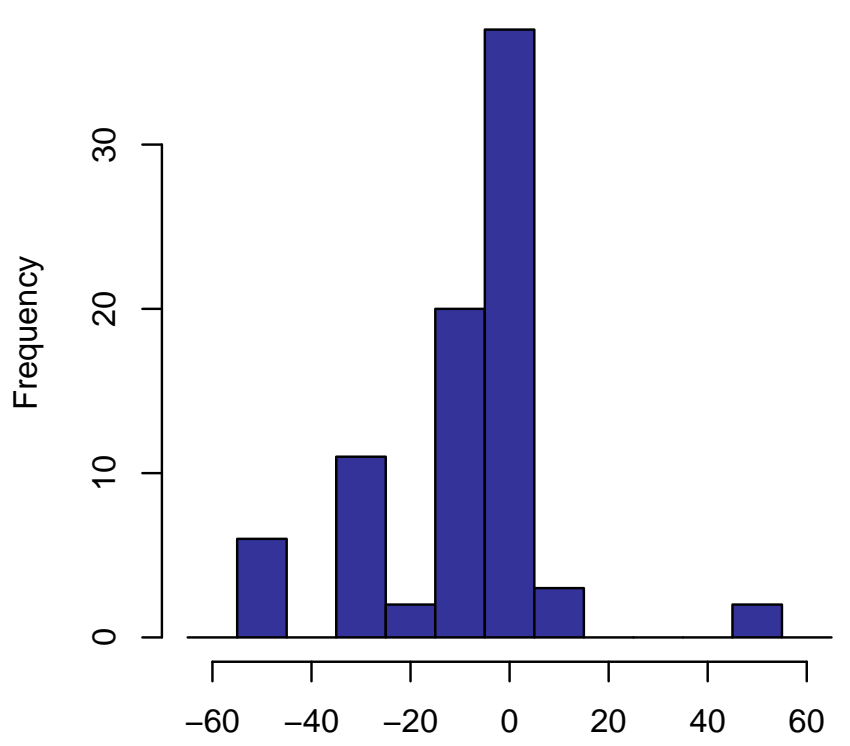

$\%$ change in electricity consumption (self-assessed)

FIGURE 3.5: Total electricity saving in PV households

Kempton and Montgomery (1982) noted that those who invest in energy efficiency are more likely to measure the savings. To assess whether or not PV households exhibited similar behaviour, respondents were asked to indicate how certain they were of their overall electricity saving. The results found that respondents were uncertain of the reported saving ( $\mu=2.7$ (uncertain) on a 7-point Likert scale; significantly different from neutral (4), Wilcox $V=$ $525, p \ll 0.001)$. No correlation was found between the certainty and the level of estimated saving (Spearman's $\rho=-0.146, S=102000, p=0.193$ ) and there was no significant difference in savings certainty by demographic or opinion grouping. Since the lack of certainty is uniform across all respondents, this suggests that any social-desirability bias ${ }^{4}$ in the self-assessed electricity savings was equally distributed.

\footnotetext{
${ }^{4}$ Social desirability bias is " 'a standard error on self-report measures due to respondents attempting to present themselves in a socially desirable light' — in other words, lying." (Fox 2005: 330).
} 


\section{Savings grouping}

Respondents were grouped into two groups according to their reported savings: those who indicated a saving $(n=39)$ and those who reported no saving or an increase $(n=42)$. No significant differences in savings were found by demographic or opinion groupings. Similarly no significant differences between the saving and no-saving groups were found for the conservation measures taken before and after the purchase of PV or the levels of appliance ownership before and after the purchase of PV. However in the case of CFLs, the savings group owned proportionally fewer CFLs before the installation of PV (44\% versus $58 \%$, Kruskal-Wallis $\left.\chi^{2}=3.75, d f=1, p=0.0528\right)$. No significant difference in CFL ownership was found after the installation of PV, suggesting that the change in electricity consumption reported by the savings group resulted primarily from the fitting of additional CFLs.

\section{Possible reasons for reported savings}

Respondents were asked to indicate whether their savings, or lack thereof, were explained by any of four suggested reasons. The first suggestion was that PV created a change in consumption by increasing awareness of electricity generation. Overall respondents felt this reason did not play a role; however it was found that those who reported an electricity saving were much more likely than non-savers to agree that they had become more aware of generation (KruskalWallis $\left.\chi^{2}=15.7, d f=1, p \ll 0.001\right)$. Respondents who were more aware of generation were also more certain of their indicated total savings assessment (Spearman's $\rho=-0.238, S=122000, p=0.0293$ ). No significant differences were found by demographic or opinion grouping.

The second reason was increased awareness of consumption and there was no overall trend. However, the saving group again claimed to be more aware 
of their consumption (Kruskal-Wallis $\chi^{2}=21.7, d f=1, p \ll 0.001$ ). No significant differences were found by demographic or opinion grouping, or by the certainty of the self-assessment. Therefore greater awareness of both generation and consumption were closely linked with greater total perceived, and perhaps actual, electricity savings.

Next the survey asked if respondents believed that the total amount of electricity used in their household had changed because they were trying to live within the amount of electricity produced by their PV system. This was rejected overall ( $\mu=5.5$ on a 7-point Likert scale; significantly different from neutral (4), Wilcox $V=2656.5, p \ll 0.001)$. However the 'savers' were significantly more likely than 'non-savers' to try and live within their electricity means (Kruskal-Wallis $\chi^{2}=5.26, d f=1, p=0.0218$ ). No significant differences were found regarding the certainty of the estimate or by demographic or opinion groupings. These findings, combined with notes that respondents wrote on the surveys, suggest that most respondents were aware that they consumed more electricity than their PV system could generate and that living within the system's generation capacity was too difficult.

The final reason suggested was that total electricity use had changed because the household was now 'green'. This was also rejected overall $(\mu=4.9$ on a 7-point Likert scale; significantly different from neutral (4) Wilcox $V=$ $1751, p \ll 0.001)$. However a significant difference by saving group was found and 'non-savers' were less likely to consider themselves as a 'greener' household post-PV (Kruskal-Wallis $\chi^{2}=4.94, d f=1, p=0.0262$ ). There were no significant differences related to the certainty in the overall saving, or by demographic or opinion grouping. Notes in the survey margins explained this finding, with most respondents indicating that they were already a green household before choosing PV and the installation of a system did not change this. ${ }^{5}$

\footnotetext{
${ }^{5}$ This finding is similar to the experience of PV households who did not purchase the sys-
} 


\subsubsection{Future actions}

Some determinants of energy use - in particular, equipment stocks - do not change frequently and therefore the surveyed households may not have had an opportunity to take all of the energy-saving measures they would like. Respondents were therefore asked what they might do in the future to save electricity. By designing these questions according to Ajzen's theory of planned behaviour methodology (2002), specific details can be gathered to identify the potential obstacles and incentives for these future energy-saving actions.

Respondents were first asked to list the three most likely next steps to save electricity in the home. These questions were open-ended so the various answers were grouped into common themes and plotted (Figure 3.6). The most popular measure by far was the installation of further microgeneration capacity to the home including micro-wind, micro-CHP, heat pumps, additional PV, and solar hot water. Minor purchases were also popular perhaps because they are easy to implement (e.g. new CFL light bulbs, energy-saving switches, etc.). It is interesting to note that although behavioural changes (such as switching off lights, turning the thermostat down, and so on) are arguably the easiest changes to make, they were less popular than major alterations such as generation, major appliance purchases, or building improvements. In keeping with the conservation chain theory, this may be because these behaviours were already being done by the respondents and there is a limit to how much households are willing to change their lifestyle; e.g. how low a thermostat setting is considered to be comfortable.

tem, i.e. those in social housing. A recent survey of Peabody Housing Trust residents from a PV-equipped estate revealed that the presence of PV made no difference to their use of energy or attitudes to energy-efficiency and the environment. However these systems did not have monitoring devices which might play a role in increasing awareness of the system's performance, especially if the panels themselves are on the top of a tower block (Ellis 2004). 


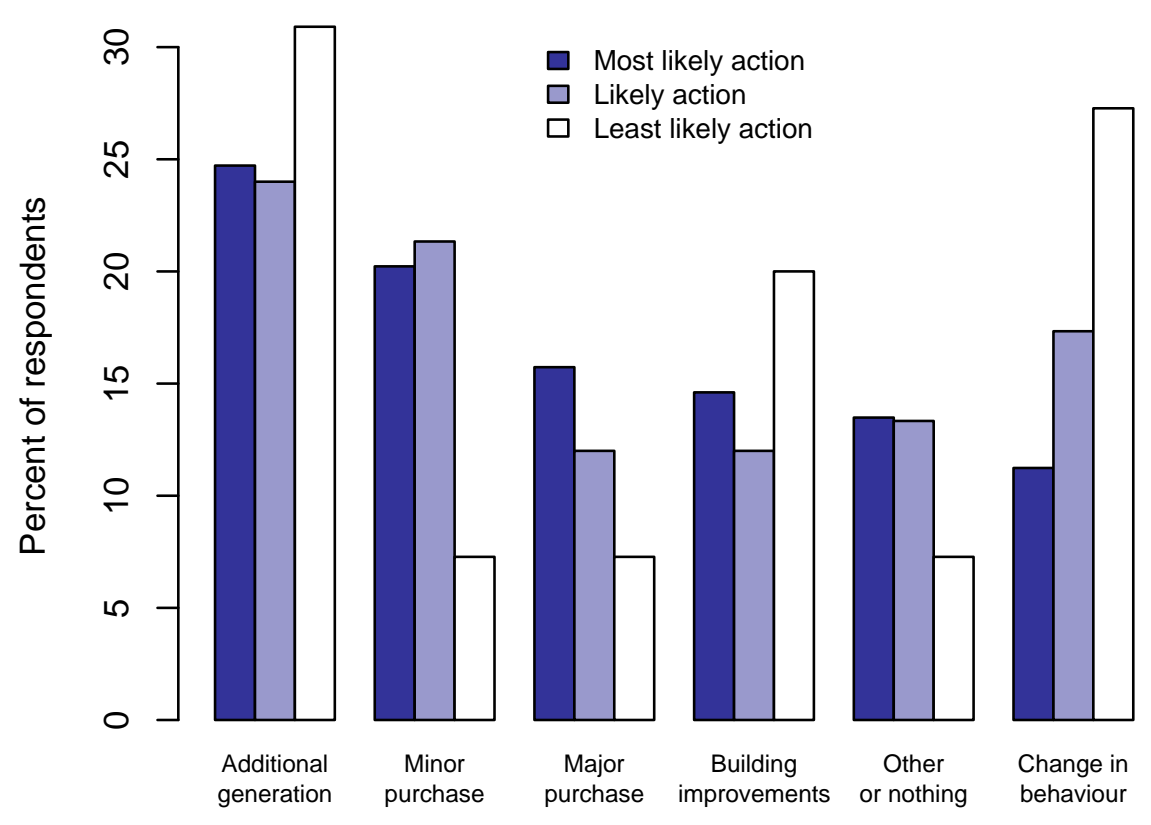

FIGURE 3.6: Future energy-saving actions, $n=91$

There are no significant differences in the most likely future energy-saving actions by demographic or opinion grouping. However those who reported an overall electricity saving slightly favoured minor purchase measures; those who reported no overall saving frequently indicated that they did not think further savings were possible or that further research would be required before $\operatorname{acting}\left(\chi^{2}=11.6, d f=5, p=0.0403\right)$.

Whether or not any of the listed measures actually take place will depend on the circumstances surrounding each particular decision. For example, a household wishing to install a micro-wind turbine must consider the cost of the installation, the suitability of local wind conditions, whether or not a trustworthy supplier can be found, and may need to obtain planning permission. The theory of planned behaviour methodology seeks to identify these potential barriers with regard to attitudes, social influences, and controlling or limiting factors. The survey adopted this approach and asked respondents to concentrate 
on their most likely energy-saving action. The following discussion focuses on the three most common future actions of the 89 valid responses: adding generation capacity (16 respondents, 18\%), installing more efficient lighting (a minor purchase; 15 respondents, 17\%), and purchasing a more efficient appliance (a major purchase; 12 respondents, 14\%).

Adding microgeneration capacity includes measures such as installing more PV panels, a micro-wind generator, a heat-pump, or solar hot water system. Table 3.22 provides a summary of the pros and cons of this option. The advantages and disadvantages were similar to those for PV itself, as shown in EST's customer survey (2004) which revealed that environmental and financial considerations are an important part of the decision. Furthermore the enabling and preventative factors found that cost, institutional factors (e.g. planning), and the potential objections of neighbours due to noise and visual impact were barriers. Overall respondents indicated that PV had made this action only slightly more likely, perhaps because these measures are expensive and household savings may have been spent installing of PV.

\begin{tabular}{lrr}
\hline Question & Most common reason & Percent $(n=16 / 89)$ \\
\hline Advantages? & Environment & $44 \%$ \\
Disadvantages? & Cost & $31 \%$ \\
Groups for? & Environmental & $44 \%$ \\
Groups against? & Friends \& neighbours & $44 \%$ \\
Enabling factors? & Cost & $31 \%$ \\
Preventative factors? & Institutional & $50 \%$ \\
\hline PV makes action... & Slightly more likely & $\mu=3.56 / 5$ \\
Significant different from neutral (3)? & Wilcox $V=30, p=0.0969$ \\
\hline
\end{tabular}

TABLE 3.22: Barriers and incentives to installing additional microgeneration

In the case of a minor action, e.g. buying more efficient light bulbs, PV made this action more likely (Table 3.23). This may be an indication that PV does indeed encourage households to be as efficient as possible and, while some mea- 
sures may be too bothersome or expensive to perform, buying more efficient lights is fairly easy. This is supported by the fact that cost was only a disadvantage for a small number of respondents and households felt that they need only the time and initiative to make the change. Furthermore purchasing lights is a household activity which does not infringe upon anyone else and therefore the support of others did not seem to be an important issue. ${ }^{6}$

\begin{tabular}{lrr}
\hline Question & Most common reason & Percent $(n=15 / 89)$ \\
\hline Advantages? & Conserve* & $80 \%$ \\
Disadvantages? & Cost & $27 \%$ \\
Groups for? & Don't know & $47 \%$ \\
Groups against? & None & $60 \%$ \\
Enabling factors? & Initiative & $20 \%$ \\
Preventative factors? & Time & $27 \%$ \\
\hline PV makes action... & More likely & $\mu=3.87 / 5$ \\
Significant different from neutral (3)? & Wilcox $V=31.5, p=0.0411$ \\
\hline
\end{tabular}

*The 'conserve' advantage refers to respondents who indicated that their future energy saving action would save electricity; they did not indicate if this saving was beneficial in terms of the environment, cost, both or other.

TABLE 3.23: Barriers and incentives to installing more efficient lighting

It was shown above that appliances in approximately $25 \%$ of PV household were A-rated. This means that purchasing more efficient appliances is an important potential saving which may be seized by PV households when their current equipment is no longer functional. Indeed 'situation' (i.e. appliances expiring) was a common enabling factor (Table 3.24) and PV made the purchase of efficient appliances significantly more likely. Both environmental groups and appliance manufacturers were thought to be supportive of these efficient purchases, with very little opposition. Again conservation and cost issues were also important.

It is worth noting that purchasing low-energy light bulbs and appliances is

\footnotetext{
${ }^{6}$ Family members might object but they were not listed by respondents as a potential opposing group.
} 


\begin{tabular}{lrr}
\hline Question & Most common reason & Percent $(n=12 / 89)$ \\
\hline Advantages? & Conserve & $67 \%$ \\
Disadvantages? & Cost & $33 \%$ \\
Groups for? & Environmental \& industry & $50 \%$ \\
Groups against? & None & $42 \%$ \\
Enabling factors? & Situation & $33 \%$ \\
Preventative factors? & Cost & $58 \%$ \\
\hline PV makes action... & More likely & $\mu=4.08 / 5$ \\
Significant different from neutral (3)? & Wilcox $V=28, p=0.0147$ \\
\hline
\end{tabular}

TABLE 3.24: Barriers and incentives to installing more efficient appliances

simply a more efficient way to maintain one's current way of life. The purchase of generation equipment on the other hand is a more radical change, in terms of both cost and reduced dependence on grid-imported energy sources. This may explain why environmental benefits were perceived only in the case of generation; for lights and appliances, these efficiency savings were viewed mainly as cost savings.

Respondents were given the opportunity to explain why owning PV made them more or less likely to perform their future energy-saving action. The responses fell primarily into two camps: those who felt that PV had no influence on their plans, e.g. "irrelevant, nothing to do with [installing a wind turbine]" or "simply we did PV first as we were putting a roof in first". The second group felt that PV made them more likely to take a future saving action because their awareness of electricity generation and consumption increased, often because of a monitoring device: "with a consumption readout (real time) I am aware of the highest users of power in the home" or "I appreciated how much can be gained from alternative power sources". No significant links were found between this motivation and overall savings or demographic attributes; however the 'informed green' group was much more likely to indicate that PV increased their commitment to energy-saving $\left(\chi^{2}=16.4, d f=3, p=0.00929\right)$. 


\section{Summary}

Assessing energy savings in PV households is difficult given the wide variety of saving behaviours that might occur. Here the focus was placed on behaviours that were well-suited to a closed-format questionnaire such as the ownership of lights, appliances, and insulation measures. This does not provide a complete picture of savings due to PV, but it has yielded several important findings. For example, the results found that owning PV made little difference to the major structural aspects of domestic energy consumption. The PV households had taken a number of household energy improvements before the purchase of PV, providing evidence of a 'conservation chain'. The only significant change since PV was switching to a green electricity tariff, a move facilitated by the installer. The installation of PV did not appear to create a shift toward more efficient appliances but this might be explained by the slow turnover of major appliances. However post-PV households were found to have installed additional CFL bulbs in their homes, although initial ownership rates were already high compared to national averages.

A small overall electricity saving of approximately $8 \%$ was found but the respondents acknowledged uncertainty in this figure. For those that did report a savings, increased awareness of generation and consumption issues and even trying to live within the generation capacity of one's system played a role in driving electricity savings. This awareness may have been encouraged by the presence of monitoring devices (more on this in §3.4). Respondents were asked to account for wider changes in their estimated energy demand and some indicated that they had built extensions (increasing demand) or had family members leave the home (decreasing demand). However quantifying these impacts is difficult and the follow-up interviews will be useful in improving confidence in these estimated savings. 
Overall PV made future saving actions more likely and the most popular future energy-saving measures were the installation of additional generation equipment, efficient lighting and appliances. The popularity of adding generation capacity can be partly explained by diffusion of innovation literature, where familiarity with PV may reduce the perceived risks of new technologies thereby increasing the likelihood of trying other generation technologies - in much the same way that $33 \%$ of homes owned solar hot water before purchasing PV. Following through on this action was dependent on external factors such as planning permission and technology costs, whereas smaller inhouse changes (lights and appliances) were mainly limited by personal initiative and situation (e.g. when appliances need replacing). Interestingly behavioural changes were only common as a final energy-saving measure; this might be because PV households had already made as many behavioural changes as they were willing to do or because they did not feel that such actions have significant energy-saving potential. Throughout these results, no significant differences were found in the responses of the different demographic and opinion groupings, suggesting that the respondents are quite homogeneous with regard to their responses to PV. 


\subsection{Monitors and meters}

Monitoring devices are perhaps the most innovative aspect of a PV household's information environment and several authors have noted that feedback from such devices can encourage energy-saving actions (Mansouri-Azar et al. 1996, Wood and Newborough 2003, Darby 2000). By providing timely and relevant information about energy consumption, monitors build energy awareness, allowing households to change their patterns of behaviour in response to displayed consumption (or for PV, generation) information. This sort of behaviour has been previously seen with off-grid photovoltaics (Schweizer-Reis et al. 2000) and therefore it was hypothesized that a similar effect might be seen with on-grid PV systems. However other factors, such as energy bills (e.g Kempton and Layne 1994), also play a role in building this tacit knowledge of energy consumption and generation. Like the billing and financial arrangements for traditional electricity supply, tariffs for microgeneration require accurate metering equipment to measure flows of electricity for settlement and reimbursement purposes (e.g. to claim the benefit from renewables obligation certificates).

The questionnaire therefore considered both metering and monitoring issues, beginning with a basic assessment of how commonly these devices were installed in PV households. Follow-up questions concentrated on how monitors are used by households and the types of information they display. Since the respondents represent the clients of only one PV installation firm, albeit the largest firm in the UK, these results are only a starting point. Further information from other stakeholders is presented in follow-up interviews and analyses (Chapter 6). 


\subsubsection{Ownership}

If monitors are to play a role in increasing awareness and stimulating behavioural responses to PV, then clearly the devices must be present in the home. The survey indicated that $86 \%$ of respondents had monitoring devices installed in their homes and the most common makes and models are listed in Table 3.25.

\begin{tabular}{lrr}
\hline Monitor model & Count & Percent \\
\hline Leiderdorp (LI-12 and LI-14) & 44 & 56.4 \\
Sunny Boy (various) & 5 & 6.4 \\
Eclipse & 4 & 5.1 \\
Other & 10 & 12.8 \\
Unknown model & 15 & 19.2 \\
\hline Total & 78 & 100.0 \\
\hline
\end{tabular}

TABLE 3.25: Most popular PV monitoring devices

Each model has its particular advantages and disadvantages, compared in Table 3.26. The Leiderdorp LI-12 unit is the simplest device and its small size and portability make it ideal for displaying PV information anywhere in the home. Sunny Boy has a number of monitoring products, most recently introducing a device similar to the Leiderdorp to the market; however most respondents had older inverter-based units which are less accessible and more difficult to observe frequently. The Eclipse is arguably the best device for information feedback as it compares generation and consumption information on a userfriendly, wall-mounted display. The price of this device fluctuates widely with respondents indicating that they paid up to $£ 800$ for the device but the manufacturer indicating in a later interview that it retails for approximately $€ 300$ (£200). The Variwatt device is not considered a display monitor but it is a required feature of all grant-receiving PV installations. 


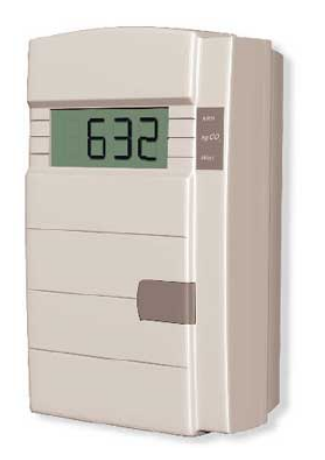

\section{Leiderdorp LI-12 (LI-14)}

\section{Cost $^{\dagger} \approx £ 150$}

Location Anywhere within home, portable

Displays Cumulative generation since installation (kWh), instantaneous output $(\mathrm{kW})$, cumulative $\mathrm{kg}$ of $\mathrm{CO}_{2}$ saved. No consumption data.

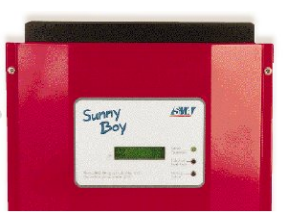

\section{Sunny Boy (various models)}

Cost $£ 200-700$

Location With inverter, though newer models are portable

Displays Detailed figures on quality and amount of generated electricity (e.g. kWh, kW, V, A, Hz etc.). Some models can be linked with a computer for further data analysis. No consumption data on most models.

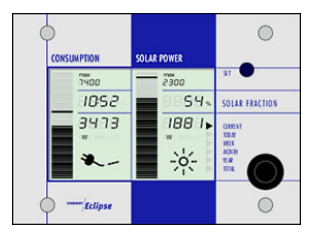

\section{Eclipse}

Cost $\approx £ 200$ (reported prices as high as $£ 800$ )

Location Wall-mounted

Displays

Cumulative and instantaneous generation and consumption, with 'solar fraction' comparison metric (e.g. PV output divided by demand). Display cycles through data by day, week, month, year and cumulative values since installation.

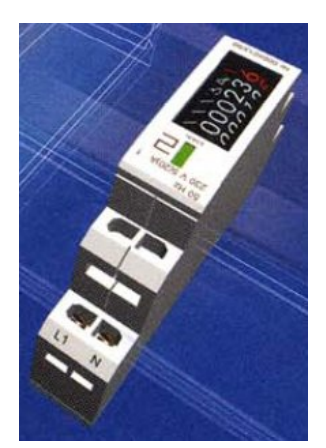

\section{Variwatt}

Cost $\approx £ 80$

Location

Near inverter

Displays

Cumulative generation since installation (kWh), required by the Major PV Demonstration grant programme.

Note Strictly speaking, the Variwatt is a generation meter not a monitor.

\footnotetext{
${ }^{+}$All costs are for an installed device.
}

TABLE 3.26: Features of the most popular PV monitors 
To provide some context for the differences in monitor ownership, respondents were asked how long they had owned their PV systems (Table 3.27). Recent purchasers of PV systems were significantly more likely to have a monitoring device (Kruskal-Wallis $\chi^{2}=4.55, d f=1, p=0.0329$ ) and the type of model owned has changed significantly, from the Sunny Boy and other devices to the Leiderdorp (Figure 3.7, Kruskal-Wallis $\chi^{2}=25.9, d f=3, p \ll 0.001$ ).

\begin{tabular}{lrr}
\hline Length of PV ownership & Count & Percent \\
\hline Less than 6 months & 22 & 24.2 \\
6-12 months & 17 & 18.7 \\
1-2 years & 29 & 31.9 \\
2-5 years & 23 & 25.3 \\
\hline Total & 91 & 100.0 \\
\hline
\end{tabular}

TABLE 3.27: Length of ownership of PV systems

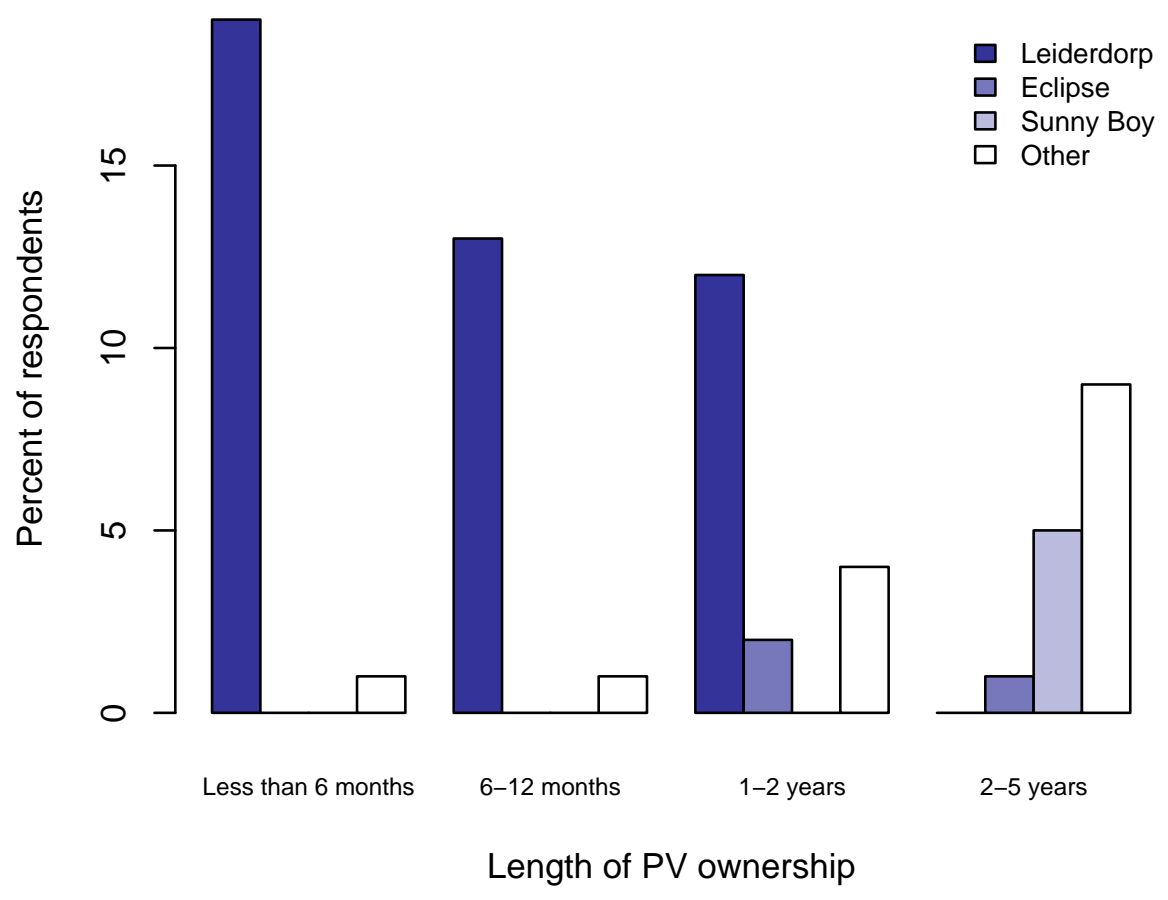

FIGURE 3.7: Monitor model by age of system 
There are also several different types of meter available. For maximum flexibility, a household would have gross metering: that is, three meters to track the electricity purchased from the grid (imported electricity), generated PV electricity (regardless of how it is used) and the electricity exported to the grid. The output of these devices could then be used to pay households for the output of their PV system. However there is currently a lack of consensus among electricity suppliers about how to reward microgenerating households; Hughes and Bell (in press), for example, describe 16 possible net metering or net billing arrangements. These issues are discussed in detail in Chapter 6 but the goal here was to identify the types of meters currently installed in PV homes.

All households had a generation meter, like the Variwatt in Table 3.26, as they are considered good practice and required by the grant process. Similarly all households must have an import meter. However only about half of the respondents had an export meter (Table 3.28). Interestingly there was a significant difference by the age of the system, as older PV system were slightly more likely to have had an import and export meter (Table 3.29). In the follow-up household interviews, it was suggested that district network operator (DNO) regions might explain the differences in ownership levels (see §4.5.4). Although DNO data were not collected by the questionnaire, no significant difference in the types of meters owned was found by administrative region (a proxy for DNO).

\begin{tabular}{lrr}
\hline Meter type & Count & Percent \\
\hline Import and export & 42 & 48.3 \\
Import & 39 & 44.8 \\
Don't know & 6 & 6.9 \\
\hline Total & 87 & 100.0 \\
\hline
\end{tabular}

TABLE 3.28: Types of meters in PV households 


\begin{tabular}{lrrrr}
\hline Age of PV system & Import & $\begin{array}{c}\text { Meter type } \\
\text { Import and export }\end{array}$ & Don't know & Total \\
\hline Less than 6 months & 8 & 8 & 3 & 19 \\
6 - 12 months & 12 & 5 & 0 & 17 \\
1 - 2 years & 14 & 13 & 2 & 29 \\
2 - 5 years & 5 & 16 & 1 & 22 \\
\hline Total & 39 & 42 & 6 & 87 \\
\hline & & $\chi^{2}=12.7, d f=6, p=0.0472$
\end{tabular}

TABLE 3.29: Meter ownership by age of PV system

\subsubsection{Patterns of use}

It is promising that so many of the surveyed PV households were found to own monitoring devices and that the Leiderdorp unit, which can display information within the family living space, was so popular. However the impact of these devices on energy consumption behaviour depends on how the monitors are actually used in daily life. To explore this topic, respondents were asked about their usage of the monitoring devices - where they are located, how frequently they are viewed and what information they provide. ${ }^{7}$

\section{Monitor location}

The monitors were located primarily to be visible in high-traffic areas such as living room or kitchen (Table 3.30). However some devices, such as certain Sunny Boy models, are not intended for installation in visible areas and therefore a significant difference in monitor visibility was seen based on device type $\left(\chi^{2}=20.8, d f=6, p=0.002\right)$. The age of the system also played a role, indicating that newer systems were more likely to have the monitor installed in a visible location (Table 3.31).

\footnotetext{
778 respondents indicated that they had a monitoring device, but not all answered the following questions: hence the totals in the tables below may not add up to 78 .
} 


\begin{tabular}{llrr}
\hline Monitor location & Count & Percent \\
\hline Visible & Kitchen & 23 & 29.9 \\
& Living & 24 & 31.2 \\
Hidden & Cupboard & 12 & 15.6 \\
& Storage & 12 & 15.6 \\
Other & 6 & 7.8 \\
\hline Total & & 77 & 100.0 \\
\hline
\end{tabular}

TABLE 3.30: Popular PV monitor locations

\begin{tabular}{lrrrr}
\hline & \multicolumn{4}{c}{ Monitor location } \\
System age & Visible & Hidden & Other & Total \\
\hline Less than one year & 30 & 7 & 1 & 38 \\
1-2 years & 12 & 7 & 3 & 22 \\
2-5 years & 5 & 10 & 2 & 17 \\
\hline Total & 24 & 6 & 47 & 77 \\
\hline \multicolumn{4}{c}{$\chi^{2}=13.7, d f=2, p=0.00833$}
\end{tabular}

TABLE 3.31: PV system age by location

\section{Viewing frequency}

The next question was how frequently the monitors were viewed. The overall pattern of viewing is shown in Table 3.32 and responses were grouped into "at least once a week" and "at most once a month" categories for the subsequent analysis. Not surprisingly, the visible devices were viewed most frequently (Table 3.33) and further investigation revealed that the Leiderdorp and Eclipse displays were typically viewed at least once a week (88\% and 100\% respectively versus $40 \%$ for the Sunny Boy and other devices, $\chi^{2}=17.3, d f=3, p<0.001$ ). This indicates that the Leiderdorp and Eclipse devices are being installed and used as suggested by their design. 


\begin{tabular}{lrr}
\hline Viewing frequency & Count & Percent \\
\hline Every day & 37 & 50.7 \\
About twice a week & 9 & 12.3 \\
Once a week & 7 & 9.6 \\
Once a month & 12 & 16.4 \\
Infrequently & 7 & 9.6 \\
Never & 1 & 1.4 \\
\hline Total & 73 & 100.0 \\
\hline
\end{tabular}

TABLE 3.32: Frequency of PV monitor viewing

\begin{tabular}{lrrrr}
\hline & \multicolumn{2}{c}{ Viewing frequency } \\
Monitor location & At least once a week & At most once a month & Total \\
\hline Visible & 37 & 7 & 44 \\
Hidden & 13 & 11 & 24 \\
Other & 3 & 2 & 5 \\
\hline Total & 53 & 20 & 73 \\
\hline & & $\chi^{2}=7.42, d f=2, p=0.0245$
\end{tabular}

TABLE 3.33: Monitor location by viewing frequency

In addition, there was a significant difference by system age with newer monitors being viewed more frequently (Table 3.34). This observation might be explained by a novelty effect, with new PV households keenly interested in the output of their system. However it could also reflect the recent popularity of the visible Leiderdorp device noted above.

\section{Monitor display metrics}

Monitoring devices typically feature a variety of metrics which users can cycle through at the touch of a button. Overall the respondents most frequently viewed the system's instantaneous performance (62\%), followed by long-term cumulative measures of performance (e.g. generation since installation, 24\%) 


\begin{tabular}{lrrrr}
\hline & \multicolumn{2}{c}{ Viewing frequency } \\
System age & At least once a week & At most once a month & Total \\
\hline Less than one year & 32 & 5 & 37 \\
1-2 years & 13 & 7 & 20 \\
$2-5$ years & 8 & 8 & 16 \\
\hline Total & 53 & 20 & 73 \\
\hline \multicolumn{4}{c}{$\chi^{2}=8.28, d f=2, p=0.0160$}
\end{tabular}

TABLE 3.34: PV system age by viewing frequency

and short-term cumulative measures of performance (e.g. daily or weekly totals, $8 \%$ ). Other metrics, such as $\mathrm{CO}_{2}$ savings or lights to indicate import and export status, were less popular (5\%).

Again however the characteristics of each device determine how it is used. This can be seen in Table 3.35, which suggests that the 'other' devices listed by respondents primarily consisted of cumulative generation counters (i.e. perhaps meters, not monitors). Significant differences were also seen by system age $\left(\chi^{2}=18.8, d f=6, p=0.005\right)$ and monitor location $\left(\chi^{2}=16.6, d f=6, p=\right.$ 0.011), with both tests indicating that instantaneous metrics were most popular on newer visible monitors. Again this is consistent with the recent popularity and features of the Leiderdorp device.

\begin{tabular}{lrrrrr}
\hline & \multicolumn{5}{c}{ Monitor model } \\
Metric & Leiderdorp & Eclipse & Sunny Boy & Other & Total \\
\hline Instantaneous kW & 35 & 2 & 2 & 4 & 43 \\
Long-term cumulative & 3 & 0 & 2 & 7 & 12 \\
Short-term cumulative & 3 & 1 & 0 & 1 & 5 \\
Other & 1 & 0 & 0 & 3 & 4 \\
\hline Total & 42 & 3 & 4 & 15 & 64 \\
\hline & & & $\chi^{2}=26.2, d f=9, p=0.00189$
\end{tabular}

TABLE 3.35: Monitor model by most popular metric 
Each metric implies a particular viewing frequency; for example, cumulative measures might be observed only occasionally (i.e. taking monthly or quarterly readings to compare with electricity bills), whereas instantaneous metrics might be observed more frequently. Table 3.36 supports this hypothesis but it is interesting to note that about a quarter of respondents viewed instantaneous measures fairly infrequently. This may be because instantaneous metrics are also an easy way to verify that the system is still performing. Alternatively as respondents become accustomed to their system's performance, they may rely on other indications of performance such as the weather.

\begin{tabular}{lrrr}
\hline & \multicolumn{2}{c}{ Viewing frequency } & \\
Metric & At least once a week & At most once a month & Total \\
\hline Instantaneous kW & 36 & 9 & 45 \\
Long-term cumulative & 7 & 9 & 16 \\
Short-term cumulative & 6 & 0 & 6 \\
Other & 4 & 0 & 4 \\
\hline Total & 53 & 18 & 71 \\
\hline & & $\chi^{2}=12.2, d f=3, p=0.00689$
\end{tabular}

TABLE 3.36: Viewing frequency by most popular metric

Finally respondents were asked what information they would like to see displayed on an ideal monitoring device. Existing options such as the instantaneous output and cumulative generation measures remained popular but surprisingly metrics emphasizing a specific benefit (e.g. $\mathrm{CO}_{2}$ or cost savings) were less popular. Instead consumers were keen to learn about their consumption, both as a standalone figure and in comparison with their PV generation (Table 3.37). Some respondents indicated that a basic meter showing generation, consumption and exports would be sufficient since other figures can be calculated from these statistics. 


\begin{tabular}{lrr}
\hline Desired metric & Count & Percent \\
\hline Generation compared with consumption & 57 & 73.1 \\
Total exported electricity & 50 & 64.1 \\
Instantaneous kW & 48 & 61.5 \\
Total electricity consumption & 42 & 53.8 \\
Warnings & 38 & 48.7 \\
CO$_{2}$ saved & 33 & 42.3 \\
Cumulative daily kWh generated & 26 & 33.3 \\
Cumulative monthly kWh generated & 26 & 33.3 \\
Cost saved & 22 & 28.2 \\
Cumulative yearly kWh generated & 22 & 28.2 \\
Cumulative weekly kWh generated & 17 & 21.8 \\
\hline
\end{tabular}

TABLE 3.37: Desired metrics on an ideal PV display monitor, $n=78$

\subsubsection{Impact on energy savings}

These insights into the use of monitors within PV household are interesting but ideally one would hope to see a connection between the presence of monitors and actual energy saving in the home. However there was no significant difference in the savings of those with and without monitoring devices (Table 3.38). This result is surprising, but perhaps understandable since the devices displayed generation information and generally did not display any consumption information.

\begin{tabular}{lrrr}
\hline & \multicolumn{3}{c}{ Saving group } \\
Monitor ownership & No saving & Saving & Total \\
\hline No & 7 & 5 & 12 \\
Yes & 35 & 34 & 69 \\
\hline Total & 42 & 39 & 81 \\
\hline & $\chi^{2}=0.0302, d f=1, p=0.862$
\end{tabular}

TABLE 3.38: Ownership of monitor by savings group

Further investigation revealed that there was no significant difference between the changes in appliances, energy-saving measures, or CFL ownership 
by monitor ownership. The sole exception was investment in carbon abatement (i.e. carbon offsets) which was more likely to be used by those without monitoring devices (Table 3.39). Given the low overall use of carbon abatement (14\% of respondents post-PV), this might suggest that these individuals chose not to get monitoring devices because they were exceptionally aware of their carbon footprint before the purchase of PV.

\begin{tabular}{lrrr}
\hline Investment in & \multicolumn{3}{c}{ Monitor ownership } \\
carbon abatement & Monitor & No monitor & Total \\
\hline Yes & 7 & 6 & 13 \\
No & 71 & 7 & 78 \\
\hline Total & 78 & 13 & 91 \\
\hline & $\chi^{2}=9.73, d f=1, p=0.00182$
\end{tabular}

TABLE 3.39: Investment in carbon abatement by monitor ownership

Finally, respondents who cited an increased awareness of generation as an explanation for their change in electricity use were significantly more likely to have a monitor (Table 3.40). The monitor also appeared to play a small, perhaps symbolic, role in reminding households that they are a 'green' household. This result provides evidence that monitoring devices help build both tacit knowledge and a commitment to energy-saving.

\begin{tabular}{lrrr}
\hline $\begin{array}{l}\text { Reason for change } \\
\text { in consumption* }\end{array}$ & \multicolumn{2}{c}{$\begin{array}{c}\text { Monitor ownership } \\
\text { Monitor }\end{array}$} & $\begin{array}{r}\text { Results of Kruskal- } \\
\text { Wallis Test }(d f=1)\end{array}$ \\
\hline Increased generation awareness & 3.96 & 5.25 & $\chi^{2}=4.09, p=0.0432$ \\
Increased consumption awareness & 3.78 & 3.91 & $\chi^{2}=0.0509, p=0.821$ \\
Live within means & 5.48 & 5.92 & $\chi^{2}=0.916, p=0.339$ \\
Now a 'green' household & 4.79 & 5.64 & $\chi^{2}=2.78, p=0.0956$ \\
\hline
\end{tabular}

* Data represent mean on a 7 point Likert scale ( 1 = Strongly agree, 7 = Strongly disagree $)$

TABLE 3.40: Reasons for electricity savings by monitor ownership 
No significant differences in energy saving were found by monitor model, age of the PV system, location of the monitor, and viewing frequency. These results are not surprising having shown the interconnectedness between the monitor model and these variables above. As a side note, it is unfortunate that the Eclipse sample was so small as this was the only monitor to show generation and consumption information. With a larger sample of Eclipse devices, it might have been possible to determine if the extra consumption information made a difference to household energy consumption. Therefore the experiences of those households with Eclipse monitors was particularly important during the interviews.

A small significant difference was found by most popular metric (Table 3.41), suggesting that the households which reported a total electricity saving paid slightly more attention to the monitor's long-term cumulative production metrics. This finding could be the result of households monitoring their progress against the long payback period of the PV system since observing the system's performance and energy bills were the most popular ways of assesing this payback (Table 3.42). However there was no significant difference between the estimated payback times of saving and non-saving groups (Table 3.43). ${ }^{8}$ In addition to the finding that cost metrics were less desirable on an ideal monitoring device, this suggests that payback may not be a strong motivation for further energy saving (or system purchase) among these respondents (see also $\S 4.2 .2)$.

Finally, no significant differences were found between any of the variables discussed here (monitor ownership, monitor model, monitor location, viewing frequency, most popular metric, and system age) by demographic or opinion groupings.

\footnotetext{
${ }^{8}$ Payback periods are calculated in $§ 5.5 .3$; under most scenarios, the payback of PV is at least 50 years.
} 


\begin{tabular}{lrrr}
\hline & \multicolumn{3}{c}{ Saving group } \\
Metric & No Saving & Saving & Total \\
\hline Instantaneous $\mathrm{kW}$ & 22 & 19 & 41 \\
Long-term cumulative & 5 & 8 & 13 \\
Short-term cumulative & 1 & 4 & 5 \\
Other & 4 & 0 & 4 \\
\hline Total & 32 & 31 & 63 \\
\hline & $\chi^{2}=6.70, d f=3, p=0.0822$
\end{tabular}

TABLE 3.41: Most popular metric by savings group

\begin{tabular}{lrr}
\hline Data source & Count & Percent \\
\hline Observation of system electricity production & 47 & 51.6 \\
Examining old energy bills & 32 & 35.2 \\
Reading or research & 31 & 34.1 \\
Talking with PV installer & 24 & 26.4 \\
Uncertain & 24 & 26.4 \\
Other & 23 & 25.3 \\
Talking with energy company & 9 & 9.9 \\
\hline
\end{tabular}

TABLE 3.42: Sources of information for determining PV payback, $n=91$

\section{Monitors summary}

These results have introduced the role of monitoring devices in PV households. It was initially thought that monitoring devices may encourage energy savings by providing relevant information to households, building the tacit knowledge and self-efficacy needed to change behaviour. While it was shown that those with monitors did experience an increase in their awareness of generation, there were no differences between those who reported an electricity saving based on the ownership of a monitor, the monitor model, its location, viewing frequency, or most commonly observed metric. This is a disappointing result but it may be explained by the fact that most of the monitoring devices were not able to display information on electricity consumption. This hypothesis is supported 


\begin{tabular}{lrrr}
\hline & \multicolumn{3}{c}{ Saving group } \\
Payback period & No saving & Saving & Total \\
\hline 5-10 years & 2 & 4 & 6 \\
10-20 years & 6 & 6 & 12 \\
20-50 years & 23 & 18 & 41 \\
More than 50 years & 5 & 9 & 14 \\
Don't know & 1 & 0 & 1 \\
\hline Total & 37 & 37 & 74 \\
\hline & $\chi^{2}=3.42, d f=4, p=0.490$
\end{tabular}

TABLE 3.43: Household estimates of PV payback periods

by the finding that $73 \%$ of respondents would like a metric to compare consumption and generation on an ideal monitor.

Monitors were common among the PV installations of respondents. The models installed have changed over the years but at the time of the questionnaire, the most common device was a simple hand-held unit. Its portability and small size enabled it to be placed in high-visibility areas of the home where it was looked at frequently. Older devices were linked primarily with the inverter or metering device and were placed out of the way and hence looked at less frequently.

The questionnaire also touched on the related issues of export meters and payback, which provide information and incentives that may encourage behavioural change. However the low rates of ownership of export meters $(48 \%$ overall and very few export meters in newer PV systems) and the long estimated payback periods suggest that financial incentives may be less important to these adopters of PV technology. However these issues may be relevant to the wider diffusion of PV and its impact on other adopters; therefore metering and payback issues are explored further in the remaining data chapters. 


\section{Conclusion}

The mail questionnaire was the first part of an assessment of the changes in energy consumption that may result from owning a PV system. While the closedformat of the survey restricted the range of behaviours upon which respondents could comment, it did encourage a good response rate $(77 \%)$ and the results have shed light on the primary goals of understanding PV household demographics, pre- and post-PV energy-saving actions, and the use of monitoring devices.

With respect to demographics and beliefs, it was found that the respondent PV households were not representative of the wider UK population: they were wealthier, better educated and more likely to own their own homes. Similarly these households also exhibited greater levels of environmental knowledge and a more pro-environmental worldview than the general public. This has translated into a series of conservation measures being taken by each household prior to the purchase of PV. Although this sample was taken from the customers of only one installer, the respondents were representative of the larger UK PV household population and so these results should be applicable to other owneroccupied PV households. Very few significant differences were seen between the demographic and opinion groupings. This suggests that the respondents were relatively homogeneous when considering how their socio-economic situation and beliefs shaped the changes in energy consumption behaviour discussed here. Overall these characteristics suggest that, according to Rogers (2003), the respondents were likely 'innovators' and not 'early adopters'; however more information on the social networks of these households is required before drawing a final conclusion and discussing the implications of such a classification.

Respondents believed that they had reduced their total electricity consump- 
tion by $8.4 \%$ since getting PV, although they were uncertain of this answer. This scepticism was well founded as a review of the changes in appliance ownership, conservation measures and other possible savings only revealed an improvement in the number of CFLs installed in the homes. However since the average household had only owned their PV system for less than two years, there may have been limited opportunities to make further changes (for example, due to a lack of funds or the long-life of appliances). Interestingly $76 \%$ of households were found to use green electricity tariffs after the installation of PV, thus reducing the carbon impact of their remaining grid electricity consumption.

The evidence suggested that those who believed they had saved electricity since installing PV had become more aware of electricity generation and consumption and may even be trying to live within the means of their system (although PV provides only about a third of annual household demand, §5.3.2). Owning PV also made future saving actions more likely and the most popular measures were installing additional generation capacity or more efficient lights and appliances. The barriers and incentives to these actions were varied, with the decision to install additional generation capacity shaped by cost and institutional factors (planning, availability of technologies, etc) but changing lights and appliances was mainly influenced by personal motivation and situation (e.g. old appliances wearing out).

Monitors play an important role in raising energy awareness (especially of generation) and $86 \%$ of respondents had such a device. There were notable variations in the type of device and its viewing patterns, with older PV systems having monitors installed in out-of-the-way locations where they were viewed infrequently; newer systems had small portable units which can be displayed in prominent areas of the home and hence were observed more often. However an alternative explanation is that the novelty of the PV system encouraged frequent viewing. Instantaneous measures of system performance were the most 
popular but there was strong demand for a metric which compares both generation and consumption. This is a key point as no significant difference was found between the electricity savings of those with and without monitors, perhaps because current devices do not display such a comparison metric. One device does exist to compare generation and consumption on an equivalent time-scale but the sample was too small to determine its influence.

These results are promising and it appears that PV systems are increasing the tacit knowledge of adopting households (through the feedback from monitors) and building their self-efficacy (e.g. the interest in further microgeneration). However three areas of further investigation remain. First the monitoring and metering findings need further examination, both to understand whether the reported rates of installation are common across the entire PV industry (instead of the one firm studied here) and to identify how the tacit knowledge provided by monitors links with actual household behaviour. Secondly, additional data are needed to confirm the estimated electricity savings discussed here. For example, the questionnaire has provided a picture of the equipment within the household and how it changed after the installation of PV. However use behaviours were not covered and further research is needed to explore the full range of potential energy-saving behaviours. Finally more information is required to understand the future energy-saving measures described here and whether or not these households feel they have reached a limit to their energysaving potential; in other words, if $\mathrm{PV}$ is part of a conservation chain, where does it end and how does PV fit on this continuum? The next chapter presents follow-up interviews to address these questions. 


\section{Chapter 4}

\section{INTERVIEWS WITH PV HOUSEHOLDS}
"You know, some people go on cruises and others get face-lifts and I get [PV] technology."

C. H., PV householder, February 2005

Electricity consumption is more than just the ownership of lights and appliances; it must also include the way in which this equipment is used. Some influences on use patterns, such as household income and family size, were identified in the questionnaire but other factors, such as lifestyle, are not assessed so easily. Additionally, questions about how monitors affect energy awareness and consumption and the realistic potential of post-PV energy saving require a more in-depth discussion of a PV household's beliefs and energy-use environment. This chapter presents interviews with the surveyed households that explore these issues and begins to place the respondents within the wider PV socio-technical system.

\subsection{Methodology}

As part of the questionnaire, respondents were asked if they were willing to be contacted for a follow-up interview and 76 of the 91 respondents initially 
agreed. The interviews were conducted from January to February 2005 by telephone to save time and money, as the respondents were located throughout the UK. In the end, 63 interviews were conducted and the average conversation lasted approximately 16 minutes.

The interviews were semi-structured and since each discussion progressed slightly differently, statistical analysis of the results was not possible. This was the original intention as the questionnaire provided statistical data on most of the relevant issues; however in hindsight it would have been beneficial to include one or two set questions, particularly regarding each household's electricity arrangements (i.e. electricity supplier, tariff etc.). The interview script was designed after piloting similar questions on twelve solar hot water households in the Oxford area in October 2004. The pilot study was also beneficial to the conduct of the interviews: the main lesson, which was invaluable when it came time to do transcripts, was to speak slowly and leave sufficient pauses for the respondents to answer.

Respondents were asked on the questionnaire to indicate a convenient time to call and as a result, it was very easy to get in touch with the interviewees. Before calling the interviewee, their questionnaire was reviewed to identify any important topics of conversation. After seeking the interviewee's permission, conversations were recorded for later reviewing and direct quoting. As a backup, notes were taken during each interview using a standardized form. The quotes presented here have been anonymized.

\subsubsection{Interview themes}

The goal of the interviews was to corroborate and provide depth to the questionnaire results. For example, the questionnaire primarily provided information on the purchase behaviour of households (e.g. buying more CFL light 
bulbs post-PV). The interviews however could describe use behaviours in greater detail, such as why there might have been changes to the overall demand for energy services or to the timing of use. Similarly longer discussions could be had about how monitoring devices were incorporated into the daily life of a PV household.

The interviews also began to address some of the socio-technical issues surrounding PV. For example, the installation process was discussed to understand how PV and the monitors came to be installed in the home. The interactions of households with other stakeholders, such as electricity suppliers and peer groups, were also considered. This helps to address key questions such as the role of microgeneration tariffs in shaping energy consumption and the potential pathways for the diffusion of both PV itself and any corresponding behavioural changes.

Therefore, following a brief warm-up section to relax the participants, the interview script explored four themes better suited to qualitative data collection:

- motivations for the purchase of PV and how these may have created a predisposition toward certain behavioural changes;

- the day-to-day use of PV and the resulting energy consumption;

- details on the use of monitors and increased energy awareness;

- interactions with peer and industry groups.

\subsection{Purchasing PV}

At the time of the interviews, the installed cost of an average PV system (2.07 $\mathrm{kW}_{\mathrm{p}}$ ) was approximately $£ 15,000$ (EST 2003b). Even with a government grant of $50 \%$, this is equivalent to the purchase of a small car, taking a luxury holiday, 
or even cosmetic surgery, as this chapter's epigraph suggests. Such an expensive purchase is unlikely to be taken without some assessment of the costs and benefits of PV. However at current electricity prices, a PV system may not pay for itself in less than 50 years (\$5.5.3). This suggests that there must be more to the purchase decision than economic rationality.

The interviews began by exploring these issues, asking respondents how they first heard of photovoltaic technology and what were the motivations and circumstances surrounding the purchase decision. As well, previous energysaving measures were discussed to place the PV purchase decision in context. Identifying these factors helps to assess the potential drivers of subsequent behavioural responses to PV and provide lessons for the wider diffusion of the technology.

\subsubsection{Becoming aware of PV technology}

Since the introduction of the modern solar cell in 1954, photovoltaics have primarily been a niche technology used in satellites and remote power applications. Occasionally some of these uses may attract the media's attention (e.g. solar car racing) but PV is generally not a technology encountered in daily life. Therefore if the technology is to be adopted, consumers must first become aware of its existence.

The media frequently provides the public with an introduction to innovative technologies but the impact of such news items will depend upon the medium itself (e.g. newspaper or radio) as well as the actual message. For example, PV households indicated that their initial awareness of PV often came through speciality media outlets. These publications, such as the New Scientist, RSPB bulletins or special television broadcasts on renewable energy and climate change, had the potential for a greater impact as these respondents had an affinity for 
the types of messages typically published through these channels. In a similar manner, though less common, some respondents indicated that friends or family knew of their interest in energy and environment issues and passed along PV-related advertisements or articles.

Initial awareness can also come from professional experience and some respondents indicated that their careers as energy consultants, environmental advisers, physicists or engineers provided the first point of contact with PV. These individuals then followed the technology over the years until they felt that the technology was sufficiently affordable and mature to consider a purchase. However, as this mechanism applies primarily to those with high levels of existing knowledge, it seems that professional experience is unlikely to be a significant contributor to the diffusion of PV amongst the general public.

An awareness of PV reflects a level of tacit knowledge but this can be enhanced by personal experience. Specifically, interacting with PV technology provides what Rogers (2003) calls 'trialability', allowing potential adopters to allay their fears about the technology. This is especially important for high-cost technologies such as PV. In some cases, this experience was gained through travel to PV regions such as Australia, Germany or the Pyrenees. For others though, personal experience was closely linked to the initial point of introduction:

"It was in our local paper that the Daventry Council were giving an exhibition of these things - we've always been ecologically-minded you know and it sounded like a good idea. So we went along and they had the photovoltaic [sic] and the solar heating."

- K. G.

Whether it came from visiting the showroom of a solar photovoltaic installer, attending an exhibition, or using the internet for research, this further information seems to have been actively sought out. It could therefore be ar- 
gued that the respondents were assessing their self-efficacy, learning about the specific costs and benefits of PV to see if they could become PV households. Conveniently, this process was assisted by a degree of cooperation between the sources of information and technology suppliers. For example, the RSPB promoted PV via its website and newsletter, emphasizing those benefits most appropriate to its audience; e.g. benefits to birds, the general environment or most notably, as a way of 'doing your bit' (RSPB 2004). They then provided a direct link to a recommended PV installer, making the adoption process easier.

The interviews therefore found that tacit knowledge about PV, and the confidence to take an adoption decision, were built in two stages: an initial awareness and more detailed information from personal experience. A similar finding was also seen in research on PV in Austria (BMWV 1998).

\subsubsection{Possible purchase motivations}

Once aware of PV, households must decide whether or not they wish to purchase the technology for their home. The motivations for this decision have implications for the diffusion of PV technology to other households but more importantly, they may also be the same motivations that encourage more sustainable use of electricity after the purchase of PV. For example, a survey of early PV adopters found that $56 \%$ of respondents were motivated by both the environment and saving money and $40 \%$ by environment alone; only $2.5 \%$ of respondents purchased PV purely to save money (EST 2004).

Environmental concern, specifically about climate change, is an obvious motivation for the purchase of PV. As indicated by the questionnaire, the respondents had a good level of understanding about the climate change problem and its link to energy consumption. Furthermore their values and worldview suggested that respondents felt they must take action on these issues. This sense of 
obligation was also seen in the interviews and it appeared to be underpinned by family values and personal responsibility. Specifically, there was a multigenerational aspect to this family concern (e.g. Page 1999). Some respondents indicated that they were raised in an environmentally-responsible manner (or in a manner compatible with environmental goals, e.g. sufficiency or frugality) and this had shaped their current lifestyle. Like their parents before them, concern for the family's future can then lead to action:

"I always have known that the world is in problems, and our children, grandkids are going to be in problems and I've got to do something here because most people are not doing anything."

- R. S.

This respondent shows an element of responsibility, accepting that individual lifestyle choices have an impact on the collective environment. Many saw this as a strong element of their decision to purchase PV, viewing it as a way to compensate for other lifestyle elements that were difficult or undesirable to change:

"We've always been environmentally-concerned and so we thought you know 'Okay, like everybody else we use cars and we use planes so what can we do to help?' So when we heard that this sort of system was available... that was in a way, an easy way to compensate for being modern, wanting to use electricity and cars."

$-D . P$.

One respondent felt that this responsibility also extended to the diffusion of PV:

"[My PV investment] is very much an environmental statement but it's also to kick-start an industry because you've got to have the early adopters who, like with VCRs and DVDs, I mean you'd buy a DVD for $£ 25$ now, go back two years and it was two hundred and fifty. So you need those people buying it at two hundred and fifty for the price to come down, in the same way with things like solar." 
Although the economics of PV are not immediately favourable, financial benefits are still an important part of the decision to purchase PV. With the grant providing assistance on the capital costs, many were attracted to the long-term savings that PV might deliver. As some respondents pointed out, this emphasis on running costs meant that investing in PV was "like having a little bit better pension" (M.B.) or investing in a building society (M.A.). Of course, most respondents were aware that PV was not an economically-rational decision and avoided any explicit cost-benefit analysis:

"It would be nice [to pay off the capital costs] but I suspect, in all honesty, that could take 20 to 30 years with the amount of money we've spent on the various things that we've done so I'm not actually going to do that calculation because it will just upset me! (laughter) "

$-N . L$.

The financial arguments for PV are complicated by the uncertainty of electricity prices over the 20 to 30 year system life. Many respondents felt that prices would inevitably rise (citing the increasing scarcity of generating fuels) and therefore photovoltaics could provide a degree of self-sufficiency. While selfsufficiency is an important part of owning a PV system (Dobbyn and Thomas 2005), PV did not provide the level of independence that many expected:

"One of my friends was interested until I told her 'well no if we have an electricity cut [the PV] doesn't work either'. ${ }^{1}$ I said the only way you get solar energy that can be used when we have an electricity cut is if you have lots and lots and lots of batteries and I said it doesn't work like that. I said if we have an electricity cut then, of course, obviously we're not producing any electricity from the solar panels so they backed away. So they were hoping I think that it would be a fallback situation but it's not of course."

$-G . M$.

\footnotetext{
${ }^{1}$ In the event of a power cut, a trip switch shuts off the system so that there is no risk of electrocution from PV-supplied electricity when a service person comes out to work on the line.
} 
Environmental concern was a core element of the decision to purchase PV. While this is by no means surprising - many respondents indicated one would hardly spend all that money to get PV if you were not already green - it is evident that environmental concern links with other issues such as family values and responsibility for consumption. Furthermore although the financial arguments for PV are not promising, the interviews have shown that a subtle reinterpretation of the cost issues allows the high capital cost to be justified on the basis of self-sufficiency and protection from future electricity prices. This alternative interpretation of cost issues may be important for policy makers, not only as an alternative argument to encourage PV diffusion but also to shape behavioural responses to the technology by leveraging the future running costs.

\subsubsection{Catalysts for purchase}

Awareness and motivation may be important pre-requisites for adoption but the high cost of PV still acts as a significant barrier for many people. To overcome this obstacle, the interviews discovered several catalytic factors which facilitated a purchase decision. These included major factors, such as financial aid (both the government grant and personal windfalls) or concurrent renovations, and minor factors, such as suitability of the dwelling to PV.

The primary catalyst for the purchase of PV was the availability of financial aid, specifically the government's 50\% grant. Although most of the households in the survey could be considered wealthy, this financial assistance was widely viewed not simply as a nice bonus but an absolute requirement - as one respondent said, "no grant, no PV" (D.R.). The following quote demonstrates the catalytic effect, showing how the grant allows long-standing motivations to be acted upon: 
"So it was a gradual awareness that finally prompted me and added to which I heard that there was a grant that was probably going to end and I thought 'why shouldn't I have some of that?' "

$-P . R$.

For many respondents however, the grant was still not enough of an incentive and purchasing PV only became feasible after receiving unexpected financial bonuses. For example, families occasionally had legacy or estate monies available when a parent died. More commonly, retirees frequently used their pension lump sum to augment the grant:

"So I thought 'we'll have those' and as luck would have it, I've got a lump sum from a pension fund. So when I turned 50 and I thought, well the government will pay half the price, I'll get the rest of it, get it done and I've not really regretted it ever since."

$-J . W$.

Home situation is another important catalyst for the installation of PV. On a basic level, many households indicated that their homes had the correct orientation for solar energy and while this is verified by the grant process, it still seemed to provide subtle encouragement for some to apply for a grant. The role of concurrent renovations was more significant however and it was estimated that $12 \%$ of all questionnaire respondents installed PV as part of a larger works programme, for example the construction of an extension. The benefit of concurrent renovations was partly convenience, e.g. minimizing disruption from different work crews, but this type of PV installation is often cheaper as well. For example, in the case of roof renovations, integrated PV roof tiles can serve the dual purpose of a roof and a PV system, saving money:

"It's the sort of thing that had we not been building the house from scratch and replacing the roof on an existing building, in truth, I don't think at the moment in terms of price sensitivity we would have done it." 
$-P . P$.

In some situations, this integration was planned. Several respondents indicated that they were building new energy-efficient buildings and PV was an integral part of the design (although there were also extensions which would likely increase the household's overall energy consumption). However as with the financial windfalls, there were cases when unexpected circumstances precipitated a PV purchase:

"Well we had a fire, which burnt off the roof so the whole roof was being replaced. It was made of local slate which isn't mined any more so it's very expensive to replace it - that's what the insurance company allowed for so we could take half of the money for the roof and allocate it to paying for the PV. So we ended up, with that and the grant, we ended up paying only a fraction of what we would normally expect to pay for a $2 \mathrm{~kW}$ system."

This quote is an excellent summary of the role which these catalysts play in PV purchase decisions. Since many of these factors were unexpected, the final purchase of PV was often more of a happy coincidence rather than the realization of a long-standing dream. Correspondingly many households perceived PV as an addition to their current lifestyle and not the definition of a new beginning.

\subsubsection{Existing energy-saving measures}

As indicated on the questionnaire, most of the interviewed households had undertaken a series of energy-efficiency measures before installing PV, such as "double-glazing, insulation in the roof, hot water tanks, energy-saving light bulbs and that sort of stuff" (P.S.). Those who had not taken a full suite of measures were often aware that more could be done but felt limited by cost or the type of housing: 
"I suppose it started with the loft insulation. Unfortunately the house is an old property - 1850s - and it's solid wall so it doesn't have a cavity. I moved onto low energy light bulbs and virtually every bulb in the house is one of those now and just generally trying to reduce energy consumption, to try and save greenhouse reduction. [sic]"

When placing PV in context with these earlier renovations, most households again felt that the purchase of PV was not a significantly different measure, except that it was often "the first major measure" (E.W.) in terms of cost.

\section{Summary}

The adoption of PV requires a number of factors working together, progressing from an initial awareness of the technology to experience with it and then the final purchase decision. Environmental concern was an important prerequisite and appeared to work in tandem with personal responsibility and selfsufficiency motivations. The government grant was invaluable for addressing the financial barriers but was not enough on its own. Specifically, catalytic factors were often required to provide the final 'push' for adoption and may take the form of unexpected renovations or inheritances, making it cheaper or easier to say 'yes' to PV. The implications of these findings for future behavioural responses to PV are uncertain; most PV households have already demonstrated a commitment to energy conservation through investment of energy saving measures and the scope for major future action is limited (\$4.3.3). However the underlying environmental concern, responsibility and self-sufficiency motivations may provide opportunities for changing behaviour. 


\subsection{Changes in energy consumption behaviour}

The questionnaire began exploring the energy consumption behaviour of PV households but the interviews provided an opportunity to gather further details on the nature of any changes in behaviour and their motivation. Specifically respondents were asked about changes in overall levels of energy consumption, shifts in the time of use, as well as the potential for future energy saving measures. The permanence of these changes is also briefly considered.

\subsubsection{Overall savings}

The mail questionnaire suggested an average $8.4 \%$ decrease in overall electricity consumption but this was a self-assessment and respondents were skeptical about their reported saving:

"I think in the questionnaire I think I said 'yes' [use less electricity] rather optimistically, with the view that it makes us more aware of it. I'm not sure we've changed our pattern of living. I'm sort of more conscious in terms of switching lights off a bit more than I might have done..."

To confirm the reported overall electricity saving, households were asked how they assessed their changes in energy use (e.g. Kempton and Layne 1994). For most respondents, energy bills were the primary source of information with one respondent, for example, indicating a saving because her monthly standing order had been reduced. However energy bills present both financial $(£)$ and physical (kWh) information on consumption and only the actual kilowatthour consumption can be used to measure a change (although the kWh reading is typically based on an estimate and not an actual reading). A few respondents 
took their own electrical measurements from the meter and determined their total electricity consumption, accounting for the electricity generated in the home as well as imported kilowatt-hours:

"In fact I know [our consumption] has changed. We've got ten years historical detailed annual figures and we were regularly before hand utilizing about $4500 \mathrm{~kW}$ [sic $\mathrm{kWh}$ ] per year, ... since we've got [PV], we've been using about 2600, 2700 a year, which with what we use directly from the PV system would get us up to about 3500, 3600 a year so I think we actually utilize in the house about $15-20 \%$ less." 2

$-G . S$.

Regardless of whether financial or physical measures were used, assessing changes in total energy use were frequently complicated by changing circumstances, for example, in energy using equipment or lifestyle. This is particularly important considering that many people adopted PV using pension lump-sums (i.e. now retired and at home more often) or installed it as part of a building renovation:

“No I don't know [if we've saved electricity] because we have a larger space to heat now and we have central heating that we didn't have before so I'd say is more efficient, but I don't actually know."

$-A . S$.

Interview respondents were asked about the specific actions they had taken that might have saved energy since the closed-format could only only identify some potential sources of saving (e.g. increased use of CFL lighting). As mentioned above, many households purchased PV as a way of offsetting the impacts of their current lifestyle and so it is not surprising that no radical changes were seen. However increases in energy awareness were frequently reported, encouraging households to make small changes such as switching off lights

\footnotetext{
${ }^{2}$ These savings were achieved by switching off unnecessary lights and appliances and by purchasing more efficient equipment.
} 
and appliances stand-by functions. This behaviour often followed an existing dislike for waste of all kinds, although PV did appear to have an additional influence:

"I'll now be thinking whether it's from the sun or not, 'Why have I got that light on?' and I'll be thinking we ought to have more of the cost-effective lights."

Interviewer: "And that thought process was always there but PV made it stronger or...?"

"PV made it stronger I think, which is an irony really because you know we only think, oh well that's technically being run free, that bulb, but you still think well, that electricity could be used for something more useful too, you know, more efficient to keep my food cold or something."

-P. R.

The results suggest that the estimated $8 \%$ electricity saving is approximately correct since, in addition to the CFL changes noted in the questionnaire, most households experienced increased energy awareness and paid more attention to where and when energy was being consumed. At least two respondents combined this increased awareness with additional investment in energy efficiency to give measured savings of more than $20 \%$. The case of D.E. is a good example and a full transcript of his interview can be found in Appendix B. Mr. E., a GCSE-educated pensioner from Essex, scored highly on the questionnaire for environmental knowledge and values and strongly identified with the home-energy saver identity. Mr. E. was very certain that he had achieved a $50 \%$ savings in electricity demand by unplugging an inefficient freezer, getting double-glazing installed ${ }^{3}$ as well as switching off unused lighting and stand-by functions. He also switched water and space heating to gas where possible (e.g. when making his tea) to reduce his electricity demand. Ultimately his electric-

\footnotetext{
${ }^{3} \mathrm{He}$ had also been recently burgled and wanted more secure windows.
} 
ity demand was reduced to less than $1300 \mathrm{kWh}$ per year (almost less than the output of his $1.44 \mathrm{~kW}_{\mathrm{p}}$ PV system).

The catalyst for this change appeared to be his Eclipse monitoring device, which shows both consumption and generation information on a comparable time scale. By his own admission, Mr. E. did not have a high level of energy awareness before the installation of PV. In contrast, another household with this same monitor (an energy consultant) reported no increase in awareness of energy generation or consumption and reported no saving since "the house is as efficient as we can get it and you know, still live a normal life" (M.F.).

These cases suggest that the earlier saving and no saving groups can be further divided as described in Table 4.1. Most notably, the revision indicates that those with the largest reductions in electricity use experienced a marked increase in their awareness of electricity generation and consumption and took appropriate action, perhaps facilitated by the fact they live in one-person households and could do as they pleased. This is supported by a number of households who indicated that they were unable to take further energy savings, despite increased energy awareness, due to family commitments:

"Members of the family don't particularly like the quality of light given by energy-saving bulbs so we have a number of them around which tend to be the lights that are on longer term and the lights that are on shorter term are more conventional bulbs... when we buy new [appliances] we go for energy-saving ones although my wife is from the other side of the Atlantic and so when we had a washing machine and dishwasher, they are North American ones and not particularly energy or water efficient."

$-P . F$.

While the efficiency gains resulting from the purchase of new lights and appliances are fairly permanent, it is difficult to tell whether or not the increases in awareness and their subsequent behaviours will become habitual (e.g. turning 
No saving

- No saving or an increase in electricity consumption

- 36 interviewees, a mix of age and income categories, largely two-person households

- $4.3 \%$ more CFLs, no change to appliance ownership, some improvements to insulation and double-glazing

- No increase in awareness of electricity generation or consumption

- Sample quote: "No I've tried not to [change the overall amount of energy used] really, I've just tried to carry on as normal ... I mean I was always very careful anyway, I didn't need to be educated on that score." - K.D.

\section{Small saving}

- Average self-assessed saving of $-9 \%$ (weighted by certainty)

- 22 interviewees, mainly families (i.e. >2 occupants) with high incomes

- $13.6 \%$ more CFLs, some improvements in appliance efficiency, some improvements to insulation and double-glazing

- Slight increase in awareness of electricity generation and consumption

- Sample quote: "I think we've probably been a bit more sensitive to when to consume and probably a little more disciplined with general little things like leaving lights on in unoccupied rooms and things like that, yeah, we're just a little more aware."' - M. N.

\section{Large saving}

- Average self-assessed saving of $-35 \%$ (weighted by certainty)

- 5 interviewees, mainly low-income single-occupant retired households

- $24 \%$ more CFLs, some changes in appliance ownership, some improvements to double-glazing and draught-proofing

- Notable increase in awareness of electricity generation and consumption

- Sample quote: "The panels themselves have led to a lot of further energy measures saving because it's made me particularly, much more aware of how much energy I was using." - D. E.

TABLE 4.1: Revised electricity saving groups 
off superfluous lights and stand-by functions). In other words, the long-term benefit of these responses to PV will depend in part on how households respond to monitoring devices over time (\$4.4.3). However the savings arising from PV may also need to be assessed against a continually rising consumption baseline:

"Our energy consumption has actually gone up since we had the solar panels put in and I think that's coincidental, but it's things like my daughter now has a computer of her own... we did get digital television with a set-top box after we got the solar panels and that's obviously on most of the time... These days, everything seems to be rechargeable so we've got so many things on chargers around the house that we didn't use to have and it's just - I think modern lifestyle's moved on quite rapidly in terms of energy use so I think overall we're actually using more energy but I'm reasonably reassured that not as much as we would have been without the solar panels."

$-D . S$.

\subsubsection{Time-of-use changes}

Electricity consumption behaviour encompasses not only the overall quantity consumed but also the time at which it is used. This behavioural response was not covered in the questionnaire and therefore the interviews placed special attention on how the patterns of use may have been been affected by the installation of PV. Although there were very few large changes in the overall amounts of electricity consumed, approximately $43 \%$ of interview respondents described changes in the time at which they used electricity.

The reported time-of-use changes primarily involved shifting large loads, such as the dishwasher or washing machine since other electrical services were required on demand (e.g. lighting). The changes were also easy to implement; there was no cost and lifestyle is not notably affected (i.e. the clothes are still clean, it is a question of timing and convenience): 
“... like today, it's a lovely sunny day so I'll use the washing machine now because I know that it'll be on solar energy, and if I was going to do any baking, I tend to wait until it's a sunny day and then do enough baking to last me for a bit."

However there were some barriers to implementing load-shifting. Most of the respondents who indicated changes in time-of-use were either at home during the day (e.g. retired, work at home, with young children) or had timing devices that would facilitate these changes. As the following quote demonstrates, this behaviour was not an option for some:

"No [time-of-use changes] because I work so I'm out of the house during the day anyway and I've always had a white meter which means that I do things like the dishwasher, washing machine, things like that, at the low rate overnight."

This quote alludes to peak/off-peak electricity tariffs (e.g. Economy 7). With such a tariff, households often shift electric loads strategically to take advantage of cheap nighttime electricity (notably for storage heaters). Approximately $24 \%$ of the interview respondents were on Economy 7-style tariffs and interestingly this familiarity with load-shifting seems to have encouraged similar strategic energy use in response to the generation of the PV system. For example, some households indicated that they had the timers needed to use their appliances when PV was generating even if they were not at home. However others did not switch because they were used to doing everything at night by routine.

Load-shifting experience was also found in households with solar thermal systems. ${ }^{4}$ Through both the pilot interviews (conducted with solar thermal households) and these interviews, it became clear that load shifting was a behaviour common to both solar thermal and PV. However the strategies behind

\footnotetext{
${ }^{4}$ The questionnaire found that $40 \%$ of PV households had solar thermal systems as well.
} 
each behaviour were slightly different. In the case of hot water, households must manage a limited resource, assisted by some storage capacity. However for $\mathrm{PV}$, the consequences of using more electricity than what is being generated are less serious because additional electricity from the grid was readily available:

"No [time-of-use changes] because the PV, I mean, you don't know where the energy is. It's not like the hot water which runs out, you know you've run out of hot water, you've got to do something. You switch on the switch [with electricity] and it still comes whether you do it or not. The economics of this strange way of charging where you get paid whether you use it or whether you pump the thing into, I don't know quite what I should do as an optimum strategy there..."

$-N . R$.

The quote indicates that if time-shifting behaviours are strategic in nature, households may need guidance to determine what is the most efficient use of their PV resource. Electricity tariffs for import, export, or generation are clearly part of these considerations and these issues will be discussed in more detail in Chapter 5 . However the signals sent by such tariffs will need to account for variations in system performance, not only during the day but also across seasons:

"It changes in the summer in that when I know that the PV is generating, I will put something like the washing machine or dishwasher on in the middle of the day when I know it will run on that, whereas in the winter, because we've got Economy 7, I run them on the nightrate, because obviously at this time of year there's not enough from the PV to run the washing machine in the day."

$-M . B$.

The permanence of these changes is uncertain. On the one hand, the decreasing novelty of the monitoring devices (§4.4.2) suggests that, unless supported 
by tariff incentives, electricity consumption may shift back to the most convenient times. However on the other hand, the initial use of monitors may have established lasting habits (e.g. using major appliances when the sun is out).

\subsubsection{Future energy savings}

The final component of the response to PV was determining what future actions these households might take and whether or not PV made these changes more likely. This is particularly important as certain actions, such as the replacement of appliances, occur on longer time scales and therefore may not yet have happened at the time of the questionnaire. The interviews investigated the scope for future energy savings, the types of measures that might happen and the facilitating circumstances.

To begin, the scope for future action is somewhat limited as most PV households had already installed many standard energy-saving measures. There were some options available though and as indicated on the questionnaire, the most popular future energy saving measures included more efficient appliances, CFL lighting or microgeneration capacity. Generation measures were especially popular as households learned to recognize the characteristics of PV generation and tried to figure out how to complement its generation, both in terms of overall quantity and time of delivery (e.g. §4.4.3). This can be limited however by the availability of suitable technologies (in the case of micro-CHP), roof space (where PV has taken up the entire roof area), or other factors (like planning issues in the case of micro-wind).

Households that felt further improvements to their home could not be made (e.g. because of the age of the building) indicated that they would reinvestigate energy-saving options (e.g. to improve insulation) and ensure that new lighting and appliances were as efficient as possible, money and circumstances permit- 
ting. In the short term, those who truly believed that they could not do more to improve the energy-efficiency of their home may switch their attention to other environmental issues:

Interviewer: "Is there something next on that list of [energy saving improvements]?"

"Not in terms of that. I'm more moving into waste recycling and things now, looking at how I can be more efficient that way."

This is an important finding especially when considering the role of PV as an offset for current lifestyle. In other words, if there are no more easy energy savings to be made without harming their lifestyle, households may seek other areas of environmentally-responsible behaviour. For example, one respondent indicated that he could not make further savings himself but by investing in renewable energy firms, he was still able to make a contribution to climate savings. Overall though, it seems that these other actions are encouraged by PV as part of a consistent environmental lifestyle:

"I suppose my main area of conflict is do I use the car or do I use my bike... I live such a busy life, I certainly use the car more than I would really like. ... When I do use [the bike] I always feel ever so healthy and good, but there are certainly times when I use the car but I shouldn't, that I should really get on my bike..."

Interviewer: "So then does having the PV, does that change the way you might make that decision?"

"Yes it makes me feel extra guilty if I use the car when I know I shouldn't."

$$
-F . A \text {. }
$$

As a side note, there might be an expectation that having spent a large amount of money investing in the energy efficiency of their homes, the respondents would be reluctant to act further given the profligate use of energy else- 
where in society. However their personal commitment to an environmentallyresponsible lifestyle means that they might not resent being asked to do more and were limited only by money and circumstance:

"When you go past all these offices with all their lights on and all their computers blaring away I think why am I wasting my time? I'm trying to do my tiny tiny little bit (laughter)"

Interviewer: "So if the government or your electricity supplier came to you and said 'we'd like you to take a further energy-saving step in your home', what would be your reaction to that?"

"Well it would depend on what it is and it depends on whether I can afford it, if the answer is, if what it is is okay and if I can afford, yes, then yes yes I would do."

$-G . M$.

\section{Summary}

These interviews have confirmed that PV did stimulate a limited behavioural response in purchasing households. For most respondents, PV did not significantly change the overall amount of energy used in the home as there was a desire to maintain an existing quality of life as well as financial or situational limitations. However a select few have identified major areas of potential savings and acted, driven by an increased awareness of energy consumption. Timeof-use changes were much more common with households switching loads to sunny periods to take advantage of 'their' electricity, although this response was limited by household situation (i.e. was someone home or were timers available to use appliances at different times?) and encouraged by similar loadshifting experiences in the past (e.g. solar hot water or Economy-7 metering). Finally if these households truly did feel that they had achieved all that they could in energy savings, evidence was found that they may explore other areas of environmental concern such as transport, waste issues, or ethical investing. 


\subsection{The impact of monitoring devices}

Increased awareness of electricity generation and consumption was one of the biggest changes respondents noted since acquiring PV. While this awareness could have been raised at several stages in the PV life cycle, for example by information provided by installers when purchasing a system, the most likely influence is the monitoring devices which were found to be installed in $86 \%$ of respondents' homes. The questionnaire revealed some of the basic use patterns of these devices and the interviews elaborate on this theme.

\subsubsection{Acquiring the device}

When purchasing a new PV system from Solar Century, a Variwatt generation meter was automatically fitted as a minimum requirement of the Major PV Demonstration grant programme. However the programme also provided an allowance of $£ 150$ for the installation of a monitoring device in a visible location within the home, a feature the EST considered "good practice". A range of devices are available and it is up to the installer and purchaser to agree on a specific unit. Typically customers got the $£ 200$ Leiderdorp LI-12 but those wishing to have more sophisticated devices could pay up to $£ 800$ for an Eclipse monitor. The interviews suggested that these monitoring devices were not initially perceived as an important part of the purchase decision and so the various options were not given much thought. As a result, most respondents went along with Solar Century's recommendation of a Leiderdorp monitor and often found that the device was more valuable than they had initially anticipated:

“Well I probably wouldn't even have thought of [getting a monitoring device] though I must say, once I was given one, it made the whole thing so much more fun and I show it to my neighbours - obviously nobody's going to make a decision from that point, because 
of that, but I do think it's a very valuable add-on which indeed I told Solar Century."

$$
- \text { R. D. }
$$

As the following quote shows, some respondents preferred to take their own measurements and opted out of the Leiderdorp, indicating that the basic Variwatt was sufficient. However one of the households with a Variwatt indicated that, although they still would not get a display monitor if they were to purchase PV again, acquiring a monitor might be useful if the house was later sold to someone without a good understanding of PV technology.

"I thought about monitoring and I thought well any monitoring device has got to be using the energy in the first place and really the point of the exercise is to cut down how much we use. I mean there is a simple meter on it, I know how much it generates and how much we export to the grid... that's enough for me really."

D. E. was presented above as one of the key energy saving households. Mr. E. had an Eclipse monitor, a device which prominently displays both generation and consumption information as well as a 'solar fraction' comparison metric. In retrospect, Mr. E. appeared to undervalue the device indicating that his significant savings might have occurred even if he had only owned a Variwatt meter. However such a meter does not show consumption information and when asked about this, he indicated that perhaps the Eclipse monitor had increased his awareness, making it possible for him to now use a Variwatt only. Again the full transcript is available in Appendix B but these summary quotes give an example of this contradiction.

“But really you don't need [an Eclipse monitor], just a Variwatt is sufficient actually really. Because you have got an import and export meter and if you really want to know the figures you can sort of look at that and add up... 
Later: ... all the little finer points, I wouldn't have probably picked up from the Variwatt but you do pick it up from the Eclipse meter."

$-D . E$.

Since the average PV system cost about $£ 7,500$ at the time of the interviews (including the grant), it is understandable that a $£ 200$ display monitor was a minor concern. Fortunately the terms of the grant and the practice of Solar Century encouraged the widespread installation of these devices. Since many households later came to appreciate the value of their monitor, such devices should be considered as a requirement of future PV installations (i.e. in addition to the Variwatt generation meter).

\subsubsection{Observation patterns}

When asked about the installation of the display monitor, one respondent noted "the option was where are we going to fit it" (L.S.). As shown in the questionnaire, the location of the monitoring device is very important and determined how frequently the device was viewed. For example, the Leiderdorp was commonly found in high traffic areas, whereas the Variwatt was more likely to be in a meter cupboard or other remote location. The respondents confirmed the Leiderdorp's suitability for high-traffic areas during the interviews, describing it as "a useful little device" (P.R.) and "fairly discrete" (L.S.). It even became part of one family's Christmas celebrations. The most frequently observed metrics were cumulative generated kilowatt-hours and instantaneous generated kilowatts. Instantaneous measures seemed to have two primary uses. First high system output was used as a signal for turning on appliances as part of the time-of-use behavioural changes described above. After some experience, households indicated that they were able to make these decisions based simply on the weather outside; that is, by looking at the monitor they developed 
a feel for how generation would vary with different cloud and brightness conditions. Viewing this instantaneous measure also appeared to create a sense of satisfaction as well:

“There's a nice kudos feeling because when you notice that you're producing a couple of kilowatts, you feel good. You think to yourself 'oh, I'm doing well today, it's exporting some, I'm doing okay' and I suppose it does make you feel good, yes."

$-M . B$.

The second major use of instantaneous data was to monitor the system's performance and verify that it is working properly. This was particularly important to those who had technical problems with trip switches or other safety devices that occasionally turn off the system's generation (a common problem, see Pearsall 2005). By checking the instantaneous output, households could quickly confirm that the system was functioning as expected. Interestingly most respondents indicated that they checked instantaneous output less frequently as time passed since the installation of PV, but those who experienced technical issues increased the frequency at which they checked their monitors. This applies to a minority of respondents and probably once the system performed smoothly for an extended period of time, their viewing frequency would also decrease:

"I look at it more often then I did because there were a couple of occasions when something must have tripped a switch so whatever was being generated didn't go through into the system, and so I do look at it more often now, so one occasion last year, one of the better months was completely lost as a result."

$-D . B$.

Evaluating the system's performance also requires a cumulative assessment. These measures of total generation were used by many households to ver- 
ify Solar Century's estimate of the system's annual output. Cumulative measures were also requested by electricity supply firms as part of generation incentive schemes. For many households, this began by taking part in a joint NPower/Solar Century pilot scheme to study micro-generating households. Participating households had to record their monthly generation on a card and return it to NPower for reimbursement; since the end of the pilot scheme measurements need only be reported to NPower every six months. Interestingly though, this programme developed a monitoring habit for many:

"Well the information was first for Juice, the NPower company that I've signed up with and for Juice, they wanted these figures for one year so that they can monitor and see and I've just kept it up basically."

- R.S.

It was initially hypothesized that some metrics might leverage specific motivations and behaviour. For example, a monitor showing consumption in pounds and pence might remind frugal individuals of the cost of consumption. The carbon-dioxide savings shown by the Leiderdorp are an example of such a measurement but it appears that this metric was perhaps too abstract for daily use by the household, although it may have played a social role in demonstrating the system's environmental benefits to others:

"I don't really take much notice of the carbon dioxide unless I'm boasting to somebody."

$-M . B$.

Many households implied that the appeal of the monitoring device lay in its novelty, referring to it as a "gizmo" or a "toy". This suggests that the viewing patterns of monitoring devices, in particular how closely the daily fluctuations in output are followed, may change as households become accustomed to the 
device's presence. Therefore for behavioural responses to PV, the best opportunity to establish new behaviours is perhaps following the initial installation of the device; otherwise some form of reinforcement (e.g. an electricity tariff) may be necessary to maintain household interest.

\subsubsection{Building energy awareness}

Respondents who indicated that PV led them to change the time at which certain appliances were used often spoke of a link between observing the monitoring device and the change in behaviour. In other words, increased awareness of generation seems to have raised questions about the corresponding consumption. The interviews explored this issue in an attempt to understand exactly how tacit knowledge was increased by owning PV and how this might impact future behaviour (e.g. through self-efficacy). Both technical and conceptual energy awareness are considered, with a focus on the role of monitoring technology.

Technical awareness describes knowledge about electricity, where it comes from, how it is generated and consumed. Increases in generation awareness were common amongst respondents, undoubtedly influenced by the high ownership of monitoring devices that display generation information. As an example, households gained an appreciation for the solar resource in the UK leading some individuals to try and dispel the stereotypes about the UK's poor suitability to PV (see $\S 4.5 .2)$.

Despite these improvements in generation awareness, there was still some confusion over where the electricity goes when not being used in the household. Monitoring devices provide no direct assistance on this matter though some respondents indicated that Solar Century provided some information at the time of the installation. Since strategic behaviours, such as changes in the 
timing of electricity demand, were seen to be related to an understanding of how PV-generated electricity is used, extra effort should be made to ensure that the issue is clear to all PV households:

"I guess if you are over-generating and you're not using at the moment... I don't know what happens to it to be honest, whether my neighbours get some free electricity or not, I don't know how the system works."

$-S . M$.

Installing additional generation capacity was the most likely future energy saving action from the questionnaire and this seems to have been motivated by an increased awareness of generation issues. For example, in the interviews, several respondents described investigating battery back-ups once they had become aware of PV's limitation as a generating technology (due to the black-out and self-sufficiency issue). Most interestingly, some respondents noted that additional generation capacity could improve the coordination of supply and demand. This awareness appeared to come from the monitoring devices as they demonstrate the variations in system output throughout the day and across seasons:

"... and the second thing that has been brought home to me, I must say, is that this form of solar energy, perhaps unlike wind energy, doesn't operate at the times when in a sense you need it most, which is when it's dark or when it's winter. So it's a problem I mean if you're going to put in a whole mix of renewables to replace everything else, this sort of solar energy won't do the trick by itself."

$-J . R$.

Explicit information on electricity consumption was only present on the most elaborate monitoring device. However the quote demonstrates that the direct generation information provided by monitors can indirectly increased 
awareness of consumption. Two households, for example, were inspired by their generation monitors to purchase third-party consumption monitors, allowing them to observe the consumption of different appliances and identify inefficient models for replacement. Another household took regular readings of their import meter to estimate consumption. In other words, the feedback from monitors and the experience of living with PV were seen to build energy-related tacit knowledge that can be used to understand domestic energy issues and set the stage for further action.

Perhaps one of the explanations for these changes in awareness is that PV triggers a shift in how households conceptualize electricity. As one respondent indicated, being "conscious of the fact that it's our electricity" (P.G.) led to more careful use of electricity (in this case, turning off lights more frequently and frequent manual monitoring of consumption). If PV helps households recognize that electricity is not just "something that comes through a wire ... it's got to come from somewhere" (S.M.), then perhaps incentives could be put in place to take advantage of this and encourage responsible uses of the electricity.

This effect might have been created by the monitor acting as a visual symbol of the PV panels, reminding households of their commitment to responsible energy use. Indeed the interviews suggested that the monitoring devices provided "the only evidence" that PV was on the roof generating electricity (M.N.). If this is the case, then the benefit might extend to others viewing the monitor:

"Funnily enough [the PV] does [increase energy awareness], the only reason being that whilst it's up on the roof and out of sight, the actual meter becomes sort of like a focal point in the house. Everybody likes to see how much energy we're generating and consequently you can see visually how many kilowatts are being produced from the roof ..."

$-N . L$. 
While sensitivity to the monitor may have been the result of one's own interest in the system, the industry also appeared to play a role in building this awareness; again this could be an example of good practice for future PV installations:

"The guy that installed it said to me 'you will find that you will suddenly become far more conscious of leaving lights on', and doing this and doing that and so on and he was right."

\section{Summary}

Modern PV installations typically include the offer of a monitoring device. Most respondents did not give the choice of device much thought but still ended up with a portable display monitor. This effective unit was typically kept in an accessible location, allowing frequent viewing as necessitated by curiosity or the requirements of one's electricity arrangement; however there was evidence to suggest that "the novelty will wear off in due course" (N.L.) and therefore monitors may be most effective when first installed (i.e. by establishing new habits) or if coupled with continuing reinforcement (e.g. tariffs, §5.5).

The devices provided primarily generation information, boosting awareness of micro-generation issues (e.g. the timing of generation) but also subtly increasing consumption awareness. For some though, PV made very little difference to their energy awareness as it appears that these individuals believed themselves to be highly aware in the first place (e.g. engineers, electricians). In other words, lay-people often had room to learn by correcting "unknown unknowns - the ones we don't know we don't know" (Rumsfeld quoted by Shanker 2002). The difficulty is to assess how these change in awareness shape the mental models which guide behaviour (e.g. Kempton 1987). However these 
results suggest that the benefit of tacit knowledge is strongly linked with selfefficacy; that is, behaviour is more likely to be the result of one's perceived knowledge and ability than some absolute level of tacit knowledge.

After an initial period of self-learning, monitors may take on a symbolic role by providing a visual reminder to households about the unique nature of electricity supply within their homes and their commitment to an environmentallyresponsible lifestyle. This effect could help maintain load-shifting and conserving behaviours, perhaps through matching behaviours. This was seen in the case of one respondent, who after owning PV for five years, replaced his refrigerator with a more efficient model; an inefficient model would clash with his "ecologically-minded" lifestyle (G.S.). Although the time scale of this research meant that long-term changes could not be observed directly, it seems likely that for the households surveyed here, with their deep-seated environmental values reinforced by the monitors, efficient appliances and other energy-saving actions will be likely to occur in the future.

\subsection{Social and industry connections}

The respondents of this research chose to install PV for unique personal values and priorities. However for ownership of the technology to grow in the long term, a supportive industry and positive peer reactions will be necessary to encourage wider appeal. In other words, to move along the diffusion curve (Rogers 2003) from 'innovators' to larger categories, consideration needs to be given to the social networks by which PV might be diffused and the barriers encountered thus far within the industry sector. This section is divided into two themes. The first two points of discussion examine the social impact of PV, including how peer groups have reacted to the system and how PV households have shared their experiences within their communities. The second ma- 
jor theme covers the role of industry, in particular the installation industry and the metering sector.

\subsubsection{Peer reaction}

Unlike other renewable energy technologies such as wind, PV has relatively few public externalities. There is no noise from the system and visual intrusion is limited to installations on pitched roofs facing the street. The major disadvantage, cost, is borne by the households alone. It is perhaps unsurprising then that most interview respondents indicated that friends, family and neighbours were largely supportive of the technology.

The response from neighbours was very positive and many expressed a keen interest in the system and how it works. However when it came to considering a purchase, "they ask what the initial outlay is and... they glaze over" (M. B.). In other words, the capital cost was a major barrier and some respondents suggested that if PV paid for itself within ten years or so, it might be easier for the general public to justify a purchase. Many respondents however believed that their neighbours were able to afford such a system but preferred to spend their money on other things such as a new swimming pool, a new car or travel. This suggests that PV might diffuse more widely if it was perceived as a status symbol.

Although some PV households were told by their neighbours that they "were nuts" because of the poor economics of the purchase decision, this reaction did not bother the respondents because social recognition was not a highly prioritized value (\$3.2.2) and they were aware of the long payback (Table 3.43). The future diffusion of PV is likely to be affected by this neighbour-neighbour interaction though and while the respondent households were careful not to "go pushing our ideas down other people's throats, ... not shouting from the 
rooftops what a wonderful system it is" (P. G.), the following quote shows that PV might create a guilt motivation in others:

"Well when you get into an argument let's say, or a discussion, about saving the planet and then you say well I've got solar PV they'll 'oh!' you know so ... it usually shuts them up on account of the fact that they haven't done anything."

- R. B.

From the questionnaire, $71 \%$ of respondents indicated that they would recommend a system to their friends unconditionally; however $23 \%$ were hesitant because it was too expensive.

Family members and other household occupants are the other major peer group. The PV purchase decision was frequently taken not by the entire family but by the household head. As a result, the reaction to the technology may have been different for those in the household that did not share the purchase motivations. For example, respondents suggested that their children were largely disinterested in the PV system although this depended on the child's age and personality. Some children were too young to have become responsible for their energy use around the home. Similarly teenagers may be seeking their independence and not share their parents' environmental concern and use patterns. The interviews therefore suggested that children between these ages (e.g. 7 to 12) were more eager to learn about the new technology, for example, using PV as a focus for school projects. Again the monitoring device, combined with parental guidance, may have provided a tangible demonstration of the importance of responsible energy use:

"[The monitor $]^{5}$ has certainly made the family more aware of our consumption, only because I point it out to them and I get my son,

\footnotetext{
${ }^{5}$ This respondent's monitor shows both consumption and generation information, as well as a comparison metric.
} 
whose twelve, he's started turning his TV off when's it on standby, before we left them all on."

The reaction of spouses also varies. Those who were involved in the purchase decision had similar changes in energy consumption behaviour. However in at least one case, the spouse did not share the same concern for energy-efficiency and so less-efficient new appliances were purchased, despite the conservation interests of one partner. In addition to these differing priorities, other family members often had less technical understanding and consequently PV electricity was used in inefficient ways:

"I have a slight suspicion that my wife thinks that because we generate electricity she can use more without having to pay for it, but I sort of go in the opposite direction and try and economize more but, it sort of cancels itself out I suppose."

$-E . W$.

At the very least however, it appears that PV has stimulated a dialogue about energy issues in the home. A similar effect also applied to visitors to the home who, like some of the family members described here, did not share the purchase motivations and yet by living with a PV system, even briefly, an awareness of domestic energy issues was created.

\subsubsection{Community outreach}

Since PV in the UK is currently in the early stages of diffusion, spreading the technology more widely will require reducing the risk and uncertainty of adoption for potential purchasers (Rogers 2003). The interviews suggested that PV households were very conscious of the barriers to wider adoption and sometimes tried to encourage others to adopt the technology. 
Personal experience with PV was a key driver for these behaviours; for example, having seen the output of a PV system, households could correct myths about the UK's climate among potential adopters. Accordingly many were keen to share this experience with others by encouraging them to visit and inquire about their system, through open days organized independently or with the assistance of the local council. In some cases, these situations were not planned:

"... within two days of the panels actually going on the roof, a lady that I hadn't spoken to, who lives three roads down from me, actually came and knocked on the door one evening and said 'now I need to know all about it please' (laughter) and I think she's actually had panels put on the roof as well... she just wanted to know how to go about it, how sympathetic the local council were ..."

This personal level of contact is most likely in areas with PV households and given the relatively small number of installations, other ways of spreading information are needed. In some cases, PV provided individuals with experience that was relevant to their profession, for example, by advising the building industry on the potential of PV. However the most common way for respondents to reach a wider audience was by writing articles on living with PV for newspapers or magazines; this was particularly common among the 'conservative green' value group (which valued social recognition). One respondent noted however that the level of interest in such articles was disappointing:

"One of the frustrations to me is to know who to go to to try and get more publicity out there from what we've done... I gather that there are various national and county bodies that deal with these kinds of things but I've got very little interest out of them when I've been to them to say 'hey do you want an example, can I do anything about publicizing it?' " 
Many respondents had an interest in the national prospects for PV. At a basic level, respondents were eager to get feedback on the grant programme to find out how many other households had adopted the technology. However regardless of how successful the MDP grant scheme was, these households were quick to see the national potential of PV. Many felt that the government should make PV mandatory in new buildings and one respondent inquired with her member of Parliament but was told it would be too expensive.

"I just hope that with economies of scale the whole thing will become a lot cheaper and far more people will use it, I've already been banging the drum about, I don't understand why it's not in every new build..."

As a side issue, it has been suggested that having PV increases the value of one's home, perhaps an important incentive for encouraging wider adoption. The interviewed households were aware of this argument but responses were largely negative. While many hoped that it would increase the value of their property, one respondent actually had a difficult time selling his PV home. His impression was that PV was not an important feature when compared with location, cost, or other issues. Another individual indicated that even if a potential buyer did notice the PV, it might not be a positive thing:

"I don't feel [PV] actually gives any added value to the house... because I don't think that many people would come around and say 'Oh yeah I must put in a little bit' ...I think you're just as likely, ...probably more likely, to get people who don't understand what they are and think 'oh $\mathrm{my}^{\prime}$, frighten them away a little bit. So I don't think it's an asset so far as increasing the value of the house." 


\subsubsection{Installation issues}

All of the respondents in these interviews were customers of Solar Century. Although this means that the installation experiences were very similar, it still provides a good opportunity to understand how the installation process works and what this means for behavioural responses and diffusion of PV. For example, one of the difficulties in purchasing a PV system is selecting a trustworthy firm to do the work. Interviewees indicated a number of sources of information on PV installations firms including environmental publications, the granting agency's list of accredited firms and word of mouth. However one of the reasons why Solar Century had been chosen was that other firms gave a poor impression:

“... when it came down to it I really didn't have any choice. I used the government's website and identified about three companies that claimed to serve Yorkshire and I think one of them never replied, one of them turned out to be in Wiltshire or somewhere like that, and they found a kind of local agent who ... was supposed to be sending me some further information and never did, and then there was Solar Century who, the way they acted towards me and as far as I'm aware the technology and so on, they've been very good. Fortunately I wasn't discouraged because I seem to have a good supplier but they were effectively the only one."

$-R . D$.

This was a marked contrast to the situation with solar hot water installers. These systems are typically advertised through mail leaflets and respondents reported high-pressure sales tactics with over-specified system designs. In fact one respondent indicated that "halfway through the sales pitch of the salesman, I suggested that he might leave, rather than being thrown out" (S. M.). According to respondents with both solar hot water and PV, the novelty of PV, combined with its technical complexity and cost issues, discouraged this type of 'cowboy' business model. 
Once Solar Century had been selected, nearly every respondent indicated a positive experience and one individual even said that Solar Century was "one of the best companies I've ever dealt with" (D. S). The high level of service included prompt responses to inquiries and courteous and tidy installation crews. However the biggest advantage was Solar Century's proficiency as a project manager, coordinating different elements of the installation so that the customer did not have to worry:

"Solar Century, the company who installed it, they made it very very easy and it would be a pain in the neck if I had to negotiate with all the different agencies and a team of scaffolders and a team of installers..."

Importantly this coordinating role also included planning issues. While most respondents did not require planning permission for their PV systems (except those in conservation areas), local councils were often confused as they had no previous experience with this technology. According to respondents, Solar Century acknowledged that this had been a problem in many installations and so they would often work directly with council officials to provide relevant information and clarify that, in most cases, formal permission was not required.

There were a few complaints about malfunctioning equipment (e.g. inverters overheating due to poor installation location) but these problems were resolved quickly in general. One customer was disappointed that nearly all of the system components were manufactured outside the UK; understandably many materials are manufactured closer to larger PV markets, such as Germany and US, although it is interesting that a Dutch monitoring device (e.g. the Leiderdorp) was installed instead of a competing unit from Wales (the Sunview, EETS 2006). 
The cost of PV and its payback was another notable issue. While many felt that Solar Century dealt with this honestly, indicating that a system would take a very long time to pay back, some indicated that it was difficult to get a straight answer because of the uncertainty regarding tariffs:

"One of the first questions I asked was, oh what's my return on it? And they said oh don't look at it like that, look at it like this, which is you know it will enhance the property, give you greater value to your house and so on, reduce $\mathrm{CO}_{2}$ blah environmental effect. And I thought well that's great but I would just like to know have you done any calculations? No no we don't do that we don't look at it like that ... I think they are trying to avoid it at the moment, yeah that's my view because the payback, they haven't sorted out their scheme for paying for rewarding installations like this."

$-N . B$.

The issues identified here, e.g. coordinating different contractors and assisting with bureaucratic obstacles, are examples of best practice and they helped consumers to have a relatively easy installation experience. This is promising for the further diffusion of PV because, by observing the success of these individuals, peer groups will be more likely to feel that they too can adopt PV.

\subsubsection{Metering and electricity supplier issues}

Although the installation process was fairly smooth overall, there were major problems when trying to coordinate metering and electricity export arrangements. As a microgenerating technology, PV is often sold on the promise of being able to sell excess electricity back to the grid; however the details of these arrangements are still being worked out by industry. While this topic is considered in greater detail in Chapter 6, the consumer's perspective is described here.

One way of paying for PV-generated electricity is for the value of kilowatthours (kWh) exported back to grid; however this requires a separate export me- 
ter. While export meters are readily available on the market, electricity suppliers currently have no obligation to install such a meter. As a result, households that wanted an export meter had to arrange and pay for the device themselves. Respondents reported prices varying from $£ 40$ to $£ 400$ depending on DNO jurisdiction. Even if cost was not an issue, households often had difficulty simply getting someone to agree to do the installation. This was also found during NPower's PV pilot project and one household summarized the situation particularly well:

"If even [NPower] can't get them to do it, what hope do I have?... [PV]'s unusual and why should they do anything for someone who's being unusual?"

$$
-P . F \text {. }
$$

As an alternative to an export-based tariff, other electricity supply companies pay PV installations for generated kilowatt-hours. While one respondent figured that a higher rate for fewer exported units was probably equivalent to a lower rate for more generated units, many felt that these arrangements were unfair. Without metering for exports, these households felt "ripped off" (T.M.) as they paid the capital cost of PV and were helping suppliers meet their renewables obligation without fair compensation. ${ }^{6}$ This complaint was particularly strong since the incentives did not track the rising costs of electricity:

"Well I got a letter saying my cost of using electricity was going to go up, and I phoned them up and said 'well am I going to get more for my electricity that I generate', and they just said well that's a separate system. Really if they're going to put their prices up they need to give my element of what I'm charging that has to go up at the same percentage."

- R. B.

\footnotetext{
${ }^{6}$ As will be shown in Chapter 6, household perceptions of what is fair in the electricity system are not entirely accurate. Many suppliers do not settle the excess electricity in the balancing process or claim the associated Rocs, reducing the value of PV electricity.
} 
Solar Century encouraged many respondents to use a particular supplier and provided assistance with this transition. However for customers not satisfied with this offer, it was very difficult to find an alternative arrangement. This appears to be because the normal points of contact within electricity companies were often unaware of their own firm's micro-generation offers:

"I do know that they have a facility for taking solar power but every time that I take it up with the normal accounting, the normal staff there, they deny it, and the supervisors deny it, but if you take it further up the chain, they say that they do have the facility so they don't really know themselves. You would be put off if you tried to approach them to sign up for taking solar electricity, you would be put off completely by the sales staff to start with, you wouldn't get passed them unless you were very lucky."

$-D . E$.

While many interviewees indicated that they were not expecting generous payments for their electricity, there is clearly some dissatisfaction with the industry's existing microgeneration offers. These difficulties may simply be part of being a technology innovator or early adopter. Making it easy for PV households to get paid for their generation will certainly encourage the diffusion of the technology but until the exact form of the tariffs is revealed, it is difficult to say whether or not these incentives will have any notable influence on occupant behaviour and electricity consumption. The interviews found no evidence of consumers explicitly responding to existing tariff structures.

\section{Summary}

The purchase of PV is an individual decision but its social context, including interactions with industry and peer groups, has important impacts on behavioural responses to PV. Regarding the further diffusion of the technology, most of the respondents appeared to be 'innovators', i.e. purchasing and using PV for 
their own reasons. However there was a subset of respondents who had taken steps to promote PV in the wider community (not necessarily among their immediate peers but often via the media). Reactions from neighbours and families were generally good but the high cost of the technology was a major barrier to further diffusion. The installation experience was also good and customers were pleased with the service of Solar Century, showing some potential best practices for the industry. Unfortunately the novelty of PV meant that metering and tariff structures did not appear to be ready for a large-scale expansion of $\mathrm{PV}$, raising questions about what sorts of tariffs might be introduced in future and how these might shape consumer behaviour.

\section{Conclusion}

The interviews represent the final point of contact with these PV households. When combined with the questionnaire, a clear picture of the households emerges as generally conscientious users of energy. For them, owing PV is part of lifestyle which seeks to minimize their impact on the environment without sacrificing a desired quality of life; there was no evidence that PV was purchased as a status symbol. This confirms the respondents as 'innovators' under a diffusion of innovation framework, with the high levels of tacit knowledge needed to decipher the pros and cons of adopting PV.

The interviews suggest that the $8 \%$ average electricity saving found in the questionnaire is reasonable (similar to the effect of feedback, Darby (2000)) although major changes in consumption were rare. This is partly because PV was installed after a number of other energy-saving measures, thus limiting the potential for significant further gains. PV was also partly viewed as a way of maintaining a lifestyle while minimizing environmental impact and so more austere behavioural responses were unlikely (i.e. 'greening' an existing lifestyle). Im- 
provements were seen however, for example, with more diligent monitoring of unnecessary lights and appliances on stand-by. The most common change was that many households altered the time at which they used electricity to take advantage of freely available solar energy, in particular when using washing machines and dishwashers. This behaviour was mainly exhibited by those who were able to use electricity during the day (e.g. retirees) or those who had previous experience with off-peak tariffs or solar hot water systems.

These behavioural responses appeared to be driven by an increased awareness of electricity issues within the home. Monitoring devices played a crucial role in raising this awareness and they typically displayed information about the system's generation performance, effectively the only reminder of the PV system's presence. However the households which saved the most also showed a keen interest in their consumption, either assisted by a more advanced monitoring system or their own observations and meter readings. Therefore although these innovators had high levels of awareness before getting PV, these results confirm that the tacit knowledge of adopting households has been further increased. More importantly, it appears that this new fluency (particularly with generation issues) gives households the confidence needed to take further steps and take an interest in their role within the electrical system (e.g. questioning their PV payments).

The future of PV initially seems promising with positive peer reactions and an installation firm setting good practice standards for the industry (e.g. planning advice and the installation of a monitor); a notable improvement on the 'cowboys' of solar hot water heating. This encourages the further diffusion of PV by demonstrating to peer groups that purchasing PV is not difficult (i.e. raising their self-efficacy). However there are a few potential trouble-spots. For example, respondents revealed that some of the actors required for the successful widespread diffusion of PV were not yet fully prepared (e.g. planning authori- 
ties, meter operators and electricity suppliers). More importantly, cost remains a significant barrier, despite the government grant, and many households were only able to afford PV after receiving an unexpected financial windfall.

The findings raise two important issues which link the households to the wider socio-technical system. First, there are questions about how industry and government envision the role of PV and consumer responses. Their aspirations for PV will shape the development of technologies and policies to incentivize PV and its use. For example the issues around export metering suggest that electricity suppliers, meter operators, and households have uncertain and poorly coordinated views of the value of PV generated and exported electricity. There may also be similar debates about how consumers might be encouraged to act (e.g. should special PV tariffs be introduced? What kinds of behaviour should be encouraged?). These topics are explored further in Chapter 6. Secondly, although the interviews have provided more confidence in the estimated behavioural responses to $\mathrm{PV}$, an analysis of quantitative supply and demand data within PV households would still be valuable. This will demonstrate the flows of electricity within PV households and hence their link with the wider grid system and tariff structures. These themes are addressed in the next chapter. 


\section{Chapter 5}

\section{ELECTRICITY SUPPLY \& DEMAND IN PV HOUSEHOLDS}

The preceding results have described the energy consumption and generation of PV households in primarily qualitative terms. However a complementary quantitative analysis could be valuable, for example, by describing the extent to which PV supply meets demand at various times of day. This information can then be used to identify the household activities that drive demand, providing a better understanding of the potential for load-shifting or demand reduction.

Microgeneration tariffs could play an important role in promoting these behavioural changes. The interviews found that a number of different tariffs exist but they had little effect on energy consumption behaviour. This was in part because the surveyed households were PV 'innovators' and expressed less interest in the system's payback than other potential adopters (e.g. friends and neighbours). However an analysis of these tariffs could indicate how to encourage the wider adoption of PV and how to promote desired behavioural responses. Of course, the level of microgeneration tariffs will depend on both the balance of microgeneration supply and demand and the priorities of electricity suppliers, regulators, and other stakeholders (Rowlands 2005). In other words, the following analyses consider household-level behavioural issues but also explore the link between PV households and the wider socio-technical system. 


\subsection{Methodology}

Load data from the households surveyed above would ideally be used to address these questions, enabling detailed generation and consumption data to be matched with a household's observed socio-economic status and other attributes. However as described in Chapter 1, this approach was not feasible. Fortunately the DTI Domestic Field Trials programme collected load data from a number of PV households, primarily to understand technical barriers and therefore encourage the wider adoption of PV. These data are also available to other researchers through the Northumbria Photovoltaics Applications Centre (NPAC), which collects and manages the data.

NPAC provided data for three PV sites throughout England: Nottingham, Totnes and Liverpool (described in Table 5.1). These sites are primarily housing association developments, implying a different socio-economic group from the owner-occupier questionnaire respondents, and so the levels of consumption and generation in these data sets are unlikely to be an accurate representation of the households surveyed in Chapters 3 and 4. Each data set contains measures of horizontal irradiance $\left(\mathrm{W} / \mathrm{m}^{2}\right)$, in-plane irradiance $\left(\mathrm{W} / \mathrm{m}^{2}\right)$, ambient temperature $\left({ }^{\circ} \mathrm{C}\right)$, array temperature $\left({ }^{\circ} \mathrm{C}\right)$, direct current $(\mathrm{DC})$ output $(\mathrm{Wh})$, alternating current (AC) output (Wh), imported electricity (Wh), and exported electricity (Wh). The data were recorded at five-minute intervals and consolidated into a single database, which was queried and analysed using $\mathrm{R}$ statistical software (R Development Core Team 2005).

The chapter is divided into four themes. First the solar resource (i.e. irradiance) and corresponding PV generation were examined to understand the unique features of PV in the UK. Particular emphasis was placed on how households might interpret environmental data as a proxy for system performance and the resulting effect on behaviour. Secondly, the electricity demand of these 


\begin{tabular}{|c|c|c|c|c|}
\hline Site & \# of systems & Size & Data coverage & Notes* \\
\hline Nottingham & 19 & $\begin{array}{l}15 \times 1.53 \mathrm{~kW}_{\mathrm{p}} \\
4 \times 1.7 \mathrm{~kW}_{\mathrm{p}}\end{array}$ & $\begin{array}{l}\text { 17-May-2002 } \rightarrow \\
\text { 31-May-2004 }\end{array}$ & $\begin{array}{l}\text { Bungalows, mainly ter- } \\
\text { raced, housing associa- } \\
\text { tion, retired tenants }\end{array}$ \\
\hline Totnes & 2 & $1.02 \mathrm{~kW}_{\mathrm{p}}$ each & $\begin{array}{l}\text { 14-May-2002 } \rightarrow \\
\text { 31-May-2004 }\end{array}$ & $\begin{array}{l}\text { 2-storey detached or } \\
\text { semi-detached owner- } \\
\text { occupiers }\end{array}$ \\
\hline Liverpool & 4 & $1.68 \mathrm{~kW}_{\mathrm{p}}$ each & $\begin{array}{l}\text { 01-Jun-2002 } \rightarrow \\
\text { 30-Nov-2004 }\end{array}$ & $\begin{array}{l}\text { 2-storey terraced, hous- } \\
\text { ing association, mainly } \\
\text { families }\end{array}$ \\
\hline
\end{tabular}

${ }^{*}$ The Nottingham and Totnes installations use mono-crystalline cells; Liverpool uses poly-crystalline.

TABLE 5.1: Summary of NPAC PV systems

households was explored to compare the timing of PV generation with electricity consumption. To assess the potential for further savings, the activities that created this demand were also considered.

Analyses were performed at an aggregate level to understand the major trends, averaging both between households and over different time periods. However the variability between households was also considered, since the unique circumstances of each household will determine its specific response to PV. Year-to-year variability was explored to see if there were any signs of a change in consumption. Finally an analysis of financial incentives assessed the potential impact of different tariffs to encourage both the diffusion of PV and the use of PV electricity within the home.

\subsection{The UK solar resource and PV generation}

The UK may not be a country traditionally associated with sunny skies but it would be unfair to dismiss its potential for PV generation completely. With a northern latitude and maritime climate, the UK's solar environment has a unique character that will determine how much solar electricity is generated and at what times. The interviews showed that an awareness of system perfor- 
mance influenced electricity consumption behaviour as well. Although most respondents became aware of the variations in PV generation through the use of a monitoring device, others felt that observing the weather was often sufficient or even preferable; as one respondent noted, the monitor output can be too variable, changing with "every passing cloud" (R.E.). Kempton and Montgomery (1982) note that these 'folk models' can be cognitively efficient, allowing households to comprehend complex technical systems. Such models then provide cues for behaviour, although discrepancies between the folk model and reality can lead to inefficient energy use (Kempton 1987). If the weather indeed acts as a proxy for the output of domestic PV systems, it is therefore important to understand the efficiency of the household's mental model (i.e. how well it compares to reality) and how it might influence household behaviour.

\subsubsection{Solar resource patterns}

The output of a PV system is primarily determined by the irradiance striking the panels (in-plane irradiance) and their temperature (array temperature) (Pearsall 2005). However a weather-based folk model of PV output that incorporates these factors would be more likely to use ambient temperature and horizontal irradiance (i.e. the irradiance striking a horizontal surface, rather than in-plane with the inclined PV panels) as these values are more easily observed without the use of special monitoring equipment. ${ }^{1}$ These general measures of the solar resource were therefore examined to see how they vary throughout the year and across the country.

\footnotetext{
${ }^{1}$ The monitoring devices identified in the questionnaire and interviews did not display irradiance or temperature information (except room temperature in some cases).
} 


\section{Irradiance}

The UK has a good solar resource with annual irradiance ranging from about $900 \mathrm{kWh} / \mathrm{m}^{2}$ in the north to $1300 \mathrm{kWh} / \mathrm{m}^{2}$ in the southwest (Jardine and Lane 2003). The recorded data were consistent with these figures, showing average annual solar resources of $847 \mathrm{kWh} / \mathrm{m}^{2}$ in Nottingham, $1195 \mathrm{kWh} / \mathrm{m}^{2}$ in Liverpool, and $1046 \mathrm{kWh} / \mathrm{m}^{2}$ in Totnes, Devon. However the figures show that irradiance is influenced by more than just the longitude or latitude of the site. ${ }^{2}$ Figure 5.1, for example, demonstrates the variations in regional irradiance, shaped by weather, topography, and other factors. Very small-scale effects, such as array shading, may also have influenced these figures.

Temporally, horizontal irradiance varies according to two main cycles. First there is a seasonal cycle, with summer accounting for $42 \%$ of the annual resource and winter $10 \%$ (Figure 5.2). ${ }^{3}$ The UK's northerly location creates this large seasonal variation: for example, the monthly average irradiance is 6.7 times greater in summer than winter in the UK but only 3.0 times greater in Mallorca, Spain (Jardine and Lane 2001, 2002); even less variation would be seen at equatorial latitudes.

The solar resource also exhibits a diurnal cycle and Figure 5.3 shows the anticipated midday rise in summer and winter. Seasonal differences were again seen in both the length of day and the magnitude of the midday peak. For example, shorter days in the winter mean that more solar resource is delivered in the midday period (58\% in the winter compared to $44 \%$ in summer). ${ }^{4}$ Geographic differences within the UK can be seen in the different times of sunrise and sunset at the three sites.

\footnotetext{
${ }^{2}$ Totnes is located at $50.26^{\circ} \mathrm{N}, 3.42^{\circ} \mathrm{W}$; Liverpool at $53.25^{\circ} \mathrm{N}, 3.00^{\circ} \mathrm{W}$; and Nottingham at $52.58^{\circ} \mathrm{N}, 1.10^{\circ} \mathrm{W}$.

${ }^{3}$ Summer was taken as weeks 25 to 38 (June 21 to September 21) and winter as weeks 51 to 12 (December 21 to March 21).

${ }^{4}$ Midday was defined as 11:00 to 14:59.
} 


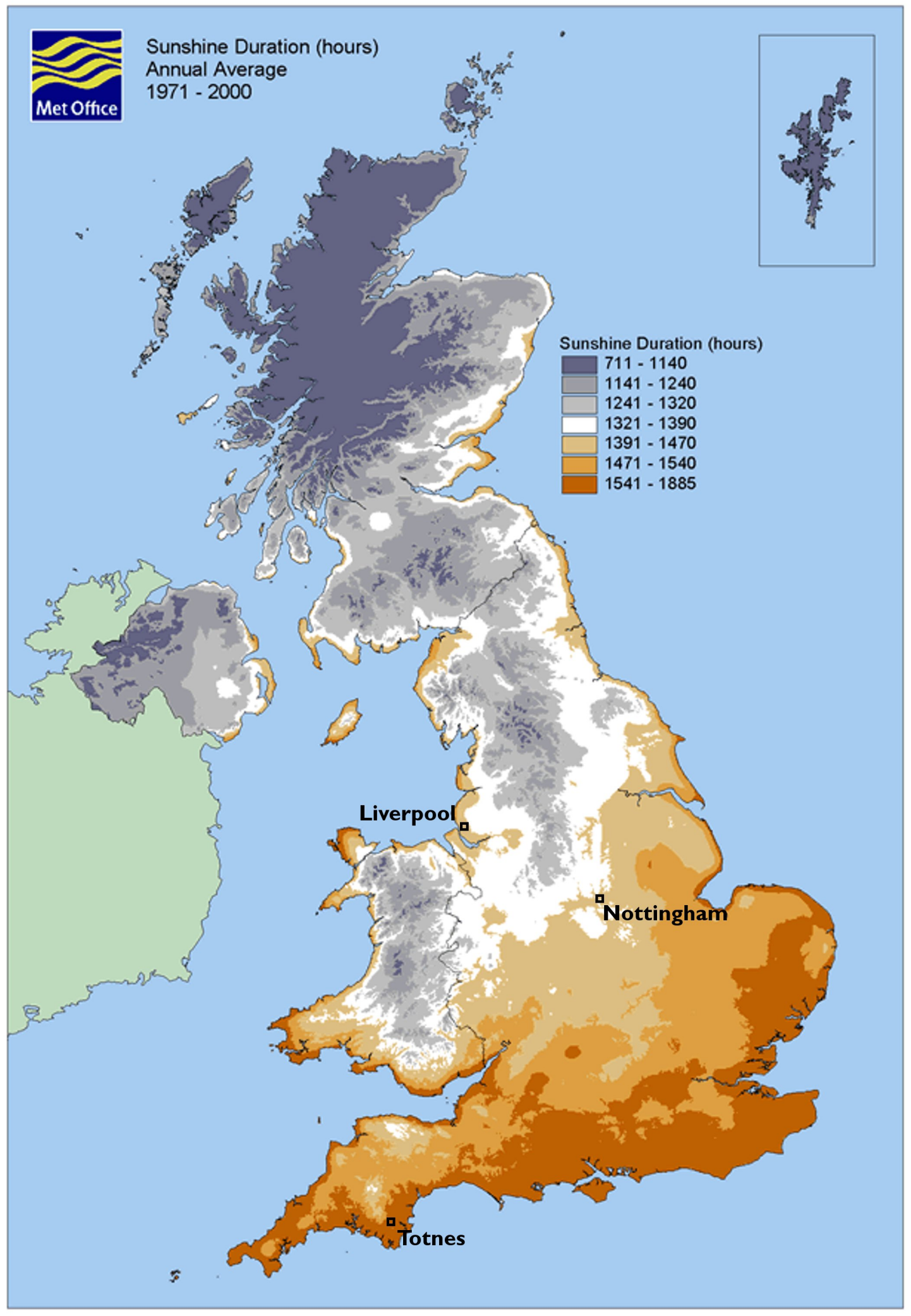

FIGURE 5.1: Annual average sunshine hours in the UK (Met Office 2005) 


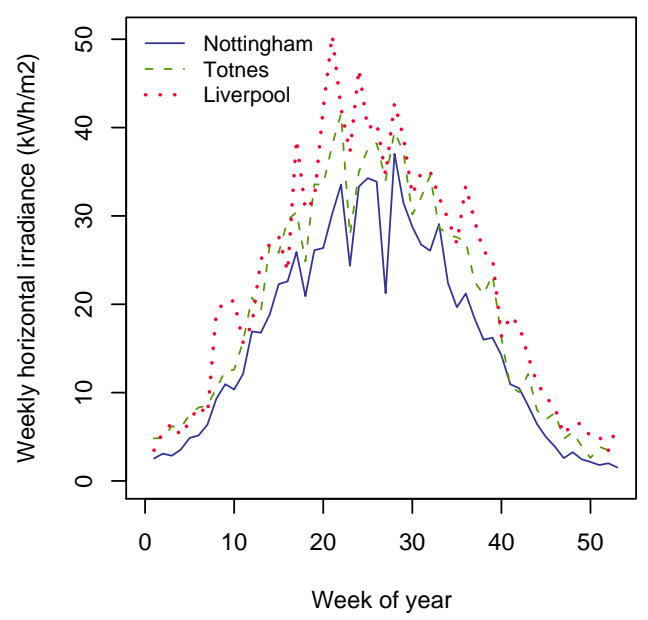

FIGURE 5.2: Annual solar resource (weekly average)

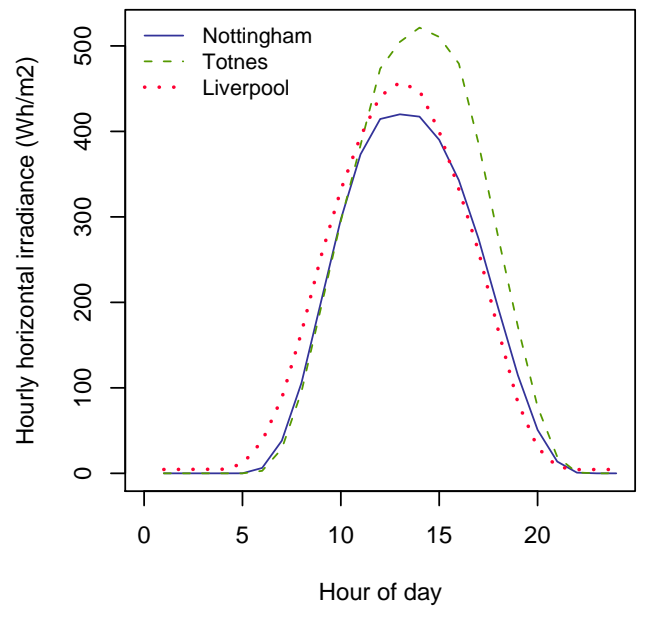

(a) Summer

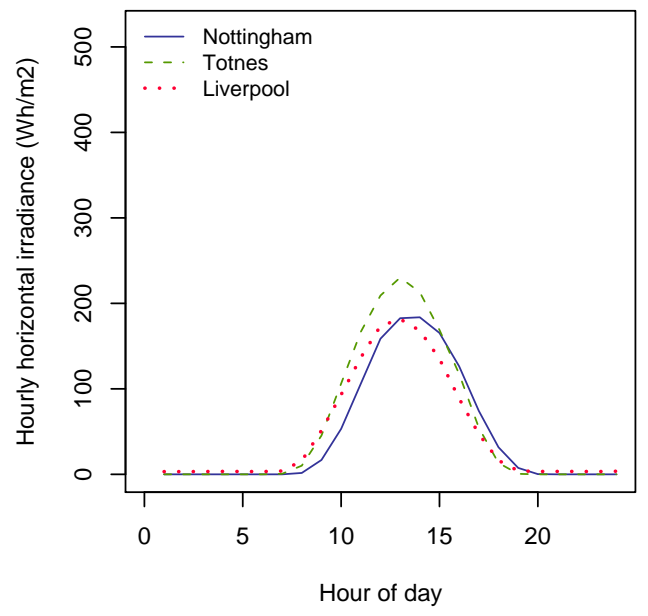

(b) Winter

FIGURE 5.3: Daily solar resource (hourly average)

Weather-based folk models may rely on these trends in horizontal irradiance but actual system output is determined by in-plane irradiance, with systems in the UK optimally installed in a southerly orientation, inclined by $30^{\circ}$ to $40^{\circ}$ (PV-UK 2005). A strong correlation was found between horizontal and in-plane irradiance values (Pearson's $r=0.943, p \ll 0.001$ ), indicating that horizontal irradiance is a good proxy for in-plane irradiance. However these irradiance 
values differ notably in the winter because of the sun's low altitude; for example, the daily maximum in-plane irradiance in winter is $63 \%$ higher than the maximum horizontal irradiance; in summer, the maximum in-plane irradiance is only $16 \%$ higher.

\section{Temperature}

Temperature is an important factor because the efficiency of solar cells decreases as they get hotter; for example with crystalline-silicon solar cells, the power output falls approximately $0.5 \%$ for each ${ }^{\circ} \mathrm{C}$ rise in cell temperature (BP Solar 2005). Only one of the interviewed households was aware of this relationship between array temperature and performance but educational efforts could introduce temperature as part of a folk model of PV performance. In this case, the lack of monitoring equipment for temperature would suggest that ambient temperature, not array temperature, would be the most easily incorporated measure of temperature. Unfortunately ambient temperatures greatly underestimate the effect of temperature on array performance. Although there is a significant correlation between array temperature and ambient temperature (Pearson's $r=0.780, p \ll 0.001$ ), Figure 5.4 shows that the array temperature can be significantly higher at times of peak irradiance. It is also important to note that the temperatures are highest in summer and at midday, mirroring the trends in irradiance. Therefore gains from increased irradiance are partly offset by lower efficiencies due to increased temperature. 


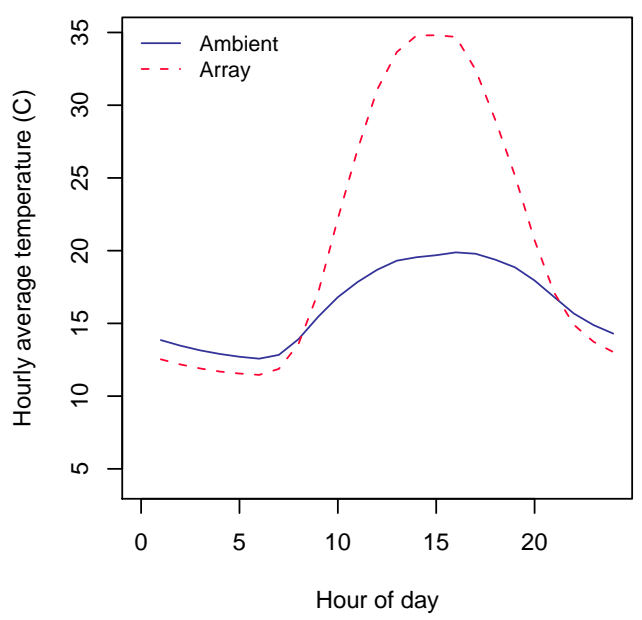

(a) Summer

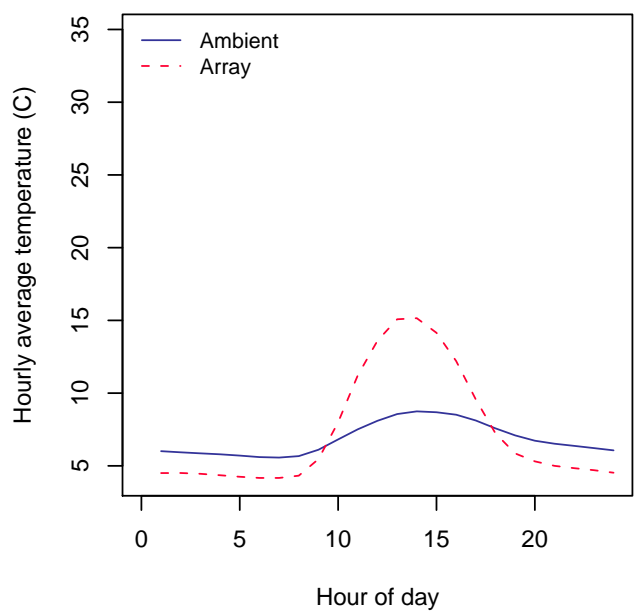

(b) Winter

FIGURE 5.4: Daily temperatures at Totnes (hourly average)

\section{The folk model reviewed}

To examine the combined effect of irradiance and temperature on actual electricity generation, a log-linear regression and ANOVA were performed on a manageable subset of the data (representing Totnes for the year 2003). This analysis allowed the 'folk' model of system performance to be compared with the 'real' model. These models are described below:

\section{The 'real' model: $\quad$ ACOutput $\propto k \cdot$ IPIrrad $\cdot$ ArrayT \\ The 'folk' model: $\quad$ ACOutput $\propto k \cdot$ HIrrad $\cdot$ AmbT}

The findings were significant at the $0.1 \%$ level and show that there was very little difference between the folk model and the real model of PV system performance (Table 5.2). This is because the irradiance explains such a large part of the variation in system performance, suggesting that a folk model based exclusively on irradiance would be quite efficient. 


\begin{tabular}{llcc}
\hline & Real & Folk \\
\hline Correlation $\left(r^{2}\right)$ & & 0.969 & 0.933 \\
\% of variance in AC output explained by: & & \\
& Irradiance & $97 \%$ & $93 \%$ \\
& Temperature & $\approx 0 \%$ & $0.25 \%$ \\
& Errors & $3.1 \%$ & $6.7 \%$ \\
\hline
\end{tabular}

TABLE 5.2: Evaluating the folk model of PV system performance

From a behavioural perspective, these environmental factors are effectively fixed. Keen households could increase irradiance by ensuring that their arrays are not shaded by trees or architectural features and even decrease temperature by cooling their arrays with water. Most households though are likely to accept these factors as given and estimate their system's performance based on their perceptions of the observable weather (i.e. sunshine).

\subsubsection{PV generation patterns}

NPAC recorded both the direct current (DC) and alternating current (AC) output of the PV systems. A direct comparison of DC and AC outputs can be useful when examining inverter performance, for example, at low light levels or in response to fluctuations in grid voltage (Pearsall 2005). For this analysis, AC output was the focus as this is the actual electricity available to the household for consumption. Since the output is dependent on the size of the array, the data were adjusted for the capacity of each system (i.e. $\mathrm{kWh} / \mathrm{kW}_{\mathrm{p}}$ not $\mathrm{kWh}$ ).

The annual output of a PV system will vary according to its size, location, cell technology and other factors with Solar Century (2004) observing a range of 680 to $870 \mathrm{kWh} / \mathrm{kW}_{\mathrm{p}}$ for UK systems; Jardine and Lane (2003) recorded outputs of 550 to $1050 \mathrm{kWh} / \mathrm{kW}_{\mathrm{p}}$ for various technologies at a site near Oxford. The output of the NPAC systems was comparable and the variations might be explained by differences in site location, cell chemistry and overall system de- 
sign (e.g. inverter sizing) (Table 5.3).

\begin{tabular}{lcc}
\hline Site & System capacity & $\begin{array}{c}\text { Annual average AC output } \\
\left(\mathrm{kWh} / \mathrm{kW}_{\mathrm{p}}\right)\end{array}$ \\
\hline Nottingham & $15 \times 1.53 \mathrm{~kW}_{\mathrm{p}}$ & 778 \\
& $4 \times 1.7 \mathrm{~kW}_{\mathrm{p}}$ & \\
Totnes & $2 \times 1.02 \mathrm{~kW}_{\mathrm{p}}$ & 892 \\
Liverpool & $4 \times 1.68 \mathrm{~kW}_{\mathrm{p}}$ & 840 \\
\hline
\end{tabular}

TABLE 5.3: Total annual AC output for NPAC sites

The annual variation in output is shown in Figure 5.5, demonstrating a similar summer peak as seen in the irradiance and temperature figures above. However, the electrical output is distributed slightly more evenly over the year with $37 \%$ of output coming in the summer and $15 \%$ in the winter (versus $42 \%$ and $10 \%$ respectively for horizontal irradiance). This difference can be explained by the negative influence of warmer summer temperatures.

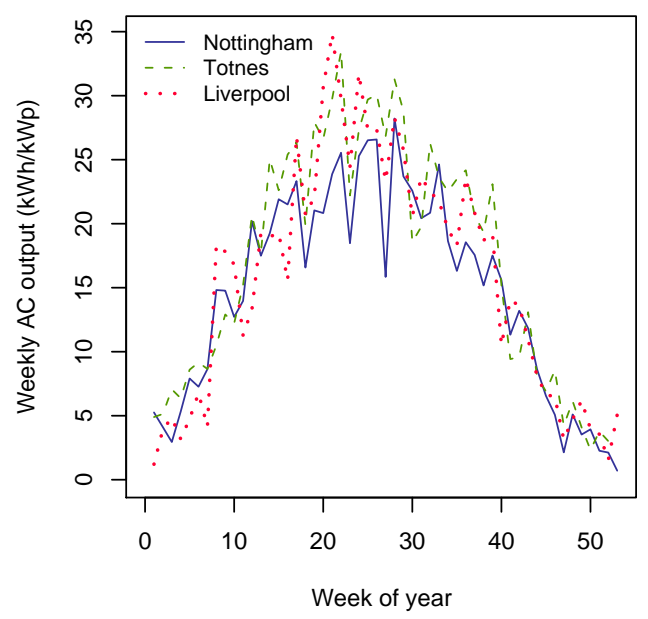

FIGURE 5.5: Annual PV generation (weekly average)

On a diurnal basis, Figure 5.6 shows the same daytime peak as the irradiance and temperature plots. Some time differences are also evident, for example, with each site exhibiting slightly different lengths of day. However these effects are unlikely to have a major effect on the timing of electricity consump- 
tion when compared with other factors, such as work hours. The negative influence of higher summer temperatures on system output can again be seen in the summer and winter midday peaks, which differ not by the factor of two seen in the irradiance plots, but closer to 1.5 .

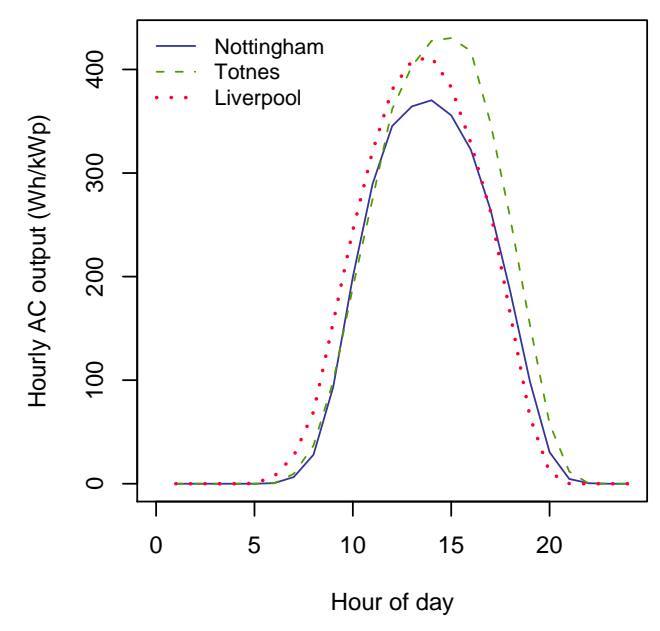

(a) Summer

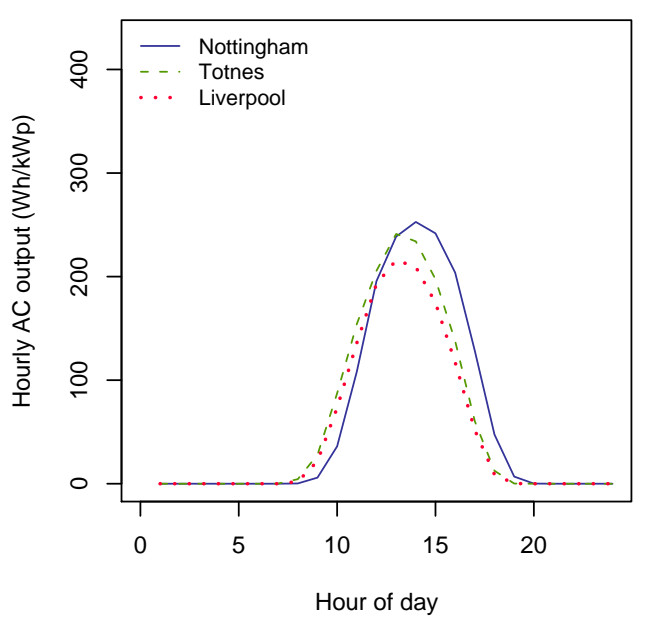

(b) Winter

FIGURE 5.6: Daily PV generation (hourly average)

\section{Summary}

Photovoltaics deliver electricity in a very predictable fashion as the two main environmental determinants of system performance, irradiance and temperature, follow clear temporal variations with a summer peak seasonally and midday peak daily. Although the electrical output of a PV system is linked to the in-plane irradiance and array temperature, a folk model based on accessible environmental measures like horizontal irradiance and ambient temperature (to a lesser extent) was found to be a good representation of actual PV output.

Location was seen as an influence on the timing and quantity of solar output. However the greatest impact of location on the behaviour of PV households may be linked to cultural factors, rather than observable physical phe- 
nomena. Palutikof et al. (2004) found that perceptions of climatic conditions may vary greatly between regions, suggesting that how the folk model is interpreted and used by PV households could vary widely between UK regions and certainly between different countries. For example, one might expect that a sunny day would present a greater 'PV opportunity' to a household in Nottingham, than one in Spain, with corresponding behavioural implications.

The results suggest that the use of monitoring devices and folk models play a central role in promoting tacit knowledge about PV electricity generation. However the actions that households might take in response to this information will also depend on the patterns of electricity demand.

\subsection{Electricity demand in PV households}

In addition to its environmental benefits, a major selling point of PV is the ability to generate electricity in the home, promoting independence from the national grid. This may in turn create a sense of ownership and responsibility for one's electricity generation and consumption, but the strength of this feeling is likely to depend on the degree of self-sufficiency achieved. Furthermore since storage is currently expensive and impractical, electricity must be continually imported and exported to and from the grid to compensate for the difference between generation and demand. These flows of electricity are likely to have an impact on the electricity system and hence they may also be of concern to electricity suppliers.

Recalling that PV produces electricity primarily in summer months and at midday, the national demand figures give some initial cause for concern as the largest peaks are seen in winter and in the evening (Figure 5.7). Although this graph includes industrial and commercial as well as domestic uses, the demand profiles are markedly different from the output of solar photovoltaics. 


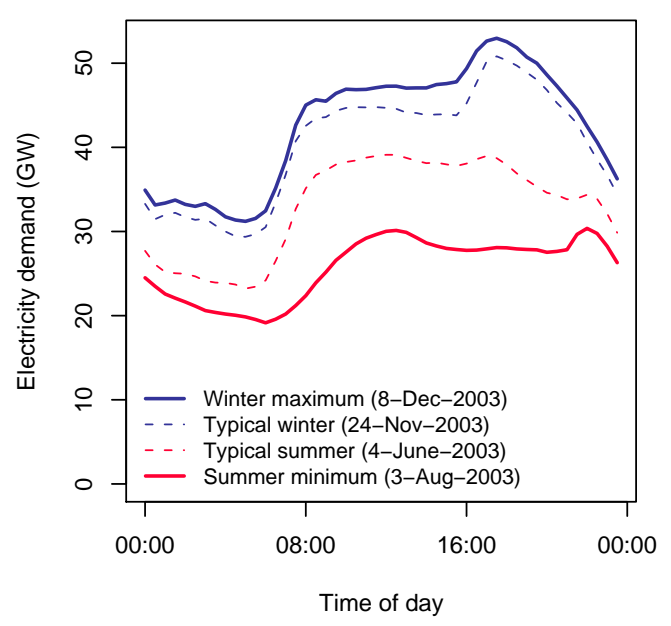

FIGURE 5.7: Electricity demand for England and Wales (National Grid 2004)

However this 'mismatch' between PV supply and demand can be reduced if households engage in load-shifting or demand reduction behaviours. Therefore the NPAC data set was used to quantify supply and demand using only domestic data and to consider the implications for household behaviour and the electricity network. The data did not record total electricity demand explicitly but it can be calculated using Equation 5.1. Demand should always be greater than or equal to zero but perhaps due to measurement errors, negative values accounted for approximately $3.5 \%$ of the 5 million data points. These points were removed before performing the analysis.

$$
\text { Demand }=\text { Import }+(\text { AC Output }- \text { Export })
$$

\subsubsection{Electricity demand patterns}

The annual electricity demand was first calculated for each location. As shown in Table 5.4, the results are comparable to UK average household electricity consumption of $3300 \mathrm{kWh}$ (EnergyWatch 2004) to $4600 \mathrm{kWh}$ (DTI 2005a). Consumption in Liverpool was much higher but according to NPAC, these house- 
holds had more occupants and more appliances than the other study sites. The difference in consumption at Liverpool might also be explained by the presence of electric heating but the weekly average demand, shown in Figure 5.8, was higher at Liverpool throughout the year. After confirming that the seasonal patterns of demand were similar at each site, the most likely explanation for the demand at Liverpool is the use of electricity for water heating. Since only $5 \%$ of interview respondents used electricity for space or water heating, their electricity demand is likely to be closer to that at the Nottingham and Totnes sites. Averaging across the three sites, $20 \%$ of annual electricity was consumed in the summer quarter and $32 \%$ in the winter quarter.

\begin{tabular}{lc}
\hline Site & Annual electricity demand $(\mathrm{kWh})$ \\
\hline Nottingham & 3070 \\
Totnes & 3160 \\
Liverpool & 6600 \\
\hline
\end{tabular}

TABLE 5.4: Total annual electricity demand for NPAC sites

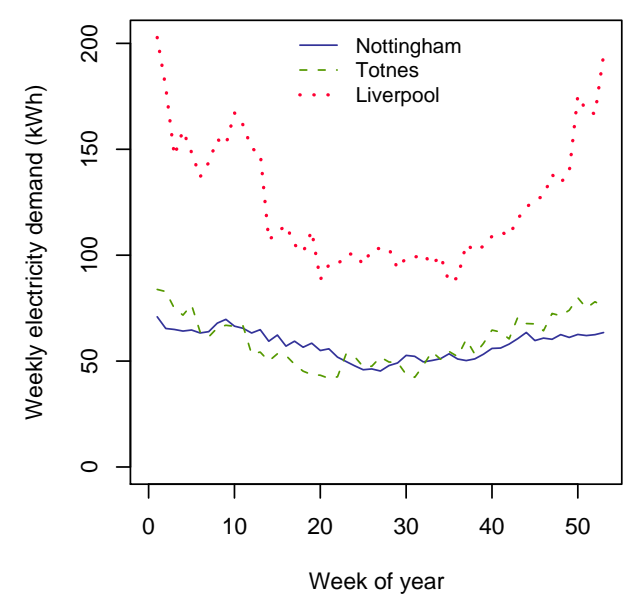

FIGURE 5.8: Annual electricity demand (weekly average)

Daily electricity demand shows household behaviour more clearly, for example, low demand at times of sleep (Figure 5.9). Although the activities that drive this demand cannot be deduced from the NPAC data, the UK Time Use 
Survey (National Statistics 2000) provides details on the types of activities that occur in a typical UK household. A recent study using this data set demonstrated its potential as a tool for domestic electricity consumption research, revealing the variation in activity profiles across times of the year and types of household (Lampaditou and Leach 2005). Having identified 263 households in the UK Time Use Survey which matched the Family and Retired household profiles described by the questionnaire, activity profiles were determined for the times of peak PV generation (midday) and peak electricity demand (evening). The figures below were calculated using the primary household member but the activities of secondary household member were also considered.

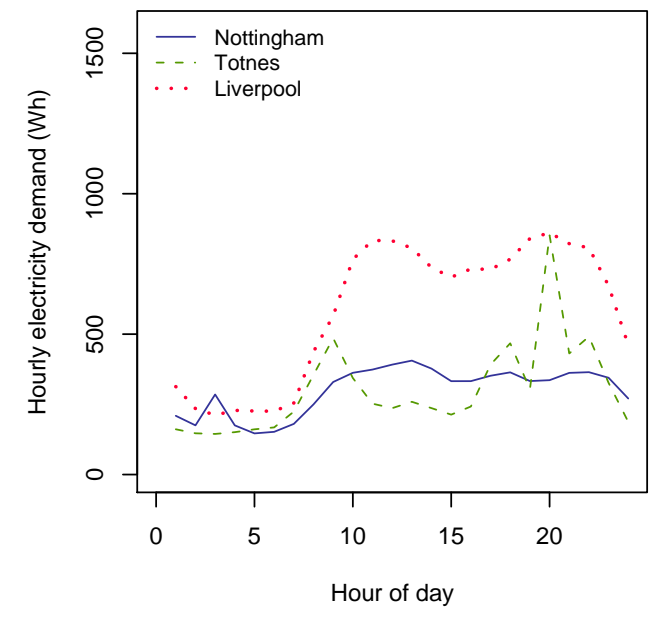

(a) Summer

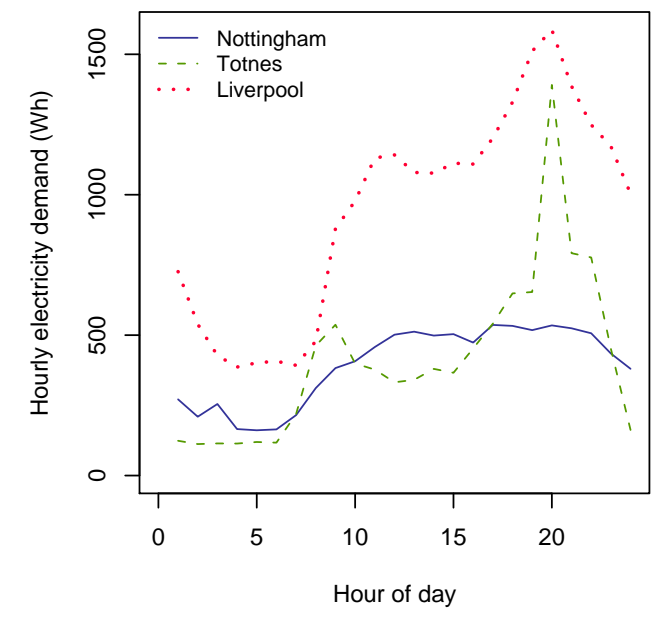

(b) Winter

FIGURE 5.9: Daily electricity demand (hourly average)

As shown in Figure 5.10, the 'family' households were typically out of the home during the day (e.g. at work) and secondary activities were associated with the care of family members or home maintenance (e.g. washing, cleaning). The 'retired' households were more likely to be at home and typical activities included gardening, preparing meals, watching TV or listening to the radio. In the evenings, both groups were engaged primarily in food preparation, eating and watching TV. 


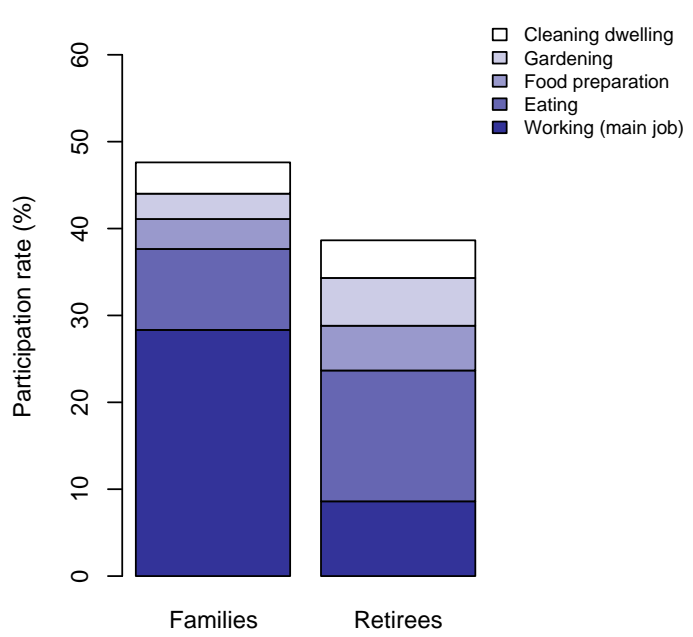

(a) Midday (11 am to $3 \mathrm{pm})$

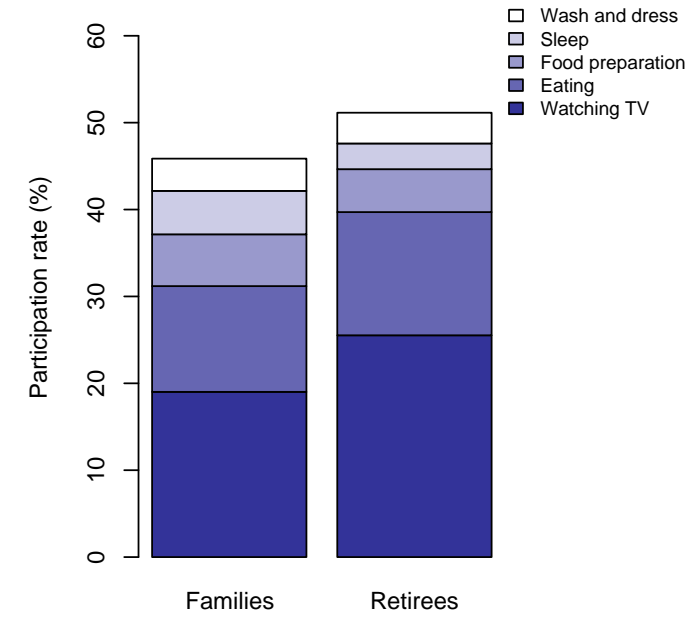

(b) Evening (5 pm to $11 \mathrm{pm})$

FIGURE 5.10: The five most common household activities at times of peak PV generation and peak electricity demand for different types of PV household (National Statistics 2000)

During the interviews, respondents indicated that washing machines and dishwashers were the most likely loads to be shifted from evening to daytime. These results support this conclusion but also suggest that:

- entertainment may be a reducible load; however these loads are unlikely to be shifted due to the nature of the programming (e.g. the 10 o'clock news is not available at midday, though programmes could be recorded to watch at a later time).

- the importance of food preparation suggests that some load shifting could be achieved, for example, if the main hot meal of the day was served at noon. However this may have little effect on electricity consumption (e.g. $80 \%$ of the questionnaire respondents had gas for space heating which may have also been used for cooking).

- lighting is not explicitly mentioned in the Time Use survey but it will be required for many activities (e.g. evening reading). It is therefore difficult 
to assess the potential savings from the use of CFLs or increased diligence in turning off unnecessary lights.

- any shift or reduction in electricity demand will be dependent on work schedules and cultural norms of behaviour. For example, those with daytime jobs may find it difficult to switch certain activities to midday. Households may also be reluctant to change activities which are regarded as 'necessary' in a broader social context (Wilhite and Lutzenhiser 1999), e.g. the frequency of cleaning (Shove 2003a).

Of course these figures only show participation in each activity and not the associated electricity consumption. For example, tumble dryers were not indicated here but could be running in the background while watching TV, consuming much more electricity. However by making households aware of the electricity required by different activities, consumers would have the information needed to determine which loads should be switched or reduced.

\subsubsection{Comparing electricity demand and PV generation}

Figure 5.11 shows the average flows of imported and exported electricity during summer and winter. There is currently a project underway to collect such data from 200 microgenerating households, covering a range of technologies including PV (organized by Beama). One of the primary outcomes of this project will be "representative export profiles", used by electricity suppliers to determine what flat-rate tariffs should be offered to microgenerating households. However the data will also help to understand the potential impact that large amounts of microgeneration might have on supply grids. For example, the NPAC data set showed a strong correlation between imports and total demand (Pearson's $r=0.966, p \ll 0.001$ ), as well as between exports and generation (Pearson's $r=0.823, p \ll 0.001$ ). In contrast the correlation between demand 
and generation is very poor (Pearson's $r=0.0856, p \ll 0.001$ ). In other words, without storage, the electricity generated by a PV household is most likely to go onto the grid and then be imported again later, rather than be used at the time of generation. This may affect the performance of the distribution grid and the types of tariffs desired by well-informed PV households (i.e. demand for units 'sold' to the grid).

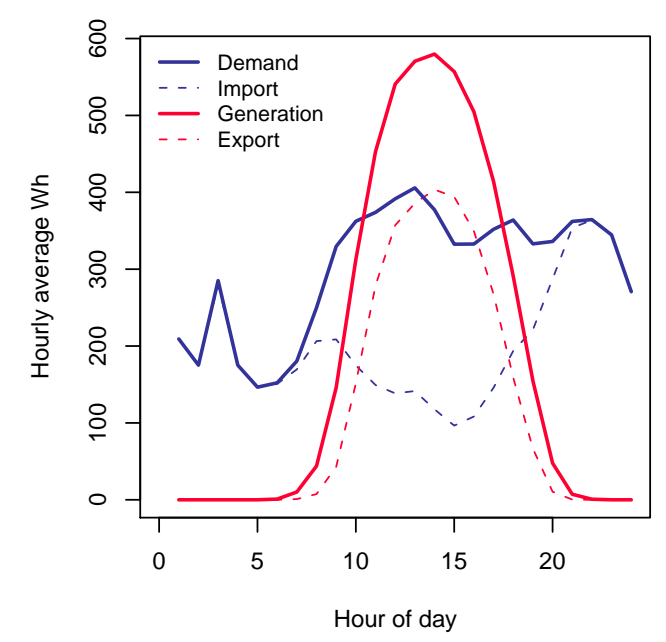

(a) Summer

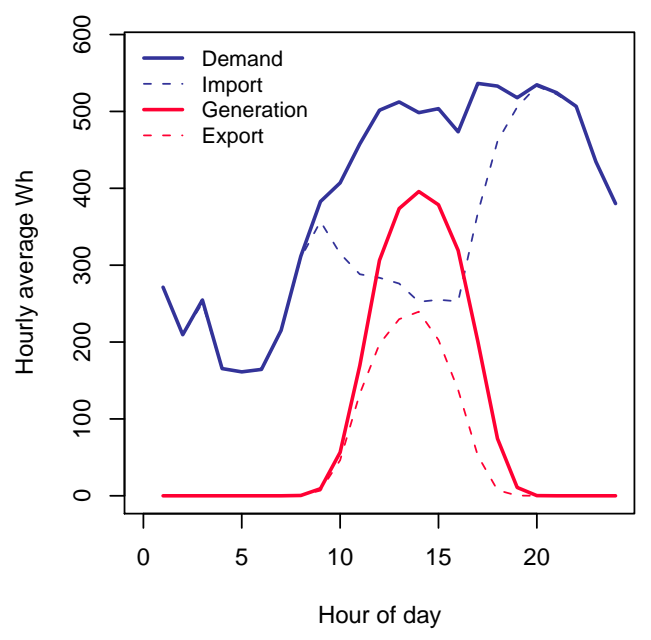

(b) Winter

FIGURE 5.11: Daily electrical activity at Nottingham (hourly average of 19 households)

The mismatch between solar generation and electricity demand is not a inherent disadvantage of PV but rather a characteristic of the UK's electricity demand. For example, Spain has a very large peak in summer electricity demand ( $97 \%$ of the annual demand peak) due to the widespread use of air conditioning (REE 2004). Therefore in other countries, such as Canada (Rowlands 2005), PV may be ideal for meeting a large share of domestic electricity demand, making the link between behaviour (e.g. turning on the air-conditioning) and the balance of supply and demand more apparent. However these results suggest that PV electricity may be less valuable for reducing the peak load on the UK electricity grid. 
Two potential behavioural responses to PV have been identified which could minimize this effect: load shifting and load reduction. Electricity suppliers may therefore decide to use PV-specific tariffs to manage the flows of import and export from these households. Two such metrics are considered here as potential behavioural cues: PV fraction and energy balance.

\section{PV fraction}

A microgeneration fraction describes the amount of demand being met by microgeneration; in this case, the PV fraction is defined as the AC output (i.e. PV generation) divided by the total electricity demand. While this metric could be calculated over any time scale, it is perhaps most useful as an instantaneous reflection of the system's status. In other words, the PV fraction indicates whether a household is importing (PV fraction $<1$ ), exporting (PV fraction $>1$ ), or balanced (PV fraction $=1$ ) at any given moment.

The annual PV fraction was examined first for context. The contribution of PV depended on both the size of the system and the household's electricity demand (Table 5.5). Figure 5.12, for example, shows that PV meets most of the summer demand requirements for Nottingham but the high demand of the Liverpool households lowers the PV fraction, despite their larger PV systems. Again all of the NPAC systems were notably smaller than the UK average of $2.07 \mathrm{~kW}_{\mathrm{p}}$ (EST 2003b), due to smaller building sizes and cost considerations (the PV systems were installed as part of larger renovation projects). Since demand levels were similar to national averages, the PV fraction of a typical EST PV household (i.e. the questionnaire respondents) might be slightly higher. 


\begin{tabular}{llll}
\hline Site & $\begin{array}{l}\text { Annual } \\
\text { demand } \\
(\mathrm{kWh})\end{array}$ & $\begin{array}{l}\text { Avg. array } \\
\text { size }\left(\mathrm{kW}_{\mathrm{p}}\right)\end{array}$ & $\begin{array}{l}\text { Annual PV fraction } \\
\text { (generation as \% of } \\
\text { demand) }\end{array}$ \\
\hline Nottingham & 3070 & 1.57 & 42 \\
Totnes & 3160 & 1.02 & 33 \\
Liverpool & 6600 & 1.68 & 25 \\
\hline
\end{tabular}

TABLE 5.5: Contribution of PV to annual electricity demand

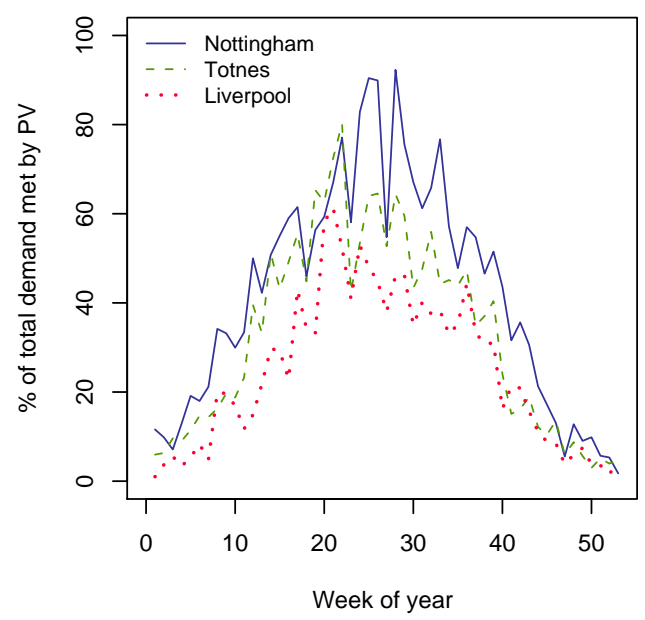

FIGURE 5.12: Annual PV fraction (weekly average)

Daily plots show how the PV fraction might influence everyday behaviour (Figure 5.13). In winter, the midday peak in generation has difficulty meeting the corresponding demand requirements but in summer, PV can provide as much as twice the electricity demand with the balance exported. While the strength of this signal varies from season-to-season, its timing is constant and households are most likely to respond to the PV fraction at midday. 


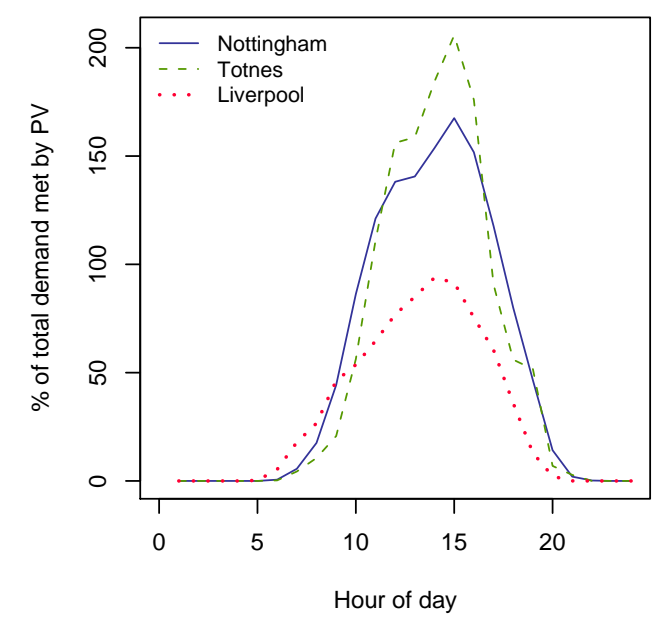

(a) Summer

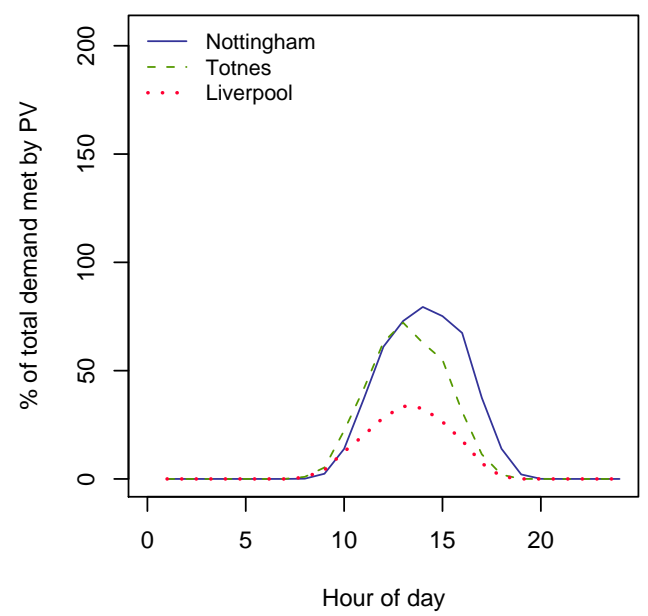

(b) Winter

FIGURE 5.13: Daily PV fraction (hourly average)

PV fraction is also a relevant metric for the grid because as it varies above and below 1, the household will be alternately importing and exporting electricity. In the following chapter, electricity suppliers indicated that households should preferably be using all of their generation within the home (PV fraction $\leq 1)$. Therefore if the suppliers wanted to control imports or exports, an incentive based on PV fraction could be introduced. For such a tariff to be effective, it would have to be linked to a monitoring device; fortunately the Eclipse monitor features a PV fraction metric and another householder had a device with different coloured lights to indicate import or export. However if the incentive for this behaviour was introduced at an excessive level, it is possible that households could intentionally achieve a low PV fraction by increasing demand. This may be unlikely, but it demonstrates that any incentive tied to PV fraction should be balanced with a consideration for overall demand.

\section{Energy balance}

If households are generally unable to meet their demand requirements at a given instant (as reflected by the low average PV fraction), then perhaps there is 
a time period over which households could budget their demand to meet supply. An 'energy balance' (strictly speaking, electricity balance) might therefore prove useful, if duly supported by monitoring equipment and incentives. This metric can be calculated over different time horizons to reflect a household's net impact on the electricity grid (Equation 5.2, where $E B$ is the energy balance and $\left.E B_{0}=0\right)$.

$$
E B_{t}=E B_{t-1}+\text { Export }_{t}-\text { Import }_{t}
$$

Figure 5.14 shows that, by the end of the year, every location is in energy 'debt', with Liverpool again standing out because of the greater household sizes, number of appliances and electric water heating. The slight plateau in the summer months at Nottingham and Totnes reflects the influence of the solar generation but this is only a temporary pause in an otherwise steadily declining balance. Therefore if an energy budget was assigned on an annual basis, the plot suggests that households might feel as though they were fighting a losing battle, lowering self-efficacy and reducing the effectiveness of the energy balance as a cue for positive behavioural changes. (Specific household budgets would vary according to each household's demand and PV system capacity).

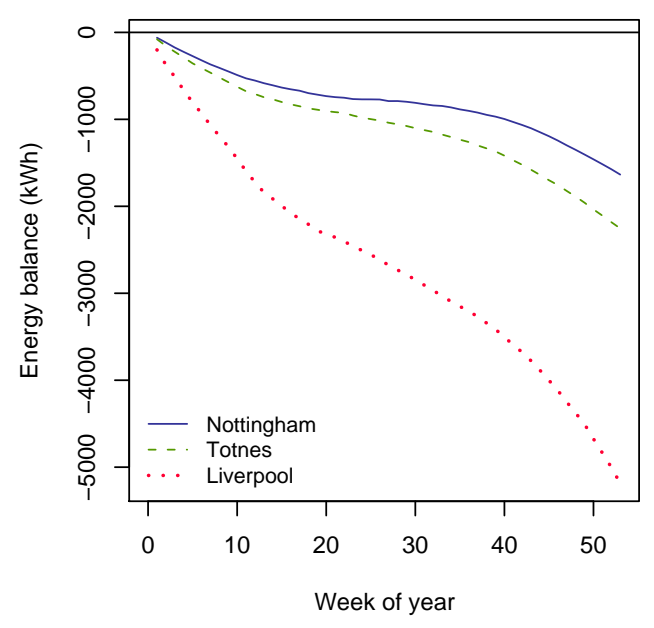

FIGURE 5.14: Annual energy budgets (weekly average) 
Daily energy budgets may be a more accessible and positive way of introducing this concept to consumers. Figure 5.15 suggests that by initiating such a programme in the summer, consumers could practice budgeting their consumption when achieving the daily target is easier (Nottingham, for example, ends an average summer day at $-1.9 \mathrm{kWh}$ but in winter, $-6.5 \mathrm{kWh}$ ). Similarly an annual energy budget could be partitioned into appropriate seasonal targets, allowing households to plan behaviour on a more manageable time scale. Using these different budget time scales might also encourage the adoption of other microgenerating technologies better suited to generation in the evening or winter (e.g. microCHP).

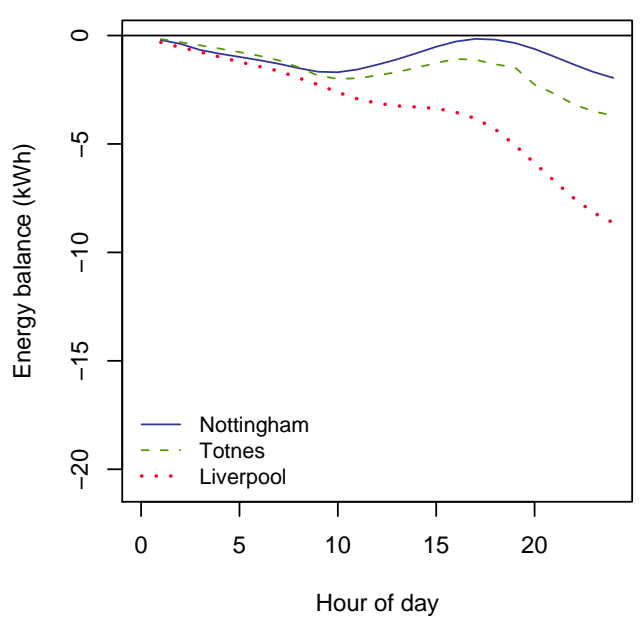

(a) Summer

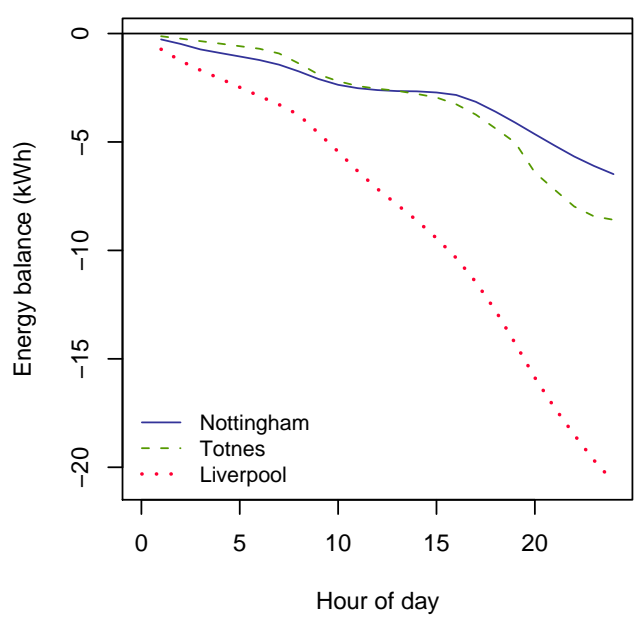

(b) Winter

FIGURE 5.15: Daily energy budgets (hourly average)

Since PV generates all of its electricity during the day, only a fraction of demand can be actively addressed using real-time signals like the PV fraction (e.g. for this data set, daylight encompasses $72 \%$ of daily summer demand (5:30 to $20: 40)$ and $39 \%$ of daily winter demand (7:30 to $17: 00)$ ). Therefore the energy balance may help tackle the remaining 30 to $60 \%$ of demand. 


\section{Summary}

These different ways of examining the relationship between electricity demand and microgeneration within PV households tell a consistent story. PV largely provides electricity at times of low demand, meaning that PV households export most of their microgenerated electricity. From a grid perspective, this may be undesirable if it requires additional capacity in the distribution network. Furthermore, summer midday exports do nothing to reduce the grid's peak demand on winter evenings.

Until storage becomes feasible, electricity suppliers and households will have to rely upon behavioural responses to minimize this mismatch. Two concepts - the PV fraction and energy budget - were presented as useful and complementary ways of viewing the link between generation and demand. For example, the PV fraction can be used to inform a household whether they are importing or exporting at any given moment and the energy budget may be a useful way to plan responsible electricity consumption over a longer time period. If combined with detailed information on the sources of electricity demand (as discussed with the UK Time Use Survey data), these metrics could build tacit knowledge about microgeneration supply and demand among PV households. These results therefore suggest that, by providing consumers with the appropriate know-how, households would be able to change their energy consumption behaviour in a way that suits their needs and circumstances.

\subsection{Variations in generation and demand}

If a behavioural change occurs in a given household, it is likely to be triggered, not by the aggregate trends of national or neighbourhood generation and consumption, but by what is happening in that specific household. At this level, 
the smoothing effect of aggregation is lost and there can be significant variability from minute-to-minute. Figure 5.16 shows this 'spikiness', demonstrating for example that it is possible to have a similar size peak in demand in both summer and winter. This section therefore expands upon the aggregate analyses above by examining the variations in generation and demand that exist between households and from year-to-year.

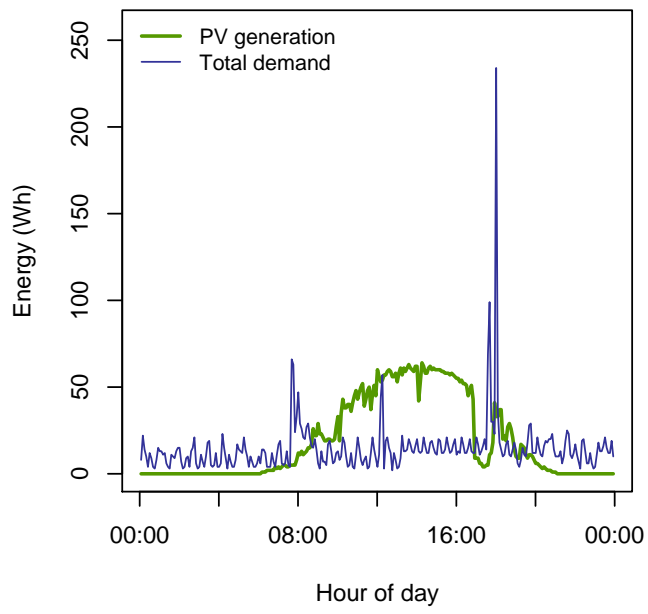

(a) Summer (21 June 2003)

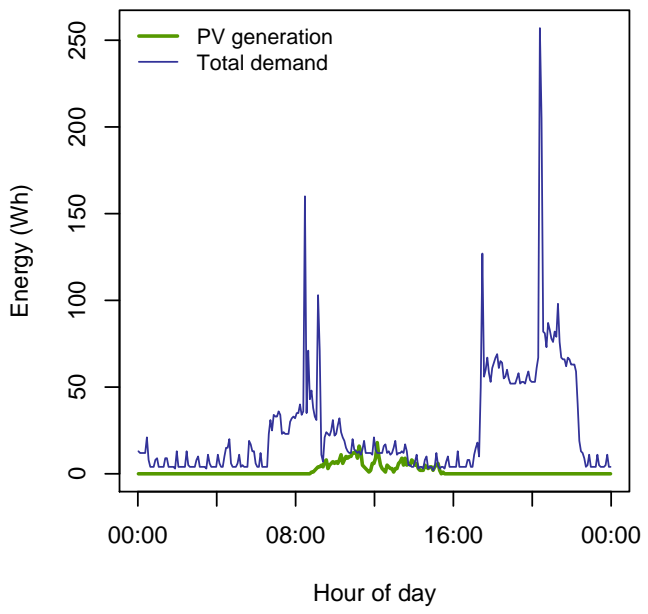

(b) Winter (21 December 2003)

FIGURE 5.16: Demand and generation for one household in Totnes $\left(1.02 \mathrm{~kW}_{\mathrm{p}}\right.$ system capacity)

The Twin Rivers study first showed that energy use in otherwise similar households could vary dramatically, in that case "by more than a factor of two" (Socolow 1978: 202). Furthermore 34\% of this difference could be directly attributed to occupant behaviour (Sonderegger 1978). The NPAC data set provides a similar opportunity to compare households. The Nottingham site was selected for this analysis as it is the largest of the three sites (19 households) and according to NPAC, the households had similar socio-economic and building design characteristics. The size of the PV systems did vary however and so generation values were equated on a per kilowatt-peak basis; demand was found to be independent of capacity and was therefore not corrected. 


\subsubsection{Household variations}

The first part of the analysis was to determine how much variation in generation and demand existed between households. To visualize this difference, a 90\% confidence interval (CI) was calculated for each time step. ${ }^{5}$ Figure 5.17 plots annual generation and demand on a weekly basis with the confidence interval in light blue. These figures show both the magnitude and the timing of variation between households, for example, demonstrating that variation in generation is much less than that of demand. This can be explained by the lack of degrees of freedom in solar generation: the households are located near each other, receiving a similar solar resource; the analysis has controlled for the difference in system capacities; therefore the remaining deviation might be explained by minor factors such as inverter performance or local shading. In contrast, electricity demand can be influenced greatly by the number of people in each household, the energy saving measures taken in each house, the types of appliances owned and the lifestyles lived. Confidence intervals for summer and winter days were also calculated and show similar trends (Figure 5.18). Overall electricity demand was approximately 5 times more variable than solar generation across annual and daily time scales.

\footnotetext{
${ }^{5}$ The 'confidence interval' represents quantile values and the $90 \%$ threshold was chosen due to the small sample size. Therefore the $90 \%$ CI spans the results of approximately 17 of the 19 households.
} 


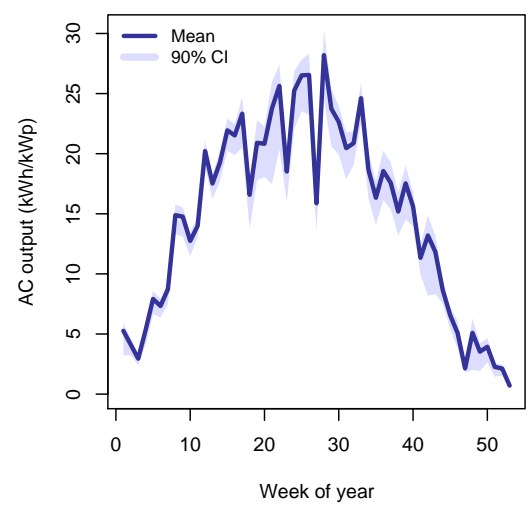

(a) PV generation

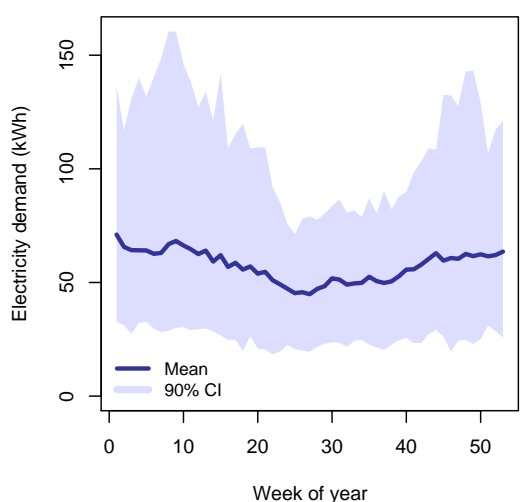

(b) Electricity demand

FIGURE 5.17: Annual PV generation and demand for 19 sites in Nottingham (weekly average)

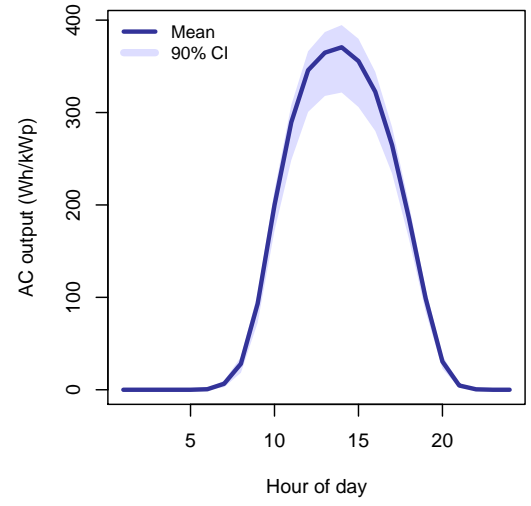

(a) Summer - generation

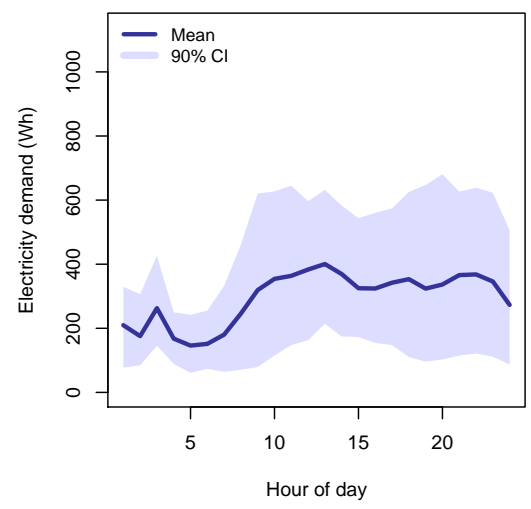

(c) Summer - demand

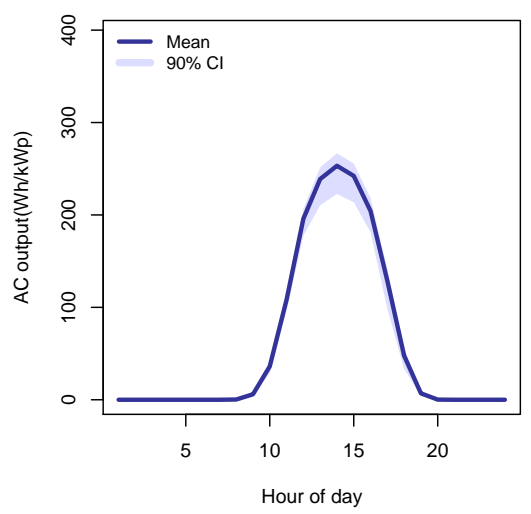

(b) Winter - generation

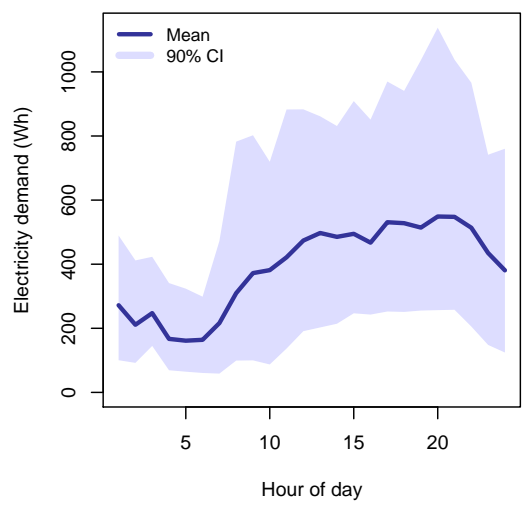

(d) Winter - demand

FIGURE 5.18: Daily PV generation and demand for 19 sites in Nottingham (hourly average) 
Despite a significant mismatch between generation and demand on average, the results suggest that a single household might be much better (or worse) off. For example, using the fifteen $1.53 \mathrm{~kW}_{\mathrm{p}}$ Nottingham households, the households with the best and the worst annual PV fractions were chosen (0.942 and 0.292 respectively) and representative days for summer and winter plotted (both Wednesdays). As Figure 5.19 shows, the solar generation profiles of each household were very similar. However demand in the low PV fraction household was characterised by large sudden spikes and a higher base load. These differences might be explained by the number of occupants or equipment stocks.

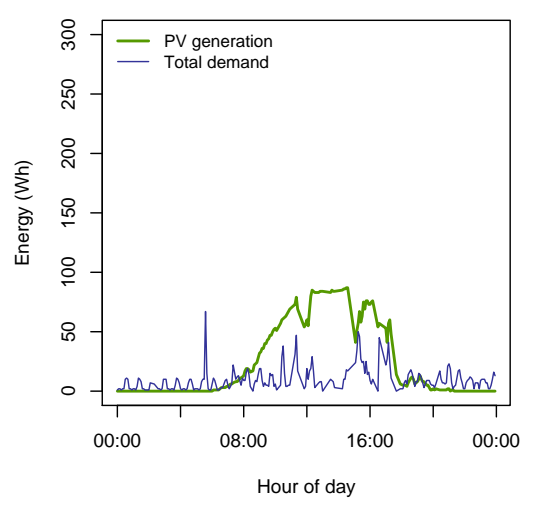

(a) 16 July 2003 - good PV fraction

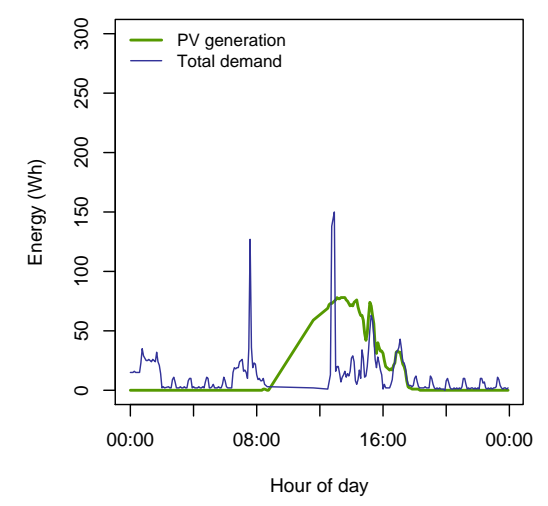

(c) 19 February 2003 - good PV fraction

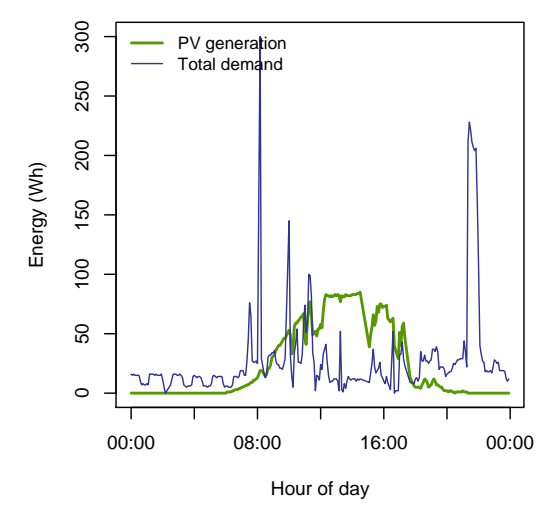

(b) 16 July 2003 - poor PV fraction

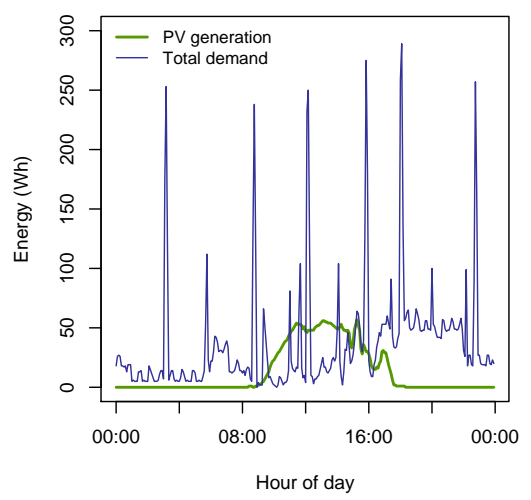

(d) 19 February 2003 - poor PV fraction

FIGURE 5.19: Demand and PV generation for two households in Nottingham (both $1.53 \mathrm{~kW}_{\mathrm{p}}$ systems) 


\subsubsection{Year-to-year variations}

No data were available to examine the consumption of the NPAC households before and after the installation of PV. However by comparing the first and second years of life with PV, it was hoped that some evidence of a gradual change in consumption might be seen. Data from the Nottingham households were taken and divided into two years: year 1 from 1 June 2002 to 31 May 2003 and year 2 from 1 June 2003 to 31 May 2004. The data were then trimmed to ensure that only complete pairs of records were used; as a result, the annual totals presented in the following tables do not match the results presented earlier.

In the first analysis, paired t-tests were used to see if there had been any change in the total demand, PV generation, imported or exported electricity. No significant differences were found (Table 5.6) but the slight increase in demand hints at the national trend in domestic electricity consumption, which has risen on average 1.5\% per annum since 1997 (DTI 2005a). No Met Office data were available to compare for differences in irradiance between the two years.

\begin{tabular}{lccrrr}
\hline Metric & Year 1 & Year 2 & \multicolumn{2}{c}{ Change } & Paired t-test \\
& mean $(\mathrm{kWh})$ & mean $(\mathrm{kWh})$ & $\mathrm{kWh}$ & $\%$ & $H_{0}: \mu=0$ \\
\hline Demand & 1914 & 2028 & 113 & 5.9 & $p=0.484$ \\
AC output & 1059 & 1044 & -15 & -1.4 & $p=0.385$ \\
Import & 1538 & 1610 & 71 & 4.6 & $p=0.647$ \\
Export & 604 & 568 & -36 & -6.0 & $p=0.110$ \\
\hline
\end{tabular}

TABLE 5.6: Year-to-year changes in electrical performance

The data were also checked for differences in the timing of electricity use or generation. For this analysis, the year-to-year change for each electrical metric was calculated on a weekly and daily basis and then compared with the average annual or daily change. For example, Figure 5.20 shows the weekly changes in electricity generation and demand from one year to the next with the weekly mean change plotted as a dashed line. T-tests found that for generation, the 
mean in autumn was slightly above the annual mean $(p \ll 0.001)$ but slightly lower in winter and spring ( $p \ll 0.001$ winter; $p=0.014$ spring). Demand showed a significant $26 \%$ rise in the summer $(p=0.002)$ and slight decreases in the autumn and winter ( $p \ll 0.001$ autumn; $p=0.0245$ winter). No significant differences were found on a daily basis.

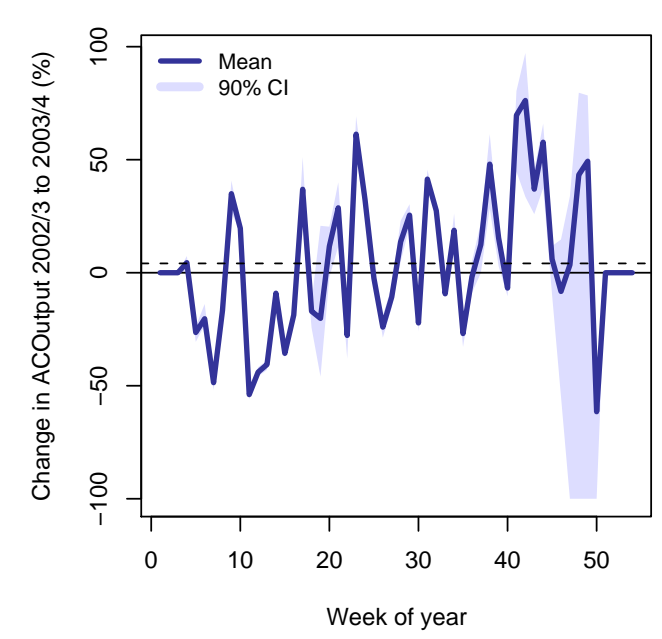

(a) PV generation

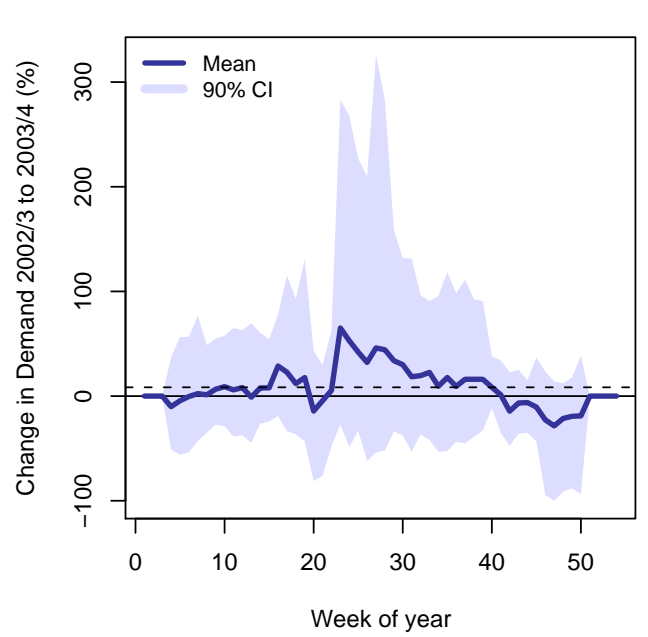

(b) Demand

FIGURE 5.20: Year-to-year changes in demand and generation for 19 households in Nottingham (dashed line indicates the average weekly change)

Despite the observed seasonal differences, the extreme variability of the generation curve does not suggest any systematic change. In contrast, electricity demand shows a consistent increase in summer and reduction in autumn. This may reflect the particularly hot summer of 2003, perhaps raising demand for refrigeration, fans, or air-conditioners (BBC News 2004). An alternative explanation could be that the PV panels were encouraging households to use more electricity in the summer (i.e. their regular demand plus the 'free' PV electricity) and less in the autumn (i.e. conserving in response to the loss of recently abundant summer electricity); however this would require further research. 


\section{Summary}

The variability of PV generation and electricity demand between otherwise similar households was explored and found that the degree of self-sufficiency achieved (as measured by annual PV fraction) could vary by more than a factor of three. For PV generation, the variations were small and could be explained as a function of each system's technical performance. However, electricity demand was more varied as it can be influenced by a large number of factors such as lifestyle, household size and appliance ownership. This provides further evidence that a household's specific response to PV will depend largely on their demand patterns (assuming equal array sizes).

No significant differences were seen in the overall year-to-year changes in generation and demand and generation shifts in particular were largely random (i.e. oscillating between negative and positive changes in successive weeks). However electricity demand showed more consistent trends, be it the increase in summer demand (due to a heat wave) or the national tendency toward greater domestic demand. ${ }^{6}$ While a pattern cannot be deduced from two years of data, these results indicate that both short-term and long-term factors may affect the degree of self-sufficiency that a PV household can achieve. Furthermore, if the short-term events are primarily uncontrollable (e.g. weather-related), then it is important that consumers be made aware of the longer-term societal trends which could undermine the self-sufficiency provided by their PV system.

\subsection{Analysis of PV tariffs}

Behavioural responses to PV do not necessarily have an explicit (i.e. financial) incentive and the interviews found evidence of intrinsic motivations, such as

\footnotetext{
${ }^{6}$ This resonates with the interview respondent discussed on page 156.
} 
households shifting loads to take advantage of their 'own' electricity. However economic incentives for PV do exist and could potentially play an important role in shaping patterns of use (even if some interview respondents indicated that the current level of these incentives was too low to inspire major changes in electricity use). Financial incentives - including grants as well as tariffs are also important in encouraging the diffusion of PV and, if these measures led to more PV installations, then there would be an opportunity for non-financial motivations of behavioural change to occur.

The interviews revealed that there are many types of PV tariff available in the UK. Households can be paid a flat-fee for their generation (hereafter named PROFILE since the tariff is determined by the features of household), per unit generated (GENERATION) or per unit exported to the grid (EXPORT). Other payment options include a hybrid of the flat-fee and export payments (named NPOWER for the NPower pilot scheme mentioned by interview respondents) and a high-rate export payment (named GERMANY after that country's well-known feed-in tariff). For context, and to estimate the savings achieved by installing PV, the cost of electricity supplied by the grid was examined as both IMPORT (the actual units purchased from the grid) and DEMAND (the total units the household would have to purchase if they did not have PV). NPAC did not have data on the tariffs used by the monitored households.

The existing tariff structures, as reported by industry respondents in the following chapter, are outlined in Table 5.7 and each has its own justification. For example, the GENERATION payment is nominally based on the renewables obligation certificate (Roc) value of the generated electricity. EXPORT payments however are paid strictly for the electricity that is returned to the grid and its value is typically the same price as the electricity purchased for import, unless a high-premium is placed on this electricity (e.g. GERMANY). The PROFILE payment is simply an easier way to administer payment for exported units; however 
without explicitly measuring generation, it does not yet qualify for Rocs.

\begin{tabular}{ll}
\hline Code & Description and notes \\
\hline $\begin{array}{c}\text { Generation payments } \\
\text { GENERATION }\end{array}$ & 5p per generated $\mathrm{kWh}$ \\
EXPORT & 7.64p per exported $\mathrm{kWh}$ \\
PROFILE & $\begin{array}{l}£ 20 \text { per quarter; used if supplier offers EXPORT but customer } \\
\text { does not have an export meter }\end{array}$ \\
NPOWER & $\begin{array}{l}\text { 10p per exported } \mathrm{kWh} \text { and } £ 30 \text { per quarter; now-defunct } \\
\text { pilot scheme }\end{array}$ \\
GERMANY & 38.2p (€0.574) per exported $\mathrm{kWh}$; tariff decreases at 5\% p.a. \\
& for newly installed systems \\
Demand charges & \\
IMPORT & 7.64p per imported $\mathrm{kWh}$ \\
DEMAND & 7.64p per imported $\mathrm{kWh}$; for total demand (i.e. regardless \\
& of whether grid-imported or PV-supplied)
\end{tabular}

TABLE 5.7: Payment plans for PV microgeneration (based on a $2.07 \mathrm{~kW}$ p system in Nottingham). Prices from industry interviews in August 2005, $\S 6.4 .1$.

The analysis focused on three questions: what is the magnitude and timing of the PV incentive, how do these payments compare with each other over the course of one year, and what is the payback of a PV system under each tariff plan. While each stakeholder (e.g. homeowner, electricity supplier, PV installation industry) is likely to have a different concept of what makes a 'good' PV tariff, this analysis aims to identify some basic considerations that will affect a tariff's effectiveness in promoting the diffusion of PV and changes in electricity consumption behaviour. The results are presented for an average UK PV system to facilitate comparison $\left(2.07 \mathrm{~kW}_{\mathrm{p}}\right.$, EST $\left.2003 b\right)$.

\subsubsection{Timing of PV incentives}

The effectiveness of PV tariffs will depend on the incentive itself, the individual's perception of it and their ability to respond (e.g. Bandura 1969). Determining the ideal magnitude of the tariff is not examined here; instead this section 
considers when tariffs might encourage households to purchase PV or consider their subsequent balance of generation and demand (i.e. how it is perceived).

The three primary types of PV incentive are constant, generation and export payments. Constant payments, e.g. PROFILE, send the weakest signals to households as they do not vary over time. As they are often used when households do not have export meters, or fail to submit their meter readings, there is no verification that the generation has actually occurred and so a non-functioning PV system would still receive the payments. However this tariff might be a good incentive for purchase since the prospective buyer can rely on a steady stream of income. This can be seen in Figure 5.21(a), as there is no variation in the payment over the course of the year; there would be some difference between households though depending on system size, house type, location and other standard information used to determine electricity tariffs. For comparison, Figure 5.21(b) shows the savings achieved by each household (i.e. their total DEMAND without PV minus their actual IMPORT). Both figures include $90 \%$ confidence intervals.

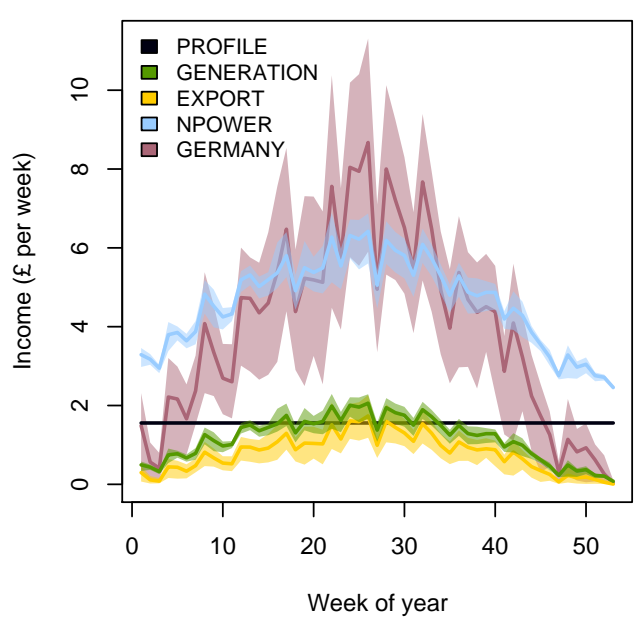

(a) Generation

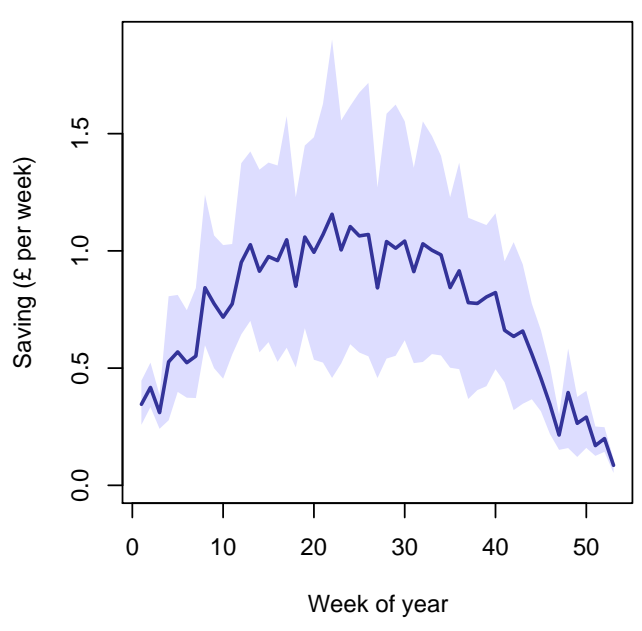

(b) Savings in demand

FIGURE 5.21: Annual payments for PV generation and demand for 19 households in Nottingham (weekly average, with $90 \%$ confidence interval) 
Unlike PROFILE tariffs, which are based on the attributes of the household and its PV system, GENERATION and EXPORT tariffs encourage households to ensure that their systems are functioning properly and producing electricity. Since they are also linked to solar output, these tariffs send their strongest signal during the summer and midday peaks in combination with the savings from reduced imports of electricity (see Figures 5.22 and 5.23). However EXPORT tariffs (especially if at a high rate, e.g. GERMANY) might encourage households to delay daytime activities until the evening in order to maximize their exports. This could potentially exacerbate the grid peak load, suggesting that EXPORT tariffs should not be set too high (experimentation would be required to determine this threshold).

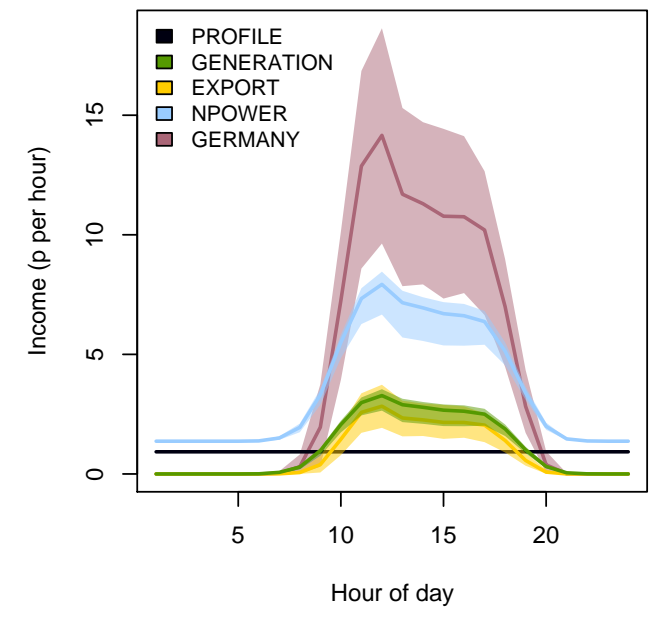

(a) Summer

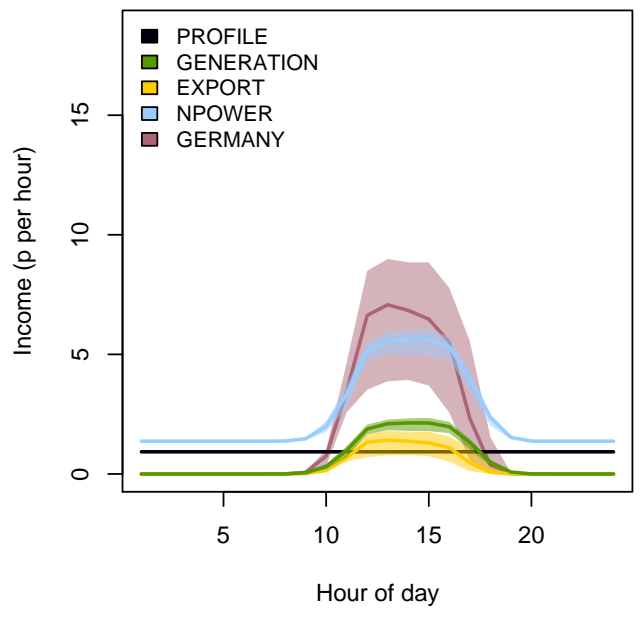

(b) Winter

FIGURE 5.22: Daily payments for PV generation for 19 households in Nottingham (hourly average, with $90 \%$ confidence interval) 


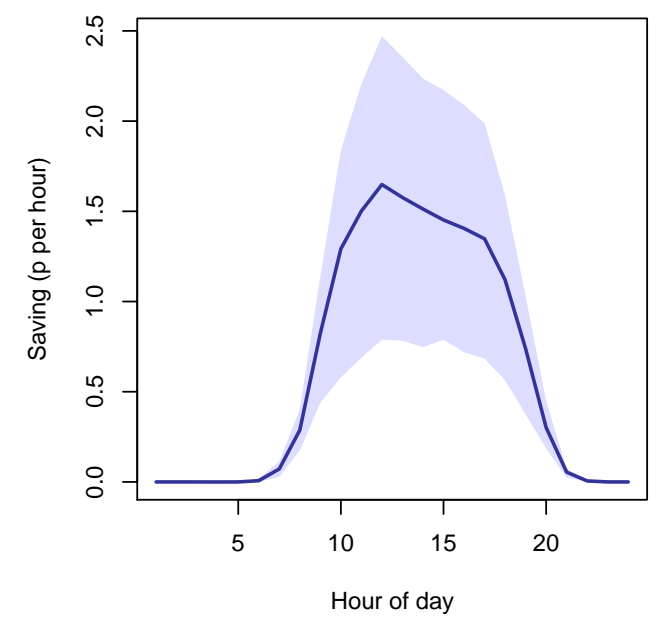

(a) Summer

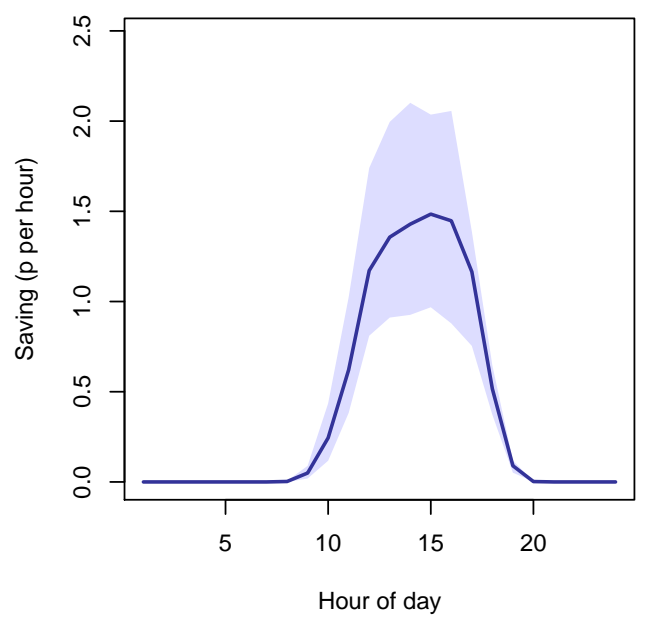

(b) Winter

FIGURE 5.23: Daily savings in electricity demand

The other payment options, NPOWER and GERMANY, are variations on these basic patterns. Germany has seen a purchase behavioural response to their tariff, with the high and guaranteed rates encouraging households to buy larger systems. $^{7}$ This would be beneficial if an energy balance policy was introduced, as generating more electricity would make it easier to meet an annual energy budget. However there might also be negative effects with larger PV systems placing greater demands on the distribution grid to absorb the resulting exports.

As a hybrid of profile and export payments, the NPOWER tariff encourages the purchase of PV and signals times of generation once installed. Given the high flat-fee component, there is less variation between households and so potential purchasers can be relatively certain of the annual income from a PV system, encouraging adoption. However this same high base payment also reduces the relative 'visibility' of the export component, meaning that the tariff signals times of generation less clearly. This tariff suggests that a combination of mea-

\footnotetext{
${ }^{7}$ The average UK small-scale $\left(<5 \mathrm{~kW}\right.$ ) installation is $2.07 \mathrm{~kW}_{\mathrm{p}}(\mathrm{EST} 2003 b)$; the average German system is $3.62 \mathrm{~kW}$ (IEA-PVPS 2004).
} 
sures may be needed to achieve both the diffusion of PV and appropriate subsequent behavioural responses.

\subsubsection{Annual payments from different tariffs}

A relative comparison of the annual incomes received from each tariff can be used to assess the costs to industry of operating these tariffs on a large scale, to determine the benefit to households, and how it might incentivize the adoption of PV. Using the nineteen systems at the Nottingham site, the data from each household was used to calculate the hypothetical annual income for each tariff (including charges for grid electricity). The results are plotted in Figure 5.24; the mean and $90 \%$ confidence intervals for each tariff were also calculated (Table 5.8).

\begin{tabular}{|c|c|c|c|}
\hline Tariff & $\begin{array}{r}\text { Mean } \\
(£)\end{array}$ & $\begin{array}{r}\text { Lower } 90 \% \\
\text { CL }(£)\end{array}$ & $\begin{array}{r}\text { Upper } 90 \% \\
\text { CL }(£)\end{array}$ \\
\hline \multicolumn{4}{|c|}{ Generation payments } \\
\hline PROFILE & 80.00 & 80.00 & 80.00 \\
\hline GENERATION & 61.45 & 50.03 & 67.30 \\
\hline EXPORT & 41.99 & 26.86 & 52.36 \\
\hline NPOWER & 244.87 & 222.03 & 256.57 \\
\hline GERMANY & 209.80 & 134.19 & 261.61 \\
\hline \multicolumn{4}{|l|}{ Demand charges } \\
\hline IMPORT & 160.74 & 59.81 & 343.99 \\
\hline DEMAND & 200.07 & 80.10 & 400.78 \\
\hline
\end{tabular}

TABLE 5.8: Annual payments for 19 PV households in Nottingham (assuming $2.07 \mathrm{~kW}_{\mathrm{p}}$ system) 


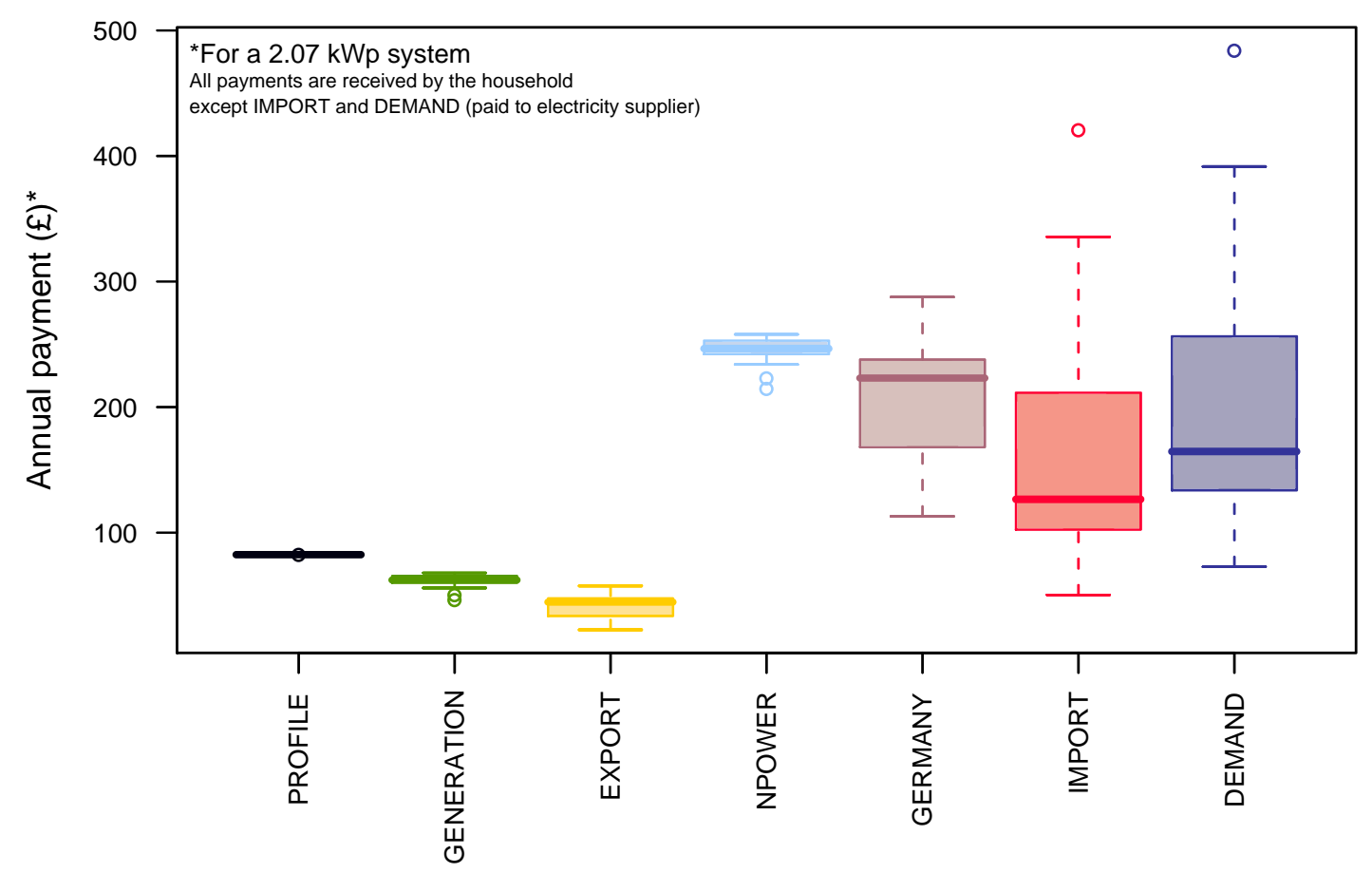

FIGURE 5.24: Annual income from different payment types. This plot shows the median and quantiles, hence the means reported in Table 5.8 does not match.

The figures in the previous section hinted at a similarity in the timing of payments received under the GENERATION and EXPORT tariffs. However a significant difference was found between the annual mean payments under these tariffs (Wilcox $W=349, p \ll 0.001$ ). ${ }^{8}$ There was also a significant difference in the variances (Bartlett's $K^{2}=4.11, d f=1, p=0.0427$ ). This can be seen in the box plot, where there is slightly greater variation in the EXPORT tariff since these payments are dependent on generation and demand. In other words, assuming the same size PV system, households with lower demand could be receiving twice as much in export payments than those with greater demand.

The second observation, perhaps surprising, is that the NPOWER pilot tariff was actually more generous than the GERMANY payment (Wilcox $W=283, p=$

\footnotetext{
${ }^{8}$ Only the EXPORT and GERMANY tariffs were found to be normally distributed and therefore non-parametric tests are used.
} 
0.002). The variances were also different (Bartlett's $K^{2}=27.1, d f=1, p \ll$ 0.001), indicating that the NPower pilot is arguably better because the income is more consistent between households (the export component of the tariff is small compared with the flat base payment). This might be significant when trying to encourage further adoption of PV, since the lack of guaranteed income under a German-style tariff (i.e. being paid only for exports) might encourage some to oversize the system at purchase.

The PROFILE tariff is currently approximated from information on the size of the PV system and the profile rate for imported electricity. This tariff is less generous than the NPOWER or GERMANY payments but the mean payment is significantly higher than the GENERATION (and therefore EXPORT) payment (Wilcox $W=0, p \ll 0.001)$. Perhaps the administrative savings afforded by the profile payment means that the electricity suppliers are able to pass along these savings to the consumer in the form of a more generous tariff; however this could not be confirmed in the industry interviews.

The financial benefit of owning PV also comes from the savings incurred by importing less electricity from the grid. Comparing the cost of imported electricity to what it would be if PV was not present, there was a significant average saving of $£ 39.21$ per year (paired Wilcox test: $V=0, p \ll 0.001$ ).

\subsubsection{The payback of PV}

The interview respondents indicated that payback was not a significant consideration in their decision to purchase PV, largely because of their environmental motivations. However, the high cost of PV does act as a major barrier to the adoption of PV by the general public (Faiers and Neame 2006). Understanding the payback issue is therefore important if the spread of PV to other households is to be encouraged. By overcoming the financial barriers to adoption, the hope 
is that these households may then experience improvements in tacit knowledge and self-efficacy, leading to a more sustainable lifestyle.

The payback of PV was calculated under the different tariff systems as follows. First, the income from each tariff was determined by scaling the smaller NPAC systems up to size of the average UK domestic PV installation (2.07 $\mathrm{kW}_{\mathrm{p}}$ ). While the price of microgeneration technologies may drop notably in the long-term (Hinnells 2005), this section is concerned with potential adoption of PV at current prices and therefore it was assumed that this system would cost approximately $£ 6000$ per installed $\mathrm{kW}_{\mathrm{p}}$ (Archibald 2005 pers. comm.). The initial cost was then reduced by a 50\% grant, available under the new Low Carbon Buildings Programme. For each yearly interval, the outstanding debt was calculated by accounting for the savings from reduced purchases of grid electricity and the benefits gained from any tariff. Each term was adjusted by its own inflation rate and discounted to get a net present value (NPV):

$$
\begin{aligned}
N P V_{t} & =N P V_{t-1}+\frac{\left(\text { ElecSavings }_{t}+m * \operatorname{TARIFF}_{t} *\left(1+i_{\text {tariff }}\right)^{t}\right)}{(1+d)^{t}} \\
\text { ElecSavings }_{t} & =\left(\text { DEMAND }_{t}-\text { IMPORT }_{t}\right) *\left(1+i_{\text {supply }}\right)^{t} \\
m & = \begin{cases}0.95^{t} & \text { for GERMANY tariff } \\
1 & \text { for all other tariffs }\end{cases}
\end{aligned}
$$

where $i_{\text {supply }}$ is the inflation rate of grid supply, $i_{\text {tariff }}$ is the inflation rate of the tariffs, $d$ is the discount rate, and TARIFF is one of the five tariffs discussed above (PROFILE, GENERATION, EXPORT, NPOWER or GERMANY). NPV $V_{0}$ is the initial grantreduced cost of the system. Three scenarios were calculated using different values for these rates (Table 5.9). 


\begin{tabular}{|c|c|c|c|c|}
\hline Scenario & $i_{\text {supply }}(\%)$ & $i_{\text {tariff }}(\%)$ & $d(\%)$ & Notes and sources \\
\hline Real data & 3.2 & 2.8 & 20 & $\begin{array}{l}\text { Inflation data from National } \\
\text { Statistics (2005) (post-liberalized } \\
\text { electricity); discount rates from } \\
\text { literature, e.g. Harrison et al. } \\
\text { (2002), Hausman (1979) }\end{array}$ \\
\hline High inflation & 9.2 & 2.8 & 20 & $\begin{array}{l}\text { Using } 2004 \text { to present electricity } \\
\text { price inflation as possible model } \\
\text { for future price rises }\end{array}$ \\
\hline $\begin{array}{l}\text { Government } \\
\text { discount }\end{array}$ & 3.2 & 2.8 & 3.5 & HM Treasury (2003) \\
\hline
\end{tabular}

TABLE 5.9: Parameters for payback scenarios

For each scenario and tariff combination, the mean payback and the upper and lower $90 \%$ confidence limits were calculated. The results are shown in Table 5.10 and indicate that using a discount rate of $20 \%$, PV will take more than 100 years to pay for itself. With an institutional discount rate, such as the government's recommended $3.5 \%$, the situation is better especially under the generous NPOWER tariff. This suggests that the 'innovating' PV households studied in the questionnaire implicitly use a lower discount rate to account for the value they place on the future consequences of climate change. It should also be noted that almost all of the payback periods are longer than the lifespan of the PV modules (25-year $80 \%$ power output warranty, BP Solar 2005) and the inverters (typical 5-year warranty, SMA 2006). 


\begin{tabular}{lccc}
\hline & \multicolumn{3}{c}{ Payback (years) } \\
Scenario and tariff & Lower $90 \%$ CL & Mean & Upper $90 \%$ CL \\
\hline Real data & $>100$ & $>100$ & $>100$ \\
PROFILE & $>100$ & $>100$ & $>100$ \\
GENERATION & $>100$ & $>100$ & $>100$ \\
EXPORT & $>100$ & $>100$ & $>100$ \\
NPOWER & $>100$ & $>100$ & $>100$ \\
GERMANY & & & \\
High inflation & $>100$ & $>100$ & $>100$ \\
PROFILE & $>100$ & $>100$ & $>100$ \\
GENERATION & $>100$ & $>100$ & $>100$ \\
EXPORT & $>100$ & $>100$ & $>100$ \\
NPOWER & $>100$ & $>100$ & $>100$ \\
GERMANY & & & \\
Government discount & 50 & 59 & 72 \\
PROFILE & 57 & 74 & $>100$ \\
GENERATION & 65 & 94 & $>100$ \\
EXPORT & 21 & 23 & 27 \\
NPOWER & 38 & 71 & $>100$ \\
GERMANY & & & \\
\hline
\end{tabular}

TABLE 5.10: PV payback periods under different scenarios for an average PV system $\left(2.07 \mathrm{~kW}_{\mathrm{p}}\right)$ in Nottingham

Figure 5.25 shows the variability of payback periods under each tariff. This indicates that, to assess payback accurately, potential adopters and their advisers must account for the performance of the proposed system and, more importantly, household demand patterns (i.e. their potential savings and exports, as seen in the GENERATION, EXPORT and GERMANY tariffs). Under the NPOWER tariff, the high flat-fee ensures that almost all households pay off their systems in less than 30 years but even this may be unacceptable to some households. One interviewee suggested that a 10-year payback period might be necessary; indeed households often consider the upfront costs of energy-efficiency investments to be an order of magnitude more important than long-term savings (Oxera 2006). Therefore, while these tariffs are important for behaviour, the wider adoption of PV might be better promoted via generous grants or deferred payment plans. 


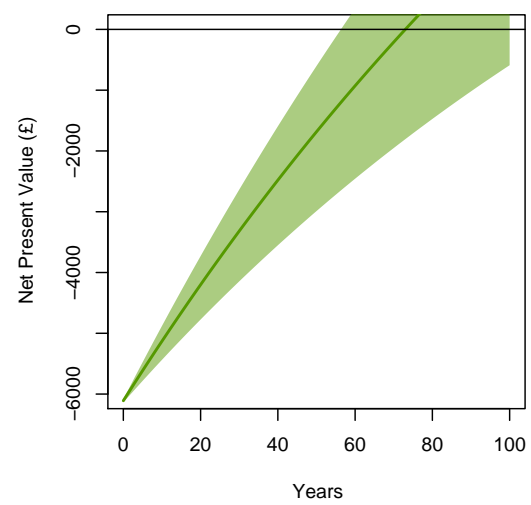

(a) GENERATION

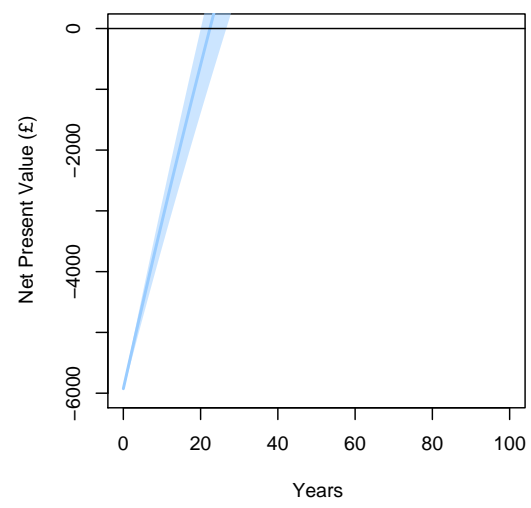

(c) NPOWER

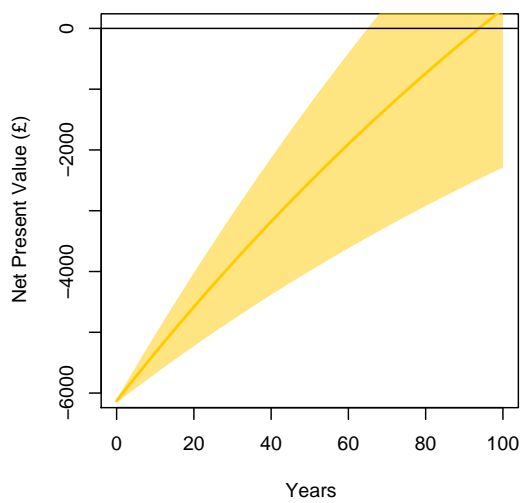

(b) EXPORT

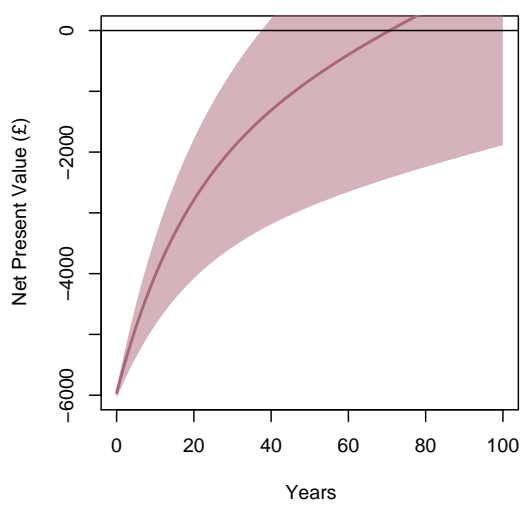

(d) GERMANY

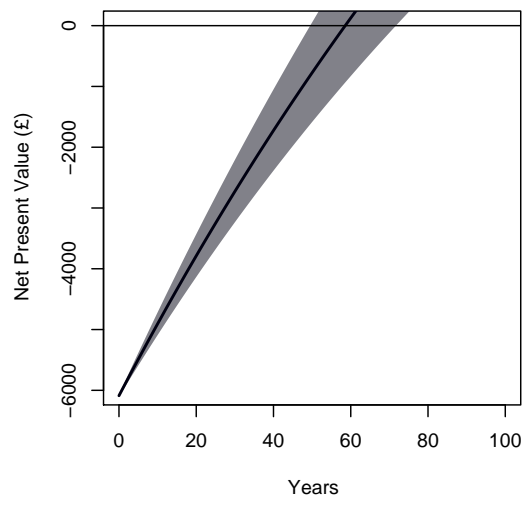

(e) PROFILE

FIGURE 5.25: Payback periods for an average PV system $\left(2.07 \mathrm{~kW}_{\mathrm{p}}\right)$ in Nottingham under various payment types (Government scenario, $i_{\text {tariff }}=2.8 \%, i_{\text {supply }}=3.2 \%, d=3.5 \%$ ) 


\section{Tariffs summary}

Microgeneration tariffs are an important issue when considering both the diffusion of PV and subsequent behavioural responses. For the 'innovators' interviewed earlier, payback was a less significant part of the adoption process than environmental concern. However even for these individuals, the upfront costs were an obstacle and the results suggested that, without an appreciation of the long-term benefits of PV (e.g. for climate change), potential adopters may pay greater attention to financial issues. The analysis suggested that addressing upfront costs directly (e.g. via larger grants) would therefore enable tariffs to be designed with a focus on consumer behaviour. Tariffs should build the tacit knowledge of consumers by reflecting the real costs and benefits of electricity flows such as generation, imports and exports (preferably on a monitor). The structure of the NPOWER tariff (i.e. a flat-fee and a per $\mathrm{kWh}$ payment), for example, could be adapted to reflect the PV fraction and energy balance concepts noted above. Determining the level of these incentives is an area for further research, particularly to understand the responses of households based on their unique attitudes and demand patterns. However tariffs are not created exclusively for the benefit of consumers and the preferences of electricity suppliers and other stakeholders are considered in the following chapters.

\section{Conclusion}

When a PV system is installed, it becomes part of a larger household energy system encompassing the building fabric, appliances and most importantly, the occupants. How these individuals respond to the system will therefore depend on the full context in which this new electricity is being generated and consumed. Chapters 3 and 4 introduced this concept by focusing on specific 
households, identifying some of their patterns of electricity consumption behaviour and their possible motivations. However, the NPAC data analysed here described the actual flows of electricity supply and demand within PV households. The data also provided an opportunity to examine the variation between PV households and the role of incentives as a cue for behavioural change.

The first finding pertains to the nature of solar generation in the UK and corresponding levels of electricity demand. It was shown that there is a notable 'mismatch' between when solar PV is generating (summer and midday) and when electricity demand is greatest (winter and evening). As a result, PV households must import and export significant amounts of electricity to meet their energy needs over the day or year. These flows of electricity may be undesirable, for example, for electricity suppliers who are concerned about the capacity of the distribution network and the potential customer demand for export metering.

It was hoped that households could be made aware of when they are generating and consuming electricity and alter their demand to make the most of their own electricity. Estimating the system's generation was shown to be a simple matter, with a weather-based 'folk' model explaining $93 \%$ of the variance in system output. However comparing generation with demand requires further sources of information. For example, the PV fraction metric was introduced as a way of demonstrating to households the proportion of their electricity that is coming from PV in real-time. An energy balance metric might be a useful complement to communicate the link between generation and demand over longer time periods. Significant variability in demand was found between households, suggesting that consumers also require information about how their specific lifestyle and equipment shapes electricity demand. Together, this information could provide households with the tacit knowledge needed to identify the causes of the generation/demand (im)balance and act in a way that 
is appropriate for their needs and lifestyle.

Tariffs paid for the electricity from PV systems are important for encouraging households to use their electricity efficiently especially if the desired behavioural changes represent societal, not personal, goals (Bandura 1977). The income from these tariffs may also shape the payback of PV systems, promoting the wider diffusion of PV. However even for the 'innovator' households studied here, upfront costs - and not the cumulative benefit of the tariffs - were the largest financial obstacle. This therefore suggests that larger grants or other mechanisms should focus on alleviating the initial costs of PV (at least until PV prices fall), while running-cost tariffs concentrate on encouraging behavioural responses. In this regard, a range of tariffs exist but some arrangements arguably send the wrong signals. For example, the PROFILE tariff provides no incentive to ensure the system's successful operation and the EXPORT tariff, if high enough, could encourage households to switch loads to the evening peak. It was therefore suggested that a hybrid NPOWER-style tariff, combining a flat-fee payment (e.g. for meeting an energy balance target) and a per kWh payment (e.g. based on PV fraction or generation) might be a better alternative.

The issue of tariffs is a reminder that PV is a socio-technical system. Indeed, the wide variety of tariffs seen suggests that this part of PV system has not yet stabilised. Designing an ideal PV tariff is therefore a difficult challenge, not least because 'ideal' is likely to mean different things to different stakeholders. The results of the questionnaire and interviews chapters also demonstrated how the energy consumption behaviour of PV households was shaped by their interactions with electricity suppliers, PV installers, and other groups. Therefore the final data chapter examines the broader socio-technical context by interviewing representatives of industry and government. 


\section{Chapter 6}

\section{INTERVIEWS WITH PV INDUSTRY REPRESENTATIVES}

The household interviews demonstrated that perceptions of PV can be influenced by interactions with other stakeholders. For example, households which indicated that their PV installer had been efficient and courteous were more likely to recommend the technology to potential adopters. Behavioural responses to PV may also be affected by institutional arrangements, for example, the types of tariffs offered by electricity suppliers. The larger socio-technical system of domestic PV is therefore important when seeking to understand how PV technology is spread and used.

The issues surrounding domestic PV can be considered in three phases: past (purchase), present (use), and future (new developments). Each stage is dominated by one or more industry actors but the influence of these stakeholders on PV households is not always direct. For example, installers and households have a direct business relationship but trade associations and government decision makers have an indirect influence through the development of new policy. The research sought to understand these relationships and ultimately how the wider socio-technical system shapes and is shaped by PV households. Interviewing key stakeholders therefore provided an opportunity to map this structure and document associated issues, such as best practices and opinions about the future direction of the industry. 


\subsection{Methodology}

Approximately 30 organizations were approached as potential stakeholders in domestic PV and ultimately 25 telephone or email interviews were conducted (Table 6.1). The interviews were semi-structured and although there were some variations in the questions for each industry sector, the main themes included the firm's history, its position within the current market, and its opinion on the future prospects for domestic PV and any obstacles to success. The interviews began in May 2005 and continued sporadically until December 2005, although each industry sector was interviewed contiguously. The average interview was about 25 minutes long and recorded to ensure the accuracy of the transcripts; however owing to the commercially sensitive nature of some information, a majority of the respondents requested that the results be presented anonymously.

\begin{tabular}{llc}
\hline Phase of PV lifecycle & Sector & \# of interviewees \\
\hline Purchase & PV installation firms & 7 \\
Use & Electricity suppliers & 5 \\
& Metering firms & 3 \\
\multirow{2}{*}{ Future changes } & Monitor manufacturers & 3 \\
& Industry organizations/lobbyists & 7 \\
\hline
\end{tabular}

TABLE 6.1: Types of PV organizations interviewed

\subsection{PV installation firms}

In March 2004, Oxford's Environmental Change Institute (ECI) conducted interviews with PV installation firms (Jardine 2004). The study revealed a growing industry but one faced with uncertainty about future government support. Similarly Stantzos (2005) found that the UK PV industry was very dependent on grant funding and had difficulty attracting alternative sources of investment. 
The interviews presented here updated these themes but focused primarily on how installer practices might influence energy consumption behaviour. For example, PV installers could promote energy awareness by drawing their clients' attention to newly installed monitoring equipment (§4.4.3). However since the household interviewees were clients of only one installation firm, interviews with other PV installation firms looked to confirm if these best practices were common throughout the industry.

Eight domestic photovoltaic installation firms were identified, representing approximately $75 \%$ of the installations performed under Stream 1 of the Major PV Demonstration grant programme (MDP), and seven were willing to be interviewed; the firms and some key points of distinction are summarized in Table 6.2. The major interview themes included customer interaction with the installation firms, the use of monitoring equipment, and policy and business issues.

\begin{tabular}{|c|c|c|c|c|c|}
\hline Firm & $\begin{array}{l}\text { Founded } \\
\text { (PV business) }\end{array}$ & Specialty & $\begin{array}{l}\text { Installations } \\
\text { per year }\end{array}$ & $\begin{array}{l}\text { Monitor } \\
\text { provided? }\end{array}$ & $\begin{array}{l}\text { Assistance \& } \\
\text { advice provided?* }\end{array}$ \\
\hline A & 1980 & $\begin{array}{l}\text { Domestic } \\
\text { on-grid } \\
(1 / 3)\end{array}$ & $\begin{array}{l}10 \text { domestic, } \\
\text { but more out- } \\
\text { sourced }\end{array}$ & Optional & Yes, both \\
\hline B & 1995 & $\begin{array}{l}\text { Social } \\
\text { housing }\end{array}$ & $\begin{array}{l}7 \quad \text { commercial, } \\
25-30 \text { domestic }\end{array}$ & Optional & Yes, advice \\
\hline $\mathrm{C}$ & $1980(1988)$ & Off-grid & $\begin{array}{l}\text { 10-15 domestic } \\
\text { on-grid }\end{array}$ & Optional & Yes, advice \\
\hline $\mathrm{D}$ & 1990 & Off-grid & Out of business & No & No \\
\hline $\mathrm{E}$ & $1997(2000)$ & All types & 38 domestic & Yes & Yes, both \\
\hline $\mathrm{F}$ & 1984 (1994) & $\begin{array}{l}\text { Off-grid, } \\
\text { wholesale }\end{array}$ & $\begin{array}{l}10 \text { domestic, } 70 \\
\text { total }<5 \mathrm{~kW}_{\mathrm{p}}\end{array}$ & Yes & Yes, advice \\
\hline G & 1992 & Domestic & 100 & Yes & Yes, advice \\
\hline
\end{tabular}

* Assistance refers to direct intervention on behalf of the client on matters such as planning approval and acquiring an export meter; Advice refers to the provision of general information on these matters. All firms arranged for grid-connection.

TABLE 6.2: Interviewed PV installers 


\subsubsection{The installation process and customer interaction}

It was demonstrated in Chapter 4 that consumer interest in PV often builds from an early introduction to the technology through advertising or mass media, to experiencing the technology in person at an exhibition or similar event. Once the decision to purchase PV is made, an installation firm must be chosen. However this could potentially be an intimidating experience: one of the respondents in the earlier ECI research indicated that "no one wants the PV industry to end up like the solar hot water industry", plagued with untrustworthy 'cowboy' installers.

To avoid this problem, the EST maintains a list of accredited PV installers and respondents indicated that this registry led to the majority of inquiries. They were uncertain as to how customers chose a specific firm, although one respondent guessed that his firm may have been popular because it was near the top of the alphabetized list. Active marketing (e.g. advertising) was not common and word-of-mouth played an important role in making potential clients aware of a given firm. However initial inquiries often came from enthusiastic individuals whose properties were unsuitable for PV technology or were located outside of the firm's coverage area. Similarly many potential customers were unaware of the financial costs and installers were keen to clarify the economics of PV from the start. After filtering these initial queries, approximately 10 to $15 \%$ of callers were viable customers but only about half of these proceeded through to completion. Therefore approximately $5 \%$ of initial inquiries to a PV firm turned into installations. Interestingly though, this success rate has changed as the industry developed and general knowledge of PV increased:

"I would say that in the early days, two to three years ago when the grant structure came out, there was more publicity for it perhaps and we were getting more inquiries where we could fend them off in the initial phone call [because of unrealistic payback expectations] 
but now actually our conversion ratio is getting better and better because we're getting a - shall we say, a higher quality of inquiry."

Although the actual installation of a PV system may take only a couple days, respondents indicated that it could take up to one year from the confirmation of an order to the final commissioning of the system, due to delays in the grant process and problems in coordinating with various contractors (particularly in the case of renovations where there was a general contractor or other on-site work). Depending on the firm, these delays were perceived to be exacerbated or alleviated by the use of subcontractors. For example, smaller firms indicated that they were often reluctant to trust subcontractors but acknowledged that by doing the installations themselves, there could be difficulties meeting customer demand. In contrast, larger firms saw subcontractors as an important way of extending their installation capacity, particularly with regard to geographic scope:

"Certainly when we first started, everything was done internally bar probably the scaffolding and the electrician who we employed locally... Recent projects have gone more down the route of using subcontractors but they are accredited installers in their own right... and we still have an installation team ourselves so more complicated projects or projects that are in areas that others didn't cover, we'll run the whole scheme."

- Firm E

From the customer's perspective, one of the best practices in PV installation was the provision of advice on related issues such as gaining planning permission, acquiring an export meter, or choosing an electricity supplier. All firms arranged the grid connection for their customers but only a few offered direct intervention to help sort out planning and metering issues. As this can be time consuming for small firms, most firms simply provide basic advice on these 
matters, for example, by recommending a particular electricity supplier. Therefore the interviews suggest that growing demand for PV may alter the types of services offered (e.g. less time available per customer) and how those services are delivered (e.g. with or without subcontractors). It should also be noted that, while most customers were satisfied with their PV systems, recent research has raised questions about the technical quality of many installations (Pearsall 2005, Jardine 2006).

\subsubsection{Monitors and meters}

The mail questionnaire in Chapter 3 revealed that $86 \%$ of respondents had a visual display monitor installed with their PV system but only the customers of one installation firm were covered. This section therefore examines the use of monitoring devices among other PV installation firms and also considers export meters, as an important part of the 'use' phase of a PV system.

All PV installations must include a generation meter as part of the grant conditions but six of the seven installation firms also offered a monitoring display device as well. In half of these cases, the devices were offered as an optional extra. This is because the monitors represent an additional expense ${ }^{1}$ and "it's not part and parcel of the process of getting [PV] to be able to demonstrate your change in behaviour" unlike large-scale demonstration projects (e.g. schools), which often include an awareness or educational mandate with the grant (Firm B). In the other three firms (accounting for approximately $75 \%$ of annual domestic PV installations), monitoring devices were standard. The primary reason for this seemed to be that the proprietors of the firms personally believed in the benefit of displaying this information:

\footnotetext{
${ }^{1}$ Respondents indicated that monitors cost between $£ 100$ and $£ 1000$ (similar to Table 3.26). EST provided $£ 150$ for a monitoring device under the MDP as it was "considered good practice" (EST 2003a).
} 
“I've got [a monitor] with my system and I just think it's the best bit. I think it's really important to see what's been produced and some of our other early customers before the grants system bought them and some of them got really enthusiastic about energy conservation."

- Firm F

The monitors offered as standard typically only showed information about the electricity generated by the PV system but the lack of consumption information did not seem to be an issue for many installers. Indeed many felt that the most important thing was to see that the system was working rather than contextualizing generation with household demand. Accordingly, the devices were typically installed in a visible place within the home (if the device facilitated this, e.g. wireless). However some installers provided anecdotal evidence (as above) that generation monitors could raise overall energy awareness, even encouraging customers to purchase consumption monitors after the installation.

One of the key attractions of a PV system is the ability to sell the generated electricity to the grid. However certain payment arrangements require an export meter and the installation firms noted that electricity suppliers were extremely reluctant to provide these devices. The installers believed that this problem occurred because there were so few PV installations that it required a disproportionate effort on the part of the electricity suppliers to service a single installation (e.g. installing, maintaining and reading the meter). Households must also pay for the meter themselves $(\approx £ 200)$, an added disincentive. As a result, most installers recommended that their customers should not bother with an export meter and instead suggested switching to an electricity supplier which paid for generated units, thereby negating the need for an export meter. 


\subsubsection{Future policy and business issues}

In recent years, demand for domestic PV has grown significantly thanks to the $50 \%$ grants provided by the Major PV Demonstration programme (MDP). However this programme expired in March 2006 and the replacement Low Carbon Buildings Programme (LCBP) had not been confirmed at the time of the interviews. The interviewees were encouraged to share their evaluation of the MDP as well as their thoughts on the future of PV in the UK. The interviewees were also asked if they participated in any lobbying activites to make their opinions known to decision makers.

All of the installation firms agreed that the grant programme had been central to the success of their businesses. ${ }^{2}$ The grants made the technology more affordable thus increasing sales but this was not the programme's only advantage:

"[The grant] legitimizes a new technology, it reduces the cost so it makes it more affordable for people to do it and also it provides some quality assurance to people, i.e. you have to become an accredited installer so it makes it safer for people to invest in it because they're going to be using companies which really exist and operate to a specific standard"

- Firm B

The previous ECI installer interviews in March 2004 indicated a great deal of uncertainty about the future of the MDP and several funding extensions since that time did not ease this concern. However the confusion over funding, specifically the upcoming LCBP grants, provided an excellent opportunity to discuss alternative PV support mechanisms. While a similar grant programme could maintain the industry's status, it was felt that substantial growth in the PV industry would only be achieved with a much larger budget. Anticipating

\footnotetext{
${ }^{2}$ The one firm that was no longer trading was the victim of fraudulent accounting.
} 
that a larger grant programme was unlikely, other support mechanisms were suggested including a German-style feed-in tariff or stamp-duty rebates on the purchase of PV houses. However the most popular option was to introduce a measure via building or planning regulations that would require a certain percentage of new-build housing to be fitted with PV:

"We've got an indication that the Low Carbon Buildings scheme won't encourage domestic-scale PV... so if that's the case, then the only thing that will encourage people to have it will be if it's in the planning regulations. So Croydon Council for instance has said that if there's a development of so many homes then a certain percentage has got to have renewable energy on it and that basically means PV because nothing else really works."

- Firm A

Importantly this quote demonstrates that PV fills an important urban niche and may thrive even under a 'technology-blind' grant programme (i.e. lowest cost). However there was a fear that shifting the focus to large-scale newbuild developments may mean fewer small private installations which are "the lifeblood of many companies in the PV industry" (Hacker 2005). This suggests that these firms will have to adapt, either becoming subcontractors to larger firms or perhaps diversifying into other renewable technologies, commercial installation, or wholesale. Some have already done this and Foxon et al. (2005: 2134) notes that these partnerships can be beneficial to "promote innovation and provide competitive advantage". Clearly though some in the industry were apprehensive about these potential changes:

"I see the industry now collapsing, I see my laying off the people that we've employed in the next few months as things start to stop and I don't see those people will come back into the industry and I see a complete waste of opportunity. It's quite disgusting to be honest." 
When finally announced, the LCBP provided $£ 80$ million of funding over three years ${ }^{3}$ for a range of microgeneration and energy-efficiency technologies (compared with the MDP's PV-only grant funding of $£ 32$ million over five years). While it is too soon to judge the success of this programme, the main concern for the installers was that government must provide a clear long-term strategy for PV if there is to be sufficient confidence for private investment to encourage continued growth. To communicate this important message to policy makers, two lobbying groups were commonly cited. However the first of these, the British Photovoltaic Association (PV-UK), was widely felt to be ineffective and many firms had left its ranks. As discussed later in §6.5.2, this was primarily due to a lack of resources and therefore the larger Renewable Energy Association (REA) has become a more popular representative. While PV is not the only technology represented by the REA, this involvement, as well as participation in industry boards and responding to consultation documents, has provided the PV industry with a way to try and secure a prosperous future.

\section{Summary}

The overall picture is of an industry in transition, trying to meet growing consumer demand on one hand but wary of faltering government support on the other. The balance of these opposing forces remains uncertain but it seems likely that there will be changes in the structure of the UK PV industry as smaller installers in particular redefine their roles relative to larger firms. The mix of firms interviewed here demonstrated some important best practices such as offering monitoring equipment and providing assistance with the bureaucratic hassles of a microgeneration installation. These firms also indicate that the MDP has been successful in promoting PV by building consumer trust with the accreditation programme.

\footnotetext{
${ }^{3}$ However £50 million remained unallocated as of May 2006.
} 


\subsection{Monitoring and metering companies}

The PV installers could be thought of as 'one-stop shops' for microgeneration since an interested customer can approach these firms and then trust them to provide the required equipment, arrange for the system to be connected to the grid, and advise on how to sell the generated electricity. This level of service encourages a positive disposition towards the technology, suggesting that the customer may be more likely to respond to the information provided by their system's metering and monitoring equipment. However the nature of this response may be quite variable as there are differences in the availability and functionality of these devices. Therefore telephone interviews were conducted with representatives of major metering and monitoring firms (Table 6.3) to understand these devices and their possible implications for household behaviour.

The interviews revealed that the two industries are extremely different and their ability to serve an emerging microgeneration market was correspondingly bound by different constraints. A similar approach was taken with each set of interviews though, focusing on common themes such as the evolution of current equipment designs, potential innovations in next-generation equipment, and the policy and business environments that affect the long-term prospects of each firm. The industries are presented separately below before considering their combined influence on PV households.

\subsubsection{Monitoring: "a spin-off of other developments"}

Monitoring devices are one of the most novel and rewarding elements of a microgeneration system, allowing households to observe the generation performance of their system and, in some cases, contrast this information with consumption data. Monitors were also found to provide a focus for the owners' 


\begin{tabular}{clll}
\hline Firm & Speciality & Interviewee & Location \\
\hline Monitoring manufacturers & & \\
A Consulting electrical engineers & Engineer & Netherlands \\
B $\quad \begin{array}{l}\text { Technical arm of large renewable } \\
\text { energy consultancy }\end{array}$ & Sales director & $\begin{array}{l}\text { Netherlands } \\
\text { \& Germany }\end{array}$ \\
C Multinational consumer electronics & R \& D director & UK \& Japan \\
$\quad$ firm & & \\
Metering manufacturers and service providers & & Engineer \\
D Meter operator & $\begin{array}{l}\text { Director of business } \\
\text { E Meter operator }\end{array}$ & UK \\
F Meter manufacturer & Senior engineer & UK \\
\hline
\end{tabular}

TABLE 6.3: Interviewed monitoring and metering companies

pride in their system and a discussion point for introducing the technology to friends and family. A range of PV monitoring devices are available and the interviews sought to describe these differences, as well as how the technologies were created and how they might evolve in the coming years.

One of the first observations was that monitoring equipment firms are not primarily based in the United Kingdom, but instead have developed in (or near) countries with more established renewable energy markets such as Japan, the Netherlands, and Germany. ${ }^{4}$ Most of the firms were small to medium-sized enterprises that developed PV monitoring devices as an extension of a core business (typically based in renewable energy technologies such as inverters). The exception was Sharp (Firm C), a well-known multinational consumer electronics firm, but similarly their monitoring device was developed to meet a local PV market (in Japan) and took advantage of in-house expertise (in power conditioning equipment and LCD displays).

In the case of the European firms, the catalyst for the development of a PV monitoring device was the firm's participation in large-scale PV projects. These projects were typically government-funded technology demonstrations

\footnotetext{
${ }^{4}$ There is one UK monitoring firm but they were not available for an interview.
} 
and accordingly monitoring equipment was required both to provide technical information on the system's performance and to raise awareness among the PV building's occupants and visitors. These early devices were then adapted for use in the domestic sector when it became clear that there was also a demand for performance information in a household context. This transition however was not driven by the requirements of government grant programmes but by the firms observing emerging markets and responding accordingly:

"... we saw that it was an interest of the early adapters [sic] at least to see what the system's output was ... there are a lot of Dutch websites of people with PV systems where they keep track of their yield and they tell other people about their experience with the systems and so there are many forums where people exchange experience so that [demand for monitoring equipment] is easily accessible."

- Firm A

The firms indicated that the design of their monitors had changed very little since the devices were first introduced nearly ten years ago. However there had been relevant technological innovations, particularly in communications technology, that led to slight alterations in the offerings. The designs of monitoring devices might be considered as one of three types:

Basic: These were the simplest monitoring devices and showed only the generation performance of the PV system, often over a variety of time-scales (e.g. instantaneous, cumulative daily or cumulative since installation). The devices cost approximately $€ 150$ (£100). One firm had recently enhanced their device by adding communication equipment so that generation information could be automatically uploaded to a website. PV households could then log on to this site and view the performance of their system plotted over time and compared with other systems in their neighbourhood or city. 
Hybrid: The second class of monitoring device displayed the generation information of a 'basic' monitor but also measured the household's electricity consumption, typically with an additional metric or indicator to compare these two flows (e.g. a green light if the household was exporting electricity or red if it was importing). A manufacturer of a 'basic' device indicated that measuring consumption information would make their device too expensive and indeed hybrid devices cost approximately $€ 300$ ( $£ 200)$. There also seemed to be a fundamentally different approach in the design of these devices with the basic device intended for quick installation by the household and the hybrid device requiring the services of a professional electrician.

Deluxe: This class of device encompassed the features of hybrid monitors but also provided an array of additional display, communication, and data analysis options. For example, Sharp recently announced a monitor that displays generation and consumption information, a system's import or export status, its financial income and, most interestingly, tracks the household's energy consumption and generation against a target over a given time period. A wide variety of communication options (e.g. synchronization with a computer) and a colour display suggest that this device could encourage frequent household interaction. However these features come at a cost and the device is expected to sell in Japan for approximately £500. ${ }^{5}$ The device, shown in Figure 6.1, is not yet available in the UK.

Monitoring devices were sold through various channels including wholesalers and direct to households within the firm's local area. The most common point of sale was via PV installation firms who "use it as a unique selling point"

\footnotetext{
${ }^{5}$ The monitor is sold with Sharp's PV inverter and cannot be purchased separately. The total package costs $¥ 300,000$ ( $€ 2100$ or $£ 1500$ ) (Sharp 2005); a similar inverter purchased separately is estimated to cost $£ 1000-1100$.
} 


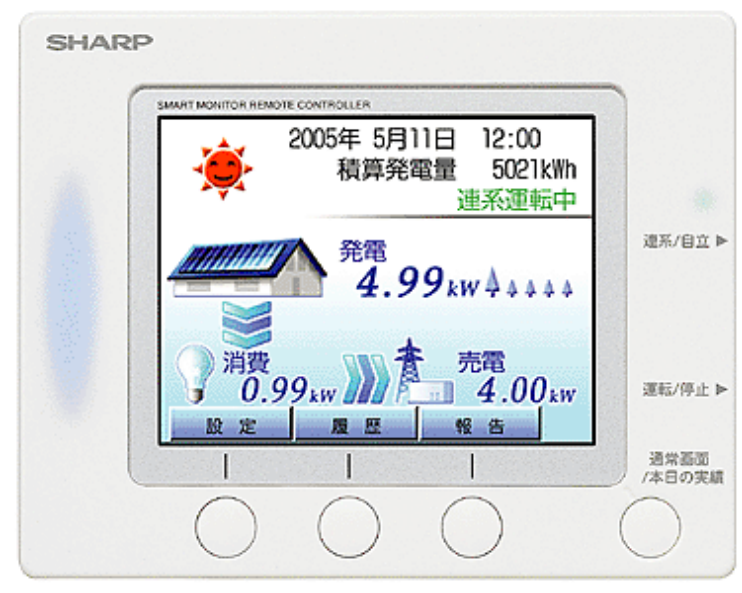

FIGURE 6.1: Sharp JH-G51X PV monitoring device

to attract customers (Firm A). However the demand for monitoring equipment is largely dependent on subsidy support:

"As soon as there's a subsidy for PV systems, like in the UK you have, then the demand for PV systems goes up and we sell more and for example in Holland, there's no subsidy at all anymore and the amount has dropped quickly so clearly it's a percentage of the number of PV systems sold."

To alleviate this problem, manufacturers were trying to expand their market by diversifying into different countries and adapting their devices for use with other microgeneration technologies. Respondents felt that these efforts could take at least five years to pay off and therefore an additional strategy was to use contacts within the architecture and building industries to promote the wider use of their products, e.g. by installing the devices in new homes. ${ }^{6}$ Despite these professional links, "it's very difficult because every euro is one euro too much for those guys" (Firm B). Customer demand for these devices may grow independently of the building sector though, as one respondent noted that rising energy prices creates general interest in monitoring.

\footnotetext{
${ }^{6}$ Both homes with and without microgeneration; one firm produces a consumption monitor (for electricity, gas and water) for non-microgenerating homes, similar to their PV device.
} 
The unfortunate result of this grant dependence is that the number of units produced was quite small (several hundred per year in the European market; although Sharp was planning to produce 2000 units per month of their device (Sharp 2005)). This prevents any large economies of scale and respondents indicated that most of the cost of the device remained in its development. This perhaps explains why the firms had not significantly altered their initial designs and suggests that future innovation in monitor design will depend on volume sales. Fortunately these firms do not sell only monitoring devices and therefore should the grant programmes cease (in the UK or elsewhere), the design expertise is likely to remain within a viable firm.

\subsubsection{Metering: "a commodity item"}

With nearly 27 million electricity meters in the UK (Ofgem 2006b), the metering industry is much larger and more complex than the monitoring sector. These firms have a long history and have faced many changes, most notably the liberalization of metering services in 2003. This has led to a specialization in services and the 'metering' industry could be considered to include manufacturers, procurers and operators. Another notable difference is that metering equipment is a statutory part of the electricity system and therefore regulated by Ofgem. These factors have shaped a complex industry and therefore any changes to this infrastructure, e.g. the installation of export meters for microgeneration, are likely to face significant institutional inertia. To understand these issues, interviews were conducted with representatives of three UK metering firms, covering both manufacturers and service providers.

Prior to the liberalization of the electricity system, local electricity supply boards owned and operated the metering equipment. Since then however, this responsibility has shifted to the district network operators (DNOs), who 
as "guardians of the network", must ensure that all supply points are properly metered (Firm E). The 'supplier hub' principle means that electricity suppliers contract for these services but $90 \%$ of domestic meters are still run by the DNOs. However the DNOs are limited in what they can charge for metering by Ofgem as part of its mandate to protect consumers ( $£ 1.12$ per meter per year) (Ofgem 2006b). This distribution price control encourages the DNOs to maximize the efficiency of their service provision and as a result, they seek to provide the minimum meter requirement and keep servicing costs as low as possible:

"...everyone has a meter and the distribution company wants to keep its installed metering base as pure as possible. So it doesn't want to have to know that 46 Acacia Avenue has a different type of meter because it just wants the guy to carry one set of tools, one meter, one set of calibration equipment so what you tend to find is historically the regions [i.e. DNOs] have concentrated on one or perhaps two metering types."

- Firm E

Accordingly, there is little incentive to offer more innovative and expensive metering services and domestic electricity meters are typically replaced with similar equipment at the end of a device's 15 to 25 year certified life. ${ }^{7}$ The most common meter currently installed in the UK households is known as a Ferrari meter, an electromechanical device which measures imported electricity only and frequently has backstops fitted to prevent reverse-flow. However Ofgem (2005) is uncertain how many meters have backstops and so there is a concern that if fitted in a microgenerating household, these meters would reverse during export and therefore incorrectly measure imported electricity. The manufacture of Ferrari meters stopped in the UK about four years ago and electronic meters, including more sophisticated security features, are the new standard.

\footnotetext{
${ }^{7}$ Refurbishment of electromechanical meters had been common practice in the old electricity system but this practice is uneconomic in the new business environment.
} 
As the following quote demonstrates, this focus on one or two types of meters has created a strong pressure in the market:

\begin{abstract}
"The base meter has become a commodity item... one of our competitors at one time was shipping in fully-built domestic electricity meters from China... at something below £5 each. Now compare that with the cost of sending somebody around to somebody's house, arranging an appointment to get in, disconnecting the old meter and installing it, so the meter became fairly negligible compared to the cost of getting it on-site and into the circuit. All the profits have been squeezed out of the business, all the manufacturers would dearly love to see an added-value product where they could differentiate the functionality, attack the market share other than by finding another few pennies off the manufacturing cost."
\end{abstract}

- Firm F

A potential source for this 'added-value' is the recent innovations in smart metering technologies (SMWG 2001). Automated meter reading (AMR), for example, provides additional communications functionality, paving the way for time-of-day pricing or other innovative tariffs as well as frequent querying of demand data for more accurate balancing and settlements under the British Electricity Trading and Transmission Arrangements (Betta). Often these meters are fitted with multiple registers, thus allowing microgenerators to record import and exported electricity separately. Despite the promise of these technologies, there are barriers to their adoption in the UK (Ofgem 2006b). The primary obstacle is cost, both in absolute terms (they are more expensive than traditional meters) and more importantly the way in which the industry structure makes it difficult to decide who will pay for such equipment:

"You're talking of a running cost of about a fiver a year [on a traditional meter]. If you look at an AMR meter, it's considerably more than that so you're talking of a payback of somewhere between ten and fifteen years. Now you then have to ask the question, who's the contract with? Because the contract, if you wanted to have a loadprofile based AMR meter, you probably sold it via the energy supply 
company but the maximum duration in the UK for a residential contract is 28 days. No one is going to screw a hundred quids worth of kit to the wall on the basis of a 28 day contract. You then say, well why wouldn't the DNO do it? And the question is why would the DNO, because the DNO gets paid on difference between what the book value of its assets is and what it's allowed to charge. So why would it ever increase the value of its assets by ten times? It's really difficult to understand who would buy this."

- Firm E

In their work, Ofgem's Smart Metering Working Group recognized that there is a "disjointed value chain" for AMR technologies but asserted that "the market itself would find solutions to many, if not all, of the perceived barriers to AMR taking off in the UK if there is enough demand" (SMWG 2001: 16). This situation could be seen as a chicken-and-egg scenario as the household interviews suggested that the institutional arrangements prevent customer demand from being realised. The respondent above interestingly referred to two other AMR markets to highlight the difference between the UK and other countries. For example in Italy, the installation of 27 million AMR meters was widely perceived within the industry as a move by the incumbent distributor to reinforce its position and prevent further liberalization of the market. Similarly in the US and Ontario, millions of AMR meters are being fitted as there is a clear financial benefit to utilities: first because the meters are read (and consumers billed) monthly (as opposed to twice a year on average in the UK (Ofgem 2006b)) and second because there are serious concerns about peak capacity in the system and AMR technology can introduce tariffs which reflect the high cost of this electricity, reducing peak demand (less of an issue in the UK (Owen and Ward 2006), especially for PV which generates off-peak). More importantly though, these cases show that AMR innovations were primarily introduced for the benefit of utilities and the impact on customers (e.g. fuel poverty concerns associated with time-of-day pricing) seem to have been given less importance. 
So where does this leave metering for microgeneration in the UK? At the moment, respondents noted that there were no actual barriers to getting an export meter if a household so desired. However given the structure of the industry, there was no economic incentive or obligation for either the DNO or the supplier to fit this equipment and the household must therefore pay the full cost, perhaps $£ 200$ or more including installation. Furthermore since only one electricity supplier pays for metered exported electricity, it is much easier to choose a supplier that instead pays for generated electricity or uses a profiled (flat-fee) tariff. Finally although generation meters are used as 'fiscal' meters for the 'sale and buy-back' agreements under which Rocs are currently allocated $(\S 1.2 .4)$, the small microgeneration market means that most of the traditional metering companies interviewed here had little interest in working with these devices at the time of the interviews.

As the following quote demonstrates, metering arrangements for microgeneration are still being developed and the existing installations of export meters have been primarily to prepare for potential shifts in the market and to maintain good customer relations:

“We don't really make any money out of microgeneration or export metering at all ....it's not a large-scale thing you know, just like perhaps a slowly growing thing,... what's important is that there are people out there who are capable of doing it and they are willing to do it and it's just a case of the supplier advising the customer the correct course of action and putting in touch with the right people so that we can come and endeavour to get suppliers metered correctly, that's all we're really there for."

- Firm D

Smart metering pilot studies have been proposed (Ofgem 2006b, Owen and Ward 2006) and hopefully these efforts will make a stronger case for the use of innovative metering in microgeneration. However, the metering industry 
appears to be content to wait for the results of these studies before committing to metering for microgeneration.

\section{Summary}

Metering and monitoring play a central role in exploiting the benefits of microgeneration. Accurate import, export and generation meters are needed to record the system's performance and set the basis of fair payments for microgenerated electricity: the questionnaire found that, while all households had import and generation meters, export meters were only present in $48 \%$ of homes. Monitoring equipment (owned by $86 \%$ of questionnaire respondents) can be used to display this and other information, encouraging responsible electricity consumption. Despite these complementary roles, no evidence was found of a significant link between monitoring and metering technologies. Similarly the two industries had very different structures and were subject to different drivers for innovation. Arguably the government therefore has a role to play in promoting these technologies, as there may be important benefits for households and society which are not reflected by commercial investment criteria. This has been seen in recent discussions about pilot projects for smart metering innovation (e.g. Ofgem 2006b). Microgeneration tariffs are central to this link between metering, monitoring and consumer behaviour and therefore the role of electricity suppliers is now examined.

\subsection{Electricity suppliers}

Like the metering industry, domestic electricity supply has undergone major changes in the last decade. The liberalization of the public electricity supply boards enabled supply companies to compete for customers with a suite of tariffs differentiated by cost or environmental credentials. Many of these firms of- 
fer some form of tariff for microgeneration, paying for the electricity generated and exported by these technologies. However in the absence of central government guidance or regulations on these tariffs (such as the German feed-in law), the reasoning for the different schemes is not immediately apparent. Therefore interviews with major electricity suppliers were conducted to understand the microgeneration market and how it might change in the coming years.

\subsubsection{Offers for microgeneration}

The interviewees and their respective microgeneration tariffs are described in Table 6.4. Like the designs of monitoring devices, many of these tariffs have an established history and according to the respondents they had not been significantly altered since they were first established by the previous public electricity supply boards. It should also be noted that all of these tariffs require the customer to get their grid electricity from the same supplier, often from a green electricity tariff as shown in the questionnaire.

\begin{tabular}{lll}
\hline Firm & Description of tariff* & \# of customers \\
\hline A & 4.5p per generated kWh & $150(75 \mathrm{PV})$ \\
B & $\begin{array}{l}\text { Paid for exports at same rate as import tariff, } \\
\text { regardless of the tariff; if no export meter, a } \\
\text { profile-based flat payment is made }\end{array}$ & meters) \\
& $\begin{array}{l}\text { 5p per generated kWh } \\
\text { no offer }\end{array}$ & $\begin{array}{l}150 \text { "mainly PV) } \\
\text { "a handful, not }\end{array}$ \\
t & $\begin{array}{l}\text { 7.64p pen or dozens" } \\
\text { charge) }\end{array}$ & 130 \\
\hline
\end{tabular}

* With all of these tariffs, the customer must also have their import contract with the same supplier.

TABLE 6.4: Payment plans for microgeneration (as of August 2005)

The diversity of the tariffs may be a result of the small market size, freeing suppliers from the strong competition seen, for example, with import tariffs. However a small market also means that it can be quite difficult to discover 
the tariffs and so customers generally take the first deal they find, often guided by the advice of their PV installer: as one programme manager said, "people like me are hidden within businesses" (Firm E). Only two of the interviewed companies listed their microgeneration plans on their website and this omission appeared to be intentional. Many respondents indicated that the tariffs were considered to be small experimental pilot schemes and made it clear that their companies were not getting very little, if any, financial benefit by offering these tariffs (e.g. the Rocs from microgenerators were a very small part of a firm's overall obligation). However there were perceived advantages in terms of customer goodwill, public relations, and the usefulness of collected data. In the words of Firm B's representative, these tariffs could therefore be considered "an aspirational product" giving electricity suppliers experience in what could become a significant market:

"I think we're at very early stages of something that could potentially be very large so we need to be in the party now as it were, understanding what's going on out there so we're ready when things really do start progressing."

- Firm E

\subsubsection{Considerations affecting microgeneration tariffs}

The interviewees identified several major barriers, preventing both the largescale adoption of PV and their ability to offer different tariffs. The three main issues were:

Balancing and settlement: To ensure the smooth operation of the national grid, electricity suppliers must report the demand of their customers on a halfhourly basis and purchase matching supplies on the wholesale electricity market via Betta. Since contracts between suppliers and generators are fixed in advance, Betta imposes penalties on those failing to meet a stated 
half-hourly quota. This 'imbalance' is a source of concern to suppliers as microgeneration could affect the estimated level of domestic demand used in the settlement process and result in penalty charges. Since domestic properties are not fitted with half-hourly meters, Ofgem has permitted electricity suppliers to estimate the demand of small generators from socalled P81 profiles (based on the size of the household and the type of generation technology) since September 2003. However at the time of the interviews, most suppliers were not using these profiles for PV customers and were therefore unable to claim the settlement value of exported electricity (with the exception of approximately 130 customers with firm B).

"Suppliers are not using this because it costs them $£ 50 / y$ to service an export contract and it's worth about the same for $1 \mathrm{~kW}$ PV or DCHP [domestic combined heat and power] so there is no value left over. There is one wind site going through P81 but I suspect that is about a $20 \mathrm{~kW}$ unit, hence much better economics."

Rocs: The renewables obligation certificates (Rocs) from microgeneration did not make a significant contribution to the suppliers' overall renewables obligation, although there was strong customer demand for Roc reimbursement and potential growth. For suppliers to offer a microgeneration tariff including the value of the Rocs, several issues must be addressed. For example, Rocs can currently only be issued to the generator, although individual households may not generate enough to claim a Roc (1 MWh of renewable generation in a year, i.e. with rounding greater than 500 $\mathrm{kWh}$ per year) or be able to decipher the 27-page application form (Ofgem 2006a) needed to make a claim. If the Roc is successfully allocated to a microgenerator, the electricity supplier then faces administrative costs and logistic barriers when trying to collect these credits from customers: 
“To gain Roc value, for example, we've got to take a reading within five days [of an Ofgem deadline] and that can be impossible for a household because if you're on holiday for the week, then that's it... another example is the fact that the Rocs are issued to the generator and then there's a three-day window there that they've got to transfer it over to us, of course if they're on holiday - which I've had happen to me — then you're missing out."

- Firm C

Since the interviews, some suppliers have started offering Roc-eligible tariffs and guidance on completing the appropriate forms but the quote suggests that the introduction of automated meter reading could assist this process. Another proposed solution to the Roc issue was outlined in the recent renewables obligation consultation and was generally supported by the electricity suppliers. It proposes the creation of Roc agents who would facilitate the certification of microgeneration installations and the accrual of Rocs to electricity suppliers or other parties (DTI 2006d).

Export metering: The export metering issues identified above - i.e. who is responsible for acquiring and paying for an export meter — were also seen as a source of uncertainty by electricity suppliers. That is, if electricity suppliers do not need to provide export metering for settlement purposes they would prefer to avoid the expense and complication of a second meter. To this end, most of the respondents indicated that they would prefer for microgeneration to be sized appropriately for the demand of the household and thus minimizing exports to the grid. Furthermore the novelty of microgeneration means that the appropriate institutions to make the sector function at commercial scales were not yet in place, as the quote below demonstrates:

"We've got around 150 customers on the portfolio and I think at maximum we've got 20 with export meters and I tell you 
the reason. There's a lot of inexperience around the industry of dealing with these sort of installations, it can take anything up to 6 weeks to get a meter fitted and that's with the companies where I've got a really good relationship... it's a case of getting on the phone and arranging it as an odd job because it's just not something catered for in contracts across the industry. It's not the easiest task that I face."

- Firm B

DTI and Ofgem have been looking at these issues for several years and there is progress being made. Electricity suppliers indicated that they were involved in these processes, through membership of industry workgroups or by responding to consultation documents. As established members of the electricity industry, suppliers also had prominent representation on policy committees (e.g. Ofgem's Distributed Generation Co-ordinating Group). However there was a recognition that the sector should not be complacent in such a quickly evolving market:

"There are so many different people involved in it that suppliers can be only seen as a small part of it. Installers are pushing for things so we've got to make sure that our views are heard."

- Firm C

\subsubsection{Strategies for a growing market}

Electricity suppliers were generally optimistic about the growth potential of microgeneration but again, high capital costs for households were seen as the main barrier to widespread diffusion of the technology. Respondents indicated that cost reductions could occur if large volumes of microgeneration were introduced through planning regulations or by working with housing developers (e.g. Merton Council's 10\% renewables policy). Although such policies raise questions about the role of PV versus lower-cost technologies, these policies could ultimately lead to more households with microgeneration and corre- 
spondingly less demand for grid supplied electricity. This appeared to be encouraging electricity suppliers to look at how their business will have to adapt in such a scenario:

“Ultimately we're in a position, that if micro DG [distributed generation] does grow, then it's going to hit our sales so if we can get into a position where actually we're selling or leasing the kit to the marketplace and retaining that customer for as long a period of time, even though it is on reduced consumption, then economically, that's better for us."

- Firm E

In other words, the energy service company (Esco) model is one of the preferred approaches to microgeneration. While there were plans to introduce interim offers, largely based on technology-specific export profiles or generation tariffs, the long term strategy (e.g. five to ten years) was to provide a 'one-stop shop' for microgeneration. The perceived benefit of this scenario was 'simplicity', allowing the electricity supplier to make arrangements with microgeneration installers, metering companies and regulators thus making the owning and operation of microgeneration as transparent as electricity is sold today:

"Normally with electricity supply, it's a case of 'we can have this or we can go somewhere else and have that from them' and that's the way I think it will pan out [with microgeneration] ... if someone offers a more complicated offering ...then that's up to them but I would think we've got to make the offering attractive without this additional complexity for the customer."

- Firm D

The potential of microgeneration as a means of affecting consumer behaviour, and hence managing electricity demand, was discussed but it was not a priority for the electricity suppliers. However there was a recognition that microgeneration could fit well with other demand-side innovations and policies such as automated meter reading and the Energy Efficiency Commitment 
(EEC), particularly once easier energy-efficiency gains are made - "there's only so many cavities that you can fill out there so where are we going to go next for carbon reduction?" (Firm E). At the time of the interviews though, there was insufficient volume in the market to assess the potential demand-side management (DSM) benefits of microgeneration. Further research is therefore likely to required before the industry will take any major steps to use microgeneration as an active demand management tool. The microgeneration strategy also addressed these issues, suggesting that PV and other microgeneration technologies ${ }^{8}$ might be included in the next round of the EEC and highlighting the need for additional research on consumer behaviour and microgeneration (DTI 2006a).

\subsubsection{Analysis of retail electricity prices}

Electricity suppliers are coming to terms with what microgeneration will mean for their business. Most interestingly this learning process appeared to be driven primarily by well-informed consumers, who often knew more about the technologies than their electricity suppliers and consequently wanted greater levels of payment. Education should work both ways though and electricity suppliers acknowledged that more should be done to inform the public about the realities of the electricity system and how microgeneration fits in:

"When [the customers] phone up and they say 'Well I'm paying you 10 pence a unit for everything that I'm taking off you, why can't you pay me that back?', what they don't understand is that you're not just paying for the power, you're paying for the metering etcetera and the whole distribution system so they think that they're entitled to have the same value back. It's difficult to get across to them that really they're not."

\footnotetext{
${ }^{8}$ Micro-CHP is currently included as an 'innovative action' for the EEC.
} 
However microgeneration does avoid many of the costs involved in traditional generation. Table 6.5 demonstrates the breakdown of an average electricity bill, showing the cost of generation, transmission, distribution, administration and so on. ${ }^{9}$ Since the interviews, the price of electricity has risen to approximately 10 pence per kilowatt hour (uSwitch.com 2006).

\begin{tabular}{lrrr}
\hline Item * & $\begin{array}{r}\text { Annual } \\
\text { cost }(£)\end{array}$ & Percent & Pence per kWh \\
\hline Generator cost (wholesale price) & 140 & 39.7 & 3.97 \\
Supply costs and profit margin & 102 & 28.9 & 2.89 \\
Distribution & 59 & 16.7 & 1.67 \\
VAT & 18 & 5.0 & 0.51 \\
Environmental (average, RO \& EEC) & 16 & 4.5 & 0.45 \\
Transmission & 13 & 3.7 & 0.37 \\
Balancing and use of system & 3.8 & 1.1 & 0.11 \\
Meter provision & 1 & 0.3 & 0.03 \\
\hline Total & 353 & 100 & 10 \\
\hline
\end{tabular}

* Some of these costs (e.g. metering) are likely included in the standing quarterly charges.

TABLE 6.5: A breakdown of UK electricity prices (Ofgem 2006d, Rhodes 2005).

Some of these services are clearly required regardless of how the electricity is supplied and used (e.g. metering). However a fair payment for microgeneration should arguably account for the value of generated and exported electricity as it compares to the components of the retail price. For example, electricity suppliers can claim the renewables obligation certificates from their microgeneration customers based on the amount of electricity these households generate. Modified settlement profiles can also be used to account for the amount of electricity generated by microgenerators; in other words, if suppliers use a profile which assumes that the households are generating, and they do not, the suppliers will incur a penalty through the settlement process. Since generation could be used entirely within the home, use of system charges should also be

\footnotetext{
${ }^{9}$ This breakdown is for an average electricity bill. The divisions are likely to be different for renewable electricity tariffs which are not dependent on fuel prices.
} 
refunded. Microgenerating households should therefore be paid for these values and the payment for generated kilowatt hours, regardless of whether they are used in the home or exported, can be calculated as follows:

Generation payment $=$ Environmental costs + Balancing and UoS costs $+5 \%$ VAT

Since the environmental cost listed by Ofgem is an average, it underestimates the market value of a Roc (approximately $£ 40$ per MWh or $4 p$ per kWh). Furthermore since generators are allowed to charge something to recoup their capital costs, PV households should arguably have a similar entitlement (though it may not be the full $3.97 \mathrm{p}$ per $\mathrm{kWh}$ because there is no need for fuel). This additional value is not considered here and therefore the minimum generation payment is as follows:

$$
\begin{aligned}
\text { Minimum generation payment } & =1.05(4 \mathrm{p} \text { per } \mathrm{kWh}+0.11 \mathrm{p} \text { per } \mathrm{kWh}) \\
& =4.32 \mathrm{p} \text { per } \mathrm{kWh}
\end{aligned}
$$

A fair payment for exported units of electricity can be determined in a similar way. Each kilowatt hour exported from a microgenerating household will be consumed by a neighbouring household. Since the meter at the neighbouring property will be unable to distinguish between a centrally-generated kilowatt hour and a microgenerated kilowatt hour, the neighbour will be charged the full retail price for the electricity. However the supplier has not provided all of the services which make up this price and so a fair value for exported electricity should account for the assumed costs of transmission, supply, and generation (suppliers would have paid 4.11p per kWh (pre-tax) in generation costs as above). As with generation, an additional charge could be introduced to allow households to recoup the costs of related capital equipment (e.g. export meters, 
assuming the industry has not paid for them). This additional charge is again omitted here and therefore the exported units should be worth at least:

$$
\begin{aligned}
& \text { Min. export price }= \text { Transmission }+ \text { Supply costs and margin } \\
&+ \text { reduced generation costs }+5 \% \mathrm{VAT} \\
&= 1.05(0.37 \mathrm{p} \text { per } \mathrm{kWh}+2.89 \mathrm{p} \text { per } \mathrm{kWh} \\
&+(3.97-4.11 \mathrm{p} \text { per } \mathrm{kWh})) \\
&=3.28 \mathrm{p} \text { per } \mathrm{kWh}
\end{aligned}
$$

This is simply a starting point for deciding a fair tariff for microgeneration and the issue is discussed further in §7.3.3. However recent research provides a reminder that what might be ideal in theory is not always achievable in practice:

"The lack of obligations on suppliers to purchase micro generation output together with their powerful position as buyers compared with domestic consumers serves to undermine the value of exports."

$$
-\operatorname{DTI}(2005 \mathrm{c}: 3)
$$

Therefore if microgenerators are to be paid fairly, changes to the regulatory framework may be required.

\section{Summary}

The results suggest that electricity suppliers have been slow to provide microgenerators with a fair payment for their electricity, mainly due to regulatory difficulties in claiming the value of microgenerated electricity and the inconvenience of doing so for a small number of customers. While technological advances and consumer demand may eventually facilitate the creation of new tariffs, there is arguably an opportunity for government to intervene more directly by setting a fair price for microgenerated electricity and encouraging the 
role of consumers (e.g. DSM) within these system. The final section therefore examines the policy makers and lobbyists who shape these decision-making processes.

\subsection{Policy makers and lobbyists}

In June and July 2005, three consultation documents were introduced by the government and electricity regulator on microgeneration issues such as metering, the renewables obligation and grant funding (DTI 2005d, Ofgem 2005, DTI 2006d). These consultations provided the industry an opportunity to reflect on the government's proposals to promote microgeneration and share their experience. Approximately 200 responses to the microgeneration strategy consultation were received by DTI, indicating that there is an active interest in the industry's development. Interviews with government and industry representatives were conducted to evaluate the consultation process and the role of consumer behaviour in microgeneration policy (Table 6.6). These discussions also provided an opportunity to consolidate the previous industry interviews and confirm the most important present and future microgeneration policy issues.

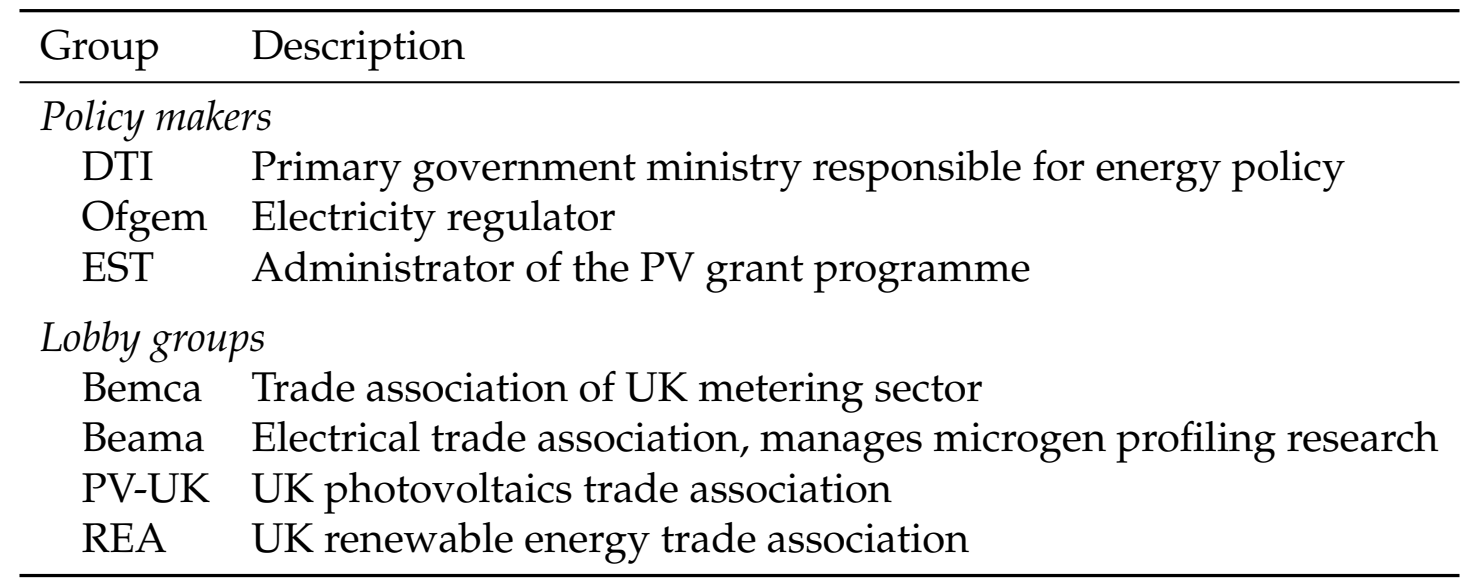

TABLE 6.6: Description of the interviewed lobby groups and policy makers 


\subsubsection{Current policy issues and lessons learned}

The interviewees in this section had strong opinions on how the industry had progressed to date and many of the themes identified above were confirmed. For example, there seemed to be a consensus that there were actually very few regulatory or legislative barriers to microgeneration and, aside from the cost issues, the most pressing barrier was the lack of arrangements for dealing with microgeneration installations quickly and efficiently (e.g. collecting Rocs). In the case of export metering, the problem was again not technology, but the cost and difficulty of making the necessary arrangements. In other words:

"[The metering] is not a problem but the system behind it is."

- Bemca

The Major Photovoltaics Demonstration Programme (MDP) was the most relevant example of microgeneration policy at the time of the interviews and its operation since 2002 had drawn attention to many of these issues. The programme was largely successful when evaluated on its own terms, for example by raising awareness of PV technology amongst the general public, encouraging good quality installations and building a strong installation industry (via the accreditation list, from 10 to nearly 60 installers since 2002). However it was hoped that the cost of PV would be significantly reduced as the market grew but initial estimates were inaccurate. Therefore, although installed costs have fallen from approximately $£ 8500$ to 9000 per $\mathrm{kW}_{\mathrm{p}}$ in 2002 to $£ 6000$ per $\mathrm{kW}_{\mathrm{p}}$ now, this is equivalent to the original hypothesized 2002 baseline cost (EST interviewee). Most of the achieved cost savings were due to reduced installation costs as the industry becomes more familiar with the technology. However since the UK grant scheme is "a drop in the ocean compared to Germany, Japan or even the American programme" (approximately 1\% of global PV module sales), the 
MDP had little effect on the costs of key technologies such as PV modules or inverters (EST interviewee), which should have been dropping according to technology learning theory (Hinnells 2005).

The government also expressed disappointment, even surprise, that greater cost savings were not achieved. Many PV installers and their trade associations had suggested that a feed-in tariff could be used to boost demand and drive material costs down, citing the success of Germany. However the government indicated that such an approach is not appropriate in the UK:

“We have a fully liberalized market where government dictating the price of electricity essentially is not something, you know, not a road that we should go down."

The primacy of the liberalized market underpins other aspects of the microgeneration sector as well. For example, Ofgem's mandate to protect the consumer is largely enforced by ensuring effective competition in the market. While social or environmental policy goals are also considered when setting regulation, Ofgem is effectively restricted to implementing government policy:

"The focus is on the customer interest and there are questions like,
'yes this might be good for reducing emissions but you know how
much is it reasonable for the customer to pay for that?'. And beyond
a certain point, if there are major significant financial implications,
then it's not a change we'd make. We'd say to government, min-
isters must take responsibility for that if they want to make those
changes." - Ofgem

These results then suggest a tension between lobbyists who would like more generous and direct support for PV and those in government who seem reluctant to step outside established ideologies and provide more direct leadership 
on microgeneration policy. The question then becomes how are these differences communicated and resolved by the various stakeholders. In other words, have the consultation and lobbying processes been effective at building 'shared visions' of PV and consumer behaviour issues?

\subsubsection{Lobbying and the consultation process}

As the PV industry changes, so has its approach to lobbying. Take, for example, the photovoltaics trade association PV-UK. Initially its members wanted a forum to share experience and provide general promotional activities for the industry. However as the PV industry grew, there was increased demand for active lobbying and policy intervention but insufficient resources were available to provide these services. This has led to a decline in membership and as of 1 April 2006, PV-UK merged with the larger Renewable Energy Association (REA) for the good of its members.

"We've got about 50 members now... recently it has decreased I have to say because the members are very keen for the industry to do more lobbying and I think that's where maybe PV-UK weren't putting all its effort into. We didn't have enough funding to do enough of it for the members to be happy and that's why there's going to be some, we're going to restructure the association to do more lobbying because that's quite important we realize that without funding, the industry it's quite fragile."

$$
-P V-U K
$$

This move will not automatically resolve the lobbying problems of the PV industry and as part of this larger group, PV will have to compete against other microgeneration technologies as well as the larger renewable technologies which form the bulk of the REA's members (e.g. wind). As a result, the REA is likely to put its larger, but still limited, resources toward issues which affect all renewables, although a dedicated microgeneration policy expert is onstaff. 
Regardless of the technology, the biggest challenge facing energy lobbyists was the structure of government. There were two concerns here: first energy issues are spread out across a number of different departments making it difficult to focus limited lobbying resources. For example, one respondent noted that encouraging microgeneration through planning regulations requires dealing with different people from those that control grant funding. This complexity was acknowledged by the DTI, the main energy ministry, but they "see the logic of it" and note that informal working relationships between government departments help to ensure that policy proposals account for the viewpoints of various departments (e.g. the Treasury, Office of the Deputy Prime Minister, Defra). While lobbyists can learn to work with this structure, the second problem is perhaps more intractable:

\begin{abstract}
"In the relatively short time I've been working directly on solar issues for example [5 years], we've had eight energy ministers and I've personally dealt with at least four different DTI officials on the same issue, and what you find is they don't actually bother reading or going back to what was agreed last year, never mind three years ago. So you are constantly having to re-educate people who are fresh to the job and really go over the same ground that we thought we'd covered some time ago. That's just a feature of how UK government works more than anything but it's particularly bad on energy issues because of the constant churn of officials and ministers."
\end{abstract}

$-R E A$

It should be noted that the primary goal of recent lobbying efforts had been to ensure the continuation of a viable grant programme and there was a general feeling that respondents "would hate to see any momentum that we' $\mathrm{d}$ built up lost" (EST). As a result, issues like consumer interactions with microgeneration had been given less attention; for example, many felt that monitors the most important element of consumer behaviour and microgeneration were already being installed as best practice and therefore no intervention was 
needed in this regard. Although there were individuals in both government and trade associations with an interest in expanding the industry's understanding of consumer behaviour, they lamented that such research was often cut due to limited funding.

In conducting these interviews, it was clear that industry and government were aware of each other's concerns even if there was not necessarily agreement on all issues. For example, both groups of stakeholders shared the common goal of long-term success in the UK microgeneration market. 'Success' is likely to be defined differently by those promoting a solar revolution (e.g. PV installers) on one hand and the government's LCBP (which aims "to see demonstrated on a wider scale emerging microgeneration technologies") on the other (EST 2006c). However regardless of how it is defined, a successful microgeneration market is likely to require improved communication between all interested parties:

"[The industry] tend to demand a lot of information but don't give up a lot of information unfortunately and it's a two-way street really. We need to know their issues as well as you know presenting our own information to them and I think that on-going dialogue is probably quite important."

This particular quote is striking since EST's own annual reports on the MDP have not been available online since the first year of the programme (e.g. EST $2003 b)$.

\subsubsection{Future prospects and challenges}

Respondents recognized that the PV industry faces major challenges. For example, at the time of the interviews, there was talk of the LCBP being a 'technologyblind' programme which might place expensive technologies like PV at a disadvantage (although it may remain useful in prestigious large-scale urban appli- 
cations). For microgeneration in general, the mood was more positive and there was a recognition that cooperation between government and industry will be required:

"I think the really exciting thing about microgeneration is that it's clear there's huge potential for these technologies and if we in government get our policies right and the industry gets its marketing and communications right, and we start to get - as we're starting to do at the moment - get big energy companies involved, putting their muscle behind it, the potential could really be quite big."

On the government side, two current European Union directives (the Measurement Instruments Directive (2004/22/EC) and the Energy End-Use Efficiency and Energy Services Directive (2006/32/EC)) could have a significant influence on microgeneration in the UK. However most respondents felt these should not pose a problem if DTI took care in implementing the associated legislation. The regulator Ofgem is an important part of this process and therefore it is encouraging that they were looking "to give a bit of leadership to the industry... now we want to be absolutely clear who does that, when do they do it and is everybody, you know across the industry, are all the players seeing this in the same way and understanding what's sensible". Some action has already been taken in this regard (e.g. allowing modified settlement profiles for microgeneration) and hopefully Ofgem will continue to ensure that microgeneration can compete on a level-playing field.

Perhaps the biggest obstacle for government though is increasing cynicism that its stated aims for microgeneration are not being adequately supported by action:

"Given that we're never going to get even close, it seems to me, to the sort of levels of direct capital grants for the Japanese have thrown at technology like PV over ten years, does it make sense to 
keep persisting with this sort of almost a pretence that the Low Carbon Buildings Programme is somehow going to deliver the economies of scale and all the rest of it they talk about in the consultation document? I mean it just isn't going to happen at the level of funding that is on the table."

For its part, the DTI acknowledged that microgeneration was a complex issue and it may be unable to satisfy all stakeholders due to its broader energy policy obligations. ${ }^{10}$ Nonetheless it was hoped that the new microgeneration strategy, including the LCBP, would present a consistent approach to these issues allowing industry to plan accordingly. For example, although the announced funding for the LCBP was much less than many in the installation industry would have liked, other measures including better regulation, planning initiatives like the Merton renewables requirement, the Code for Sustainable Buildings, and legislation such as the Sustainable and Secure Buildings Act (2004) and the Climate Change and Sustainable Energy Act (2006) may overall lead to a more supportive environment for microgeneration.

\section{Summary}

This section has shown that there is an active debate between industry and government regarding the future of microgeneration in the UK. Recent consultation documents have provided a focus for these activities but informal networks also play a major role in developing future solutions and sharing the lessons learned by the industry to date. While recent efforts have primarily concentrated on ensuring a next-generation grant programme, there was an awareness of consumer behaviour issues and hopefully these will gain importance in the coming years.

\footnotetext{
${ }^{10}$ For example, the REA respondent noted that microgeneration might "get totally sidetracked by this nuclear debate", referring to the perceived nuclear focus of the Energy Review.
} 


\section{Conclusion}

The primary goal of these interviews was to explore how industry actors shaped the experiences of PV households during the purchase, present use and future use stages of the PV life cycle. A diverse range of stakeholders was identified including representatives from the established centralised electricity system and the newer microgeneration technologies. The connections between these actors included business relationships, regulatory obligations, and formal and informal lobbying discussions. For households though, direct interaction was primarily limited to the electricity suppliers, grant providers, and PV installers.

At the purchase stage, it was shown that PV installers have established several best practices which encourage households to take an interest in their PV system (e.g. the installation of a monitoring device). However, obstacles to the informed use and fair payment of PV-generated electricity became apparent almost immediately. For example, PV installers promote the idea of selling one's electricity to the electricity suppliers (either by exporting it to the grid or being paid for the renewable electricity generated). However electricity suppliers and metering companies, who are used to dealing with millions of customers, are still developing the procedures to deal with microgenerators. Furthermore, an emerging discrepancy was seen between the idealized model of home microgeneration and the commercial reality of the electricity sector (e.g. favouring flat-payment for microgeneration rather than fair payment for generated and exported electricity). At the very least, this reflects a need for better communication between stakeholders to help understand each other's position and build 'shared visions' of PV and microgeneration technology. Without this cooperation, members of the incumbent electricity system are in danger of missing an opportunity to engage with microgeneration households. A typical respondent said that he couldn't "see too much happening until the market decides which 
way is up." (metering Firm E). Yet through their tariffs, metering equipment, and established links with regulators and policy makers, these incumbent firms could arguably be doing more to initiate and pilot new strategies for microgeneration.

Using the vocabulary of market transformation theory (e.g Foxon et al. 2003), PV could be moving from small-scale niche to large-scale technology. However, as with the industry stakeholders, government is embedded within established actor-networks which appear to hamper their ability to introduce changes. For example, the central government was extremely reluctant to promote more radical support policies such as a feed-in tariff. Certainly steps are being taken to improve the prospects of microgeneration but the interviews found a high degree of scepticism among microgeneration representatives. Consequently many interviewees indicated that it would be local government, especially the London boroughs, pushing microgeneration forward and not Whitehall (e.g. 75 councils are planning to adopt 'Merton rule'-style policies (Solar Century $2005 b)$ ). One respondent even claimed that if such a policy were to be adopted nationally, an annual microgeneration market of $£ 750$ million could be created, compared with the $£ 19$ million per year PV market that currently exists. Therefore, while the research has shown that both central government and the existing electricity sector could lead microgeneration innovation, it appears that both parties are holding back, waiting for other stakeholders to act.

The final assessment should not be too negative. For example, industry and government have largely failed to consider the aspirations of consumers, how they use microgeneration technology, and the potential benefits of involving them in emergent microgeneration systems (e.g. for demand-side management). However current initiatives, such as metering innovation pilots, could draw households into the development of new microgeneration frameworks and, given their increased levels of tacit knowledges, their contribution could 
be significant. This suggests that the PV actor-network has not yet solidified and the challenge is therefore to ensure that these potential niches are explored, allowing consumers to avoid being locked-in to consumption frameworks that are not significantly different from the status quo.

The four data chapters have highlighted the ways in which photovoltaics can alter the behaviour of households and raised concerns about the direction of the industry as a whole. Although the research has seen only small changes in energy-consumption behaviour resulting from the installation of $\mathrm{PV}$, there is reason to believe that greater changes could occur in the long-run if the wider socio-technical frameworks were more supportive. Therefore the final chapter will review the results and consider how PV can make the most contribution to energy policy goals. 


\section{Chapter 7}

\section{DISCUSSION AND CONCLUSION}

The thesis began with a description of a household in the near future, producing electricity from solar PV panels and taking an active interest in the system's output. Today this scenario is a reality for approximately 1400 households in the UK, thanks largely to the promotion of PV technology through a series of government grant programmes. However assessing the energy policy benefits of these initiatives (e.g. for climate change mitigation or security of supply) requires more than simply counting the number of installations. Specifically, the role of consumer behaviour must be examined as a number of researchers have suggested that PV and other microgenerating technologies may lead to changes in household energy consumption behaviour (e.g. Haas et al. 1999, Dobbyn and Thomas 2005).

Using a socio-technical systems framework, it was shown that PV is not a fixed artefact, designed and then diffused, but a technology that is likely to continue evolving as early-adopting households, electricity suppliers, and other stakeholders interpret and shape the technology according to their beliefs and aspirations. Consumer behaviour was also presented as an activity which is influenced by this socio-technical context, as well as individual goals and perceptions. Using these concepts, three research questions were chosen to address the overall issue of consumer behavioural responses to photovoltaics: 
- describe the behavioural responses of 'active' PV households (i.e. those that chose to install PV system for themselves);

- explore the mechanisms by which these responses occur (including the role of monitoring devices);

- assess how these behaviours might be influenced by the technologies of industry or the policies of government.

This chapter answers these questions by reviewing the data collected from interviews, questionnaires, and numerical sources. The implications of the research for theory and policy are then discussed as well as some comments on the limitations of the study and the opportunities it presents for future work.

\subsection{Domestic photovoltaics: a double-dividend?}

The energy policy benefits of PV might traditionally be evaluated in terms of the grid-supplied electricity it directly replaces: that is, each kilowatt hour of photovoltaic electricity negates demand for a kilowatt hour of centrallygenerated electricity. Using this 'one-to-one' assumption, the effect of PV on climate change and security of supply can be calculated. ${ }^{1}$ However this simple assessment of the technical potential of PV fails to account for PV's impact on household behaviour. By engaging households in the production of electricity, it was hypothesised that consumers would become more aware of the impacts of their consumption and develop more sustainable patterns of energy use. Therefore, the true potential of photovoltaics may lie in its ability to create a 'double-dividend': providing low carbon renewable electricity and encouraging reductions in demand through efficiency and conservation. The

\footnotetext{
${ }^{1} \mathrm{PV}$ may also provide fuel poverty benefits to lower-income households but the issue is less relevant to the respondents of this study, due to their high income.
} 
evidence for a double-dividend is considered by reviewing the main results of the research, including both household energy consumption behaviour and the associated industry and policy issues. The discussion follows the respondents from their decision to purchase PV, to their present patterns of energy use, and finally to the policy considerations that may shape future energy savings.

\subsubsection{Purchasing PV}

Due to data limitations, the research only examined UK households that purchased PV for themselves; i.e. 'active' PV households (after Dobbyn and Thomas 2005). These respondents were representative of PV households at the time of the research but they did not reflect the public at large. The most critical differences were found in income and education levels with 77\% of PV households having degree-level education and $40 \%$ earning more than $£ 50,000$ per year (compared with 30\% and 13\% nationally). Significant differences were also found on psychological characteristics, with PV households exhibiting much greater levels of environmental knowledge and concern than the general public. A strong preference for altruistic values, such as environmentalism and equality, over concern for social recognition or traditional values (e.g. politeness, obediance) was seen as well. According to diffusion of innovation literature (Rogers 2003), this suggests that the surveyed households might be described as individualistic 'innovators', rather than socially-motivated opinion-leading 'early adopters'. Correspondingly the diffusion of PV is less likely to be promoted by person-to-person relationships; this could be seen in the way respondents either shared their PV experience with the media at large or were wary of forcing their views upon others.

The surveyed PV households own their homes and have demonstrated a desire to improve its energy efficiency. Ownership of insulation measures and 
efficient lighting were all significantly greater than the national average and interestingly, 33\% of households had installed solar hot water systems before getting PV. During the follow-up interviews, respondents often indicated that these earlier investments in energy conservation were part of "trying to reduce energy consumption, to try and save greenhouse reduction [sic]" (A.F.). However given the high cost of PV $\left(\approx £ 6000\right.$ per $\left.\mathrm{kW}_{\mathrm{p}}\right)$, environmental motivations may be insufficient to explain the purchase of PV, "the first major measure" (E.W.) for many.

Like BMWV (1998), this research found that the purchase decision was often proceeded by a long period of general awareness and eventually some form of personal exposure to PV. However even with knowledge of PV technology, high environmental concern, and the assistance of the government grants, additional catalysts were still required before a decision to purchase PV was made. Convenience factors (e.g. concurrently building an extension or replacing the roof) and financial windfalls (e.g. pension lump-sums or a bequest) were both important, primarily by reducing the net cost to the household. However $74 \%$ of respondents believed that their systems would pay back in more than 25 years suggesting that economics played only a facilitating role in the purchase decision and payback was not a motivation in its own right. Instead, the purchase was motivated largely by environmental concern and a sense of personal responsibility, for example, with households adopting PV to "compensate for being modern" (D.P.) (i.e. using cars and planes). The possibility that PV was purchased as a status symbol was rejected in light of the low priority respondents gave the 'social recognition' value in interview discussions.

Although all of the surveyed PV households were customers of Solar Century (a firm which represented one-sixth of the UK domestic PV market at the time of the research), interviews with other installation firms suggested that the socio-demographic and value characteristics seen here were typical of 'active' 
PV households more generally. Other members of the public have expressed an interest in PV but were put off by its high cost with installers reporting that only about $5 \%$ of initial inquiries led to actual PV installations. Although cost therefore continues to be a major barrier to adoption, the industry has largely avoided the 'cowboy' image problem of the solar hot water industry (e.g. Jardine 2004) as the Major PV Demonstration Programme's accreditation system has given the industry legitimacy and built consumer confidence.

The number of certified installers has grown from approximately ten in 2002 to 57 today (interviews, EST 2006a), providing customers with a wider variety of firms to choose from. While there are differences between these firms, based on the locations served and the level of service provided, most PV households experienced a professional and courteous installation process. For example, it was seen that installers acted as project managers, coordinating subcontractors and offering advice on planning concerns or electricity suppliers. Growth has also necessitated changes in business models, with installation firms developing networks of subcontractors in order to cope with demand. Hopefully these new arrangements will maintain a high level of personal service as evidence suggests that a clear technical understanding of the installation is important for developing positive consumer responses (Dobbyn and Thomas 2005). Indeed the present research found that the advice of installers led some households to become more aware of their energy consumption and generation.

\subsubsection{Living with PV}

The primary interest of the research was to investigate whether PV would alter the energy consumption of adopting households, for example by encouraging different purchase or use behaviours. These changes are reflected in two aspects of electricity consumption: the overall quantity and the time of use. 
Respondents claimed an average overall electricity saving of $8.4 \%$ but this was a self-assessment and the uncertainty of these values was acknowledged. Using detailed data, significant changes were only found in the ownership of CFL lights (increasing from $49 \%$ to $58 \%$ of household lighting points) and the use of a green electricity tariff (from $51 \%$ to $76 \%$ of respondents, often encouraged by the installer). This last point suggests a greater carbon benefit from PV as households were using green electricity for all their electricity needs. Interestingly those who reported an overall saving said that they were significantly more aware of electricity generation and consumption and were even likely to try and live within the means of their PV system. PV however did not alter the self-identity of households, who already thought of themselves as 'green'. The increase in awareness led respondents to be more careful about turning off lights and stand-by functions. No major changes in appliance ownership were seen, perhaps because of the short length of time since the respondents purchased PV (75\% of respondents had owned their systems for less than 2 years).

The most notable behavioural response was that $43 \%$ of respondents changed the time at which they used electricity to take advantage of their PV generation. This behaviour was seen in households that were physically able to shift the loads, either because they were home during the day (e.g. the 'retired' respondent group) or they had timers fitted to major appliances. The most commonly shifted loads were dishwashers and washing machines and evidence from the UK Time Use survey (National Statistics 2000) suggested that shifting other loads may be more difficult as they are constrained by culture or lifestyle (e.g. when to have a hot meal, watching a favourite TV programme). Most of a PV system's output comes in summer (37\% of annual production vs. $15 \%$ in winter) and the interviews suggested that load-shifting was more common at this time of year. Many respondents reported using the weather to determine when appliances should be used and it was shown that a 'folk' model (based 
on the ambient irradiance) was very effective in predicting system performance. Experience with solar hot water systems or dual-rate (i.e. peak/off-peak) tariffs also prepared some households to make these scheduling changes.

Households that changed their times-of-use did so primarily to try and use their PV electricity in the home. Conveniently this is the preference of the electricity industry, partly because it makes for more efficient use of electricity (there will be some losses if the electricity is distributed to neighbouring properties). However using electricity in the home also minimizes the demand for export metering to measure flows of electricity back to the grid. It was discovered that there was confusion regarding who should install and pay for these meters (e.g. metering companies, electricity suppliers, DNOs, or households). To avoid the export meter issue, some electricity suppliers preferred to pay PV households for all of their generated units of electricity, regardless of whether they are used in the home or exported. Industry research is also underway to develop profiles that will allow suppliers to settle the electricity through the wholesale market, while paying households a flat-payment for their microgenerated electricity. As shown by the analysis of the field trials data however, these profile payments would provide very little incentive for households to engage in load-shifting behaviour; similarly a high export tariff (e.g. like Germany's feed-in tariff) might not be desirable as it could encourage PV households not to use their own electricity.

Metering and monitoring systems are an essential part of domestic PV installations as these devices facilitate the information and payment mechanisms needed to engage consumers and promote specific behavioural changes. While there are technical parallels between monitoring devices and meters, the two industries are markedly different. Metering companies, for example, have millions of customers and operate in a regulated and fiercely competitive market. In contrast, monitoring firms are primarily small and medium-sized enterprises 
that have developed their products in parallel with government-led PV support programmes and so these firms are typically based in countries with larger PV sectors than the UK (i.e. Germany, Japan). PV installers in the UK are nonetheless enthusiastic about monitoring technology and offer the devices either as an option or as a standard piece of equipment to differentiate themselves from competitors. For the interested consumer, there is a variety of monitors available ranging from simple displays of generation information to more complex devices that compare generation and consumption and even set consumption targets for households.

The research found that monitoring devices were widely owned by PV households ( $86 \%$ of the sample) and monitors installed in a prominent household location were best for encouraging frequent household interaction. However given the young age of the PV installations, there are questions about whether the frequency of viewing was due to the novelty of the technology. Furthermore the monitors used here primarily displayed generation information and it was not clear how these devices encourage interest in consumption. Households with consumption-displaying monitors were seen to be significantly more aware of their consumption and its sources. Five such interviewees reported an average post-PV electricity saving of $35 \%$; a good example was D.E. who discovered that a seldom used deep-freezer was wasting large amounts of energy. He subsequently unplugged this appliance, installed double-glazing and ultimately reduced his electricity demand to less than $1300 \mathrm{kWh}$ per year (less than the output of his PV system).

It should be noted that monitors also appear to have a symbolic function, reminding households of their investment in PV (since the panels themselves may be hidden on the roof) and even demonstrating this commitment to responsible environmental behaviour to family and friends. Although the time scale of this research meant that long-term changes could not be observed di- 
rectly, this symbolism suggests that an interest in energy issues might be maintained. However the potential for future energy saving is mixed. On one hand, many households indicated that their ability to take further action was limited by the structure of the house, the cooperation of their family, their lifestyle, or simply cost. The questionnaire also found that the potential for further action was limited by the extensive measures already taken by many respondents. Some possibilities for further energy or carbon savings still existed, for example, as old appliances wear out and are replaced with more efficient models. Most interestingly, respondents were often eager to install additional generation capacity that complemented the summer peaks of PV (e.g. microCHP or micro-wind). Even for those who felt that they could do no more to save energy, improvements in other kinds of environmental behaviour were being sought, for example, in recycling, socially-responsible investing, or transportation (e.g. cycling instead of taking the car). These responses therefore suggest that the PV experience of these households has been broadly positive and they have the confidence to continue in their 'innovator' role and try further options where feasible.

\subsubsection{The future of PV in the UK}

The energy consumption of households is also shaped by the actions of industry and government. One of the first issues explored here was the potential for the further diffusion of PV, in the hope that the behavioural responses seen above might be encouraged in a wider variety of households. Interviews with stakeholders from across the UK PV sector portrayed an industry in transition, for example, with PV installers and lobby groups struggling to adapt to the uncertain nature of government funding over the past five years. While it is too early to tell whether the new Low Carbon Buildings Programme will deliver the de- 
sired long-term stability, the industry feared that without the strong support of government, their accumulated expertise and capacity may be greatly reduced or lost. Funding concerns have already had an effect on the way in which PV firms lobby policy makers, as the smaller PV-UK group has merged with the larger Renewable Energy Association to try and make these complaints more visible. Indeed lobbying, both via formal consultation and informal discussion, was shown to be an important feature of how the industry addresses problems and develops strategies for the future. However this dialogue was mainly between industry and government. Communication with households appeared to be lacking, most notably on expectations for PV tariffs.

While cost remains the largest barrier to the diffusion of $\mathrm{PV}$, there was also confusion among electricity suppliers, meter operators, and other stakeholders about how to welcome microgenerators into the existing electricity network. As an electricity supplier pointed out, "simplicity" will be important for a successful solution, allowing households to interact with a single actor. After choosing their preferred microgeneration technology, an energy service company for example could then be trusted to bring the system online and easily deal with the questions of metering, tariffs, and so on. To this end, the regulator Ofgem has been streamlining procedures for claiming of Rocs (via amalgamation agents) and settling microgenerated electricity (via the new profiles being gathered by Beama). Other potential elements of a microgeneration system, such as the use of advanced metering technologies, are proving more difficult to resolve due to cost and responsibility issues, but exploratory pilot studies have been proposed (e.g. Ofgem 2006b).

Many industry respondents indicated that their current strategies for microgeneration were intended to build experience and prepare for large-scale growth. However almost all stakeholders, except for central government, felt that the Low Carbon Buildings grant programme would be insufficient to cre- 
ate this demand. Other policy measures were frequently suggested although some measures, such as a feed-in tariff, are strongly resisted by the Department of Trade and Industry (as in the interviews). Microgeneration and PV are also being promoted by local government with many councils requiring microgeneration as a fraction of new-build developments (e.g. LBM 2006). The biggest implication of this so-called 'Merton rule' is that these new-build homes might be occupied by a different type of occupant from the owner-occupiers surveyed here. Recent research suggests that these 'passive' adopters of microgeneration may have the greatest potential for behavioural change (Dobbyn and Thomas 2005) (though no comment was made about the role of monitors in this research). Therefore the question is whether the experiences of current adopting households can be used to develop a microgeneration system that maximizes the potential for energy consumption changes in this new market.

\section{Summary}

The first research question sought to describe the changes in energy consumption that resulted from the installation of PV. The research found evidence of a 'double-dividend', resulting overall in approximately an $8 \%$ saving in total electricity demand. Load-shifting, changes in lighting and electricity supply, and an increased awareness of energy supply and demand all suggest that PV should not be evaluated therefore purely as a direct substitute for grid-supplied electricity. The existing commitment and investments of these respondents arguably limited their potential for further savings but there was still a desire to invest in additional environmentally-responsible technologies and behaviours. This suggests that the double-dividend effect may have a greater influence on households without a lengthy history of energy saving and awareness. The roles of industry and government are therefore important to encourage the pro- 
motion of PV to new audiences and to do so in such a way that all households, including the commited households surveyed here, can continue to learn about their energy consumption and move towards sustainability.

\subsection{Contribution to theory}

Abrahamse et al. (2005) suggest that the outcomes of domestic energy interventions should be assessed for their effectiveness, attribution (i.e. was the change in behaviour actually caused by the intervention) and permanence. Having considered the effectiveness of $\mathrm{PV}$, the remaining questions can be addressed. Permanence is considered briefly here by examining the socio-technical network that is needed to support lasting changes in energy consumption (the policy elements of this question are considered in §7.3). However the first concern is attribution - or as the second research question stated, identifying the mechanisms which caused the observed changes in energy consumption behaviour.

Previous literature on PV demonstrated the variability of behavioural responses, with some studies showing no change in overall consumption (Erge et al. 2001) and others showing both increases and decreases (e.g. Haas et al. 1999). However the studies largely failed to offer any explanations for these variations, either by discussing the psychological mechanisms underlying the changes or by considering the wider socio-technical context of behaviour. Several possible mechanisms for the observed behavioural responses have been encountered (e.g. increased awareness, self-identity, etc.) but these factors need to be consolidated and correlated with the range of responses seen. Since the design of the methodology and human nature makes it extremely difficult to isolate the effect of a single mechanism, the goal of this section is to offer a unified explanation of the observed behavioural responses in the hope that these 
theoretical findings might lead to practical recommendations. Two questions from the literature are of particular relevance: the role of users within emergent socio-technical systems (e.g. Weber 2003) and the hypothesis that PV forms part of an energy conservation chain (Haas et al. 1999).

\subsubsection{Mechanisms for encouraging a behavioural response}

A framework based on social cognitive theory (Bandura 1977, 1986) was proposed to categorize energy consumption interventions and demonstrate that behaviour is influenced by antecedent determinants, consequent determinants, and the mediating effect of 'cognitive control' (i.e. the combination of tacit knowledge and self-efficacy that enables individuals select, interpret and respond to external events according to their goals and beliefs). This framework is now applied to PV-related behaviour including the initial purchase decision, its use and the future prospects for energy saving.

The study's interest in the purchase of PV was based on the premise that the motivations for adopting PV would, at least partly, shape the subsequent behaviour of these households. In a social learning framework, this continuity comes from cognitive control and it can be argued that these factors, which determine how information is selected and used by households, were ultimately responsible for making a PV purchase decision. For example, a home energysaver self-identity and a sense of personal environmental responsibility meant that the surveyed households could justify the PV purchase decision despite its high cost. ${ }^{2}$ Similarly a potential antecedent determinant of PV purchase that PV acts as a status symbol — was downplayed by the individual's lack of emphasis on social recognition values.

Diffusion of innovation literature stresses that the decision to adopt a tech-

\footnotetext{
${ }^{2}$ Although the importance of purchase catalysts (e.g. roof repairs or receiving a pension lump-sum) should not be dismissed.
} 
nology is largely based on perceptions of the technology's advantages and disadvantages (Rogers 2003). For example, recent research suggests that potential adopters, who ultimately choose not to get PV, often have difficulty identifying its relative advantage over existing modes of electricity provision (Faiers and Neame 2006). However adopting PV requires more than simply interpreting its technical characteristics; the technology must also be compatible with the moral economy of the household (Hirsch 1994). Cognitive control plays a central role in this assessment. In other words, the respondents' long-standing attitudes to energy use and its environmental impact (reflected by their installation of other energy-saving measures) suggest that PV can be interpreted by these households as another element of an existing energy-conscious lifestyle and environmental worldview. Therefore the subsequent use of energy after the installation of PV should also reflect the long-standing environmental awareness and concern of these households.

Once in the home, PV introduces new antecedent and consequent determinants of behaviour. Specifically the installation of PV introduces households to a variety of sources of energy information including feedback from monitors, information from installers and electricity suppliers, as well as learning from everyday experience with PV (e.g. trying to get an export meter, finding out that PV tariffs do not follow rises in standard tariffs). The result is growth in tacit knowledge and, by extension, "the ability to learn unaided, evaluate information, invent solution to problems and share knowledge with others" (Darby in press: 9). This was seen in the household's evaluation of the generation characteristics of PV. By learning when PV produces electricity compared to their demand, many households expressed an interest in finding complementary forms of microgeneration. This suggests that some households are very near - perhaps even beyond - the point of 'critical capability' (Darby 2003), seeking out and using information independently as they move towards sus- 
tainability.

The increase in tacit knowledge is remarkable given the respondents' high initial levels of energy knowledge, but for 'passive' adopters (i.e. those who do not meet the characteristics of the 'innovators' studied here), the introduction of PV could have an even greater effect. For these households with low tacit knowledge, a PV installation could provide a abundance of new information and experience about issues which may not have been contemplated before. Furthermore, without a history of energy-saving action, there may be significant potential for action. However Dobbyn and Thomas (2005) found that 'passive' households who were not given information on their PV system did not show any change in behaviour; in some 'passive' adopter cases, occupants of PV buildings did not even know the technology was installed (e.g. Jardine 2004)).

It might therefore be said that the increase of tacit knowledge that results from the installation of PV gives households a sense of control, building their self-efficacy by meeting "the human inclination for competence" (de Young 2000: 506). At a basic level, the influence of self-efficacy on behaviour can be seen in the significant increase in CFL lighting, a simple controllable action. In the longer term though, social learning theory suggests that self-efficacy can help individuals persevere with a course of action through difficult circumstances (Bandura 1997). Combined with commitment to energy issues (de Young 1993), tacit knowledge and self-efficacy therefore set the stage for long-term sustainable energy use behaviour and, although diverse, the behavioural responses to PV observed in this study might be placed within the auspices of a social learning framework.

Of course, whether PV ultimately leads to sustainability or simply 'greens' existing modes of behaviour will depend largely on socio-technical factors. For example, the interviews revealed that some households were struggling to rec- 
oncile their environmental beliefs with the rising energy-intensity of modern lifestyles (e.g. in appliance usage). Load-shifting behaviour also has constraints and only $43 \%$ of respondents showed this form of action; had there been a higher payment for exported electricity, more respondents at home during the day, or more consumption information on monitors, this effect might have been more common. Therefore the behaviour of PV households needs to be understood within its socio-technical context, particularly to assess the durability of these systems and the potential to shift them towards sustainability.

\subsubsection{Socio-technical constraints on PV behavioural responses}

The research revealed an emerging socio-technical PV system encompassing tariffs, monitors, and a wide variety of industry stakeholders. However the literature review raised questions about the role of the respondents within this network, specifically whether these pioneering households can help guide these systems towards a sustainable model of microgeneration for the benefit of future adopters and users. The household-focused actor-network (based on Cowan 1989) was defined by considering the extent to which the influence of this one actor could be felt (Law 1989). The industry interviews, for example, tried to cover stakeholders with whom households might have direct contact such as the grant providers, electricity suppliers, and PV installers. Some indirect connections were considered to be very important and were explored as well, including the grant funder DTI and electricity regulator Ofgem.

Using the results of the interviews, the PV actor-network was described and analysed using Pajek software (Batagelj and Mrvar 2006) (Appendix C). Two questions were considered, beginning with the role of households within the actor-network. As noted in $\$ 2.2 .3$, early users can contribute to the development of a new technology through risk assessment, the development of new 
features or uses and other roles. However for these benefits to be realised, the users and producers must have some means of interacting in order to build a 'shared vision' of the technology's future. Weber (2003) suggested that strategic niche management is one such approach, allowing users and producers to develop new technologies within a space protected from the actions of incumbent stakeholders. The interviews found only one notable example of this, the NPower pilot study, where consumers and electricity suppliers shared data and assessed a potential tariff structure for PV. However this pilot has ended and it appeared that the relationships between microgenerating households and industry were beginning to solidify, as seen in the shift away from export metering.

Figure 7.1 shows that households and their technologies (e.g. meters, electricity tariffs, monitors) are the focus of the domestic PV actor-network. Four major reciprocal relationships can be seen. Three of these - between installers, electricity suppliers, and the EST - involve the household occupants directly. The fourth link, with Ofgem, reflects how the technologies within a household are influenced by regulation. Importantly Ofgem is also the centre of links with major stakeholders in the electricity system including metering companies, DNOs, and lobbyists. This suggests an indirect link between households and industry and this was seen in the industry interviews, where lobby groups emphasised the importance of discussion between industry and government but gave little attention to the role of households (e.g. for demand-side management). Research by Devine-Wright and Devine-Wright (2005) confirms the isolation of households, revealing that microgenerators are not perceived by existing members of the electricity system as fellow energy 'citizens' (i.e. useful contributors to the system). This suggests that incumbent stakeholders are more likely to accommodate microgenerating households within existing structures (or their own future ideals) rather than actively engaging with them to 
explore new possibilities. However the relationship between Ofgem and DTI, specifically the disproportionate 'power' of these nodes, indicates that the leadership of DTI could influence Ofgem and the rest of the system; notably there is no direct link between households and DTI.

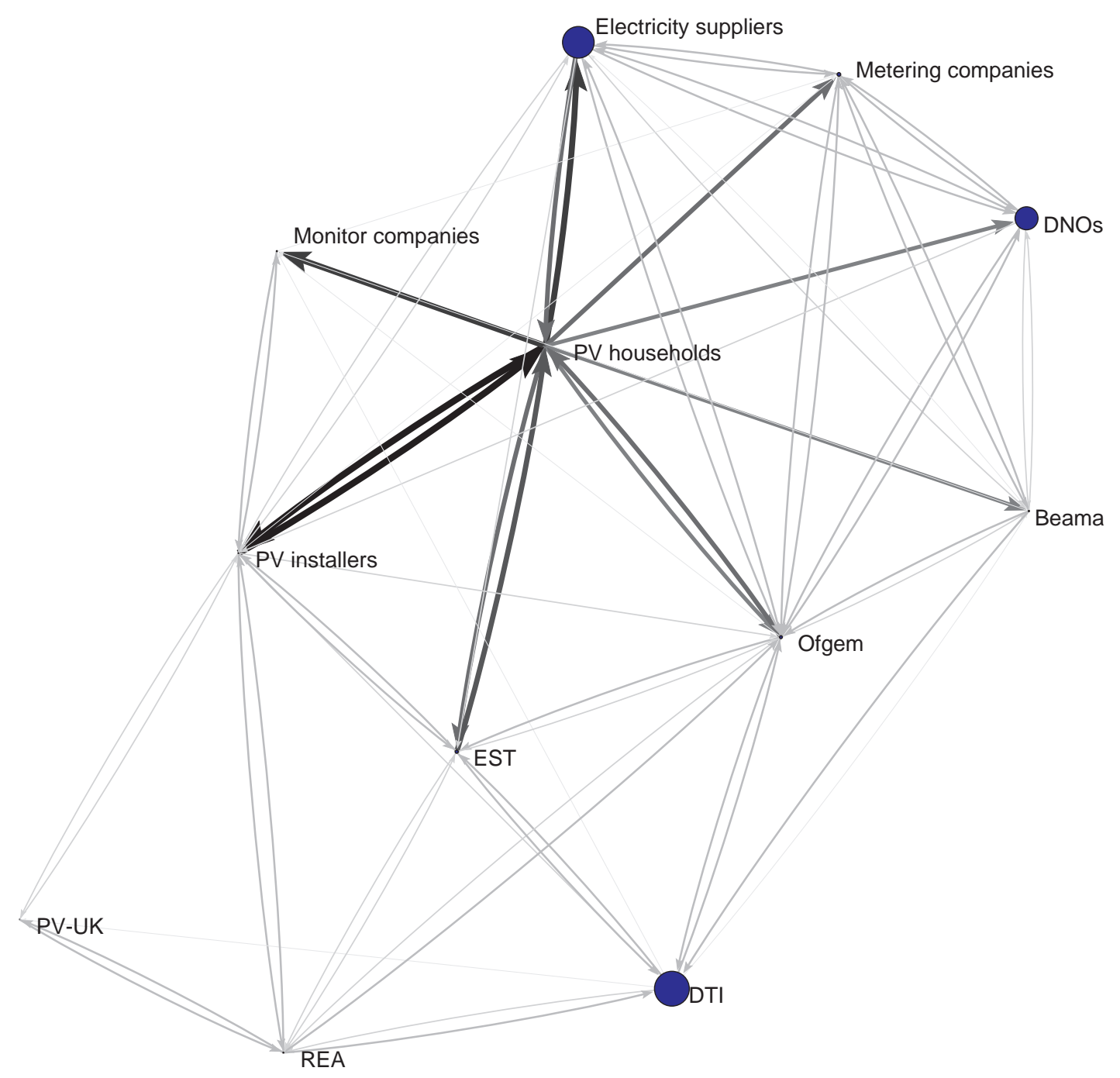

FIGURE 7.1: The domestic PV actor-network. Links indicate the strength and directionality of relationships. The size of the vertex represents the ability of a stakeholder to influence the network (accounting for their control of information and resources). The 'PV households' actor includes domestic artefacts, such as electricity tariffs, meters and monitors. 
If the goal is to encourage a more active role for households, a means of transforming this network must be found. The second analysis was therefore more exploratory and considered how the links between the households and the existing electricity system might be improved. Law (1992a: 6) notes that "a relatively stable network is one embodied in and performed by a range of durable materials". This suggests that the role of specific technologies and artefacts should be examined. Figure 7.2 demonstrates that electricity tariffs and meters are intimately linked with the existing electricity system. Marvin et al. (1999: 109) cites these relationships as an obstacle to smart metering innovations as "take-up of these [smart metering] potentials is strongly framed by the competing commercial priorities established by privatization and liberalization". In contrast, new technologies like the monitoring devices and PV panels are peripheral and loosely embedded. The figure therefore suggests that if the 'distance' between microgenerating households and the existing electricity system is to be reduced, a link might be made between monitoring devices and meters. For example, although valuable on their own, monitors were shown in the interviews to be complementary to meters and could encourage communication between electricity suppliers and households (e.g. by displaying tariff information). The recent proposals for smart metering pilot studies (Ofgem 2006b, Owen and Ward 2006) should therefore emphasise that visible monitors as an integral part of any new metering technology. In practice, this connection might be forged by following established links: for example, from monitoring companies to PV installers, to EST, to DTI and Ofgem, and back to the electricity suppliers and metering firms. The more direct link, via households, may be unfeasible because of their limited ability to influence the network as shown above. 


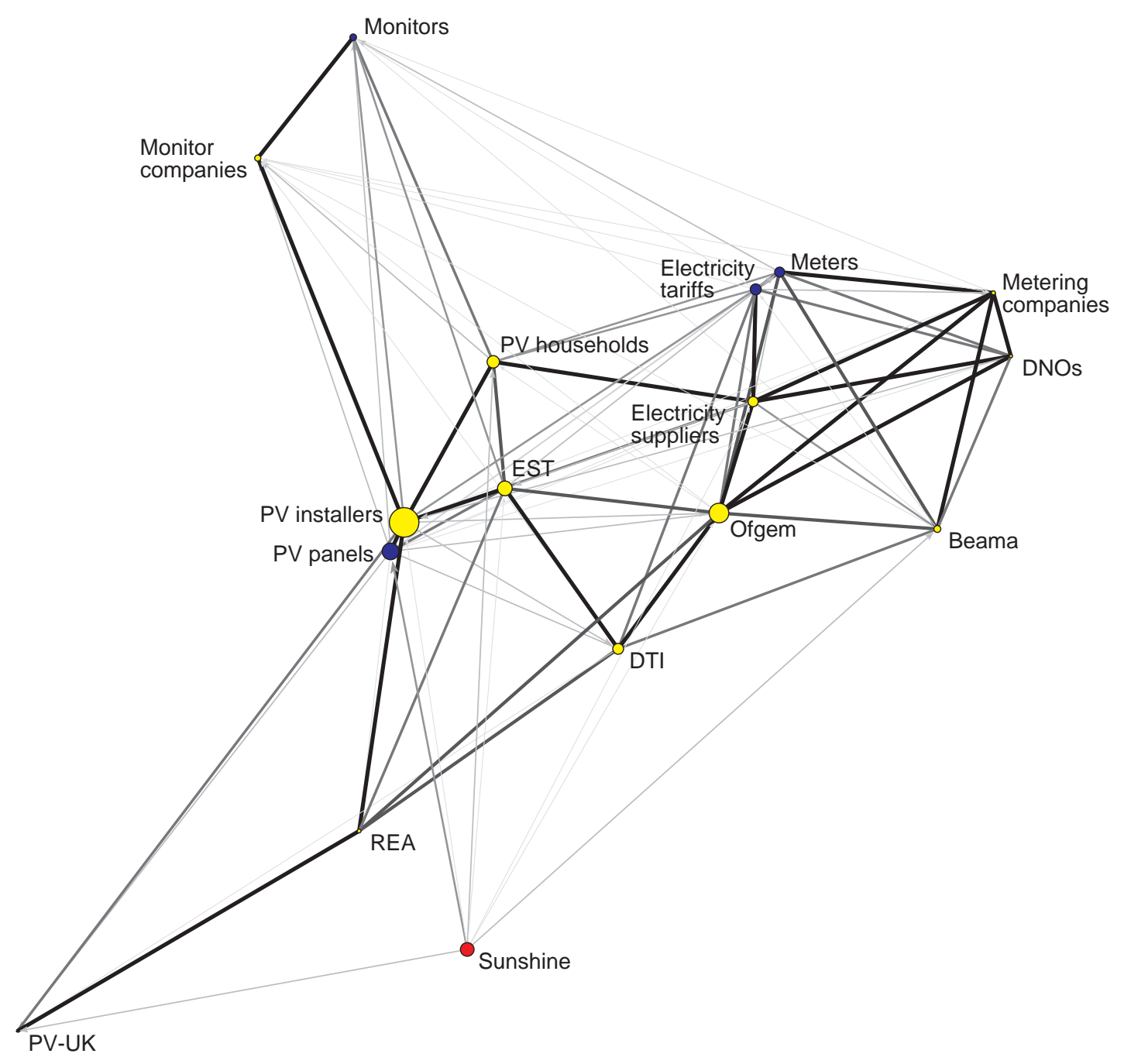

FIGURE 7.2: The role of technology within the PV actor-network. Nodes are coloured blue for technology, yellow for individual or organization, and red for other; node size represents control over information flows within the network. The distance between nodes reflects the strength of the connection (closer is stronger). 
This analysis has used a bounded network but it is worth mentioning some of the other potential influences on the emerging PV socio-technical system. First, the graphs above suggest that the DTI has a great deal of control over the network; however microgeneration is influenced by the actions of more than one government department and Keirstead (in press $b$ ) suggested that these departments are not 'joined-up' in their policy goals and implementation. This extends to coordination of local and central government policy as well, with some boroughs and councils actively promoting microgeneration while parts of central government are backing away from similar measures (e.g. ODPM 2005). Secondly, PV households are not exclusively members of the PV actor network; they have other aspirations and roles as well. For example, considering the parallel example of do-it-yourself home repairs, behaviour might not simply be the result of an energy saving self-identity but a combination of personal, cultural, and material influences (Williams 2004, Fox 2005, Watson and Shove 2005a):

“... many DIY projects, ..., are emergent from the shifting relationship between households and their home, as the changing composition, routines, priorities, possessions, capabilities and competencies of the household have to be fitted into the basically intractable structure of a house."

- Watson and Shove (2005b: 8)

In other words, to aid the analysis, the thesis has assumed that PV households are 'black-boxed', influenced only by the domestic PV system stakeholders shown. However the stakeholders discussed here are not concerned solely with PV and microgeneration issues. Therefore promoting more sustainable energy use in PV households may require some of these black-boxes to be reopened and incorporated into discussions on microgeneration and consumer behaviour. 
The analysis has shown that the role of households within the PV actornetwork is somewhat limited. Furthermore the interviews suggested that the arrangements for microgeneration currently being developed (e.g. profile payments) could solidify, maintaining households as passive members of the electricity system. However it is worth remembering that large technical systems are not static (Joerges 1988, Law 1989) and significant changes are still possible. By seeking better links between monitors and meters, this shift might be achieved.

\subsubsection{PV and the conservation landscape}

The research has shown that PV is part of a conservation chain (after Haas et al. 1999), purchased after a series of more traditional investments in energy efficiency. However in addition to evidence supporting this concept, some contradictions have also been found: for example, not all households had a full complement of energy-saving measures installed before choosing PV (e.g. 83\% had double-glazing, 20\% had an A-rated fridge) and a diverse range of future energy saving actions were being considered by the respondents. This suggests that the notion of a single linear 'chain', ending with the purchase of PV, is insufficient. Instead, PV might be considered as an element of a multidimensional conservation landscape.

The conservation landscape concept is not new; Shove (1998: 1109), for example, referred to the "bumpy and uneven terrain" of socio-technical change as a way to "recognize the multiple contexts in which expertise and experience are formed". Shipworth (2005) has tried to take this concept further, moving "beyond metaphor", by using Bayesian belief networks to explore domestic energy consumption. The concept of landscape espoused here is somewhere between the metaphor and model extremes. First, an abstract landscape metaphor is of 
limited practical value as it offers no specific suggestions on what the dimensions of this landscape might be, and hence how the metaphor might be used to resolve a practical question. Conversely, the model approach is apt to get bogged down in mathematical detail and, by explicitly detailing the various dimensions and their interactions, the explanatory simplicity of the metaphor is lost.

As discussed above, the energy consumption behaviour of PV households was influenced by broadly internal and external factors. For example, the sociotechnical context of energy consumption influences the behaviours and equipment that are available to households. Cognitive control (encouraged post-PV by increased tacit knowledge and self-efficacy) was then shown to be a fundamental part of how household's interpret and respond to these circumstances. These two dimensions therefore provide the conceptual basis for an energy conservation landscape.

The landscape concept offers several contributions to the conservation chain hypothesis and other literature. First, it suggests that the purchase of PV is not necessarily the culmination of an inevitable chain. The households surveyed here applied cognitive control, using their tacit knowledge and self-efficacy, to overcome socio-technical obstacles (e.g. by re-interpreting cost issues) and justify the purchase PV. However if socio-technical change made PV more accessible (e.g. panels were installed in housing developments), households without such a strong environmental background (e.g. less tacit knowledge) could also become adopters; this is arguably the case with the passive adopters discussed in Dobbyn and Thomas (2005). The conservation chain therefore represents only one possible path across the landscape and the varied responses to PV seen here and in other literature indicate that each path presents, not only different ways of obtaining PV, but also different opportunities for subsequent energy consumption. 
The practical corollary is that a more efficient use of energy can be achieved through changes to cognitive control factors, socio-technical context or both. However as Shove (1998) notes, strategies to move across this landscape are only valid at a specific point in time. For example, if a household acquires PV through a socio-technical change, this new experience may increase their tacit knowledge, build self-efficacy, and perhaps even give them the ability to shape the socio-technical dimension. Therefore, the point at which an individual becomes able to use a wide variety of information and sustain the learning process is constantly shifting. In other words, it is difficult to assess whether PV households have achieved self-sustaining learning ('critical capacity', Darby 2003) and are on the road to sustainable energy use, without accounting for the full socio-technical and psychological context. Therefore the innovators studied here and potential new adopters arguably see quite different landscapes before them and hence have different prospects for future action. In practice, this suggests that developing cognitive control (e.g. building tacit knowledge by offering potential or 'passive' adopters PV-related information and experience) would give households the widest possible scope for energy-saving behaviour. Cognitive control can also be developed relatively easily compared to socio-technical change, which may require the cooperation of many stakeholders (e.g. changing tariffs).

Finally the landscape metaphor can help discuss whether PV represents the end of the conservation path. In the interviews, respondents noted many options for future energy saving but observed that socio-technical obstacles were often a major barrier (e.g. the cost, lack of available funds and planning arrangements for new types of microgeneration). The end of a household's energy conservation path may therefore come when these barriers are perceived to be unassailable, perhaps leading to the pursuit of other goals (e.g. recycling or transport as seen in the interviews). This suggests that the conservation land- 
scape might not be viewed in energy terms, but with respect to general environmental concern.

There are dangers in taking this metaphor too far, debating whether the progress a household has any other parallels with a physical landscape and the axes proposed here are merely conceptual and difficult to measure in practice. However the conservation landscape approach makes it clear that achieving energy conservation is not a deterministic linear 'chain', but a dynamic multidimensional journey.

\section{Summary}

The second research question sought to identify the mechanisms for the observed changes in energy consumption. First, the ownership and use of PV found in this research were determined to a large extent by cognitive control factors such as self-identity, a sense of personal responsibility for consumption, and a commitment to environmental issues. Importantly it was shown that PV installations increase the tacit knowledge of adopting households, building self-efficacy and the confidence to take further measures. These factors initially raise hope that general and durable changes in behaviour will occur but supportive socio-technical factors are also required to facilitate the widest range of sustainable energy consumption behaviours. Taken together, these two factors place PV on a dynamic conservation landscape. Uniquely this analysis suggests that monitoring devices occupy both cognitive and socio-technical roles and therefore should be the focus of efforts to promote behavioural responses to PV.

In Chapter 2, several questions were raised about the role of PV households within the socio-technical system. The results and discussion above suggest that the ability of households to change their role within the microgeneration 
system will depend on high levels of energy-related tacit knowledge. Specifically, PV was found to have provided information and experience about the supply and demand of electricity (e.g. via monitors) that could encourage households to assess their role within the electricity system. Therefore although it was shown that the PV actor-network may be moving towards reinforcing existing roles, there is potential for strategic niches to expand the role of PV households as energy citizens (e.g. metering trials combined with monitoring equipment).

\subsection{Contribution to policy and industry}

This research has shown that PV can provide a double-dividend of green electricity and reduced energy demand through behavioural changes. Furthermore it found that the nature of the response is not solely dependent on the psychology of the consumer; technologies and policies play an important role by facilitating specific behaviours. This suggests that, if the full potential of PV is to be realised, government and industry should be aware of how their products and policies shape the energy consumption behaviour of households. The third research question was therefore concerned with how these stakeholders might actively encourage desirable behavioural responses by offering appropriate incentives and user-friendly equipment. Three specific issues are considered: how the new PV grant programme might encourage sustainable consumption behaviour, assessing what electricity tariffs should be offered to PV households, and considering how metering and monitoring innovation might promote continued consumer engagement. 


\subsubsection{Defining a 'good' behavioural response to PV}

Before recommendations on the promotion of positive behavioural responses to PV can be provided, the goals of these interventions must be identified. In other words, what is a 'good' behavioural response to PV? The energy white paper (DTI 2003) provides an obvious starting point and by these criteria, behaviours should be encouraged that further the four goals of the white paper. This analysis is deceptively simple though as shown by the issue of climate change. The electricity generated by PV is carbon-free and therefore it is most effective when displacing the most carbon-intensive grid electricity. However in the UK, this occurs during winter evening peaks when marginal generation comes from coal-fired plant (National Grid 2003), a time at which PV is clearly not generating. Even for other microgeneration technologies, designing an incentive to promote microgeneration export during this peak period may be difficult as existing time-of-day tariffs (e.g. Economy 7) are not directly focused on carbon emissions. The effectiveness of this measure could then vary, for example, as the changing economics of fuels shift coal-fired generation toward base load uses (Peacock and Newborough 2004). It is also worth remembering that $76 \%$ of PV respondents were on green electricity tariffs and so from their perspective, PV has no carbon offset value. Therefore what constitutes a 'positive' behaviour response to PV will likely be interpreted differently depending on an individual's perspective.

It might then be best to identify some core principles that are broadly 'positive', rather than being overly prescriptive. One of the benefits of this approach is that PV is only one microgeneration technology and PV-specific solutions may be less applicable to other technologies (e.g. PV's peak generation is summer midday, as opposed to winter evening peaks with microCHP). Behavioural responses to microgeneration in general are therefore positive if they influence 
any of the following considerations:

- reduce greenhouse gas emissions;

- contribute to the security of grid electricity supply, e.g. by reducing peak demand;

- do not create additional burdens for fuel-poor households;

- raise household energy-related tacit knowledge and self-efficacy; e.g., by giving consumers more information and control regarding their electricity consumption and its generation.

There are ethical issues related to changing behaviour, for example, if these changes discriminate against the fuel poor and Bandura (1969) suggests that the best solution is to provide consumers with choices about their behaviour and its consequences (including impacts on society at large). Therefore a large part of the challenge in promoting these behavioural changes is to find methods that provide households with information about the costs and benefits of their electricity use, both at the household and grid levels.

\subsubsection{Promoting the effective diffusion of PV}

Ensuring that the adoption of PV leads to further energy conservation is a twostep process: the technology must be adopted and it must be delivered in such a way so as to facilitate an on-going commitment to energy saving. The research has identified two relevant issues. First, even for wealthy households, the cost of PV is likely to be a major barrier for potential adopters. Secondly, even for well-informed households, the installation process (both the interaction with the installer and the monitors they sell) is a valuable opportunity to get adopters thinking about sustainable energy consumption in a wider sense. There are questions however about whether the government's new PV grant 
programme, the Low Carbon Buildings Programme (LCBP), has sufficiently addressed these concerns.

The first question is how many households will acquire PV because of the LCBP. This analysis is complicated at the moment because the $£ 80$ million budget has not yet been fully allocated between small and large-scale streams and the LCBP incorporates a range of energy-efficiency and microgeneration technologies. It is therefore difficult to say whether the LCBP's $£ 80$ million for multiple technologies over three years will give the same benefit to PV as the Major PV Demonstration programme's budget of $£ 32$ million over 5 years. At the household level, the programmes are initially equivalent with $50 \%$ of installation costs being provided up to $£ 3000$ per $\mathrm{kW}_{\mathrm{p}}$ (to a maximum $£ 15,000$ ) but the LCBP will phase out support for household installations in favour of larger developments over three years.

Even with these grants, the research suggested that the up-front costs may still be too high to encourage a large-scale adoption of PV (especially for households that do not fit the 'innovator' profile seen here). At least two approaches are available to reduce the purchase costs. First the government could provide very large grants (i.e. greater than the existing $50 \%$ ) as technology learning literature suggests that these upfront investments help reduce costs in the long-run (e.g. IEA 2000, Hinnells 2005, EST 2005b). Given the government's reluctance to interfere in the market (e.g. no feed-in tariff, 'technology-blind' programmes), larger grants seem unlikely. A more promising alternative may be to spread the cost of PV over the system's lifetime. Jager (2006), for example, has suggested that a solar mortgage might assist in this regard; similarly the energy service company (Esco) model would also allow households to ammortise the cost of PV over longer time periods. With respect to consumer behaviour, the Esco/solar mortgage approach has advantages as it would provide households with a monthly reminder of their sustainable energy investment. The LCBP's 
emphasis on microgeneration in large housing developments may also help indirectly, as the cost of the PV would be a small porition of the house's total purchase price (for both owner-occupiers or social landlords).

One of the improvements of the LCBP over the previous MDP is that grant recipients are required to have installed four energy efficiency measures: $270 \mathrm{~mm}$ of loft insulation where practicable, cavity wall insulation (if applicable), low energy light bulbs in all appropriate fittings, and basic heating controls such as thermostats and a timer. Similarly new developments which benefit from the grants must be energy-efficient. This reinforces the conservation chain concept by framing the adoption of PV as part of a larger energy-saving lifestyle and may encourage the development of an energy-saving self-identity. Evidence of this effect has already been seen in some social microgeneration housing, provided that tenants are made aware of the energy-saving features:

“... because it was a low energy house we were really careful with the lights, bought A-rated appliances and became frantic recyclers, we were really excited about it, we thought it was going to be a whole new way of living."

- 'Passive' adopting solar-thermal household, Dobbyn and Thomas (2005: 34)

However there is a risk that some households, particularly passive adopters, may miss the energy-conscious lifestyle implied by these other efficiency measures. If the goal is to build tacit knowledge in support of an energy-efficient lifestyle, then a variety of information should be used to make these messages explicit. One proposal would be the inclusion of a 'Microgenerators starter pack' for all recipients of a LCBP grant (especially occupants of development properties). The goal of these packs would be to explain the basic features of the technology, demonstrate how monitors and meters can be used to track generation and consumption, and describe the different electricity tariffs available. In addition to this general information, profiles of other microgenerator 
and energy-saving households ${ }^{3}$ and advice on potential next steps could be included; these early steps should be simple in order to build up confidence. The information pack would therefore send households a message that living in a microgenerating household is only part of a sustainable lifestyle and provide specific information on how to progress toward this vision.

Of course the most important element of the household's information environment is the monitoring device. While the research found that a basic device is already a common installation practice in the industry, it should be a requirement of all LCBP projects since one of the programme's aims is to investigate the potential of microgeneration "to change the attitudes and behaviour of consumers" (EST 2006c). Furthermore these devices should display generation and consumption data. This could be implemented by the installer accreditation programme, perhaps creating a 'star' certification for those who include appropriate monitors as standard practice.

The LCBP is just one way in which PV might be adopted by households. For example, Watson et al. (2005) note that there are at least three different business / deployment models for microgeneration, each with potentially different impacts on consumers. Under the 'company-control' model, for example, microgeneration might be dispatched by suppliers as a replacement for centralised generation; this would require better communication between households and companies, perhaps facilitated by metering technologies rather than direct household involvement. Alternatively with a 'community micro-grid' consumers could have an stake in a local grid company and manage their microgeneration more directly. This second scenario seems like a very promising way to raise tacit knowledge but it may require significant time investments from participants and be unsuitable for some households. The final 'plugand-play' scenario would involve very little disruption to existing electricity

\footnotetext{
${ }^{3}$ A number of these case studies are already available on the web (EST 2006b).
} 
arrangements, with consumers providing most of the initiative (as in the current situation).

Therefore, by concentrating primarily on the diffusion of PV technology, government and industry risk missing an excellent opportunity to engage with consumers. Some promising initiatives have been taken, such as requiring energy-efficiency measures before receiving a grant; however more effort could be spent on ensuring that microgenerating households are established within an information-rich environment that promotes the development of tacit knowledge and facilitates sustainable energy use.

\subsubsection{Encouraging appropriate behavioural responses to PV}

In Chapter 5, microgeneration tariffs were presented as an important part of the PV socio-technical system. Three major kinds of tariff were outlined: payments for exported electricity, payments for generated electricity and flat (or profile) payments based on microgeneration technology and system capacity. Each scheme provides different signals to consumers about when they should use their electricity. For example, high export payments may encourage households to shift loads away from times of peak generation in order to export their most valuable electricity. Flat payments may have little impact on consumer behaviour because they are paid long after the consumption behaviour occurred (although these payments may be easier for electricity suppliers to administer). If positive behavioural responses are judged against the goals of energy policy, it may also be extremely difficult to select a single tariff that delivers benefits on all dimensions of policy for all microgeneration technologies. This section considers how tariffs for microgeneration might be used to promote sustainable energy use in PV households.

In §6.4.4, retail electricity prices were examined and the requirements of a 
minimum fair payment for microgeneration presented (e.g. $4.32 \mathrm{p}$ per generated $\mathrm{kWh}, 3.28 \mathrm{p}$ per exported $\mathrm{kWh}$ ). However the government or electricity suppliers could introduce further incentives into this framework to encourage demand management, further carbon savings, or other goals. For example, electricity suppliers might offer an additional premium for exports during winter evening peaks (obviously not possible for PV) or encourage reductions in overall electricity demand by setting targets for microgeneration households and providing a flat payment if it is achieved. Similarly government could introduce regulation allowing microgenerators to be reimbursed for the incurred costs of generation equipment and meters. The challenge with these additional rewards is that they should be used in such a way that "people's intrinsic motives to conserve [or install further generation if many conservation measures already done] can be nurtured and developed" (de Young 2000: 522). In other words, they must not be too obvious or consumers might be become dependent on them (Bandura 1977).

If these tariffs were introduced, there would be immediate questions about how they should be funded. For example, the German feed-in tariff is paid for by a small levy on all electricity bills. However DTI's reluctance to introduce a feed-in tariff as shown in the interviews suggests that there may be insufficient political leadership for this policy to succeed in the UK. It should be noted though that the government's chief scientist has suggested that such a levy might be used to fund a new round of nuclear power stations (BBC News 2005); if this policy is considered for nuclear power, it must also be an option for microgeneration. There may also be difficulties in getting the electricity supply industry to agree with the proposed export and generation tariff structures. This resistance would be due primarily to the additional costs of installing the necessary metering equipment (though households might pay the metering costs themselves) and collecting and processing the data. The industry's apparent 
preference for flat-profile payments is consistent with this reasoning as it requires no extra equipment and little administrative effort, but this arrangement gives households very little incentive to take an interest in the performance of their system. Smart metering innovation may reduce some of these expenses (e.g. reading costs) but it appears that the present market is not delivering these innovations. Therefore political and regulatory intervention may be required if microgeneration is to reach its full potential (Ofgem 2006b).

An effective tariff structure for microgeneration households should be viewed as part of the wider learning experience triggered by adopting these technologies. For example, households initially need to understand the various components of their retail electricity price so that they can recognize when they are being paid a fair price. More sophisticated tariffs aimed at changing consumption behaviour, especially load-shifting behaviour, require accurate (e.g. halfhourly) information on the costs and benefits of generating and exporting with respect of climate change, grid performance and other issues. Monitors are required to ensure that these signals are communicated to households, hence the need for a link between meters (for administering the tariffs) and monitors. The next section will therefore examine how monitoring equipment might be designed and implemented to facilitate these types of tariffs and generally encourage sustainable energy use among consumers.

\subsubsection{Maintaining an energy-efficient lifestyle}

Monitors have been shown to be a valuable source of information for households, both in this research and elsewhere (e.g. Darby 2000). However there is still a great deal of diversity in the design of the devices and they are not automatically installed in microgenerating households (and may not include consumption information). Therefore this section will consider how industry and 
government might use these devices to build tacit energy knowledge among PV households and encourage commitment to a low-carbon lifestyle.

The first step is to ensure that the devices are actually installed in homes. Although PV installers frequently install the monitors, it was recommended above that these devices should be a requirement of all new microgeneration installations. Secondly monitors are most effective when they engage consumers. This means that they must be installed in a visible location and monitor manufacturers should also ensure that the designs encourage user interaction (again this could be promoted via the accreditation programme and best practice guidelines). An important part of this engagement is the inclusion of consumption, as well as generation, information. Although it was shown that small monitoring firms may find it difficult to introduce these innovations into their devices due to cost constraints and low turnover, the new Sharp monitor is an excellent example of how consumption and generation information can be displayed in an engaging manner (e.g. providing the comparison of generation and consumption that $73 \%$ of survey respondents requested).

Monitors arguably have two roles for developing tacit knowledge among households. The first is to provide specific feedback on consumption and generation, which as Darby (2000: 9) notes, must be "accessible, attractive and clear". This suggests that the complexity of the tariff structures proposed above, although explained in detail to consumers at some point (e.g. through the microgenerators information pack), should be condensed into metrics which can be interpreted at a glance. The PV fraction and energy balance concepts outlined in Chapter 5 can be used to present this information. Figure 7.3 demonstrates a possible design, incorporating simple traffic light summaries of the current generation and consumption situation with seasonal consumption targets to guide long-term savings behaviour. The figures shown use the minimum generation and export tariffs from $§ 6.4$.4; the overall levels of consumption are fictional but 
based approximately on the average UK household electricity consumption of $3300 \mathrm{kWh}$ per year (EnergyWatch 2004). It is worth noting that one idea, comparing consumption with that of the neighbours, was rejected by respondents in a recent UK report (Roberts et al. 2004) though it has shown promise internationally (Iyer et al. 2006).

Since it is anticipated that many households receiving PV through the LCBP will lack the necessary tacit knowledge to interpret the monitor information fully, the monitors might also provide specific recommendations on possible energy-saving measures. Ultimately these devices could communicate with all appliances in the home, providing households with detailed information on where and when electricity is being consumed (Harrison 2005, Ueno et al. 2006). Until these innovations come to fruition though, monitor data may be analysed off-site and mailings provided to give this additional advice. This information would work with the long-term energy saving information shown on the monitors above. A pilot programme using these concepts, particularly the energy budget, might also offer suggestions on how the wider question of personal carbon allowances (Hillman and Fawcett 2004, Boardman et al. 2005) might work in practice.

For the ideal situation of well-informed households supported by fair tariffs to be achieved, there will need to be cooperation between electricity suppliers, monitor designers, PV installers and PV households. For example, the interviews found that many households were unhappy with their microgeneration tariffs partly because they did not understand the constituents of the retail price of electricity. While monitors may help to resolve this specific area of confusion, the larger conclusion is that it was only by offering microgenerators anything, e.g. the NPower pilot, that this problem was identified. This therefore suggests that all stakeholders have an interest in experimenting with monitoring technology at this early stage so that it may ultimately be a useful tool for 


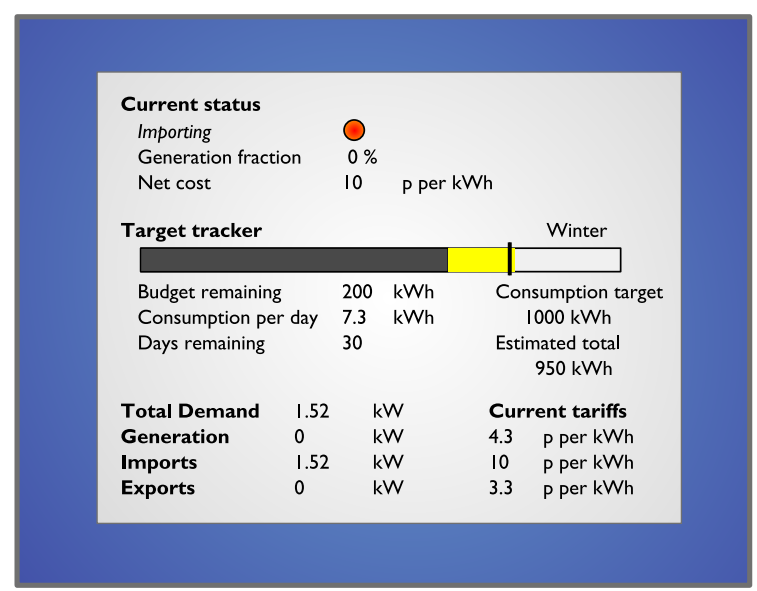

(a) No microgeneration output, near seasonal consumption target

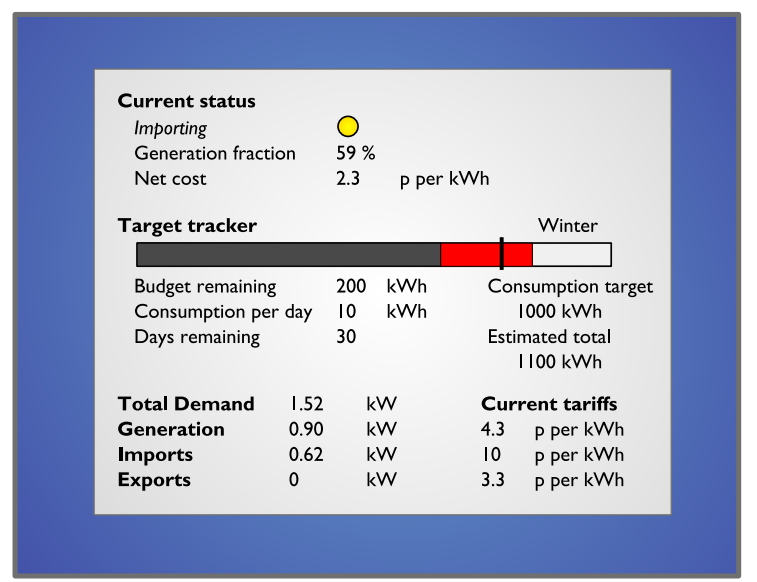

(b) Microgeneration output with additional imports, failing on seasonal consumption target

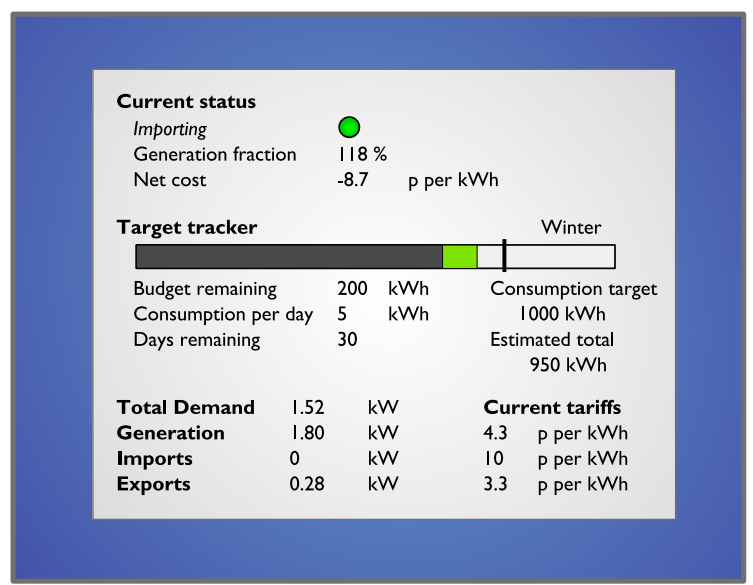

(c) Microgeneration output with exports, exceeding seasonal consumption target

FIGURE 7.3: A monitor design for microgenerating households 
all. Fortunately the microgeneration strategy (DTI 2006a) recommended that a smart-metering pilot programme be conducted. However no evidence has been provided yet to suggest that this pilot will be connected with the microgeneration installations of the LCBP or that consumers will be actively engaged in the process. Indeed recent research indicates that a possible motivation for industry to involve consumers, e.g. demand-side management of peak demand, may not be an important concern; alternative arguments, such as future proofing of the metering stock, might therefore be used to promote more ambitious pilot schemes (Owen and Ward 2006). Regardless of how it is achieved, industry and government need to be aware that if these opportunities to engage households are not explored now, while microgeneration technology is relatively new, innovative metering and monitoring technologies could simply become a method of 'technical control' (after Law 1992b), reinforcing existing industry arrangements and unsustainable electricity consumption.

Monitors arguably represent an 'obligatory passage point' on the way to an active role for microgenerating households. In other words, by linking these devices with meters and electricity tariffs, the major stakeholders in the PV system (government, households, electricity suppliers, installers and so on) are brought together. For this reason, monitoring systems should be piloted within protected niches so that stakeholders can work together to develop an acceptable meaning for these artefacts, developing new policies and mechanisms that engage microgeneration households rather than simply reinforcing existing arrangements. Otherwise, the potential of PV and microgeneration technologies to promote the 'double-dividend' may be lost. 


\section{Summary}

The third research question asked how policy makers and industry might ensure that PV promotes positive behavioural responses in adopting households. It was assumed that the goal of these interventions is to give households the ability to choose their consumption patterns within a framework that fairly reflects the societal costs and benefits of generation and consumption, on both short and long time scales. The recommendations, regarding the circumstances of installation, the use of tariffs, and the role of monitors, were premised on the belief that each stakeholder has a different interpretation of a fair microgeneration system and what behavioural responses are appropriate. Therefore these early days of microgeneration should be viewed as an opportunity to develop systems and technologies that work for all stakeholders: the 'shared visions' of sustainability (Michaelis 2003). The microgeneration strategy and LCBP make some progress towards this goal but more can be done to engage households, e.g. by insisting that monitors including consumption information are installed with new microgeneration systems. Similarly while the existing tariffs for microgeneration fail to involve households in any meaningful discussion of this system, new pilot programmes on smart metering innovation could, if linked with advances in monitoring technology, provide the niche needed to engage microgenerating households with the wider electricity system. The evidence therefore suggests that the PV actor-network is not yet fixed and there are real opportunities to ensure that the system is oriented in a manner consistent with sustainable energy consumption.

From the consumer's perspective, the ability to respond to this information, take further energy-saving steps, develop or expand an energy-saving self-identity is closely linked with well-developed tacit knowledge. Almost all of the suggestions outlined here have essentially been aimed at increasing 
this knowledge by providing new experiences, general information or specific feedback. The goal of these interventions however is not to force consumers into specific modes of behaviours: behavioural change is "not accomplished by telling [people] what to do... People are likely to resist doing what they are told to do and may even attempt to undermine the entire effort; furthermore, such an approach would be a waste of talent and ingenuity" (Kaplan 2000: 505). Instead, the challenge is to apply the lessons from this and other research to "engage the powerful motivations for competence, being needed, making a difference, and forging a better life" (ibid).

\subsection{Study limitations and opportunities for further research}

The research has contributed to debates surrounding microgeneration and consumer behaviour but the wider applicability of the results is restricted by a number of factors. To begin, the study only examined households with solar photovoltaics; other microgeneration technologies may lead to quite different responses. For example, microCHP and small-scale wind have lower initial costs, suggesting that less environmental commitment may be needed to balance economic considerations. Once installed, these technologies also provide electricity at different times, possibly affecting load-shifting behaviour. Another limitation of the study was the characteristics of the sample. Although the respondents here represented nearly one-sixth of UK PV households at the time of the research, the active-purchasing, owner-occupier PV household may become less common, particularly as the Low Carbon Buildings Programme encourages the installation of PV in social housing or other large developments. These future 'passive' PV adopters may have markedly 
different socio-economic, attitudinal and value characteristics, and hence behavioural responses (at least initially).

This study could have been most improved by measuring the actual change in electricity consumption of PV households. As noted in $§ 1.5 .1$, this was not possible due to time restrictions and difficulties in identifying sample households. Ironically, the difficulty of getting a cooperative research agreement with the industry partners of the Beama project reinforces the interview finding that data are not being shared sufficiently between different stakeholders (especially households). Hopefully, interest in this kind of consumer research will grow, encouraged perhaps by the microgeneration strategy. For the moment though, the thesis has reported the approximate magnitude of changes that can be expected and the uncertainty of respondent self-assessments suggests that these estimates should be used cautiously.

There are several outstanding questions regarding behavioural responses to microgeneration that could be addressed by further research. The following list describes these areas of study with some topics designed to address the methodological weaknesses discussed here and other topics intended as new directions for research:

- A comprehensive study of household electricity consumption and generation, coupled with detailed social survey data. Ideally this would incorporate data from at least a year before and after the installation of the microgenerating technology. A basic alternative would be to monitor the energy consumption of households within new microgeneration developments closely. A variety of microgeneration technologies should be examined as well.

- A longitudinal study of the effect of microgeneration on household electricity consumption, in order to understand the role that the novelty of mi- 
crogeneration technology may play in changing energy-use behaviours, as well as the effect of capital equipment purchases over time.

- Experimental studies on the benefits of different microgeneration tariffs and monitor designs could provide useful recommendations for government and industry seeking to encourage behavioural responses to microgeneration.

- Modelling the effect of behavioural responses to microgeneration and associated tariffs could be useful to understand the policy benefits of different scenarios against different criteria. For example, how much of a contribution could microgeneration-related load shifting make to reducing peak demand at a national or local grid level? What might be the effect of different tariff levels?

- Review the effectiveness of alternative microgeneration support mechanisms. Specifically examine local council initiatives (e.g. the Merton rule) to assess the different demographic and value characteristics of these passive microgeneration adopters and their behavioural responses.

- Identify the limits of behavioural change from microgeneration. In other words, what is the maximum saving that could result from microgeneration? If a full suite of response actions are taken (e.g. new efficient appliance, load shifting, etc.), does the resulting energy consumption achieve some level of sustainability, e.g. zero net electricity imports or carbonneutrality?

As Abrahamse et al. (2005) notes, studies of domestic energy consumption interventions have often overlooked their limitations and over-interpreted their findings. This study has therefore made a contribution to the understanding of behavioural responses of a specific group of individuals to a specific type 
of microgeneration technology. While PV may not be the perfect technology for encouraging behavioural responses to microgeneration in the UK (due to its cost and generation characteristics), many of the mechanisms and policy issues identified here are relevant to other technologies and hopefully this will provide researchers with a starting point for future studies.

\section{Conclusion}

In Small is Beautiful (1973), E.F. Schumacher noted that solutions to real-life problems require elements of both order and freedom. Considering energy policy, it can be argued that electricity generation has done exceedingly well at providing order, using centralized institutions and coordinated infrastructure to provide electricity cheaply and transparently to millions of households in the UK. However this invisibility reflects a distance between the actions of individuals and their consequences, hence removing from households the freedom to choose less damaging forms of electricity production and consumption. Indeed the inability of individuals to feel that they have any impact on climate change or other large-scale energy policy issues is a major issue (e.g. Norgaard 2003). The solution, suggests Schumacher (1973: 49), is therefore "to insist on the virtues of smallness - where this applies": in other words, appropriate combinations of small and large-scale institutions (e.g. microgeneration versus centralised generation).

The research has shown that microgeneration may assist in restoring the balance between small and large. At a societal scale, microgeneration technologies such as PV are socio-technical artefacts that require a network of manufacturers, electricity suppliers, regulators, funders and other stakeholders to work successfully. The existing electricity institutions have begun to provide order to the introduction of microgeneration in the UK's future electricity networks 
through regulations and technologies, but the research found that these initiatives may not be sufficiently ambitious to achieve the full potential of microgeneration.

The primary contribution of this thesis has been to emphasis the small-scale benefits of a microgeneration technology like PV. By bringing households directly into contact with the consequences of their electricity demand, even the most committed energy-savers were still able to learn something about the impact of their lifestyle on the environment. Monitoring devices, electricity tariffs, and even the symbolism of the PV panels themselves, therefore all represent ways in which the order of large-scale systems can facilitate the freedom of individual choice and behaviour. The challenge is to encourage the interaction of micro and macro: promoting the diffusion of PV and microgeneration technologies, developing the institutions and mechanisms for a flexible and supportive electricity generation system, and ultimately engaging with consumers, building their energy-related tacit knowledge and empowering them to take action in their own home. In this way, the small-scale behavioural responses to PV may lead to a large-scale sustainable future. 


\section{Appendix A}

THE QUESTIONNAIRE 


\section{TELL US ABOUT YOUR PV}

\section{Photovoltaic (PV) Household Survey}

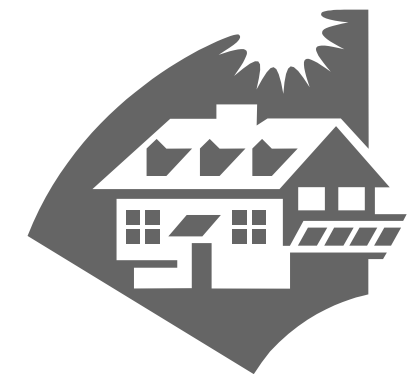

\section{Environmental Change Institute UNIVERSITY OF OXFORD}

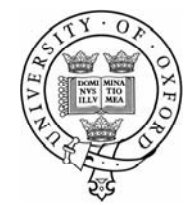

\section{About this survey}

This survey is being conducted for research at the Environmental Change Institute, University of Oxford. The study focuses on UK households with solar photovoltaics and their use of energy. The results will be used for a student's doctorate and the information you provide will remain anonymous.

The survey is to be completed by the head of the household and should take 15 to 20 minutes. Please answer all the questions to the best of your ability and thank you for your cooperation.

Tr PRIZE All questionnaires returned by Friday 10 December 2004 will be entered in a draw for a $£ 20$ Blackwell’s Book Shop gift certificate.

Please send completed surveys to:

James Keirstead

Environmental Change Institute c/o Zoology, University of Oxford

Oxford, OX1 3PS

Tel: 01865281208

Email: james.keirstead@ouce.ox.ac.uk 


\section{About yourself}

1. Gender:
Male
Female

2. What is your age?
18-30
$31-44$
$\square$ 45-64
Over 65

3. What is your highest level of education?
$\square$ Degree or other higher education
$\square$ A-level or equivalent
$\square$ GCSE or equivalent
$\square$ No qualification

4. What is your household income?
$\square \quad$ Less than $£ 14,999$
—15,000-24,999
$\square £ 25,000-34,999$
$\square £ 35,000-49,999$
$\square £ 50,000-100,000$
More than $£ 100,000$

5. How many people, including yourself, live in your household?
$\square 1 \square 2$
$3 \square 4$
45
6 or more

6. How long have you lived in your current home?
$\square$ Less than 2 years
$\square \quad 2-5$ years
$\square$ 5-10 years
$\square$ 10-20 years
$\square$ More than 20 years

7. Do you own or rent your current home?
Own
Mortgage
Rent
Other: 


\section{Background questions}

8. Climate change is caused by a hole in the Earth's atmosphere.
Definitely true
-

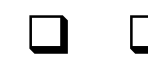
$\square \square \square \square$
Definitely not true

9. Every time we use coal, oil or gas, we contribute to climate change.
Definitely true
$\square \square \square$

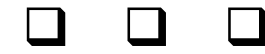
Definitely not true

10. Solar photovoltaics use the energy of the sun to:
$\square$ Heat water
$\square$ Generate electricity
Don't know

11. Solar photovoltaics don't work in the UK because it's not sunny enough.
Strongly
disagree

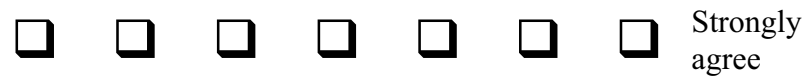

12. Modern science will solve our environmental problems with little change to our way of life.
Strongly
$\square \square \square \square \square \square \square \square \begin{aligned} & \text { Strongly } \\ & \text { agree }\end{aligned}$

13. Many of the claims about environmental threats are exaggerated.
Strongly
$\square \square \square \square \square \square \square\left(\begin{array}{l}\text { Strongly } \\ \text { agree }\end{array}\right.$

13. I do what is right for the environment, even when it costs more money or takes more time.
Strongly
disagree

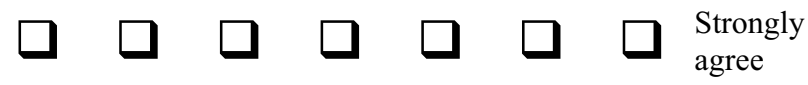

14. Compared to people in general, a home energy saver is more likely to
Pay attention to
their energy bills
$\square \square \square$

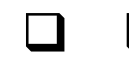
Not pay attention to their energy bills

15. Compared to people in general, I am more likely to
Pay attention to
energy bills

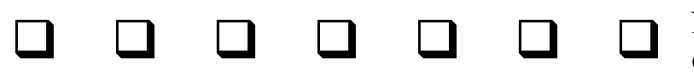
Not pay attention to
energy bills 
16. Compared to people in general, a home energy saver is more likely to

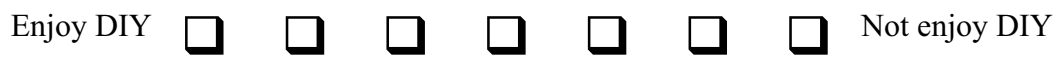

17. Compared to people in general, I am more likely to

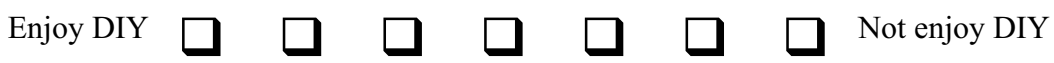

18. Please rank the following groups of words in order of importance to you as guiding principles in your life (from $1=$ most important to $5=$ least important).

Clean, polite, independent, helpful, responsible, obedient

Protecting the environment, unity with nature, respecting nature

Exciting and varied life, curiosity, comfortable and prosperous life

Social recognition, ambitious, lasting contribution

Sense of belonging, equality, family security

\section{Energy use at home}

19. What might you do next to reduce your household's electricity consumption, in addition to any steps you've already taken? Please list three options, from most likely (1) to least likely (3).

1 .

2 .

3.

Please answer the following questions for your most likely action on line (1) above.

20. What do you believe are the advantages of this action?

21. What do you believe are the disadvantages of this action? 
Photovoltaic Household Survey

22. Are there any individuals or groups who would approve of this action?

23. Are there any individuals or groups who would disapprove of this action?

24. What factors or circumstances would enable to you to do this action?

25. What factors or circumstances would make it difficult or impossible for you to do this action?

26. Owning a PV system has made me more/less likely to take this action.

$$
\text { Less likely } \square \square \square \square \square \text { More likely }
$$

27. Please elaborate: what is it about owning a PV system that makes this action more or less likely?

28. What fuels do you use in your home:
Gas Oil Electricity Other
a) For water heating? $\square \square \square$
b) For space heating? 
29. Before getting PV, our household had done the following. Tick all that apply.

$\begin{array}{ll}\text { Insulated } & \text { Loft } \\ & \text { Floor } \\ & \text { Walls } \\ & \text { Pipes } \\ & \text { Hot-water tank } \\ \text { Installed } \quad \text { Double-glazing } & \text { An efficient boiler } \\ & \text { Solar hot water heater } \\ & \text { Draught-proofing on windows and doors } \\ \text { Recycled or composted most household waste } \\ \text { Installed low-flow shower heads or other water-saving } \\ \text { measures } \\ \text { Used public transport, cycled or walked for most short } \\ \text { journeys } \\ \text { Switched to green electricity } \\ \text { Invested in carbon abatement (e.g. Future Forests, } \\ \text { Climate Care) }\end{array}$

30. Before getting PV, our household had the following appliances:

\begin{tabular}{lccccc} 
& \multicolumn{5}{c}{ Energy Label Rating } \\
& A & B & C or lower & Unknown & Don't own \\
\hline Fridge-freezer & $\square$ & $\square$ & $\square$ & $\square$ & $\square$ \\
Fridge & $\square$ & $\square$ & $\square$ & $\square$ & $\square$ \\
Freezer & $\square$ & $\square$ & $\square$ & $\square$ & $\square$ \\
Dishwasher & $\square$ & $\square$ & $\square$ & $\square$ & $\square$ \\
Washing machine & $\square$ & $\square$ & $\square$ & $\square$ & $\square$ \\
Tumble dryer & $\square$ & $\square$ & $\square$ & $\square$ & $\square$
\end{tabular}

31. Before getting PV, $\%$ of our household lights were low-energy compactfluorescent lightbulbs (CFLs)

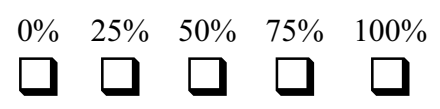


Photovoltaic Household Survey

32. Since getting PV, our household has done the following. Tick all that apply.

Insulated Lof

Floor

Walls

Pipes

Hot-water tank

Installed Double-glazing

An efficient boiler

Solar hot water heater

Draught-proofing on windows and doors

Other Recycled or composted most household waste

Installed low-flow shower heads or other water-saving measures

Used public transport, cycled or walked for most short journeys

Switched to green electricity

Invested in carbon abatement (e.g. Future Forests, Climate Care)

33. Since getting PV, our household has the following appliances:

\begin{tabular}{lccccc} 
& \multicolumn{5}{c}{ Energy Label Rating } \\
& A & B & C or lower & Unknown & Don't own \\
\hline Fridge-freezer & $\square$ & $\square$ & $\square$ & $\square$ & $\square$ \\
Fridge & $\square$ & $\square$ & $\square$ & $\square$ & $\square$ \\
Freezer & $\square$ & $\square$ & $\square$ & $\square$ & $\square$ \\
Dishwasher & $\square$ & $\square$ & $\square$ & $\square$ & $\square$ \\
Washing machine & $\square$ & $\square$ & $\square$ & $\square$ & $\square$ \\
Tumble dryer & $\square$ & $\square$ & $\square$ & $\square$ & $\square$
\end{tabular}

34. Since getting PV, _ $\%$ of our household lights are low-energy compact-fluorescent lightbulbs (CFLs)

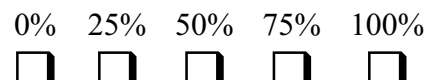


2 The total amount of electricity is equivalent to the electricity your household would need from the grid if you did not have a PV system.

35. The total amount of electricity used in our household is more/less than before we had a PV system.

Much less $\square \underset{-50 \%}{\square} \underset{-25 \%}{\square} \square_{0} \underset{+10 \%}{\square} \underset{+25 \%}{\square} \underset{+50 \%}{\square}$ Much more

36. I am certain of this answer.

Very certain $\square \quad \square \quad \square \quad \square \quad \square \quad \square \quad \square$ Not very certain

37. Since getting PV, the total amount of electricity used in our household has changed because we are more aware of how electricity is generated.
Strongly
agree
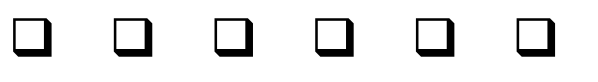
Strongly disagree

38. Since getting PV, the total amount of electricity used in our household has changed because we are more aware of how much electricity we consume.
Strongly
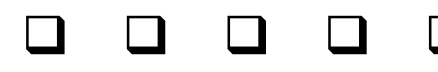
Strongly
agree
disagree

39. Since getting PV, the total amount of electricity used in our household has changed because we try to live within the amount of electricity produced by our PV system.
Strongly
agree
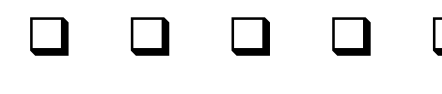
Strongly
disagree

40. The total amount of electricity used in our household since PV has changed because we are now a 'green' household.
Strongly
agree

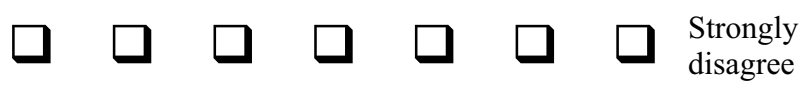

41. Can you think of any changes in your household since getting PV that might affect the amount of energy you use? For example, having more or fewer people in the household. 


\section{Your PV system}

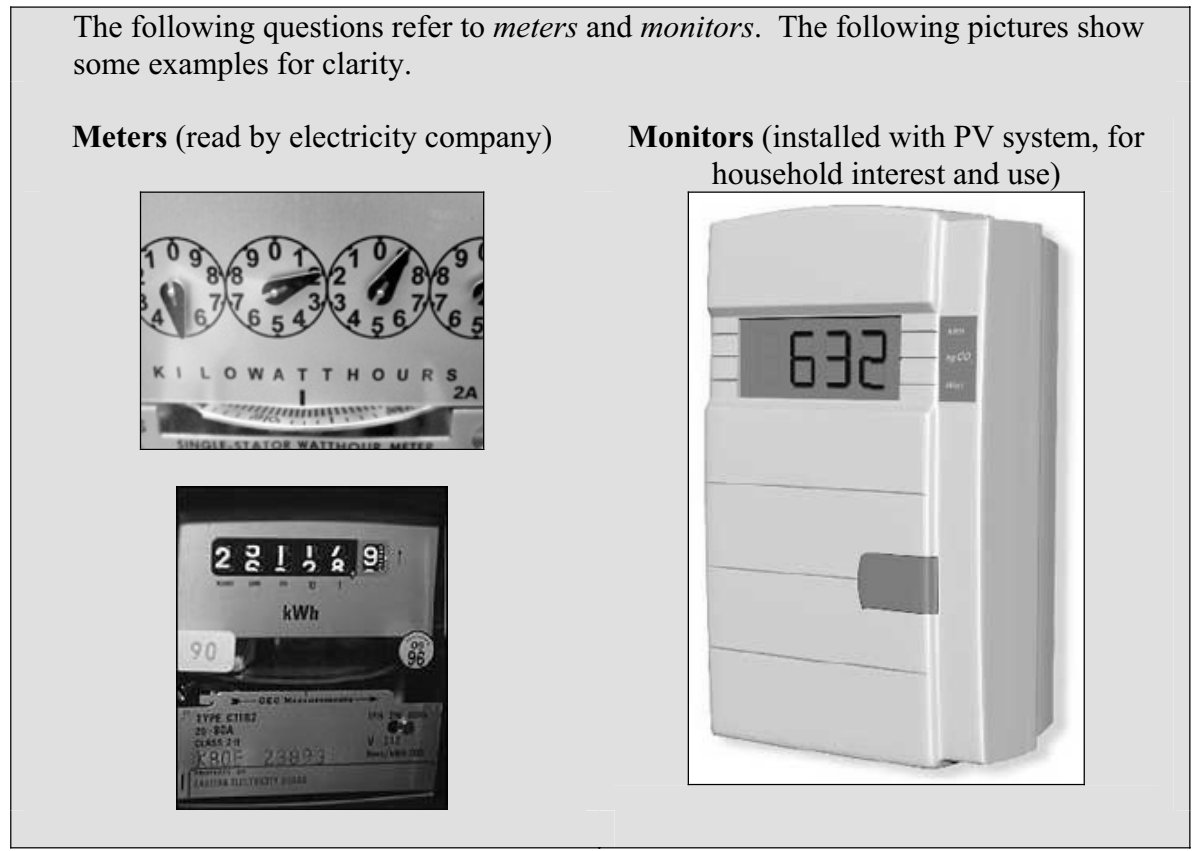

42. How long have you had your PV system?
$\square$ Less than 6 months
$\square$ 6-12 months
$\square 1-2$ years
$\square 2-5$ years
$\square$ More than 5 years

43. Does your PV system feature a display monitor, similar to the one pictured above right?

\section{$\square$ Yes $\square$ No $\square$ Don't know}

If yes, please proceed to question 44. Otherwise, please proceed to question 49 .

44. Where is the display monitor located in your home?

45. If known, please indicate the make and model of your display monitor (e.g. Leiderdorp LI-12.) 
46. What information does the display monitor show? Please tick all that apply.

Instantaneous electricity production $(\mathrm{kW})$

Cumulative electricity production $(\mathrm{kWh})$

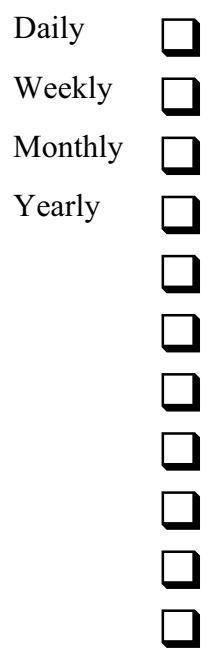

Total monthly electricity production $(\mathrm{kWh})$

Total electricity exported to grid

Total household electricity consumption

Carbon-dioxide $\left(\mathrm{CO}_{2}\right)$ saved $(\mathrm{kg})$

Cost savings ( $($ )

Your PV generation compared to total consumption

Warning or system faults

Other:

47. What information on the display monitor do you look at most frequently? Select one.

Instantaneous electricity production $(\mathrm{kW})$

Cumulative electricity production $(\mathrm{kWh})$

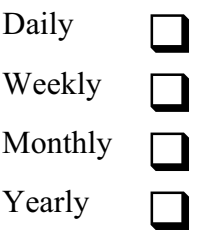

Total monthly electricity production $(\mathrm{kWh})$

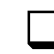

Total electricity exported to grid

Total household electricity consumption

Carbon-dioxide $\left(\mathrm{CO}_{2}\right)$ saved $(\mathrm{kg})$

Cost savings ( $(\mathfrak{)}$

Your PV generation compared to total consumption

Warning or system faults

Other: 
Photovoltaic Household Survey

48. How often do you look at your system's display monitor?
$\square$ Every day
$\square$ About twice a week
$\square$ Once a week
$\square$ Once a month
$\square$ Infrequently
$\square$ Never

49. What information about your PV system's performance would you like to have readily available? Please tick all that apply.

Instantaneous electricity production $(\mathrm{kW})$
Cumulative electricity production $(\mathrm{kWh})$
Total monthly electricity production $(\mathrm{kWh})$
Total electricity exported to grid
Total household electricity consumption
Carbon-dioxide $\left(\mathrm{CO}_{2}\right)$ saved (kg)
Cost savings (£)
Your PV generation compared to total consumption
Warning or system faults

Other:

50. What type of meter does your household have?
Import
Export
Import and Export
Don’t Know

51. Our PV system will pay for itself in:
$\square$ Less than 2 years
2-5 years
$\square$ 5-10 years
$\square$ 10-20 years
$\square$ 20-50 years
$\square$ More than 50 years

52. Please tick all that apply. I know our system will pay for itself in this time period from:

$\square$ Examining old energy bills

$\square$ Talking with our energy company

$\square$ Reading or research

$\square$ Other: $\square$ Talking with our PV installer

$\square$ Observing our PV system's electricity production

$\square \quad$ I'm not certain how long it will take to pay off 


\section{Closing questions}

53. Would you recommend a PV system to your friends or family?

$\square$ Yes

$\square$ No, poor performance

No, other: $\square$ No, too expensive

$\square$ No, bad experience with installation

$\square$ Don't know

54. Would you be willing to participate in a follow-up 20-minute phone interview?
$\square$ Yes
$\square$ No

If yes, please provide your telephone number and convenient time to call:

Tel:

Preferred call time:

55. Please provide your contact name and address for the draw prize. Again your results will be confidential - the name provided here is only used for prize purposes.

Name:

Address:

City:

Postcode:

Email:

56. Do you have any further thoughts on how PV has affected energy use in your home?

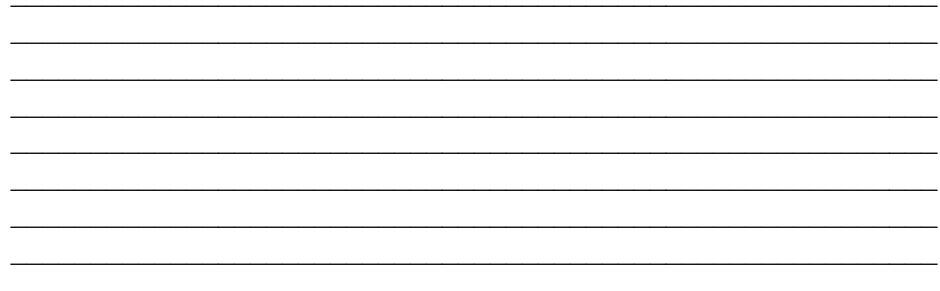

Thank you for your time. You can get more information on the Environmental Change Institute and this research at http://www.eci.ox.ac.uk. Please return this survey to James Keirstead, Environmental Change Institute, c/o Zoology, University of Oxford, Oxford, OX1 3PS as soon as possible. 
APPENDIX A: THE QUESTIONNAIRE 


\section{Appendix B}

\section{A SAMPLE INTERVIEW}

This appendix contains the transcript of a discussion with D. E., one of the most interesting PV households surveyed. Mr. E. is a 45-64 year old pensioner with A-level education. He lives on his own in Essex, in a home which he owns and has lived in for more than 20 years. The phone call was placed on 3 February 2005 at 1 pm and the transcript begins after asking for permission to record the interview.

JK: Thanks. I just wanted to start by asking you how you first heard of the technology?

DE: We're talking about PV technology, you mean?

JK: Yeah.

DE: Well the very first instance actually was, erm, I remember getting a little miniature sort of battery charger from a local electrical store. You know one of those things that just charges up...

JK: Sort of like the...

DE: Two A, AA batteries sort of.

JK: Yeah, yeah. 
DE: And I think - yes actually that was significant because from that, I did sort of plan on making up something more like a marine PV system.

JK: Yeah.

DE: Running at twelve or twenty-four volts and running low consumption things from that.

JK: Right.

DE: And it was actually at that stage, when I came in to retire and sort of looking at that, that I followed up a couple of things and got involved with, erm, the local energy trust through a note that they put through the door, that asked you to go along and get a free bulb from them and so on, and they did actually talk me into going along to a solar hot water system introduction.

JK: Yup.

DE: But I knew I was mainly interested in PV and actually while I had gone to that solar water system forum, the government made its first announcement about introducing grants available for solar PV.

JK: Right.

DE: So that's how it progressed.

JK: And that's how you — then you ended up going from there to purchasing a system.

DE: Yes that's right.

JK: Right. So was the PV system unique, or had you sort of taken other sorts of energy saving measures around the home? 
DE: Yes, I had what — one minute, I'm going to turn the radio off. Just a minute.

JK: Sure yup.

DE: Yes. Other energy measures? Well the panels themselves have led to a lot of further energy measures saving because it's made me particularly, much more aware of how much energy I was using.

JK: Right. Why is that sorry? Why do they make you more aware of what you're using?

DE: Well I think I can actually remember that prior to getting to the panels, I didn't really know how much I was spending on, or how much energy I was consuming in a year at all. I'd got no real idea. I just paid the bills without thinking about them very much and that was it. Obviously I knew certain things to cut down on, and leaving the electric fire on all day or something like that, so I was sort of fairly energy efficient in the first place but it did highlights things, like for example, in particular my freezer was actually using more electricity than everything else put together.

JK: Right.

DE: And as I'm living alone and my lifestyle, I've found that quite conveniently I could empty the freezer and live using just the refrigerator.

JK: Right.

DE: So that in fact saved me an awful lot in the first place and that's an example. Also double-glazing, which I'd resisted but mainly because of the techniques of the double-glazing salesman. 
JK: Yeah.

DE: They're - what they were telling me just didn't sort of seem to ring true because I didn't use a lot of energy in heating in the first place and so the figures they were giving me weren't true but what I did — but then partly because of an actual theft that I had in the house, I did decide to increase my security which went along with getting double-glazing.

JK: Right.

DE: And what I didn't realize, which all the salesmen never thought of telling me, was not so much that I'm going to save energy by putting in doubleglazing - well not save on cost on energy but that, I'm naturally, ambiently, much warmer.

JK: Right yeah.

DE: So that's certainly a clear benefit, a very great benefit which I hadn't thought of.

JK: Right. So I'm just wondering, sort of, the mechanism by which you became more aware. Is there something...

DE: I've always been interested in conservation.

JK: Right.

DE: Yes all my life.

JK: So is there, was there a device that came with PV that sort of showed how much you were generating and that helped you or...

DE: Not really. I went on the introduction to the solar hot water heating, which covered partially the same ground I think, not the same technology obviously, and then of course putting that together with this little miniature 
battery-charging unit that I had, that you know sort of really clarified, I think that's the sort of mechanism that clarified me to look at solar PV and what I particularly liked about solar PV is that I'm often not at home and that sort of thing, and I don't use a lot of hot water, or don't necessarily use much hot water, but what I do - the hot water I do use is usually just from, most efficiently produced by boiling, warming up in a kettle so a hot water system didn't appeal to me but what I liked about the solar system was that it was fully automatic, you could just forget it's there.

JK: Yeah yeah.

DE: One year's into the next virtually whereas with the water system you can't. You've got to do a little maintenance on it, or keep a check on it, so that was a big plus.

JK: So does your awareness of, your increased awareness of energy, does that extend to the time at which you use energy? You're mentioning sort of that your absolute consumption has changed by unplugging the freezer and things, but what about the time of day that you use energy? Has that changed at all?

DE: Yes slight extents. I am, in fact, looking at that a little more. I tend to put things on that consume low power for sort of chunks of ten, twelve hours maybe. I tend not to just put them on at night, put them on at day when I'm likely to get the power from the solar panels so it probably actually switched me a little bit away from nighttime usage to daytime usage. Not very ecological I suppose.

JK: Did you have Economy 7 or something that was...

DE: No I didn't. 
JK: No so you just sort of used it at nighttime out of habit?

DE: Yes that's right yes. Yes.

JK: Yeah. OK.

DE: Although I used to actually think, I can remember, I used to think that it was probably more ecological to use it at night than at day.

JK: Right.

DE: So well that would be on not very significant electricity consumption.

JK: Right. So your interest then in, when you got PV, was it, I mean I guess what was your sort of primary motivation in getting the PV?

DE: I think it was really, it was really to, sort of, the satisfaction for a sound ecological measure, something I could do to contribute to a carbon dioxide reduction.

JK: Right.

DE: Just as myself. And also to get a little bit more in control of actually what I was actually consuming.

JK: Right yeah. On your survey you noted that you've got two, sort of, monitoring devices. You've got one inside the stairs, the Variwatt, and then an Eclipse meter outside. I was wondering how often do you look at those devices?

DE: The Eclipse I look at, oh, several times a day in fact actually I glance at it and yes, I do find that quite interesting to see what's going on.

JK: And what does it display? 
DE: It displays - I've got a lot of criticisms of it actually, a lot, but it's what I've got and so I use it and it actually displays current consumption, current production from the solar panels, so from that you can deduce whether or not you're importing or exporting electricity, by pressing buttons you can see how much you've made for the whole day, how much you've used for the whole day and there are other totals by pressing further buttons to see. Unfortunately you can't - you have to press buttons to actually see the figures rather than what I think would be better is to have a screen that somehow gave all the figures on one screen.

JK: Sorry, where is it located in your home?

DE: It's actually located above, externally so that I can see it right now as I'm on the phone to you, above the stairs cupboard door.

JK: Right.

DE: That's - it really has to go, I suppose you could extend a cable but it should go really fairly near to the fuseboxes.

JK: So now, did you — did that unit come with your installation, with your PV system?

DE: It was an extra, an optional extra. But it was quite an expensive optional extra.

JK: And why did - sorry.

DE: It was about eight hundred and fifty pounds, it was eight hundred and fifty pounds, and for that I am not, not really pleased with it, no. It gave a bit of trouble to start with, which they sorted out and that was teething troubles in the actual design. 
JK: Right.

DE: And I'm not sure that they're still making this particular model now because I know they, I noticed that their website has disappeared.

JK: Right.

DE: It looked as though, it looks to me as if it was sort of hurried through a bit but also some of the external design that I don't think is particularly good and it also was designed to give an annual reading, which you extracted, or an annual total which you extracted through a card reader and they never ever got 'round to producing the software to be able to read the card so that's something they just sort of abandoned. I would have done much better to have got a unit, I think probably produced by the solar panel manufacturers or rather the - what do you call them? - the converter. Is it a converter?

JK: Oh the inverter?

DE: Inverter! That's it. They produce a modem that you plug into the mains and get readings in that fashion from the inverter and I would have done much better to have got that which I believe is about two-hundred and something pounds, which is considerably less.

JK: Right.

DE: But really you don't need — just a Variwatt is sufficient actually really. Because you have got an import and export meter and if you really want to know the figures you can sort of look at that and add up. I think probably one of the things that would be nice is just a simple meter which showed whether you were importing or exporting. I know they wouldn't want to 
put in a meter that was, had a pointer on it, you know one of those governed by magnets, not sort of a modern thing to do and I don't suppose it's quite as safe but something like that, like you would see maybe on one of the old cars where it shows you whether it was charging or discharging, something like that would be useful.

JK: I guess I've got two questions on that. One would be why did you decide to get that device when you first got the system if it cost this premium?

DE: Well actually I did ask a number of questions as to what it did, to Solar Century, the people who supplied it, and they didn't seem to have quite the answers and it was because I got the impression that that was the deluxe thing of the three - I think there were three things that they offered - then I thought 'That must be the best' so I thought 'Well I don't really know the answers but I'll go for the best'.

JK: And now was that sort of the 'in for a penny, in for a pound' sort of thought?

DE: Yes sort of, that's right yes. And I think it actually turned out to be wrong.

JK: Right. And I guess the follow-up to that would be, you're sort of saying now that a Variwatt would be sufficient, I'm just wondering if your familiarity and ability to calculate these things from just a Variwatt, if that has arisen because of this extra awareness given to you by the Eclipse monitor? I mean because it's sort of more visible.

DE: No, I don't think so. I think — the Variwatt I have got also is not as, I think they've modified that now actually and it's got a bigger readout and so on but no, I think I would have known how to use the Variwatt and the other meters quite easily. I think the Eclipse meter that I do have does make it 
readily obvious as to what's going on. I don't have to open the cupboard door and write down a couple of figures and maybe use a stopwatch or anything like that so it does actually make it instantly obvious but the figures it's giving, the Eclipse, is not really all that important. I think if it broke down now, I would say I wouldn't think about replacing that meter. I would just really quite, fairly happily rely on the Eclipse [sic, Variwatt]. I think it is a far more robust item.

JK: And this - sorry this raising of awareness that you've been talking about that's sort of a more...

DE: The Eclipse has raised my awareness of just when I'm generating the power and how much power I'm generating and so on, yes, it has done that.

JK: Right but without that, you feel the Variwatt would have been sufficient?

DE: I wouldn't have been as aware, I wouldn't have known quite just how much it was, just wouldn't have realised so easily, how much it was making early in the morning and the difference between when say an aircraft vapour trail goes over the sun and all that sort of thing, all the little finer points. I wouldn't have probably picked up from the Variwatt but you do pick it up from the Eclipse meter.

JK: Yeah well that's fascinating. Are you on an export meter?

DE: Yes I am.

JK: So is that - do you get paid for what you export or for what...

DE: Yes I do.

JK: Yes. Who are you with, sorry, for your electricity supplier? 
DE: I'm now with PowerGen. I did sign up with TXU but they were taken over by Powergen and the account was transferred over including the solar facilities of course.

JK: Right. And was that a difficult thing to get set up? The, you know, the meter...

DE: It wasn't easy to start with because no one seemed to know who - I think I was almost one of the first in London to have these panels set up and it was a lot of, a lot of people didn't seem to know much about what would be done to get set up but there was one fairly local company, TXU at that time. I'm just in the London Electricity Board from TXU which hit me a little bit, but they had done something, TXU, and I was advised to go to them and they did take over my account but being slightly out of their area meant that I had to bear the cost of putting in the meter and the meter itself, which if you're looking at real economies is something - I think it was about a hundred and twenty five, a hundred and thirty pounds for the meter - which is more than a year's production of electricity from the solar panels, it makes about eighty pounds a year. So on that sort of basis, it was a bit of a lot but I still had the 'in for a penny, in for a pound' sort of attitude as you say, so...

JK: Were you given other options at the time, 'cause I noticed that your system's one of the older ones, as you say, one of the first ones?

DE: Yeah no I wasn't at that time. It was a matter of having spent a bit of time to actually find even one and I know subsequently, I know for example with London Electricity and also they've come back to me and tried to persuade me to join them again, I used to be one of their customers and I do know that they have a facility for, now, for taking solar power but 
every time that I take it up with the normal accounting, the normal staff there, they deny it, and the supervisors deny it, and you just kind of get past that but if you take it up, further up the chain in London Electricity, they say that they do have the facility so they don't really know themselves. You would be put off if you tried to approach them to sign up for taking solar electricity, you would be put off completely by the sales staff to start with, you wouldn't get passed them unless you were very lucky.

JK: Yeah.

DE: I know there are several other companies now that take solar electricity and they may be beneficial to the arrangement that I have but I don't have any trouble with my arrangement so I just leave it as it is. I've got a feeling that they do actually round it up a little bit so I'm not actually seriously losing out.

JK: You get paid the same amount as what you pay for your imports?

DE: I'm not actually sure what it is now because they've just changed it to one of these threshold type accounts where you, where you don't pay a standing charge, I used to, until just a couple of months ago, I used to have to pay a standing charge and then there was a flat rate for the electricity and they used to give me back that same rate for the electricity but I know they're always sending me a cheque that rounds things up as they say.

JK: Right.

DE: And they never ever give me what the figures are except it looks reasonably satisfactory so I haven't queried it but I suspect that I'm probably getting the rate back that's above the threshold rate. I would imagine that's what's happening. So that's about six pence a unit sort of thing. 
JK: How have your family and friends and neighbours reacted to the system?

DE: When the system was put up, the neighbours I think clearly thought, they seemed to think it was an asset to the area, they tended think it sort of put them on the map with sort of high, in a high-tech way sort of thing. It's a, I think you'd probably call it a sort of working-class, terraced-house sort of environment and I've not heard a bad thing against it at all. Even one word.

JK: Yeah.

DE: What I have heard is you know 'oh yeah that's interesting' sort of thing from several people so I've only heard positive results. I live alone so I haven't got any one to persuade or protect myself from.

JK: Right. Let's just see. I mean, I guess just sort of overall have your expectations for the system been met by your experiences?

DE: Yes I think they have. I mentioned the meter which I would do otherwise now. I think my vague expectations that I have is that when it becomes cloudy, as it is at the moment, there's hardly anything being produced at the moment, it's just sort of dull overcast day and I think there's probably about fifty watts being made. That would have been less, I would expected more of an even generation - when the sun comes out it shoots up to about a kilowatt when it's more or less square onto the solar panels, when the clouds come over it drops right down to a hundred watts - that's far more variable then I thought though if I'd have thought about what I knew at the time when the panels were put in, I knew there was that sort of difference in the power of the sun, which is not - in other words I did know that what you see with your eyes is very much smoothed out through the action of your eyes rather than through 
photography I'm thinking of, which shows you that you know what the real powers of the sun are and I think I would have expected it to be more even.

JK: Yeah.

DE: You know, I sort of looked, I knew what the overall production was likely to be in a year and I can even remember sort of thinking about purchasing sort of units that used low power so that I could sort of use them fairly reliably from the power, from the solar panels. That's something I realise now is pretty much rubbish because you may have far more power one minute then you're actually using and the next minute it's gone so you know I think you can forget all that sort of thing.

JK: Were you surprised by the change in awareness that you underwent about energy issues?

DE: I wouldn't say that I was surprised but looking back on it, I'm probably a little bit surprised on how unaware I was, yes. Yes it's something I — it's a strong asset to it. Yes because I actually knew the principles and I would know how to measure my electricity and how to add things up and so on but you've just not got the two-hand awareness and I think I have been - I am now surprised that I was so unaware, yes.

JK: Right. So what does that - so how does all this bode for, do you think, for future energy consumption in the home? Do you think...

DE: I think there's probably not going to be a lot of change now because I've got things down pretty much to a convenient rock bottom.

JK: Yup. 
DE: My energy consumption is very low and I'm quite comfortable about that. It's not an inconvenience.

JK: Sorry to do you know roughly how many kilowatt-hours you would use in a year?

DE: I would think now, overall, it's probably something — well I'll just tell you what it - yes it's about, I've got last year's figures just in front of me. Just a moment.

JK: Sure.

DE: No I'd have to do some adding up but...

JK: Oh that's okay I was just, if you knew it off the top of your head, I was curious but...

DE: Yeah let's see on - it's something like six hundred kilowatt hours consumption I think, [unintelligible] find the right dates

JK: Yeah no that's OK.

DE: I think it's, it's between six and eight hundred kilowatts hours consumption.

JK: Per?

DE: Per year.

JK: Per year? Wow.

DE: Which is quite low.

JK: Yeah. 
DE: It actually makes about one thousand one hundred - the year before last, I had one thousand three hundred but that was a fairly sunny year. That was produced by the solar panels so I am actually making more then I consume.

JK: That's quite amazing. And then you've got - you have some gas is that right?

DE: Yes gas. I have actually switched to using, particularly to using gas on a gas cooker to boil kettles for hot water and so on, whereas I would have before used electric kettles. But partly because of cost, but also looking at carbon dioxide and all the rest of it, I realise it's far more sensible to warm the, heat the water up with the gas cooker, which - that has been a pointed change, yes. That I now make a cup of coffee with a kettle on the gas cooker, or cup of tea, and previously I probably would have used an electric hob or something like that.

JK: Right. Well I think that's most of the questions I had. Do you have anything else you'd like to add or?

DE: No I don't think so. I think if I feel any sort of roughness it would be over the Eclipse meter and that's about it. I don't feel - well yes there is that, two other things, I probably mentioned it on the questionnaire. I don't feel it actually gives any added value to the house, that's used as a selling point very often, because I don't think that many people would come around and say 'Oh yeah I must put in a little bit' or think of putting a little bit onto the value of the house because of that. I think you're just as likely to get people who don't, probably more likely, to get people who don't understand what they are and think 'oh $\mathrm{my}^{\prime}$, frighten them away a little bit so I don't think it's an asset so far as increasing the value of the house. 
The other thing is I'm not planning on moving. I've now retired early and whilst originally I might have thought of moving, I've come down to wanting to stay here, now that's important so far as it is concerned because now I've got it there to move would be losing all that really, it's not portable.

JK: Yeah, yeah.

DE: That's something to consider I think. So I think you wouldn't want to go to all the trouble of installing it when you might be moving in a couple of years.

JK: Yeah certainly.

DE: That's something to consider. That I'd say is probably, that's about as far as I'd go really as for the extra thoughts on it.

JK: No that's excellent information. Thank you very much for taking the time to speak with me.

DE: That's OK. I hope it's of use to what's going on. I've seen one other in the local area and he actually sort of somehow found out my address, through the local council, through trickery, which I thought 'Oh that's not very good' so far as security of information is concerned and he came round and sort of asked a few questions so I know where he lives and I've actually looked out for his house and I've seen his solar panels up but I've not actually seen any others up at all and hopefully we'll see some more go up. You see them in Germany and on the continent, oh there's lots in Germany but not here yet.

JK: No well, slowly slowly I guess.

DE: Yeah. OK? 
JK: Thanks a lot.

DE: Alright thanks very much.

JK: Great. Good bye.

DE: Bye. 


\section{Appendix C}

\section{ANALYSING THE PV ACTOR-NETWORK WITH PAJEK}

Pajek is a software package for the analysis of large networks, freely available from the internet (Batagelj and Mrvar 2006). The programme can perform a range of network calculations but its use in the thesis was restricted to two simple roles: determining the PV household's place within the wider actornetwork and exploring how technologies facilitate connections between different stakeholders.

\section{Network set-up}

Pajek networks consist of two main entities: vertices (or nodes) and arcs or

edges (one or two-way links between vertices). Before using the software, the user must therefore create an input file describing the nodes and their connections. Power in networks is typically described as control over flows of information and resources (Burt 1992); these principles are applied in the network design below. 


\section{Vertices}

According to actor-network principles, socio-technical networks can be comprised of both human and non-human elements. Therefore, using the data from the interviews and the literature review, 17 different actors were identified including households, large and small organizations, technologies, and even sunshine itself. Pajek also allows the characteristics of vertices to be described. For example, the ability of an actor to influence a network might depend on the resources it controls (e.g. money). This information was added by indicating the approximate annual budget of each organization. Furthermore the network can be divided into household/non-household or actor/technology categories (or 'partitions') to facilitate the analysis. This information is summarized in Table C.1.

\section{Arcs and edges}

The connections between vertices are described in terms of their directionality (e.g. one-way arcs or two-way edges) and magnitude. For the following analyses, these links describe the qualitative relationship between two stakeholders:

$$
\begin{aligned}
& 3=\text { Primary relationship; e.g. money and information exchanged } \\
& 2=\text { Secondary relationship; e.g. information exchanged } \\
& 1=\text { Tertiary relationship; e.g. contextual factor or consideration }
\end{aligned}
$$

These data are summarized in Table C.2 overleaf. 


\begin{tabular}{llrcc}
\hline ID & Name & Annual budget $(£)^{*}$ & HH cat. ${ }^{\dagger}$ & ${\text { Tech. } \text { cat. }^{\ddagger}}^{{ }^{\prime}}$ \\
1 & PV households & 42500 & 1 & 1 \\
2 & PV panels & 6000 & 1 & 2 \\
3 & Monitors & 100 & 1 & 2 \\
4 & Meters & 1 & 1 & 2 \\
5 & Electricity tariffs & 290 & 1 & 2 \\
6 & PV installers & $2,800,000$ & 2 & 1 \\
7 & Electricity suppliers & $7,645,000,000$ & 2 & 1 \\
8 & Monitor companies & $10,000,000$ & 2 & 1 \\
9 & Metering companies & $100,000,000$ & 2 & 1 \\
10 & DNOs & $4,000,000,000$ & 2 & 1 \\
11 & DTI & $6,500,000,000$ & 2 & 1 \\
12 & Ofgem & $50,000,000$ & 2 & 1 \\
13 & EST & $72,000,000$ & 2 & 1 \\
14 & REA & $5,000,000$ & 2 & 1 \\
15 & PV-UK & 500,000 & 2 & 1 \\
16 & Beama & $10,000,000$ & 2 & 1 \\
17 & Sunshine & - & 1 & 3 \\
\hline
\end{tabular}

${ }^{*}$ Annual budget data are order-of-magnitude estimates based on the results of the survey, the cost of technologies and online sources (where available).

${ }^{\dagger}$ Household/non-household categorization: 1 = part of the household's PV system; 2 = external.

$\ddagger$ Actor/technology categorization: $1=$ an individual or organization; $2=$ a technology or artefact; $3=$ other.

TABLE C.1: Description of PV actor-network nodes 


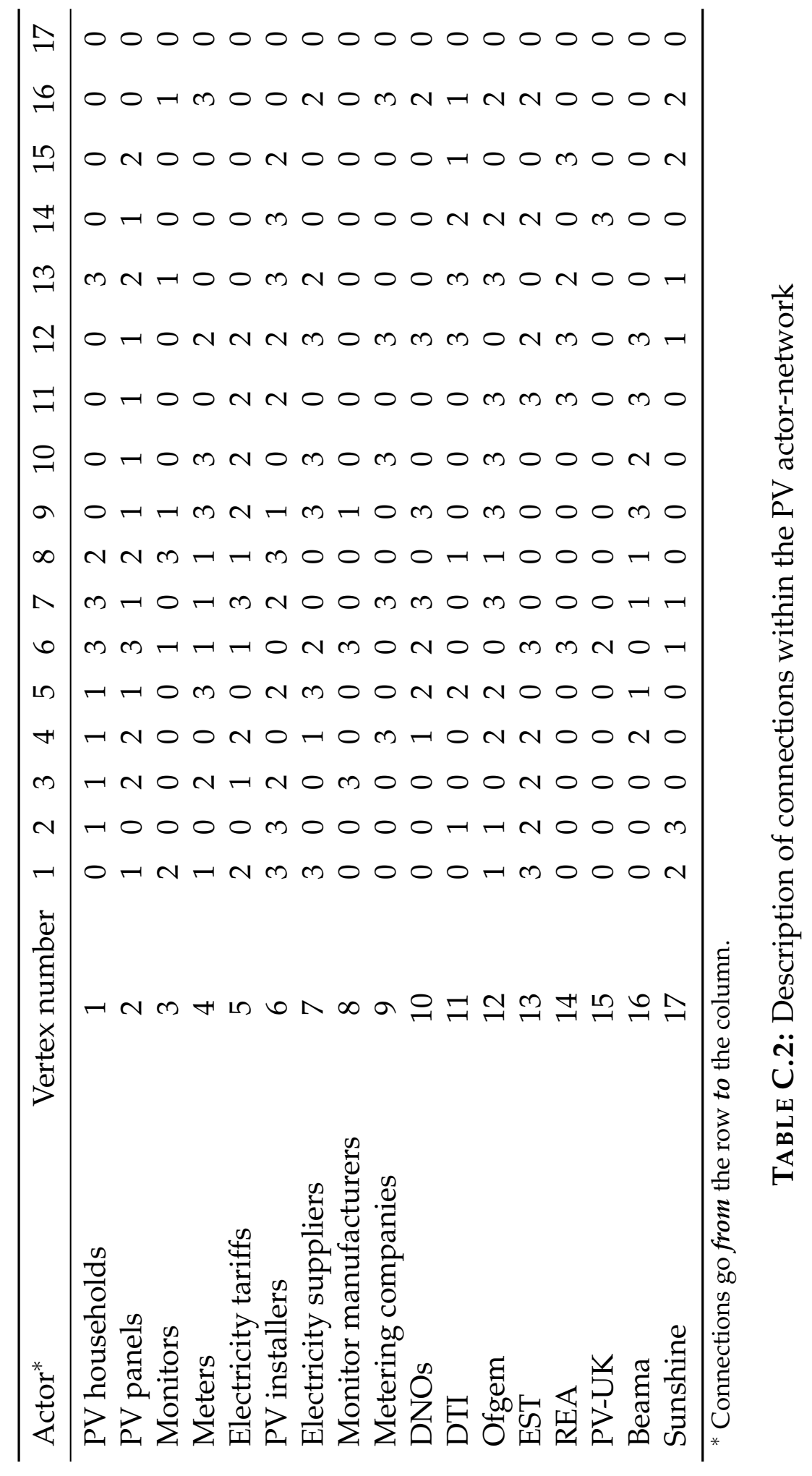




\section{Analysis}

Two analyses were performed, regarding the roles of PV households and their technologies within the actor-network. The primary goal was to determine the most important stakeholders and identify opportunities for establishing new links that facilitate the sustainable use of microgenerated electricity. The following sections describe how the analysis was performed; the results are presented and discussed in $\S 7.2 .2$.

\section{The role of PV households}

The data were loaded into Pajek and the analysis conducted as follows:

1. To simplify intra-household relationships (e.g. the links between the household occupants, monitoring devices, meters, PV panels and so on), the household partition was condensed into a single 'PV household' actor. The annual budget of this new actor was calculated as the sum of the constituent vertices.

2. A 'structural holes' analysis was then performed. This determines the constraint of each node based on its connections with other vertices.

3. A new vector was created to describe the nodes, based on their ability to influence the network (i.e. the inverse of the 'aggregate constraint' returned by step 2 above) and their available resources (the budgets described in step 1).

4. The results were then plotted.

When interpreting the graph (Figure 7.1, p. 292), the lines represent the strength of the connection between nodes with directionality indicating which party initiated the relationship. The size of the nodes represents a stakeholder's 'power' 
within the network. For example, the links between the REA and the DTI show the largely one-way nature of the REA's lobbying efforts and its limited influence compared to the DTI.

\section{The role of technologies}

As noted in Chapter 7, the strength of a network often depends on the durability of key materials as these artefacts embody negotiated network arrangements. Therefore the second analysis examined the technologies of the PV actor-network to determine their connections with key stakeholders. After loading in the basic data, the following steps were taken:

1. The actor/technology partition was loaded to facilitate colour-coding of the technologies.

2. The structural holes analysis was performed again to identify the constraint on all nodes within the network, including the technologies.

3. A new vector was created to describe the nodes, based on their ability to influence the network. To make the results more clear, this vector was raised to the $10^{\text {th }}$ power and did not consider the budget data used above.

4. The results were then plotted.

The graph (Figure 7.2, p. 294) can be interpreted similarly to the previous analysis. However bi-directional arcs have been converted to edges for legibility (i.e. lines without arrows). The distance between nodes reflects the working arrangements of the actors much more clearly (e.g. the close link between PV installers and PV panels). 


\section{REFERENCES}

Abrahamse, W., Steg, L., Vlek, C. and Rothengatter, T. (2005) 'A review of intervention studies aimed at household energy conservation', Journal of Environmental Psychology, 25(3): 273-291.

Ajzen, I. (1991) 'The theory of planned behavior', Organizational Behavior and Human Decision Processes, 50(2): 179-211.

Ajzen, I. (2002) 'Constructing a TpB questionnaire: conceptual and methodological considerations'. URL: http://www-unix.oit.umass.edu/ aizen/ pdf/tpb.measurement.pdf. Accessed: 8 December 2005.

Alfredsson, E. (2003) " "Green" consumption - no solution for climate change', Energy, 29(4): 513-524.

Ammons, R. B. (1956) 'Effects of knowledge of performance: a survey and tentative theoretical formula', Journal of General Psychology, 54: 279-299.

Amsterdamska, O. (1990) 'Surely you must be joking, Monsieur Latour!', Science, Technology and Human Values, 15(4): 495-504.

Archibald, K. (2005) Telephone interview. Personal communication, 24 November 2005.

Asher, A. (2005) 'Fuel poverty is "new social evil"'. URL: http://news.bbc. co.uk/1/hi/business/4656517. stm. Accessed: 11 February 2006.

Baird, J. C. and Brier, J. M. (1981) 'Perceptual awareness of energy requirements of familiar objects', Journal of Applied Psychology, 66(1): 90-96.

Baker, P. (1991) A model of household gas and electricity expenditures for the UK: the IFS Simulation Program for Energy Demand (SPEND), IFS working paper series (no. W92/5). London: Institute for Fiscal Studies.

Baladi, S. M., Herriges, J. A. and Sweeney, T. J. (1998) 'Residential response to voluntary time-of-use electricity rates', Resource and Energy Economics, 20(3): 225-44.

Bandura, A. (1969) Principles of behavior modification. New York and London: Holt Rinehart and Winston.

Bandura, A. (1977) Social learning theory. Englewood Cliffs, NJ: Prentice-Hall. 
Bandura, A. (1986) Social foundations of thought and action: a social cognitive theory, Prentice-Hall series in Social Learning Theory. Englewood Cliffs, NJ: Prentice-Hall.

Bandura, A. (1997) Self-efficacy: the exercise of control. New York: W.H. Freeman.

Banks, N. (1998) Cultural values and the adoption of energy efficient technologies, DPhil thesis, University of Oxford.

Banks, N. (1999) 'Causal models of household decisions to choose the energy efficient alternative: the role of values, knowledge, attitudes and identity'. URL: http: //www.eci.ox.ac.uk/lowercf/pdfdownloads/ECEEE99_NB.pdf. Accessed: 14 January 2005.

Batagelj, V. and Mrvar, A. (2006) 'Pajek: program for large network analysis', version 1.14. URL: http://vlado.fmf .uni-lj.si/sub/networks/ pajek.

BBC News (2004) '2003 summer hottest in 500 years'. URL: http: //news . bbc . co.uk/1/hi/world/europe/3536819. stm. Accessed: 27 June 2006.

BBC News (2005) 'No choice over nuclear - Beckett'. URL: http://news.bbc . co.uk/1/hi/uk/4476058. stm. Accessed: 6 February 2006.

BBC News (2006a) 'British Gas raises prices by 22\%'. URL: http://news . bbc . co.uk/1/hi/business/4723648. stm. Accessed: 28 February 2006.

BBC News (2006b) 'House power plan "disappointment"'. URL: http: //news . bbc.co.uk/1/hi/sci/tech/4858766. stm. Accessed: 16 May 2006.

BBC News (2006c) 'Powergen in big energy price rise'. URL: http: //news . bbc . co.uk/1/hi/business/4758032. stm. Accessed: 28 February 2006.

BBC News (2006d) 'Scottish Power ups energy prices'. URL: http://news . bbc . co.uk/1/hi/business/4698346. stm. Accessed: 11 February 2006.

Berman, B. (2005) 'The meaning of hybrids'. URL: http://www .hybridcars . com/hybrids-symbols-of-identity.html. Accessed: 1 March 2006.

Berman, D. and O'Connor, J. (1997) Who owns the sun? People, politics, and the struggle for a solar economy. White River Junction, VT: Chelsea Green Publishing.

Bernard, H. R. and Pelto, P. J. (1987) Technology and social change, 2nd edn. Prospect Heights, IL: Waveland Press.

Berry, S. (2006) 'REA welcomes microgeneration strategy release but calls for tangible policy measures', Renewable Energy Association. URL: http://www.r-p-a.org.uk/article_default_view.fcm?articleid= 1818. Accessed: 18 May 2006. 
Bijker, W. (2001) 'Social construction of technology', in N. J. Smelser and P. B. Baltes, eds, International encyclopedia of the social and behavioral sciences, pp. 15522-15527. Elsevier.

Bijker, W. E. (1992) 'The social construction of fluorescent lighting, or how an artifact was invented in its diffusion stage', in W. E. Bijker and J. Law, eds, Shaping technology/building society: studies in sociotechnical change, Inside technology, pp. 75-102. Cambridge, MA: MIT Press.

Bijker, W. E. (1997) Of bicycles, bakelites, and bulbs: toward a theory of sociotechnical change, Inside technology. Cambridge, MA: MIT Press.

Bijker, W. E., Hughes, T. P. and Pinch, T. J., eds (1989) The social construction of technological systems: new directions in the sociology and history of technology. Cambridge, MA: MIT Press.

Bijker, W. E. and Law, J. (1992) 'General introduction', in W. E. Bijker and J. Law, eds, Shaping technology/building society: studies in sociotechnical change, Inside technology, pp. 1-14. Cambridge, MA: MIT Press.

Bishop, N. and Watson, M. (2005) Delivering a low-carbon economy. London: United Kingdom Petroleum Industry Association.

Blumer, H. (1969) Symbolic interactionism: perspective and method. Englewood Cliffs, NJ: Prentice-Hall.

BMWV (1998) Diffusion of photovoltaics in Austria: the 200kW wide-range test collateral sociological research. Vienna: Austrian Federal Ministry of Science and Transport.

Boardman, B. (1991) Fuel poverty: from cold homes to affordable warmth. London: Bellhaven Press.

Boardman, B. (2004) 'Achieving energy efficiency through product policy: the UK experience', Environmental Science and Policy, 7(3): 165-176.

Boardman, B., Darby, S., Killip, G., Hinnells, M., Jardine, C., Palmer, J. and Sinden, G. (2005) 40\% House. Oxford: Environmental Change Institute.

Boardman, B., Lane, K., Hinnells, M., Banks, N., Milne, G., Goodwin, A. and Fawcett, T. (1997) DECADE: domestic equipment and carbon dioxide emissions. Transforming the UK cold market. Oxford: Environmental Change Institute.

Boardman, B. and Palmer, J. (2003) Final report: consumer choice and carbon consciousness for electricity (4CE). Oxford: Environmental Change Institute.

Boczkowski, P. J. (1999) 'Mutual shaping of users and technologies in a national virtual community', Journal of Communication, 49(2): 86-108. 
Boczkowski, P. J. (2004) 'The mutual shaping of technology and society in videotex newspapers: beyond the diffusion and social shaping perspectives', The Information Society, 20(4): 255-267.

Bower, J. L. and Christensen, C. M. (1995) 'Disruptive technologies: catching the wave', Harvard Business Review, 73(1): 43-53.

BP Solar (2005) 'Solar products'. URL: http://www.bp.com/subsection.do? categoryId=3050527\&contentId=3060177. Accessed: 1 September 2005.

Brandon, G. and Lewis, A. (1999) 'Reducing household energy consumption: a qualitative and quantitative field study', Journal of Environmental Psychology, 19(1): 75-85.

BRE (2002) Annual technical report: PV domestic field trial. Dept. of Trade and Industry.

Brechling, V. and Smith, S. (1992) The pattern of energy efficiency measures amongst domestic households in the UK, IFS commentary (no. 31). London: Institute for Fiscal Studies.

Brent Ritchie, J. R., McDougall, G. H. G. and Claxton, J. D. (1981) ‘Complexities of household energy consumption and conservation', Journal of Consumer Research, 8(3): 233-243.

Brown, P. (2003) 'Life in 2020: solar power, hens in the garden and a robot in the loo', The Guardian, 27 October 2003.

Bruun, H. and Hukkinen, J. (2003) 'Crossing boundaries: an integrative framework for studying technological change', Social Studies of Science, 33(1): 95116.

Bull, M. (2005) 'No dead air! The iPod and the culture of mobile listening', Leisure Studies, 24(4): 343-355.

Burt, R. S. (1992) Structural holes: the social structure of competition. Cambridge, MA: Harvard University Press.

Callero, P. L. (1992) 'The meaning of self-in-role: a modified measure of roleidentity', Social Forces, 71(2): 485-501.

Callon, M. (1986a) 'The sociology of an actor-network: the case of the electric vehicle', in M. Callon, J. Law and A. Rip, eds, Mapping the Dynamics of Sciene and Technology: Sociology of Science in the Real World, pp. 19-34. London: Macmillan.

Callon, M. (1986b) 'Some elements of a sociology of translation: domestication of the scallops and the fishermen of Saint Brieuc Bay', in J. Law, ed., Power, Action and Belief: a new Sociology of Knowledge?, Vol. 32, pp. 196-233. London: Routledge. 
Callon, M. (1989) 'Society in the making: the study of technology as a tool for sociological analysis', in W. E. Bijker, T. P. Hughes and T. J. Pinch, eds, The social construction of technological systems: new directions in the sociology and history of technology, pp. 83-103. Cambridge, MA: MIT Press.

Callon, M. (1991) 'Techo-economic networks and irreversibility', in J. Law, ed., A Sociology of Monsters? Essays on Power Technology and Domination, pp. 132161. London: Routledge.

Callon, M. (2001) 'Actor network theory', in N. J. Smelser and P. B. Baltes, eds, International encyclopedia of the social and behavioral sciences, pp. 62-66. Elsevier.

Campbell, C. (1994) 'The desire for the new: its nature and social location as presented in theories of fashion and modern consumerism', in R. Silverstone and E. Hirsch, eds, Consuming technologies: media and information in domestic spaces, pp. 48-64. London: Routledge.

Capasso, A., Grattieri, W., Lamedica, R. and Prudenzi, A. (1994) 'A bottomup approach to residential load modelling', IEEE Transactions on Power Systems, 9(2): 957-64.

Carey, M. J., Burlakov, V. M., Henry, B. M., Kirov, K. R., Webster, G. R., Assender, H. E., Andrew, G., Briggs, D., Burn, P. L. and Grovenor, C. R. (2004) 'Nanocomposite titanium dioxide/polymer photovoltaic cells: effects of $\mathrm{TiO} 2$ microstructure, time, and illumination power', in Z. H. Kafafi and P. A. Lane, eds, Organic Photovoltaics IV, Vol. 5215, pp. 32-40. San Diego, CA: International Society for Optical Engineering.

Chappells, H. and Shove, E. (2005) 'Debating the future of comfort: environmental sustainability, energy consumption and the indoor environment', Building Research and Information, 33(1): 32-40.

Chappells, H., van Vliet, B. and Southerton, D. (2004) 'Conclusions', in D. Southerton, H. Chappells and B. v. Vliet, eds, Sustainable consumption: the implications of changing infrastructures of provision, pp. 144-150. Cheltenham: Edward Elgar.

Clancy, D. and O'Loughlin, D. (2002) 'Identifying the "energy champion": a consumer behaviour approach to understanding the home energy conservation market in Ireland', International Journal of Nonprofit and Voluntary Sector Marketing, 7(3): 258-270.

Climate Change and Sustainable Energy Act (2006) Enacted: 21 June 2006, ch. 19. URL: http://www.opsi.gov.uk/acts/acts2006/ukpga_20060019_en.pdf.

Clinch, J. P., Healy, J. D. and King, C. (2001) 'Modelling improvements in domestic energy efficiency', Environmental Modelling and Software, 16(1): 87106. 
CoalPro (2005) 'Memorandum submitted to the Select Committee on Environmental Audit by the UK Coal Producers', UK Parliament. URL: http://www.publications.parliament.uk/pa/cm200506/cmselect/ cmenvaud/584/584we13.htm. Accessed: 16 May 2006.

Cogoy, M. (1995) 'Market and non-market determinants of private consumption and their impacts on the environment', Ecological Economics, 13(3): 169-180.

Collins, H. M. and Yearley, S. (1992) 'Epistemological chicken', in A. Pickering, ed., Science as Practice and Culture, pp. 301-326. Chicago: Chicago University Press.

Collins, J. (2004) 'A micro-generation manifesto', Green Alliance. URL: http: // www.green-alliance.org.uk/publications/MicrogenerationManifesto/. Accessed: 10 August 2005.

Corrocher, N. (2003) 'The diffusion of internet telephony among consumers and firms: current issues and future prospects', Technological Forecasting and Social Change, 70(6): 525-544.

Cowan, R. S. (1989) 'The consumption junction: a proposal for research strategies in the sociology of technology', in W. E. Bijker, T. P. Hughes and T. J. Pinch, eds, The social construction of technological systems: new directions in the sociology and history of technology, pp. 261-280. Cambridge, MA: MIT Press.

Cowen, R. S. (1983) More work for Mother: the ironies of household technology from the open hearth to the microwave. New York: Basic Books.

Cramer, C. (1985) 'Social and engineering determinants and their equity implications in residential electricity use', Energy, 10(12): 1283-1292.

Darby, S. (2000) 'Making it obvious: designing feedback into energy consumption', in B. Boardman and S. Darby, eds, Effective advice: energy efficiency and the disadvantaged, pp. 92-101. Oxford: Environmental Change Institute.

Darby, S. (2003) Awareness, action and feedback in domestic energy use, DPhil thesis, University of Oxford.

Darby, S. (in press) 'Social learning and public policy: lessons from an energyconscious village', Energy Policy.

Darley, J. M. (1977/78) 'Energy conservation techniques as innovations, and their diffusion', Energy and Buildings, 1: 339-343.

Darley, J. M. and Beniger, J. R. (1981) ‘Diffusion of energy- conserving innovations', Journal of Social Issues, 37(2): 150-171.

Darroch, J. and Jardine, A. (1998) 'Consumer behaviour and micro economics: connected, disconnected or on hold?'. URL: http://130.195.95.71:8081/ www/ANZMAC1998/Cd_rom/Darroch203.pdf. Accessed: 6 May 2004. 
Davies, N. and Munzinger, M. (2003) PV Domestic Field Trial Second Annual Technical Report. London: Dept. of Trade and Industry.

de Young, R. (1993) 'Changing behavior and making it stick: the conceptualization and management of conservation behavior', Environment and Behavior, 25(4): 485-505.

de Young, R. (1996) 'Some psychological aspects of reduced consumption behavior: the role of intrinsic satisfaction and competence motivation', Environment and Behavior, 28(3): 358-409.

de Young, R. (2000) 'Expanding and evaluating motives for environmentally responsible behavior', Journal of Social Issues, 56(3): 509-526.

Deaton, A. and Muellbauer, J. (1980) Economics and consumer behavior. Cambridge: Cambridge University Press.

Defra (2006a) '2004 UK climate change sustainable development indicator and greenhouse gas emissions final figures', Dept. for Environment, Food and Rural Affairs. URL: http://www.defra.gov.uk/news/2006/060123b. htm. Accessed: 16 May 2006.

Defra (2006b) 'Action in the UK: UK climate change programme', Dept. for Environment, Food and Rural Affairs. URL: http://www.defra.gov.uk/ environment/climatechange/uk/ukccp/index.htm. Accessed: 16 May 2006.

Devine-Wright, H. and Devine-Wright, P. (2005) 'Representing the demand side: "deficit" beliefs about domestic electricity users', in F. Bartiaux and A. G. Selnæs, eds, ECEEE Summer Study, Vol. 3, pp. 1343-1348. Mandelieu, France: European Council for an Energy Efficient Economy.

Dholakia, R. R., Dholakia, N. and Firat, A. F. (1983) 'From social psychology to political economy: a model of energy use behaviour', Journal of Economic Psychology, 3(3-4): 231-247.

Dillman, D. A. (1983) 'Lifestyle and home energy conservation in the United States: the poor accept lifestyle cutbacks while the wealthy invest in conservation', Journal of Economic Psychology, 3(3-4): 299-315.

Dobbyn, J. and Thomas, G. (2005) Seeing the light: the impact of micro-generation on our use of energy. London: Sustainable Development Commission.

DoE (2005) 'Solar timeline', US Dept. of Energy, Energy Efficiency and Renewable Energy. URL: http://www.eere.energy.gov/solar/solar_timeline. html. Accessed: 8 February 2006.

DTI (2003) Our energy future: creating a low carbon economy. London: Dept. of Trade and Industry. 
DTI (2005a) Digest of United Kingdom Energy Statistics 2005. London: Dept. of Trade and Industry.

DTI (2005b) The Electricity (Fuel Mix Disclosure) Regulations 2005. London: Dept. of Trade and Industry.

DTI (2005c) Metering, settlement and export reward: options for microgeneration. London: Dept. of Trade and Industry.

DTI (2005d) Microgeneration strategy and low carbon building programme: consultation. Dept. of Trade and Industry.

DTI (2005e) 'The UK fuel poverty strategy and annual monitoring', Dept. of Trade and Industry. URL: http://www.dti.gov.uk/energy/consumers / fuel_poverty/fuel_strategy. shtml. Accessed: 11 February 2006.

DTI (2006a) Our energy challenge: power from the people. London: Dept. of Trade and Industry.

DTI (2006b) Our energy challenge: securing clean, affordable energy for the long-term. London: Dept. of Trade and Industry.

DTI (2006c) 'Quarterly energy prices', Dept. of Trade and Industry. URL: http://www.dti.gov.uk/energy/statistics/stats-publications/ quarterly-energy-prices/index.html. Accessed: 16 May 2006.

DTI (2006d) The Renewables Obligation: 2005/6 Renewables Obligation Review. London: Dept. of Trade and Industry.

DTI (2006e) 'Welcome to the Sustainable Energy Policy Network', Dept. of Trade and Industry. URL: http://www.dti.gov.uk/energy/sepn/index. shtml. Accessed: 30 January 2006.

Duke, R., Williams, R. and Payne, A. (2005) 'Accelerating residential PV expansion: demand analysis for competitive electricity markets', Energy Policy, 33(15): 1912-1929.

Dunlap, R. E., Van Liere, K. D., Mertig, A. G. and Jones, R. E. (2000) 'Measuring endorsement of the New Ecological Paradigm: a revised NEP scale', Journal of Social Issues, 56(3): 425-442.

Dwyer, W. O., Leeming, F. C., Cobern, M. K. and Porter, B. E. (1993) 'Critical review of behavioral interventions to preserve the environment: research since 1980', Environment and Behavior, 25(3): 275-321.

EC (1997) Photovoltaic solar energy: best practice stories. Brussels: Office for Official Publications of the European Communities.

EC (2006) Preliminary report of sector inquiry under Art. 17 Regulation 1/2003 on the gas and electricity markets. Brussels: European Commission. 
ECI (2004) 'PV questionnaire', Environmental Change Institute. URL: http: //www.eci.ox.ac.uk/lowercf/questionnaire.htm. Accessed: 14 January 2005.

Economist (2005) 'Inconspicuous consumption', The Economist, 20 Dec 2005.

EETS (2006) 'Sunview displays', Energy Equipment Testing Service Ltd. URL: http: //www . eets . co.uk/Sunview-Display.htm. Accessed: 25 June 2006.

Eichhammer, W., Boede, U., Gagelmann, F., Jochem, E., Schleich, J., Schlomann, B., Chesshire, J. and Ziesing, H. J. (2001) Greenhouse gas reductions in Germany and the UK - coincidence or policy induced? An analysis for international climate policy. Karlsruhe Brighton Berlin: Fraunhofer Institute, SPRU (University of Sussex), Deutsches Institut für Wirtschaftsforschung.

Eikeland, P. O. (1998) 'Electricity market liberalisation and environmental performance: Norway and the UK', Energy Policy, 26(12): 917-927.

Ekins, P. (2004) 'A habitable planet? "No thanks, I'd rather have airconditioning at home." ', The Edge, 16: 10-12, June 2004.

Electricity Act (1989) Enacted: 27 July 1989, ch. 29. URL: http: //www . opsi .gov . uk/ACTS/acts1989/Ukpga_19890029_en_1.htm.

Electricity (Microgeneration) Bill (2005) Tabled: 7 April 2005. URL: http: //www . publications . parliament.uk/pa/cm200405/cmbills/113/2005113.htm.

Elliott, D. A. (1994) 'Regulation, technology strategy and energy policy: the missing link', Technology Analysis and Strategic Management, 6(3): 305-315.

Ellis, R. (2004) Residents' photovoltaic survey. Personal communication, 22 July 2004.

Energy Act (2004) Enacted: 22 July 2004, ch. 20. URL: http: //www . opsi .gov . uk/ acts/acts2004/20040020.htm.

EnergyWatch (2004) 'EnergyWatch'. URL: http: //www.energywatch.org.uk/ media/show_release.asp?article_id=786\&display_type=. Accessed: 22 March 2004.

Erge, T., Hoffman, V. U. and Kiefer, K. (2001) 'The German experience with grid-connected PV-systems', Solar Energy, 70(6): 479-487.

EST (2003a) 'The Major Photovoltaic Demonstration Programme: small scale grid-connected application form', Energy Saving Trust. URL: http://www . est.org.uk/solar/downloads/St1ConnForm_fin.pdf. Accessed: 11 December 2003.

EST (2003b) Major Photovoltaics Demonstration Programme: annual report summary, April 2002 - March 2003. London: Energy Saving Trust. 
EST (2004) PV grant recipient customer satisfaction survey. Personal communication, 15 September 2004.

EST (2005a) 'Major Demonstration Project Programme - project data at 23/9/05', Energy Saving Trust. URL: http://www.est.org.uk/uploads/ documents/housingbuildings/InfoForInstallers23_9_05.pdf. Accessed: 22 May 2006.

EST (2005b) Potential for microgeneration: study and analysis. Energy Saving Trust.

EST (2005c) 'Solar PV', Energy Saving Trust. URL: http://www.est.org.uk/ housingbuildings/funding/solarpv/. Accessed: 31 January 2006.

EST (2006a) 'Accredited installer register', Energy Saving Trust. URL: http://www . est.org.uk/uploads/documents/myhome/Accredited\% 20Installer\%20Register4.pdf. Accessed: 25 April 2006.

EST (2006b) 'Case studies', Energy Saving Trust. URL: http://www .est.org . uk/myhome/casestudies/. Accessed: 15 May 2006.

EST (2006c) 'Frequently asked questions: low carbon buildings programme', Energy Saving Trust. URL: http://www.est.org.uk/ housingbuildings/funding/lowcarbonbuildings/faqs. Accessed: 15 May 2006.

Eyre, N. (1998) 'A golden age or a false dawn? Energy efficiency in UK competitive energy markets', Energy Policy, 26(12): 963-972.

Faiers, A. and Neame, C. (2006) 'Consumer attitudes towards domestic solar power systems', Energy Policy, 34(14): 1797-1806.

Fernandez, V. P. (2001) 'Observable and unobservable determinants of replacement of home appliances', Energy Economics, 23(3): 305-323.

Festinger, L. (1957) A theory of cognitive dissonance. Evanston, IL: Row Peterson.

Filippini, M. (1995) 'Electricity demand by time of use: an application of the household AIDS model', Energy Economics, 17(3): 197-204.

Fontana, A. (2004) 'Symbolic interaction: methodology', in International Encyclopedia of the Social and Behavioural Sciences, pp. 15347-15350. Elsevier.

Fouquet, R. (1998) 'The United Kingdom demand for renewable electricity in a liberalised market', Energy Policy, 26(4): 281-293.

Fox, K. (2005) Watching the English: the hidden rules of English behaviour. London: Hodder.

Foxon, T. J., Gross, R., Chase, A., Howes, J., Arnall, A. and Anderson, D. (2005) 'UK innovation systems for new and renewable energy technologies: drivers, barriers and systems failures', Energy Policy, 33(16): 2123-2137. 
Foxon, T. J., Makuch, Z., Macarena, M. and Pearson, P. (2003) 'Innovation systems and policy-making processes for the transition to sustainability', in K. Jacob, M. Binder and A. Wieczorek, eds, Governance for Industrial Transformation. Conference on the Human Dimensions of Global Environmental Change, pp. 96-112. Berlin: Environmental Policy Research Centre.

Fuchs, D. A. and Arentsen, M. J. (2002) 'Green electricity in the market place: the policy challenge', Energy Policy, 30(6): 525-538.

Gardner, G. T. and Stern, P. C. (1996) Environmental problems and human behavior. London: Allyn and Bacon.

Geller, E. S., Berry, T. D., Ludwig, T. D. and Evans, R. E. (1990) 'A conceptual framework for developing and evaluating behavior change interventions for injury control', Health Education Research, 5(2): 125-137.

Giddens, A. (1991) Modernity and self-identity: self and society in the late modern age. Cambridge: Polity Press.

Gilg, A., Barr, S. and Ford, N. (2005) 'Green consumption or sustainable lifestyles? Identifying the sustainable consumer', Futures, 37: 481-504.

Gökalp, I. (1992) 'On the analysis of large technical systems', Science, Technology and Human Values, 17(1): 57-78.

Glendinning, C. (2003) 'Notes toward a neo-luddite manifesto', in R. C. Scharff and V. Dusek, eds, Philosophy of technology. The technological condition: an anthology, pp. 603-605. Oxford: Blackwell.

Goldblatt, D. L., Hartmann, C. and Dürrenberger, G. (2005) 'Combining interviewing and modelling for end-user energy conservation', Energy Policy, 33(2): 257-271.

Gopalakrishnan, S., Wischnevsky, J. D. and Damanpour, F. (2003) 'A multilevel analysis of factors influencing the adoption of internet banking', IEEE Transactions on Engineering Management, 50(4).

Green Alliance (2006) 'Microgeneration strategy launched', Green Alliance. URL: http://www.green-alliance.org.uk/mediaroom/ MicrogenStrategyPR/. Accessed: 16 May 2006.

Greening, L. A. (2004) 'Effects of human behaviour on aggregate carbon intensity: comparison of 10 OECD countries for the period 1970 through 1993', Energy Economics, 26(1): 1-30.

Greenpeace (2005) Decentralising power: an energy revolution for the 21st century. London: Greenpeace. 
Gregory, G. D. and Di Leo, M. (2003) 'Repeated behavior and environmental psychology: the role of personal involvement and habit formation in explaining water consumption', Journal of Applied Social Psychology, 33(6): 1261-1296.

Haas, R. (2005) Email conversation re: Haas et al (1999) paper. Personal communication, 8 December 2005.

Haas, R., Ornetzeder, M., Hametner, K., Wroblewski, A. and Hübner, M. (1997) Sozialwissenshaftliche Begleitforschung zum österreichishen 200-kW-PVBreitentest. Gruppe Angepaßte technologie.

Haas, R., Ornetzeder, M., Hametner, K., Wroblewski, A. and Hübner, M. (1999) 'Socio-economic aspects of the Austrian $200 \mathrm{kWp}$ photovoltaic-rooftop programme', Solar Energy, 66(3): 183-191.

Hacker, R. (2005) 'Response to the consultation on Microgeneration Strategy and Low Carbon Buildings Programme', PV-UK. URL: http://www. greenenergy . org.uk/pvuk2/reference/PV-UKMicrogenLCBConsultation . PDF. Accessed: 3 October 2005.

Hackett, B. and Lutzenhiser, L. (1991) 'Social structures and economic conduct: interpreting variations in household energy consumption', Sociological Forum, 6(3): 449-470.

Hamilton, R., Hewer, P. and Howcroft, B. (2000) Consumer behaviour and the usage and adoption of home-based banking in the United Kingdom, LUBC research paper 146/00. Loughborough: Loughborough University Banking Centre.

Hammond, G. P. (2004) 'Towards sustainability: energy efficiency, thermodynamic analysis, and the "two cultures" ', Energy Policy, 32(16): 1789-1798.

Hardyment, C. (1988) From mangle to microwave: the mechanization of household work. Cambridge: Polity Press.

Harrison, G. W., Lau, M. I. and Williams, M. B. (2002) 'Estimating individual discount rates in Denmark: a field experiment', The American Economic Review, 92(5): 1606-1617.

Harrison, R. (2005) Breakout session at ECEEE summer study. Personal communication, 3 June 2005.

Hart, M. and de Dear, R. (2004) 'Weather sensitivity in household appliance energy end-use', Energy and Buildings, 36(2): 161-174.

Harvard University Program on Technology and Society (1972) A final review, 1964 - 1972. Cambridge, MA: Harvard University Press.

Hausman, J. A. (1979) 'Individual discount rates and the purchase and utilization of energy-using durables', The Bell Journal of Economics, 10(1): 33-54. 
Heberlein, T. A. and Warriner, G. K. (1983) 'The influence of price and attitude on shifting residential electricity consumption from on- to off-peak periods', Journal of Economic Psychology, 4(1-2): 107-130.

Heffner, R. R., Kurani, K. S. and Turrentine, T. S. (2005) 'Effects of vehicle image in gasoline-hybrid electric vehicles', Institute of Transportation Studies, University of California. URL: http://www.its.ucdavis.edu/publications/ 2005/UCD-ITS-RR-05-08 .pdf. Accessed: 1 March 2006.

Held, M. (1983) 'Social impacts of energy conservation', Journal of Economic Psychology, 3(3-4): 379-394.

Helm, D. (2002a) 'A critique of renewable policy in the UK', Energy Policy, 30(3): 185-188.

Helm, D. (2002b) 'Energy policy: security of supply, sustainability and competition', Energy Policy, 30(3): 173-184.

Henryson, J., Hakansson, T. and Pyrko, J. (2000) ‘Energy efficiency in buildings through information - Swedish perspective', Energy Policy, 28(3): 169-180.

Herstatt, C. and von Hippel, E. (1992) 'From experience: developing new product concepts via the lead user method: A case study in a "low-tech" field', Journal of Product Innovation Management, 9(3): 213-221.

Hillman, M. and Fawcett, T. (2004) How we can save the planet. London: Penguin.

Hinchliffe, S. (1995) 'Missing culture: energy efficiency and lost causes', Energy Policy, 23(1): 93-95.

Hinchliffe, S. (1996) 'Helping the Earth begins at home: the social construction of socio- environmental responsibilities', Global Environmental Change, 6(1): 53-62.

Hinnells, M. (2005) 'The cost of a $60 \%$ cut in $\mathrm{CO}_{2}$ emissions from homes: what do experience curves tell us?', in P. Ekins, ed., British Institute of Energy Economists Conference. St. John's College, Oxford: British Institute of Energy Economists.

Hirsch, E. (1994) 'The long term and the short term of domestic consumption: an ethnographic case study', in R. Silverstone and E. Hirsch, eds, Consuming technologies: media and information in domestic spaces, pp. 1-11. London: Routledge.

Hitchcock, G. (1993) 'An integrated framework for energy use and behavior in the domestic sector', Energy and Buildings, 20(2): 151-157.

HM Treasury (2003) Green Book: appraisal and evaluation in central government. London: The Stationary Office. 
Hughes, L. and Bell, J. (in press) 'Compensating customer-generators: a taxonomy describing methods of compensating customer-generators for electricity supplied to the grid', Energy Policy.

Hughes, T. P. (1983) Networks of power: electrification in Western society, 1880-1930. Baltimore, MD: Johns Hopkins University Press.

HybridCars.com (2005) 'Hybrid Cars discussion. Topic: fast cars'. URL: http://www.hybridcars.com/discussion/discussthread.php?thread_ id=149\&replies=6. Accessed: 21 March 2006.

IEA (1997) Indicators of energy use and efficiency: understanding the link between energy and human activity. Paris: International Energy Agency.

IEA (2000) Experience curves for energy technology policy. Paris: International Energy Agency.

IEA (2005) World Energy Outlook. International Energy Agency.

IEA-PVPS (2004) Germany national status report 2003: implementation of PV systems. International Energy Agency.

IEA-PVPS (2005) 'IEA Photovoltaic Power Systems Programme', International Energy Agency. URL: http://www.oja-services.nl/iea-pvps/. Accessed: 31 January 2006.

Ironmonger, D., Aitken, C. and Erbas, B. (1995) 'Economies of scale in energy use in adult-only households', Energy Economics, 17(4): 301-310.

ISI (2006) 'ISI Web of Knowledge', Manchester Information and Associated Services. URL: http: //wok . mimas . ac.uk/. Accessed: 19 May 2006.

Iyer, M., Kempton, W. and Payne, C. (2006) 'Comparison groups on bills: automated, personalized energy information', Energy and Buildings, 38(8): 988996.

Jager, W. (2006) 'Stimulating the diffusion of photovoltaic systems: a behavioural perspective', Energy Policy, 34(14): 1935-1943.

Jardine, C. (2004) The technical and social evaluation of photovoltaics. Personal communication, 16 August 2005.

Jardine, C. (2006) Performance of the West Oxfordshire District Council PV array. ECI brown bag seminar. Personal communication, 18 May 2006.

Jardine, C. and Lane, K. (2001) PV Compare: 18 month summary report for Alqueria. Oxford: Environmental Change Institute.

Jardine, C. and Lane, K. (2002) PV Compare: 18 month green electricity from Begbroke, UK. Oxford: Environmental Change Institute. 
Jardine, C. and Lane, K. (2003) Photovoltaics in the UK: an introductory guide for new consumers. Oxford: Environmental Change Institute.

Jardine, C. N., Boardman, B., Osman, A., Vowles, J. and Palmer, J. (2004) Methane UK, ECI research report 30. Oxford: Environmental Change Institute.

Jenny, A., López, J. R. D. and Mosler, H.-J. (in press) 'Household energy use patterns and social organisation for optimal energy management in a multiuser solar energy system', Progress in Photovoltaics: Research and Applications.

Jensen, O. M. (2005) 'Consumer inertia to energy saving', in S. Attali and K. Tillerson, eds, ECEEE Summer Study, Vol. 3, pp. 1327-1334. Mandelieu, France: European Council for an Energy Efficient Economy.

Joerges, B. (1988) 'Large technical systems: concepts and issues', in R. Mayntz and T. P. Hughes, eds, The development of large technical systems, Schriften des Max-Planck-Instituts für Gesellschaftsforschung, Köln ; v. 2, pp. 9-36. Boulder, CO: Westview Press.

Johnson, M. B. (1971) Household behaviour: consumption, income and wealth, Penguin Education. Harmondsworth: Penguin.

Kaiser, F. G. and Shimoda, T. A. (1999) 'Responsibility as a predictor of ecological behaviour', Journal of Environmental Psychology, 19(3): 243-253.

Kaiser, F. G., Wölfing, S. and Fuhrer, U. (1999) ‘Environmental attitude and ecological behaviour', Journal of Environmental Psychology, 19(1): 1-19.

Kaplan, A. W. (1999) 'From passive to active about solar electricity: innovation decision process and photovoltaic interest generation', Technovation, 19(8): 467-481.

Kaplan, S. (2000) 'Human nature and environmentally responsible behavior', Journal of Social Issues, 56(3): 491-508.

Kasulis, J. J., Huettner, D. A. and Dikeman, N. J. (1981) 'The feasibility of changing electricity consumption patterns', Journal of Consumer Research, 8(December): $279-290$.

Katzev, R. D. and Johnson, T. (1983) 'A social-psychological analysis of residential electricity consumption: the impact of minimal justification techniques', Journal of Economic Psychology, 3(3-4): 267-284.

Keirstead, J. (in pressa) 'Evaluating the applicability of integrated domestic energy consumption frameworks in the UK', Energy Policy.

Keirstead, J. (in press $b$ ) 'The role of central government in the UK's emerging domestic photovoltaics industry', Energy Policy. 
Kempton, W. (1987) 'Variation in folk models and consequent behaviour', American Behavioural Scientist, 31(2): 203-218.

Kempton, W. and Layne, L. (1994) 'The consumer's energy analysis environment', Energy Policy, 22(10): 857-866.

Kempton, W. and Montgomery, L. (1982) 'Folk quantification of energy', Energy - the international journal, 7(10): 817-827.

Kirov, K. R., Burlakov, V. M., Xie, Z., Henry, B. M., Carey, M. J., Grovenor, C. R., Burn, P. L., Assender, H. E., Andrew, G. and Briggs, D. (2004) 'Non-steadystate operation of polymer/TiO2 photovoltaic devices', in Z. H. Kafafi and P. A. Lane, eds, Organic Photovoltaics V, Vol. 5520, pp. 68-75. Denver, CO: International Society for Optical Engineering.

Klein, H. J. (1983) 'Changes in attitudes and behaviour by using solar energy', Journal of Economic Psychology, 4(1-2): 167-181.

Klein, H. K. and Kleinman, D. L. (2002) 'The social construction of technology: structural considerations', Science, Technology, and Human Values, 27(1): 2852.

Kline, R. R. (2001) 'Technological determinism', in N. J. Smelser and P. B. Baltes, eds, International encyclopedia of the social and behavioral sciences, pp. 1549515498. Elsevier.

Kline, S. J. (2003) 'What is technology?', in R. C. Scharff and V. Dusek, eds, Philosophy of technology: the technological condition: an anthology, pp. 210-212. Oxford: Blackwell.

Kooreman, P. (1996) 'Individual discounting, energy conservation, and household demand for lighting', Resource and Energy Economics, 18(1): 103-14.

Kooreman, P. and Wunderink, S. (1997) The economics of household behaviour. Basingstoke: Macmillan.

Kurokawa, K. and Ikki, O. (2001) 'The Japanese experiences with national PV system programmes', Solar Energy, 70(6): 457-466.

Labay, D. G. and Kinnear, T. C. (1981) 'Exploring the consumer decision process in the adoption of solar energy systems', Journal of Consumer Research, 8(December): 271-278.

Lampaditou, E. and Leach, M. (2005) 'Evaluating participation of residential customers in demand response programs in the UK', in F. Bartiaux and A. G. Selnæs, eds, ECEEE Summer Study, Vol. 3, pp. 1271-1282. Mandelieu, France: European Council for an Energy Efficient Economy.

Latour, B. (1983) 'Give me a laboratory and I will raise the world', in K. D. Knorr-Cetina and M. J. Mulkay, eds, Science Observed: Perspectives on the social study of science, pp. 141-170. London: Sage. 
Latour, B. (1987) Science in action: how to follow scientists and engineers through society. Cambridge, MA: Harvard University Press.

Latour, B. (1991) 'Technology is society made durable', in J. Law, ed., A Sociology of Monsters? Essays on Power Technology and Domination, Sociological Review monograph, pp. 103-131. London: Routledge.

Latour, B. (1999) ‘On recalling ANT', in J. Law and J. Hassard, eds, Actor Network and After, pp. 15-25. Oxford: Balcket.

Law, J. (1989) 'Technology and heterogeneous engineering: the case of Portuguese expansion', in W. E. Bijker, T. P. Hughes and T. J. Pinch, eds, The social construction of technological systems: new directions in the sociology and history of technology, pp. 111-134. Cambridge, MA: MIT Press.

Law, J. (1992a) 'Notes on the theory of the actor-network: ordering, strategy and heterogeneity', Centre for Science Studies, Lancaster University. URL: http: //www. comp. lancs.ac.uk/sociology/papers/law-notes-on-ant.pdf. Accessed: 26 June 2004.

Law, J. (1992b) 'The Olympus 320 engine: a case study in design, development, and organisational control', Technology and Culture, 33(3): 409-440.

Law, J. (1997) 'Traduction/Trahison: notes on ANT', Centre for Science Studies, Lancaster University. URL: http: //www . comp. lancs . ac .uk/soci ology/ papers/law-traduction-trahis on.pdf. Accessed: 26 June 2004.

Law, J. and Hassard, J. (1999) Actor network theory and after, Sociological review monographs. Oxford: Blackwell.

LBM (2006) 'The 10\% renewable energy policy', London Borough of Merton. URL: http://www.merton.gov.uk/living/planning/plansandprojects/ 10percentpolicy.htm. Accessed: 1 February 2006.

Leggett, J. K. (2001) The carbon war: global warming and the end of the oil era. New York: Routledge.

Leonard-Barton, D. (1981a) 'The diffusion of active residential solar energy equipment in California', in A. Shama, ed., Marketing Solar Energy Innovations. New York: Praeger Press.

Leonard-Barton, D. (1981b) 'Voluntary simplicity lifestyles and energy conservation', Journal of Consumer Research, 8(December): 243-252.

Lovell, H. (2005) The governance of emerging socio-technical systems: the case of low energy housing in the UK, PhD thesis, University of Cambridge.

Lutzenhiser, L. (1992) 'A cultural model of household energy consumption', Energy, 17(1): 47-60. 
Lutzenhiser, L. (1993) 'Social and behavioural aspects of energy use', Annual Review of Energy and the Environment, 18: 247-289.

Lutzenhiser, L. (1994) 'Innovation and organization networks: barriers to energy efficiency in the United States housing industry', Energy Policy, 22(10): 867-876.

Lutzenhiser, L. and Hackett, B. (1993) 'Social stratification and environmental degradation - understanding household $\mathrm{CO}_{2}$ production', Social Problems, 40(1): 50-73.

Lutzenhiser, L. and Shove, E. (1999) 'Contracting knowledge: the organizational limits to interdisciplinary energy efficiency research and development in the US and the UK', Energy Policy, 27(4): 217-227.

Luyben, P. (1982) ‘Prompting thermostat setting behaviour: public response to a presidential appeal for conservation', Environment and Behaviour, 14(1): 113128.

Mackay, H. and Gillespie, G. (1992) 'Extending the social shaping of technology approach: ideology and appropriation', Social Studies of Science, 22(4): 685716.

MacKenzie, D. A. and Wajcman, J. (1999) The social shaping of technology, 2nd edn. Buckingham: Open University Press.

Maiteny, P. (2002) 'Mind in the gap: summary of research exploring "inner" influences on pro-sustainability learning and behaviour', Environmental Education Research, 8(3): 299-306.

Management of Energy in Buildings Bill (2006) Tabled: 22 June 2005. URL: http://www .publications.parliament.uk/pa/cm200506/cmbills/022/ 2006022.htm.

Mansouri-Azar, I., Newborough, M. and Probert, D. (1996) 'Energyconsumption in UK domestic households: impacts of domestic electrical appliances', Applied Energy, 54(3): 211-285.

Marsh, D. and Marshall, N., eds (2004) The Guardian Style Guide. London: The Guardian.

Martin, E. W. (2000) 'Actor-networks and implementation: examples from conservation GIS in Ecuador', International Journal of Geographic Information Science, 14(8): 715-738.

Marvin, S., Chappells, H. and Guy, S. (1999) 'Pathways of smart metering development: Shaping environmental innovation', Computers Environment and Urban Systems, 23(2): 109-126. 
Mayntz, R. and Hughes, T. P., eds (1988) The development of large technical systems, Schriften des Max-Planck-Instituts für Gesellschaftsforschung, Köln (v. 2). Frankfurt am Main: Campus.

McBride, N. (2003) 'Actor-network theory and the adoption of mobile communications', Geography, 88(4): 266-276.

McCracken, F. (2001) 'Diderot unities and the Diderot effect', in D. Miller, ed., Consumption: critical concepts in the social sciences, Vol. 3: disciplinary approaches to consumption, pp. 120-135. London: Routledge.

McLean, C. and Hassard, J. (2004) 'Symmetrical absence/symmetrical absurdity: critical notes of the production of actor-network accounts', Journal of Management Studies, 41(3): 493-519.

McMakin, A. H., Malone, E. L. and Lundgren, R. E. (2002) 'Motivating residents to conserve energy without financial incentives', Environment and Behavior, 34(6): 848-863.

Menges, R. (2003) 'Supporting renewable energy on liberalised markets: green electricity between additionality and consumer sovereignty', Energy Policy, 31(7): 583-596.

Merriam, S. B. and Caffarella, R. S. (1991) Learning in adulthood: a comprehensive guide, Higher and Adult Education Series. San Francisco: Jossey-Bass.

Met Office (2005) 'Sunshine duration (hours), annual average 1970-2000'. URL: http://www.met-office.gov.uk/climate/uk/averages/19712000/ss/17. gif.

Meyer, N. I. (2003) 'European schemes for promoting renewables in liberalised markets', Energy Policy, 31(7): 665-676.

Michaelis, L. (2003) 'Sustainable consumption and greenhouse gas mitigation', Climate Policy, 3(SUPPL 1): S135-S146.

Michalik, G., Khan, M., Bonwick, W. and Mielczarski, W. (1997) 'Structural modelling of energy demand in the residential sector: 1 - Development of structural models', Energy, 22(10): 937-947.

Midttun, A. and Koefoed, A. L. (2003) 'Greening of electricity in Europe: challenges and developments', Energy Policy, 31(7): 677-687.

Miller, D. (1991) Material culture and mass consumption. Oxford: Blackwell.

Miller, D. (1997) Modernity: an ethnographic approach: dualism and mass consumption in Trinidad. Oxford: Berg.

Miller, D. J. (2006) 'Early impressions of Escape hybrid driver', HybridCars.com. URL: http: //www . hybridcars . com/escape-hybrid-driver. html. Accessed: 1 March 2006. 
Milne, G. and Boardman, B. (2000) 'Making cold homes warmer: the effect of energy efficiency improvements in low-income homes', Energy Policy, 28(67): 411-424.

Misa, T. J. (1988) 'How machines make history, and how historians (and others) help them to do so', Science, Technology, and Human Values, 13(3-4): 308-331.

Mitchell, C. and Connor, P. (2004) 'Renewable energy policy in the UK 19902003', Energy Policy, 32(17): 1935-1947.

Moisander, J. (2004) 'Motivation for ecologically oriented consumer behaviour', Lancaster University, Department of Sociology. URL: http: //www . lancs.ac.uk/users/scistud/esf/lind2 .htm. Accessed: 13 January 2004.

Monnier, E. (1983) 'Energy inputs and household behaviour in France', Journal of Economic Psychology, 4(1-2): 197-207.

Mott MacDonald (2004) UK coal production outlook: 2004-16. London: Dept. of Trade and Industry.

MTP (2005) 'BNDL01: data sources and assumptions for energy scenarios in the domestic lighting sector', Market Transformation Programme. URL: http://www.mtprog.com/ApprovedBriefingNotes/ BriefingNoteTemplate. aspx?intBriefingNoteID=105. Accessed: $\quad 30$ June 2006.

Murdoch, J. (1997) 'Inhuman/nonhuman/human: actor-network theory and the prospects for a nondualistic and symmetrical perspective on nature and society', Environment and Planning D: Society and Space, 15(6): 731-756.

Murdoch, J. (1998) 'The spaces of actor-network theory', Geoforum, 29(4): 357374.

Mutch, A. (2002) 'Actors and networks or agents and structures: towards a realist view of information systems', Organization, 9(3): 477-496.

National Grid (2003) 'Seven year statement: demand profiles'. URL: http://www .nationalgrid.com/uk/library/documents/sys_03/default. asp?action=mnch2_7.htm\&Node=SYS\&Snode=2_7\&Exp=Y. Accessed: 30 June 2006.

National Grid (2004) 'Seven year statement: actual national grid summer and winter demands for 2003/2004'. URL: http: //www.nationalgrid.com/uk/ library/documents/sys_04/dddownloaddisplay.asp?sp=sys_Figure2_3. Accessed: 30 June 2006.

National Statistics (2000) The UK 2000 Time Use Survey. London: National Statistics. 
National Statistics (2004a) Greenhouse gas emissions from transport. London: National Statistics.

National Statistics (2004b) Regional Trends No. 38. London: The Stationary Office.

National Statistics (2005) 'Consumer Price Index', The Stationary Office. URL: http://www.statistics.gov.uk/statbase/tsdtables1. asp?vlnk=mm23.

Accessed: 30 June 2006.

NCC (2005a) Desperately seeking sustainability : summary of NCC research into information and advice on sustainable lifestyles. London: National Consumer Council.

NCC (2005b) Sustainable consumption: making it work for consumers. London: National Consumer Council.

NEF (2006) 'Previous project: PV-Domsys', National Energy Foundation. URL: http://www.nef .org.uk/services/previousprojects.htm. Accessed: 1 March 2006.

Neumayer, E. (1999) 'Global warming: discounting is not the issue, but substitutability is', Energy Policy, 27(1): 33-43.

Norgaard, K. M. (2003) Denial, privilege and global environmental justice: the case of climate change. SUM Working Paper 2003.02, University of Oslo.

Nye, D. (1990) Electrifying America: social meanings of a new technology. Cambridge: MIT Press.

ODPM (2001) English house condition survey (main report). London: Office of the Deputy Prime Minister.

ODPM (2005) Low or zero carbon energy sources - report 4: final report. London: Office of the Deputy Prime Minister.

OECD/IEA (2002) Distributed generation in liberalised electricity markets. Paris: Organisation for Economic Co-operation and Development/International Energy Agency.

Ofgem (2002a) 'Decision and direction in relation to modification proposal P81: "Removal of the requirement for half hourly metering on third party generators at domestic premises"', Office of Gas and Electricity Markets. URL: http://www.ofgem.gov.uk/temp/ofgem/cache/cmsattach/ 9605_P81_DecisionLetter.pdf. Accessed: 31 January 2006.

Ofgem (2002b) 'Distributed generation: "the way forward"', Office of Gas and Electricity Markets. URL: http: //www.distributed-generation.gov . uk/documents/26distgenfactsheet_1.pdf. Accessed: 16 April 2004.

Ofgem (2005) The regulatory implications of domestic-scale microgeneration: a consultation document. Office of Gas and Electricity Markets. 
Ofgem (2006a) 'Application for accreditation for generating stations $50 \mathrm{~kW}$ or less', Office of Gas and Electricity Markets. URL: http://www .ofgem.gov.uk/temp/ofgem/cache/cmsattach/14657_ Accreditation_Small_FINAL.doc. Accessed: 30 May 2006.

Ofgem (2006b) Domestic metering innovation. Office of Gas and Electricity Markets.

Ofgem (2006c) 'Gas probe: conclusions document', Office of Gas and Electricity Markets. URL: http://www.ofgem.gov.uk/temp/ofgem/cache/ cmsattach/13462_Gas_Probe_Conclusions_document_Final_doc.pdf. Accessed: 10 February 2006.

Ofgem (2006d) 'Update: household energy bills explained', Office of Gas and Electricity Markets. URL: http://www.ofgem.gov.uk/temp/ofgem/cache/ cmsattach/14692_energypricesupdateapr6.pdf. Accessed: 15 May 2006.

ONS (2004) Living in Britain: results from the 2002 General Household Survey. London: Office of National Statistics.

Oreszczyn, T., Hong, S. H., Ridley, I., Wilkinson, P. and Group, W. F. S. (2006) 'Determinants of winter indoor temperatures in low income households in England', Energy Policy, 38(3): 245-252.

Ornetzeder, M. (2001) 'Old technology and social innovations. Inside the Austrian success story on solar water heaters', Technology Analysis and Strategic Management, 13(1): 112-115.

Ornetzeder, M. and Rohracher, H. (2006) 'User-led innovations and participation processes: Lessons from sustainable energy technologies', Energy Policy, 34(2 SPEC. ISS.): 138-150.

Osborn, T. J. and Briffa, K. R. (2006) 'The spatial extent of 20th-century warmth in the context of the past 1200 years', Science, 311(5762): 841-844.

Owen, G. and Ward, J. (2006) Smart meters: commercial, policy and regulatory drivers. London: Sustainability First.

Oxera (2006) Harvesting a windfall: energy efficiency for households. Oxford: Oxford Economic Research Associates.

Page, E. (1999) 'Intergenerational justice and climate change', Political Studies, 47(1): 53-66.

Painter, J., Semenik, R. and Belk, R. W. (1983) 'Is there a generalized energy conservation ethic? A comparison of the determinants of gasoline and home heating energy conservation', Journal of Economic Psychology, 3(3-4): 317-331.

Palutikof, J. P., Agnew, M. D. and Hoar, M. R. (2004) 'Public perceptions of unusually warm weather in the UK: impacts, responses and adaptations', Climate Research, 26(1): 43-59. 
Park, A., Curtcie, J., Thomson, K., Jarvis, L. and Bromley, C., eds (2001) British Social Attitude: the 18th report: public policy, social ties. London: SAGE Publications.

Parker, P., Rowlands, I. H. and Scott, D. (2003) 'Innovations to reduce residential energy use and carbon emissions: an integrated approach', Canadian Geographer, 47(2): 169-184.

Payne, A., Duke, R. and Williams, R. H. (2001) 'Accelerating residential PV expansion: supply analysis for competitive electricity markets', Energy Policy, 29(10): 787-800.

Peacock, A. and Newborough, M. (2004) The 40\% House Project: Task 4 - Power and Demand. Edinburgh: Heriot Watt University.

Pearsall, N. M. (2005) 'Performance issues for UK BIPV systems', in M. S. Imbabi and C. P. Mitchell, eds, World Renewable Energy Congress, pp. 446-451. Aberdeen: Elsevier.

Pickering, A. (1993) 'The mangle of practice: agency and emergence in the sociology of science', American Journal of Sociology, 99(3): 559-589.

Pinch, T. J. and Bijker, W. E. (1984) 'The social construction of facts and artefacts: or how the sociology of science and the sociology of technology might benefit each other', Social Studies of Science, 14(3): 339-441.

PIU (2002) The energy review. London: Performance and Innovation Unit.

Poortinga, W., Pidgeon, N. and Lorenzoni, I. (2005) Public perceptions of nuclear power, climate change and energy options in Britain: summary findings of a survey conducted during October and November 2005. Tyndall Centre for Climate Change Research.

Poortinga, W., Steg, L. and Vlek, C. (2004) 'Values, environmental concern and environmental behaviour: a study into household energy use', Environment and Behavior, 36(1): 70-93.

Punch, K. (2005) Introduction to social research: quantitative and qualitative approaches, 2nd edn. London: Sage.

PV-UK (2005) 'Can a PV system be installed on my building?', British Photovoltaic Association. URL: http://www.greenenergy.org.uk/pvuk2/ technology/installation.html. Accessed: 16 August 2005.

$R$ Development Core Team (2005) `R: a language and environment for statistical computing', version 2.1.1. URL: http: //www.R-project.org.

RCEP (2000) Energy - the changing climate. London: Royal Commission on Environmental Pollution. 
REE (2004) The Spanish electricity system: preliminary report 2004. Red Eléctrica de España.

Resurgence (2006) 'Renewable energy systems for urban regeneration in cities of Europe'. URL: http: //www .resurgence.info/. Accessed: 1 March 2006.

Rhodes, M. (2005) 'Meeting climate change targets: the role of microgeneration and energy efficiency', Encraft Ltd. URL: http: //www .encraft.co.uk/ SERA\%20presentation.pdf. Accessed: 15 May 2006.

Richardson, B. J. and Chanwai, K. L. (2003) 'The UK's climate change levy: is it working?', Journal of Environmental Law, 15(1): 39-58.

Rip, A. (1995) 'Introduction of new technology: making use of recent insights from sociology and economics of technology', Technology Analysis and Strategic Management, 7(4): 417-431.

Ritzer, G., Goodman, D. and Wiedenhoft, W. (2001) 'Theories of consumption', in G. Ritzer and B. Smart, eds, Handbook of Social Theory, pp. 410-427. London: Sage.

Roberts, S., Humphries, H. and Hyldon, V. (2004) Consumer preferences for improving energy consumption feedback. Bristol: Centre for Sustainable Energy.

Robson, C. (2002) Real world research: a resource for social scientists and practitionerresearchers, 2nd edn. Oxford: Blackwell.

Rogers, E. M. (2003) Diffusion of Innovations, 5th edn. New York: The Free Press.

Rohracher, H. (2001) 'Managing the technological transition to sustainable construction of buildings: a socio-technical perspective', Technology Analysis and Strategic Management, 13(1): 147-150.

Rohracher, H. (2003) 'The role of users in the social shaping of environmental technologies', Innovation, 16(2): 177-192.

Rohracher, H. and Ornetzeder, M. (2002) 'Green buildings in context: improving social learning processes between users and producers', Built Environment, 28(1): 73-84.

Rokeach, M. (1973) The nature of human values. New York: The Free Press.

Rosa, E. and Machlis, G. (1983) 'Energetic theories of society: an evaluative review', Sociological Inquiry, 53(2,3): 152-178.

Rosa, E., Machlis, G. and Keating, K. (1988) 'Energy and society', Annual Review of Sociology, 14: 149.

Rowlands, I. H. (2005) 'Solar PV electricity and market characteristics: two Canadian case-studies', Renewable Energy, 30(6): 815-834. 
Rowlands, I. H., Scott, D. and Parker, P. (2003) 'Consumers and green electricity: profiling potential purchasers', Business Strategy and the Environment, 12(1): 36-48.

RSPB (2004) 'Going solar and RSPB energy', Royal Society for the Protection of Birds. URL: http: //www.rspb.org.uk/supporting/shopping/energy/. Accessed: 25 February 2005.

Sachs, W. (1983) 'Are energy-intensive life-images fading? The cultural meaning of the automobile in transition', Journal of Economic Psychology, 3(4): 347365.

Schnaiberg, A. (1975) 'Social syntheses of the societal-environment dialectic: the role of distributional Impacts', Social Science Quarterly, 56(1): 5-20.

Schot, J. W. (1992) 'Constructive technology assessment and technology dynamics: the case of clean technologies', Science, Technology and Human Values, 17(1): 36-56.

Schultz, P. W. and Zelezny, L. (1999) 'Values as predictors of environmental attitudes: evidence for consistency across 14 countries', Journal of Environmental Psychology, 19(3): 255-265.

Schumacher, E. F. (1973) Small is beautiful: a study of economics as if people mattered. New York: Harper and Row.

Schweizer-Reis, P., Schulz, M., Vallvé, X., Vosseler, I., Ramírez, E. and Serrano, J. (2000) Successful user schemes for photovoltaic stand-alone systems: solar energy for rural electrification - lessons learned. Freiburg: Fraunhofer-Institut für Solar Energiesysteme ISE.

Scopus (2006) 'Scopus', Elsevier. URL: http://www. scopus.com. Accessed: 19 May 2006.

Sefton, T. (2004) Aiming high: an evaluation of the potential contribution of Warm Front towards meeting the Government's fuel poverty target in England. London: Centre for Analysis of Social Exclusion, London School of Economics.

Seligman, C. and Darley, J. (1977) ‘Feedback as a means of decreasing residential energy consumption', Journal of Applied Psychology, 62(4): 363-368.

Seligman, C., Kriss, M., Darley, J. M., Fazio, R., Becker, L. and Pryor, J. (1979) 'Prediction of summer energy consumption from homeowners' attitudes', Journal of Applied Social Psychology, 9(1): 70-90.

Sexton, R. J., Brown Johnson, N. and Konakayama, A. (1987) 'Consumer response to continuous-display electricity-use monitors in a time-of-use pricing experiment', Journal of Consumer Research, 14(June): 55-62. 
Shanahan, G. (2003) 'UK government support for PV', in IEA-PVPS, ed., IEAPVPS International Conference. Osaka, Japan: IEA-PVPS.

Shanker, T. (2002) 'Reporter's notebook: on tour with Rumsfeld, the jacket stays on and the monkey stays away', The New York Times, 16 June 2002.

Sharp (2005) 'Sharp to introduce new line of power conditioners for residential solar power generating systems featuring a "color power monitor"'. Accessed: 5 June 2005.

Shih, C. F. and Venkatesh, A. (2004) 'Beyond adoption: development and application of a use-diffusion model', Journal of Marketing, 68(1): 59-72.

Shipworth, D. (2005) 'Synergies and conflicts on the landscape of domestic energy consumption: beyond metaphor', in F. Bartiaux and A. G. Selnæs, eds, ECEEE Summer Study, Vol. 3, pp. 1381-1391. Mandelieu, France: European Council for an Energy Efficiency Economy.

Shorrock, L. D. and Dunster, J. E. (1997) 'The physically-based model BREHOMES and its use in deriving scenarios for the energy use and carbon dioxide emissions of the UK housing stock', Energy Policy, 25(12): 1027-1037.

Shorrock, L. D. and Utley, J. I. (2003) 'Domestic energy fact file 2003', Building Research Establishment. URL: http://projects . bre.co.uk/factfile/. Accessed: 10 February 2006.

Shove, E. (1998) 'Gaps, barriers and conceptual chasms: theories of technology transfer and energy in buildings', Energy Policy, 26(15): 1105-1112.

Shove, E. (2003a) Comfort, cleanliness and convenience: the social organization of normality. Oxford: Berg.

Shove, E. (2003b) 'Users, technologies and expectations of comfort, cleanliness and convenience', Innovation, 16(2): 193-206.

Shove, E. and Warde, A. (2002) 'Inconspicuous consumption: the sociology of consumption, lifestyles, and the environment', in R. E. Dunlap, F. Buttel, P. Dickens and A. Gijswijt, eds, Sociological theory and the environment : classical foundations, contemporary insights, pp. 230-251. Oxford: Rowman and Littlefield.

Shove, E., Watson, M. and Ingram, J. (2005) 'Products and practices: selected concepts from science and technology studies and from social theories of consumption and practice'. URL: http://www.dur.ac.uk/designing. consuming/papers/products\%20and\%20practices.pdf. Accessed: 5 April 2006.

Siegenthaler, U., Stocker, T. F., Monnin, E., Lüthi, D., Schwander, J., Stauffer, B., Raynaud, D., Barnola, J.-M., Fischer, H., Masson-Delmotte, V. and Jouzel, J. (2005) 'Stable carbon cycle-climate relationship during the late Pleistocene', Science, 310(5752): 1313-1317. 
Siero, F. W., Bakker, A. B., Dekker, G. B. and van den Burg, M. T. C. (1996) 'Changing organizational energy consumption behaviour through comparative feedback', Journal of Environmental Psychology, 16(3): 235-246.

Silverstone, R. and Haddon, L. (1996) 'Design and domestication of information and communication technologies: technical change and everyday life', in R. Mansell and R. Silverstone, eds, Communication by Design: the politics of information and communication technologies, pp. 44-77. Oxford: Oxford University Press.

Silverstone, R., Hirsch, E. and Morley, D. (1994) 'Information and communication technologies and the moral economy of the household', in R. Silverstone and E. Hirsch, eds, Consuming technologies: media and information in domestic spaces, pp. 15-31. London: Routledge.

Simpson, D. (2000) Rethinking economic behaviour: how the economy really works. Basingstoke: Macmillan.

SMA (2006) 'Sunny Boy 2100U'. URL: http://www.sma-america.com/ftp/ Sunny\%20Boy\%202100\%20Datasheet.pdf. Accessed: 28 May 2006.

Smits, R. (2002) 'Innovation studies in the 21st century: questions from a user's perspective', Technological Forecasting and Social Change, 69(9): 861-883.

SMWG (2001) A report to DTI from the Smart Metering Working Group. Smart Metering Working Group.

Socolow, R. H. (1978) 'The Twin Rivers program on energy conservation in housing: highlights and conclusions', Energy and Buildings, 1(3): 207-242.

Solar Century (2004) HI customer system performance: feedback and statistics. Personal communication, 11 October 2004.

Solar Century (2005a) 'Please get serious about the survival technologies, solarcentury tells UK Government'. URL: http://www . solarcentury . co.uk/ news/newsitem. jsp?newsid=428. Accessed: 31 January 2006.

Solar Century (2005b) 'What is the "Merton Rule" and how is it affecting all major development projects?'. URL: http: //www . solarcentury . com/news / newsitem. jsp?newsid=424. Accessed: 30 January 2006.

Solem, M. N. (2001) 'Choosing the network less traveled: perceptions of internet-based teaching in college geography', Professional Geographer, 53(2): 195-206.

Sonderegger, R. C. (1978) 'Movers and stayers: the resident's contribution to variation across houses in energy consumption for space heating', Energy and Buildings, 1(3): 313-324. 
Southerton, D., Hand, M., Warde, A. and Shove, E. (2003) Sustainable domestic technologies: changing practice, technology and convention. Manchester: ESRC Sustainable Technologies Programme.

Southerton, D., Warde, A. and Hand, M. (2004) 'The limited autonomy of the consumer: implications for sustainable consumption', in D. Southerton, H. Chappells and B. v. Vliet, eds, Sustainable consumption : the implications of changing infrastructures of provision, pp. 32-48. Cheltenham: Edward Elgar.

Spooner, D. (1995) 'The 'dash for gas' in electricity generation in the UK', Geography, 80(4): 393-406.

Stantzos, N. (2005) Financing climate change entrepreneurship: assessing the potential of solar energy start-ups to attract investments in the UK, MSc thesis, University of Oxford.

Stern, G. A., Sorooshian, P., Ridge, R. S. and Watts, R. K. (1988) 'Reducing household electricity consumption peaks', Sociology and Social Research, 72(4): 252-256.

Stern, P. (1993) 'A second environmental science: human-environment interactions', Science, 260: 1897-1899.

Stern, P. C. (1992) 'What psychology knows about energy conservation', American Psychologist, 47(10): 1224-1232.

Stern, P., Dietz, T. and Guagnano, G. (1995) 'The new ecological paradigm in social-pyschological context', Environment and Behaviour, 27(6): 723-743.

Stokes, M., Rylatt, M. and Lomas, K. (2004) 'A simple model of domestic lighting demand', Energy and Buildings, 36(2): 103-116.

Stokes, M., Rylatt, M., Mardaljevic, J., Lomas, K. and Thomson, M. (2002) 'Solar city: managing the uptake of solar energy technology from an electricial supply network perspective', in Proceedings of the 5th Symposium of International Urban Planning and Environmental Association. Oxford: International Urban Planning and Environmental Association.

Strang, V. (1997) 'Contextualising values and behaviour', European Council for an Energy Efficient Economy. URL: http://www. eceee.org/library_ links/proceedings/1997/pdf97/97p4-67-B.pdf. Accessed: 24 August 2004.

Strathern, M. (1994) 'Foreward: the mirror of technology', in R. Silverstone and E. Hirsch, eds, Consuming technologies: media and information in domestic spaces, pp. vii-xiii. London: Routledge. 
Stutzman, T. and Green, S. (1982) 'Factors affecting energy consumption: two field tests of the Fishbein-Ajzen model', Journal of Social Psychology, 117: 183201.

Supergen (2005) 'Supergen networks'. URL: http: //www . supergen-networks . org. uk/. Accessed: 28 February 2006.

Sustainable and Secure Buildings Act (2004) Enacted: 16 September 2004, ch. 22. URL: http: //www.opsi.gov.uk/acts/acts2004/20040022.htm.

Taviss, I. (1970) Technology and the individual. Cambridge, MA: Harvard University Program on Technology and Society.

Thomas, S. (2004) Electricity liberalisation: the beginning of the end. London: Public Service International Research Unit, University of Greenwich.

Thompson, P. B. (2002) 'Consumer theory, home production, and energy efficiency', Contemporary Economic Policy, 20(1): 50-59.

Thomsen, K. E., Schultz, J. and Poel, B. (2005) 'Measured performance of 12 demonstration projects - the IEA Task 13 "advanced solar low energy buildings"', Energy and Buildings, 37(2): 111-119.

Tversky, A. and Kahneman, D. (1986) 'Rational choice and the framing of decisions', Journal of Business, 59(4): 251-78.

Ueno, T., Sano, F., Saeki, O. and Tsuji, K. (2006) 'Effectiveness of an energyconsumption information system on energy savings in residential houses based on monitored data', Applied Energy, 83(2): 166-183.

UKERC (2006) 'About the UK Energy Research Centre', UK Energy Research Centre. URL: http://www.ukerc.ac.uk/content/view/121/101/. Accessed: 20 March 2006.

UNEP (1995) 'What is sustainable consumption?', United Nations Environment Programme. URL: http: //www. uneptie.org/pc/sustain/about-us/ about-us.htm. Accessed: 1 March 2006.

UNFCCC (2006) 'Greenhouse gas inventory data', United Nations Framework Convention on Climate Change. URL: http://ghg.unfccc.int/default. htf. Accessed: 10 February 2006.

uSwitch.com (2006) 'uSwitch.com: gas and electricity'. URL: http://www . uswitch.com/Energy/index. asp. Accessed: 15 May 2006.

Utterback, J. M. (1994) Mastering the dynamics of innovation: how companies can seize opportunities in the face of technological change. Boston, MA: Harvard Business School Press. 
van Houwelingen, J. H. and van Raaij, W. F. (1989) 'The effect of goal-setting and daily electronic feedback on in-home energy use', The Journal of Consumer Research, 16(1): 98-105.

van Raaij, W. F. and Verhallen, T. M. (1983a) 'A behavioural model of residential energy use', Journal of Economic Psychology, 3(1): 39-63.

van Raaij, W. F. and Verhallen, T. M. (1983b) 'Patterns of residential energy behaviour', Journal of Economic Psychology, 4(1-2): 85-106.

Varma, A. (2003) 'UK's climate change levy: cost effectiveness, competitiveness and environmental impacts', Energy Policy, 31(1): 51-61.

Veblen, T. (1899) The theory of the leisure class. New York: Penguin.

Verhallen, T. M. and van Raaij, W. F. (1981) 'Household behaviour and the use of natural gas for home heating', Journal of Consumer Research, 8(December): 253-257.

Verhoef, E. T. and Nijkamp, P. (2003) 'The adoption of energy-efficiency enhancing technologies: market performance and policy strategies in case of heterogenous firms', Economic Modelling, 20(4): 839-871.

von Hippel, E. (2001) 'Innovation by user communities: learning from opensource software', MIT Sloan Management Review, 42(4): 82-86.

Vowles, J., Boardman, B. and Lane, K. (2001) 'Suspecting standby? Domestic levels and the potential for household-level reductions in the UK', in ECEEE Summer Study. Mandelieu, France: European Council for an Energy Efficient Economy.

Vringer, K., Aalbers, T. and Blok, K. (in press) 'Household energy requirement and value patterns', Energy Policy.

Waddams Price, C. (2005) 'The effect of liberalizing UK retail energy markets on consumers', Oxford Review of Economic Policy, 21(1): 128-144.

Warm Homes and Energy Conservation Act (2000) Enacted: 23 November 2000, ch. 31. URL: http://www.opsi.gov.uk/acts/acts2000/20000031.htm.

Watson, J. (2004a) 'Co-provision in sustainable energy systems: the case of micro-generation', Energy Policy, 32(17): 1981-1990.

Watson, J. (2004b) 'Selection environments, flexibility and the success of the gas turbine', Research Policy, 33(8): 1065-1080.

Watson, J., Sauter, R., Bahaj, B., James, P., Myers, L., Gann, D., Venables, T. and Wing, R. (2005) Integrating micro-generation into energy networks and buildings ('Unlocking the power house'): project progress report, end year 1. Sussex: ESRC Sustainable Technology Programme. 
Watson, M. and Shove, E. (2005a) 'DIY and the restlessness of domestic interiors'. URL: http://www.dur.ac.uk/designing.consuming/papers/ DIY $\% 20$ and $\% 20$ the $\% 20$ restlessness $\% 20$ of $\% 20$ domestic $\% 20$ interiors.pdf. Accessed: 5 April 2006.

Watson, M. and Shove, E. (2005b) 'Doing it yourself? Products, competence and meaning in the practices of DIY'. URL: http://www.sifo.no/files/ Watson_Shove.pdf. Accessed: 5 April 2006.

Weber, K. M. (2003) 'Transforming large socio-technical systems towards sustainability: on the role of users and future visions for the uptake of city logistics and combined heat and power generation', Innovation, 16(2): 155176.

Weber, L. (1997) 'Some reflections on barriers to the efficient use of energy', Energy Policy, 25(10): 833-835.

Weber, M., Roth, G. and Wittich, C. (1968) Economy and society: an outline of interpretive sociology. New York: Bedminster Press.

Wheelock, J. and Oughton, E. (1994) The household as a focus for comparative research, Centre for Rural Economy working paper series (4). Newcastle: Dept. of Agricultural Economics and Food Marketing, University of Newcastle upon Tyne.

Wicks, M. (2005) 'Speech to Micropower conference', Dept. of Trade and Industry. URL: http: //www.dti.gov.uk/ministers/speeches/wicks070705. html. Accessed: 28 February 2006.

Wilhite, H. and Lutzenhiser, L. (1999) 'Social loading and sustainable consumption', Advances in Consumer Research, 26: 281-287.

Wilk, R. (2002) 'Consumption, human needs, and global environmental change', Global Environmental Change - Human and Policy Dimensions, 12(1): 5-13.

Williams, C. C. (2004) 'A lifestyle choice? Evaluating the motives of do-ityourself (DIY) consumers', International Journal of Retail and Distribution Management, 32(4/5): 270-278.

Williams, R. and Edge, D. (1996) 'The social shaping of technology', Research Policy, 25(6): 865-899.

Willis, R. (2005) Small or atomic? Comparing the finances of nuclear and microgenerated energy. Green Alliance.

Winner, L. (1993) 'Upon opening the black box and finding it empty: social constructivism and the philosophy of technology', Science, Technology and Human Values, 18(3): 362-378. 
Winnett, R. and Ester, P. (1983) 'Behavioral science and energy conservation: conceptualizations, strategies, outcomes, energy policy applications', Journal of Economic Psychology, 3(3-4): 203-229.

Winnett, R., Love, S. and Kidd, C. (1982-1983) 'The effectiveness of an energy specialist and extension agents in promoting summer energy conservation by home visits', Journal of Environmental Systems, 12(1): 61-70.

Winskel, M. (2002) 'When systems are overthrown: the "dash for gas" in the British electricity supply industry', Social Studies of Science, 32(4): 563-598.

Wolvén, L. E. (1991) 'Life-styles and energy consumption', Energy, 16(6): 959963.

Wood, G. and Newborough, M. (2003) 'Dynamic energy-consumption indicators for domestic appliances: environment, behaviour and design', Energy and Buildings, 35: 821-841.

Wright, F. (2004) 'Old and cold: older people and policies failing to address fuel poverty', Social Policy and Administration, 38(5): 488-503.

Wüstenhagen, R., Markard, J. and Truffer, B. (2003) 'Diffusion of green power products in Switzerland', Energy Policy, 31(7): 621-632.

Yates, S. M. and Aronson, E. (1983) 'A social psychological perspective on energy conservation in residential buildings', American Psychologist, 38: 435444. 